\title{
ASSESSING COMPLEXITY: GROUP COMPOSING AND NEW ZEALAND'S NATIONAL CERTIFICATES OF EDUCATIONAL ACHIEVEMENT
}

BY

VICKI ELIZABETH THORPE

\begin{abstract}
A thesis
submitted to the Victoria University of Wellington in fulfilment of the requirements for the degree of Doctor of Philosophy
\end{abstract}

Victoria University of Wellington 



\begin{abstract}
This socio-cultural study investigated the assessment of group composing for a secondary school qualification, and the implications such assessment might have for teacher practice. It examines the validity of the contributions of group-composing students and classroom music teachers to the common purposes of learning, teaching, and assessment.
\end{abstract}

The research was carried out in two cycles of practitioner inquiry where the researcher worked in collaboration with two teachers in their respective secondary schools to teach and assess group composing for New Zealand's secondary school qualification, the National Certificates of Educational Achievement (NCEA). A wide range of data were gathered during the collaboration, including teacher and student interviews, recorded discussions, classroom materials and assessment documents, resulting in a rich data set. In the classroom, conceptual models of composing and creativity were used to bridge the discourses of formal and informal music learning, with the aim of engaging the students as thoughtful, independent artists, able to communicate their creative intentions clearly to each other, and to their teacher. During data analysis, cultural historical activity theory (CHAT) was used to analyse and interpret the complexities and contradictions associated with group composing and its assessment.

A significant finding is that the incorporation of group composing into established senior secondary music programmes required teachers to make changes to their practice. The teachers' experiences as learners, musicians and teachers, and their perceptions of professional identity, were found to be key factors in the extent to which they were able to make those changes. If the assessment of group composing was to be valid, then all participants, teachers and group composers alike, needed to engage with each other in the closely interrelated practices of composing, teaching and assessment.

Multiple forms of musical authorship, particularly those of rhythm-section or novice players, proved to be problematic for the assessment system. What were regarded as valid contributions by some members of a group-composing ensemble were not necessarily regarded as valid by the teacher. Arriving at a final grade for each group-composing student not only required grading the music but also entailed the evaluation of portfolios of student achievement data, derived from collaborative 
interactions within the group. The teacher needed to interpret a complex mix of interpersonal, musical and social relationships among students. Therefore, a broad, socio-cultural assessment perspective was required, necessitating holistic, rather than atomised, judgments to be made across the entire compositional process.

This thesis offers possible insights into how music teachers might reconcile the validity demands of a national assessment system with the considerable challenges posed by the ethical requirement to meet the diverse needs of their students. It adds to on-going debates in the literature about the nature of disciplinary knowledge in music education, what constitutes music curriculum in the $21^{\text {st }}$ century, and how such curriculum knowledge might be assessed. It also throws new light upon the complexities and challenges of conducting collaborative action research in schools. 


\section{Acknowledgements}

I should like to thank Mark Stone and Dorothy Buchanan whose ideas about composing, teaching, and assessment began this research journey for me.

In guiding my progress, I acknowledge the expertise, support and guidance of my supervisors, Dr Anne Hynds and Dr Joanna Higgins, and Professor Luanna Meyer and Dr Jan Bolton. Thanks to Victoria University of Wellington for the grants that allowed me the necessary time and resources to make the project possible. Thanks too, to my colleagues at the Faculty of Education for their understanding and support during this project.

My thanks must also go to Dr Graham McPhail for reading the manuscript and giving me valuable feedback, to Susan Kaiser for her editing and formatting expertise, and to Clare Howard for her administrative support. I am very grateful to Charlotte Yates, Dr Tracey Rohan, and Simon and Rachel Tipping for lending me their houses as writing retreats.

I particularly wish to acknowledge and thank my husband, Roger Perkins, for his patience, understanding, and unflagging support over the course of my work, and for offering many helpful editorial suggestions along the way.

Finally, I would like to thank the teachers and their students who welcomed me so warmly into their communities, particularly "David", "Alice", and "Sarah". They are at the heart of this thesis and it would not have been possible without their generosity and willingness to share their classrooms and their practice with me. 


\section{Table of Contents}

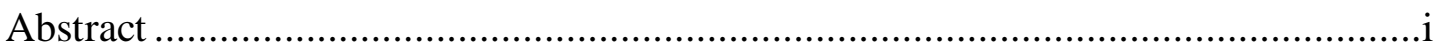

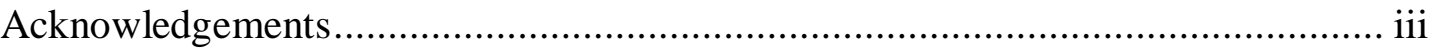

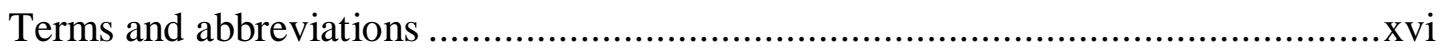

Chapter 1 Introduction .................................................................................. 1

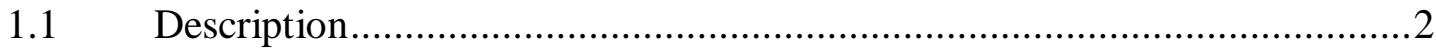

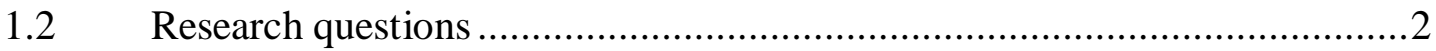

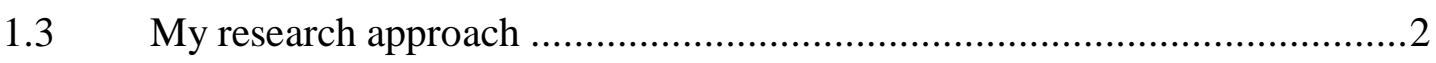

1.3.1 Research background ................................................................ 3

1.3.1.1 Master's research (Thorpe, 2008)...............................................3

1.3.1.2 Experiences as a musician ........................................................4

1.3.1.3 Changing professional role ...................................................

1.3.2 My general stance as a researcher ......................................... 4

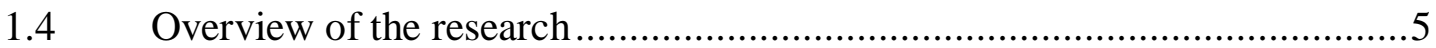

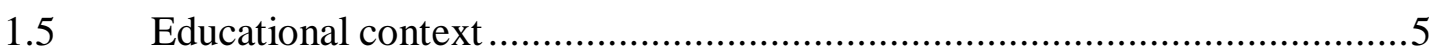

1.5.1 Music Education in New Zealand ................................................5

1.5.2 Senior secondary school curriculum and assessment in New Zealand 1945-2002 ................................................................... 7

1.5.2.1 My professional experience of composing and assessment during

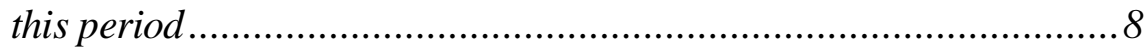

1.5.2.2 Disparity, inequality and cultural inclusivity..............................9

1.5.3 The National Certificates of Educational Achievement ..................9

1.5.3.1 NCEA Music: then and now..................................................... 10

1.5.3.2 The problem with NCEA Music and the national curriculum .......11

1.5.4 AS91092 and issues for my research ......................................13

1.5.4.1 Issues raised by the inclusion of group composing into the assessment ......................................................................... 14

1.6 Composing, teaching and assessment as practice ................................. 16

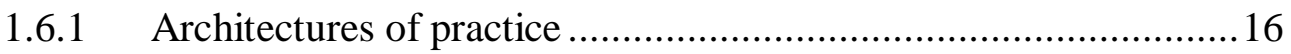

1.6.2 Practice, identity and community ....................................... 17

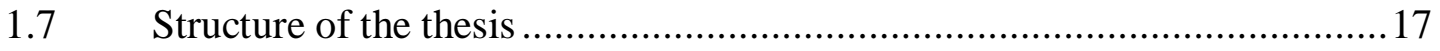

Chapter 2 Review of literature ........................................................ 21

2.1 Informal and formal music learning ............................................... 21

2.1.1 Green's research ..............................................................22

2.1.2 Curriculum and assessment implications of informal music

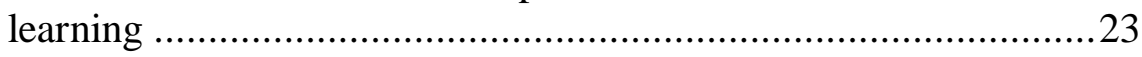

2.2 Theories and conceptions of assessment ….........................................25

2.2.1 Purpose and function of assessment ........................................26

2.2.2 Theories of learning and their relationship to assessment ............27 


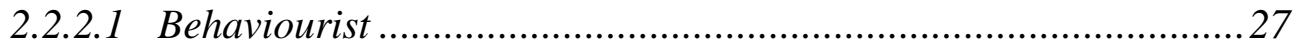

2.2.2.2 Social-constructivist ..............................................................28

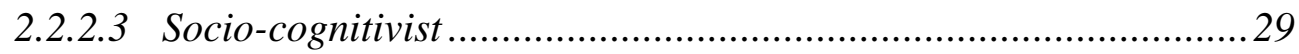

2.2.2.4 Socio-culturalist ................................................................... 31

2.2.3 Assessment conceptions of teachers and students......................32

2.2.3.1 Teachers' assessment conceptions ................................................33

2.2.3.2 Conflicting views of assessment's purposes and functions............33

2.2.3.3 Students' assessment conceptions ..............................................34

2.2.4 A broad assessment conception is required for group composing .36

2.3 Studies of the assessment of learning in groups ......................................38

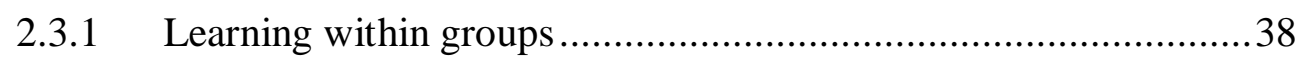

2.3.2 Grading achievement in groups................................................. 39

2.4 Creativity and its relationship to assessment ........................................4

2.4.1 Theories and conceptions of creativity ........................................42

2.4.1.1 Creativity as conceptualised in music education .........................43

2.4.1.2 Creativity conceptions of teachers ........................................... 44

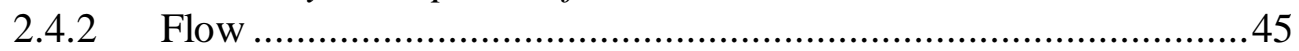

2.4.3 Educational theories and their relationship to creativity and

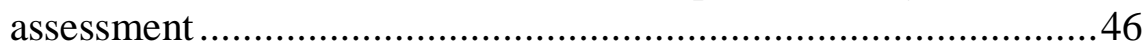

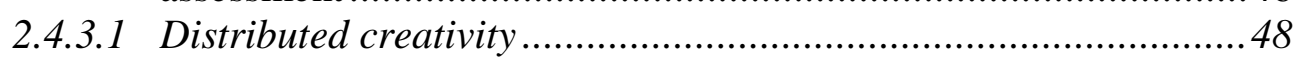

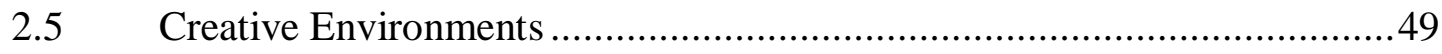

2.5.1 Physical environment: quiet, space and enough time .................49

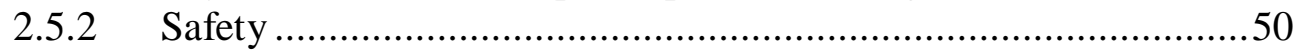

2.6 Studies of creative processes in composing ..........................................51

2.6.1 Models of creative musical processes........................................51

2.6.1.1 Collaborative creative processes in bands .................................55

2.7 Assessment practices in music education............................................5

2.7.1 Assessment practices of American primary and secondary music

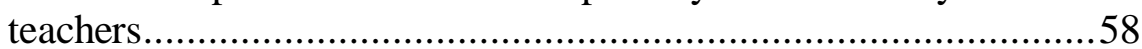

2.7.2 Assessment practice of English and Scottish secondary music

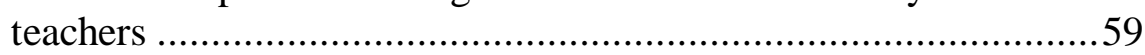

2.7.3 Using taxonomies and rubrics ............................................60

2.7.4 Using consensual assessment technique (CAT) ........................61

2.7.5 Using peer assessment ...................................................63

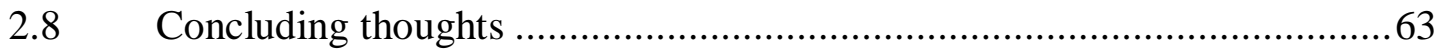

Chapter 3 Methodology

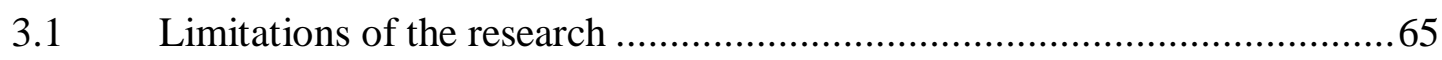

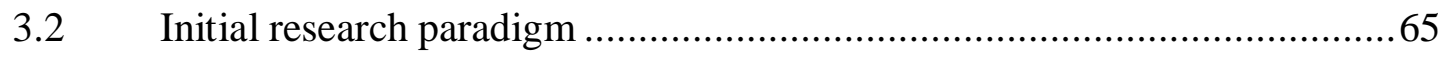

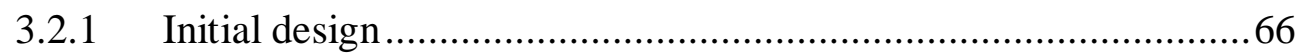

3.3 Pilot Study

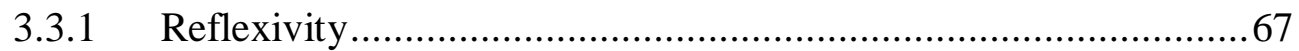

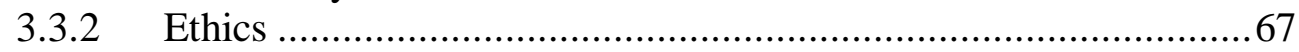

3.3.3 Data Collection..................................................................69 


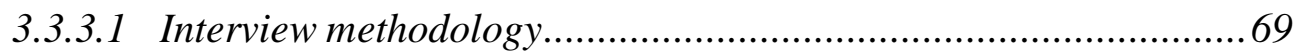

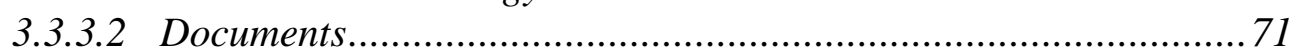

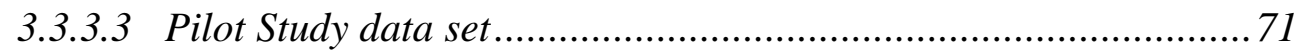

3.3.4 Data analysis methodology ...................................................... 71

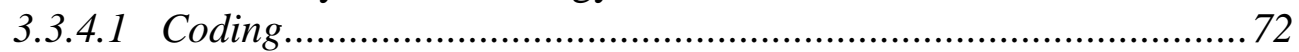

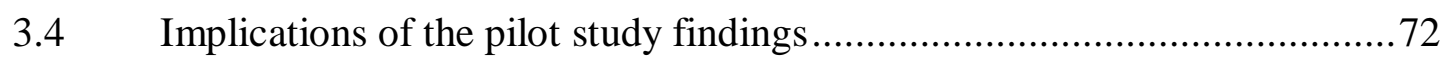

3.4.1 Should I participate in the research?......................................73

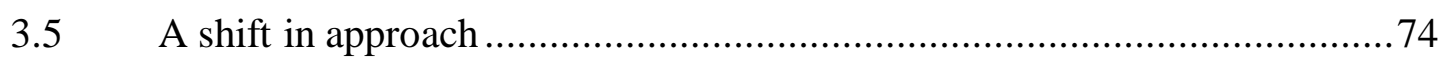

3.5.1 Research subjectivity and validity ............................................ 74

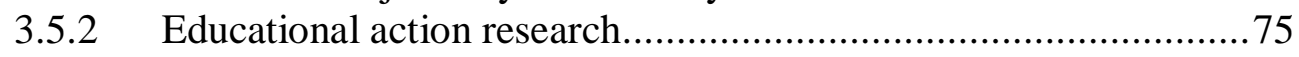

3.5.3.1 Positioning myself in the research .......................................... 76

3.5.3.2 Research models..................................................................... 76

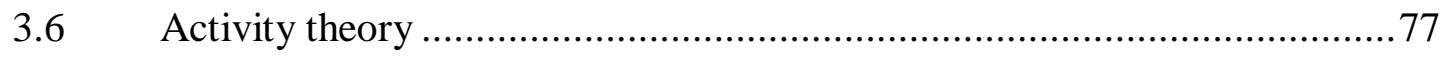

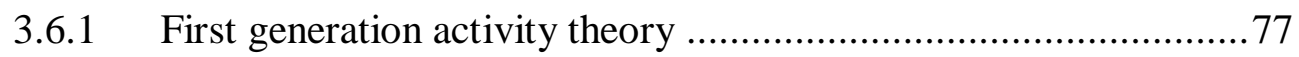

3.6.2 Cultural historical activity theory ........................................... 78

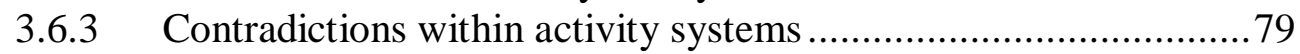

3.6.4 How activity theory is used in this study .................................. 80

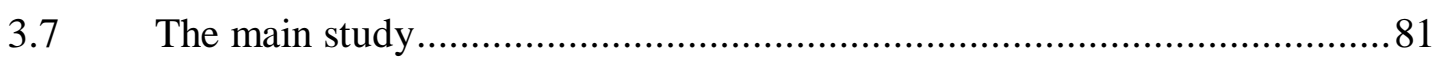

3.7.1 Alice and David................................................................ 81

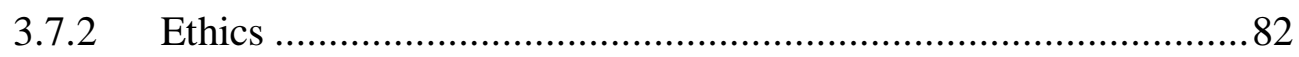

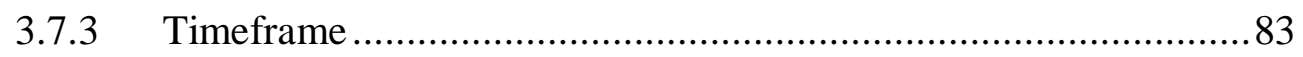

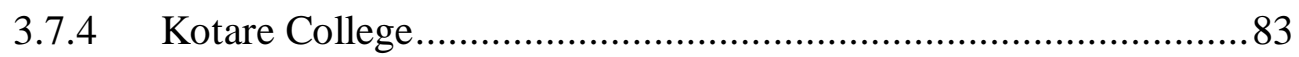

3.7.4.1 Kotare student participants................................................. 83

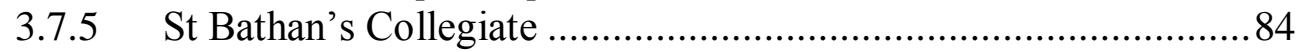

3.7.5.1 St Bathan's student participants................................................. 84

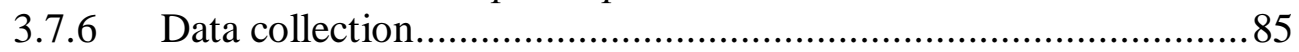

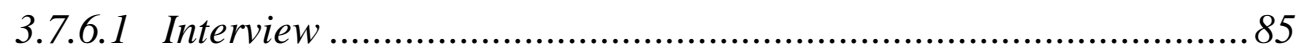

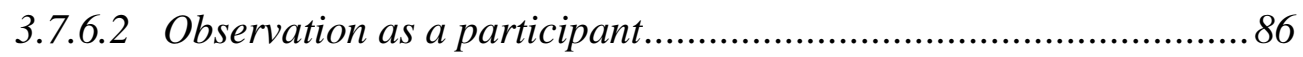

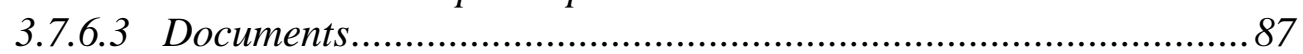

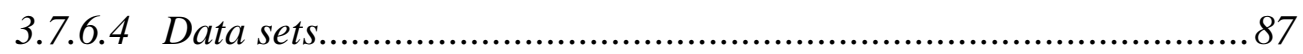

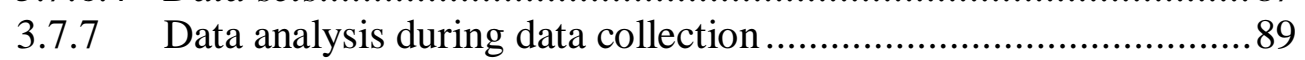

3.7.7.1 Data analysis following data collection ..................................... 90

3.7.7.2 CHAT as a conceptual framework for analysis ......................... 91

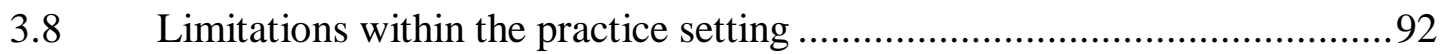

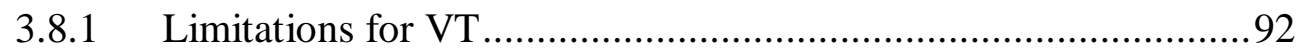

3.8.2 Limitations: Alice and David ..................................................93

3.8.3 Limitations: students......................................................... 94

3.8.4 Limitations: School and NZQA structures .............................. 94

3.9 Credibility, trustworthiness and validity in practitioner research ................94

3.9.1 Triangulation ............................................................... 95

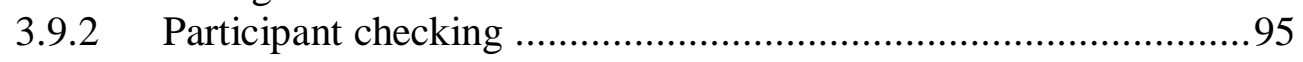

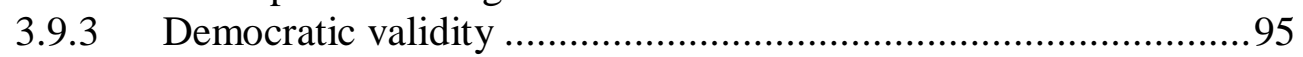

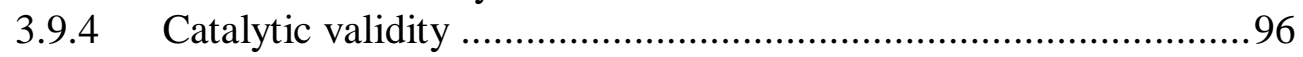

3.9.5 Interpretive validity and research "selves" ...............................96 
3.10 Power, position and identity in this research .......................................97

3.10.1 Kotare: insider-outsider roles and relationships ......................... 98

3.10.1.1 Ethics when working with Alice and her students ....................... 99

3.10.1.2 Should I stay or should I go? ...............................................99

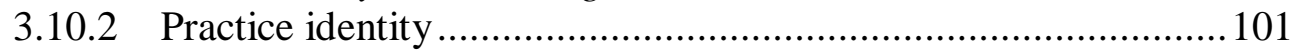

3.10.3 Practitioner research or teacher professional development?........103

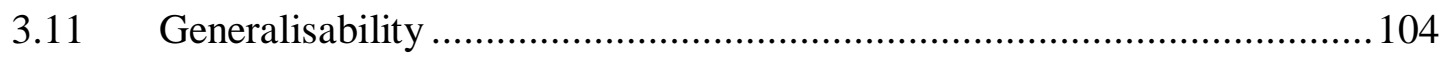

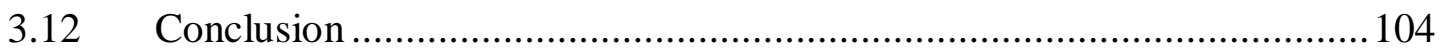

Chapter 4 Pilot study: Manuka High ................................................... 107

4.1 Choosing group rather than individual composing ................................ 107

4.1.1 Lack of knowledge and skills ................................................. 107

4.1.2 Safety and confidence in a group .......................................... 108

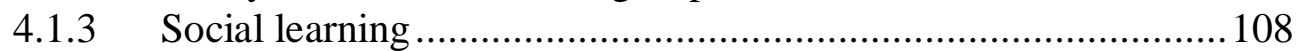

4.1.4 Sarah's beliefs about why students chose group composing ....... 109

4.2 Composing in response to a written task .............................................. 109

4.2.1 Notation and performance disrupt the creative process...............110

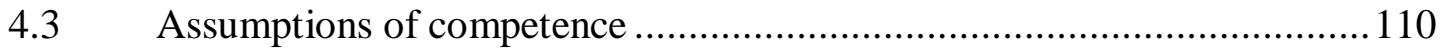

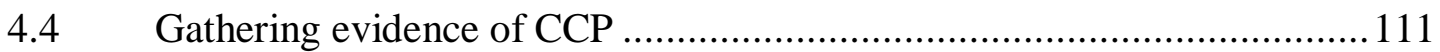

4.4.1 Novices are at risk when CCP is summatively assessed .............112

4.4.2 Verification rather than assessment of CCP .............................112

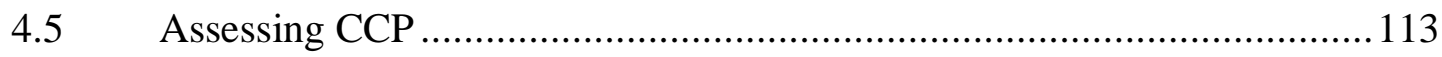

4.5.1 Assessing CCP is too difficult ............................................... 114

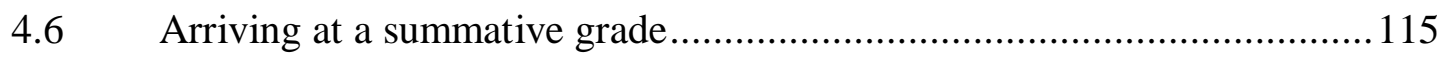

4.6.1 The students grade themselves .................................................115

4.6.1.1 Individual versus group grades.......................................... 116

4.6.2 Factors influencing Sarah's assessment judgement ..................116

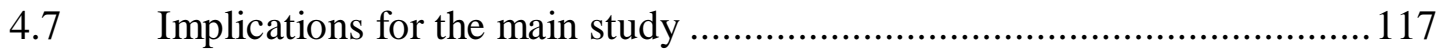

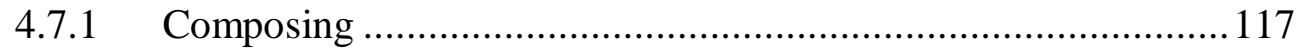

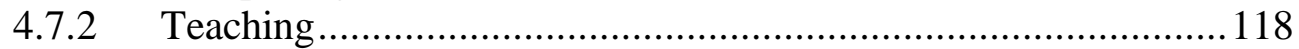

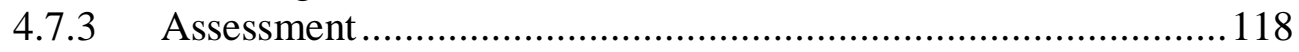

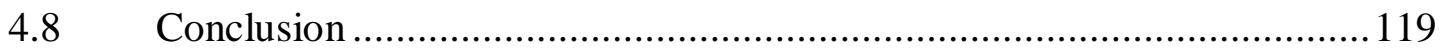

Chapter 5 Kotare College .......................................................................... 121

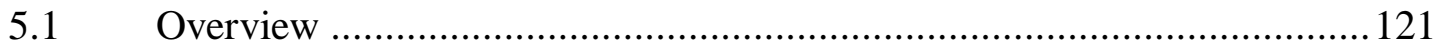

5.2 Cycle 1: Learning about composing ................................................... 122

5.2.1 Connecting the concept of composing to the achievement standard 123

5.2.2 Making connections to students' music....................................123

5.2.3 Noise, space and resourcing prove to be significant problems ....124

5.2.4 Using a theoretical model to make the process explicit ..............125

5.2.4.1 Modifying the model to make it more student-friendly................ 125

5.2.4.2 Gathering CCP data using the theoretical model...................... 126 
5.3 Cycle 2: Student achievement in group composing .............................. 128

5.3.1 Making the assessment criteria explicit ...................................128

5.3.2 Heavy Rock and Blues Rock .............................................. 129

5.3.3 Low achievement............................................................. 130

5.4 Cycle 3. Summatively assessing the compositions ................................ 131

5.4.1 Gathering CCP data and grading Blues Rock's first composition.. 131

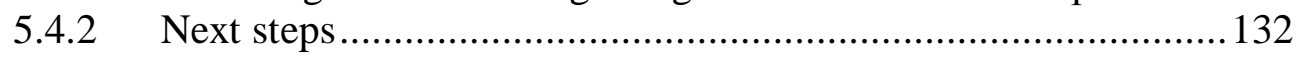

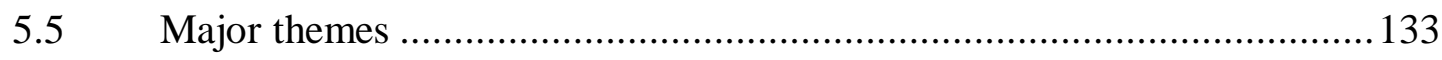

5.6 Theme 1: Communication when group composing ............................... 133

5.6.1 Communicating through shared stylistic knowledge..................133

5.6.2 Appropriate resourcing is needed for effective communication .. 136

5.6.3 Low musical skill impedes communication............................ 137

5.7 Theme 1: Assessment as communication ................................................. 138

5.7.1 Conceptualising group composing to communicate about

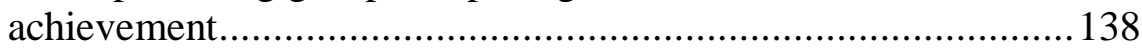

5.7.1.1 Micro and macro CCP........................................................ 139

5.7.1.2 Using the model to grade the first Blues Rock composition ........ 139

5.7.2 Limitations of written feedback ................................................ 141

5.7.3 Articulating the assessment criteria ......................................... 142

5.7.4 Conceptions of creativity influence its assessment ................... 143

5.8 Theme 2: Students' reasons for group composing ................................ 144

5.8.1 Practical, real world considerations make group composing a valid activity ............................................................................... 144

5.8.2 Musical reasons for choosing group not solo composing ........... 145

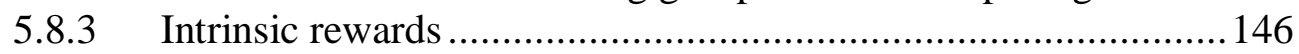

5.8.4 Assessing lower-achievement students' CCP ........................... 148

5.9 Theme 3: Teacher and student expectations of success and achievement in

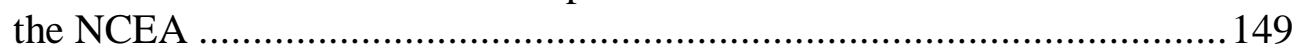

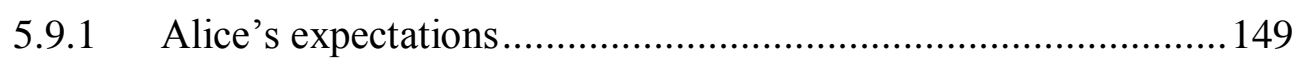

5.9.2 Student expectation of success ........................................... 149

5.10 Theme 4: Assessment validity and its relationship to group processes..........150

5.10.1 Teacher identity and conceptions of valid assessment ...............151

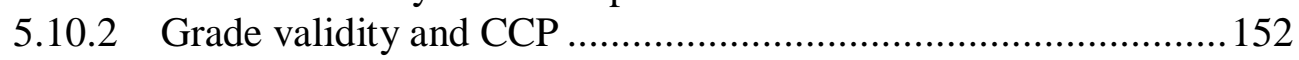

5.11 Summary: six implications for the subsequent cycle of research ..............152

5.11.1 Musical skills and knowledge are crucial ...............................152

5.11.2 Specific stylistic knowledge is crucial................................... 153

5.11.3 The conceptual model acted as a framework for both learning and assessment ...................................................................... 153

5.11.4 Group composing seems to have positive psycho-social outcomes .......................................................................... 154

5.11.5 Group composing grades may not be as valid as those for solo composing ...................................................................... 154

5.11.6 Professional isolation may affect assessment validity and teacher confidence 


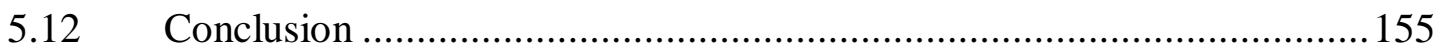

Chapter 6 St Bathan's Collegiate ........................................................... 157

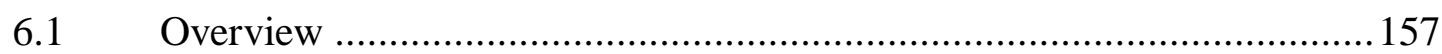

6.2 David's beliefs and professional knowledge about group composing ....... 159

6.3 Findings from the Pikachu interview .................................................. 161

6.4 Cycle 1. Preparing the students for group composing ............................. 163

6.4.1 Back-engineering ...................................................................164

6.4.1.1 Written analysis of the chosen style for back-engineering .......... 166

6.5 Cycle 2. Group composing in a specific style ...................................... 167

6.6 Cycle 3. Summative assessment ....................................................... 169

6.6.1 Assessment practice issue for David ........................................169

6.6.2 Grading the compositions ..................................................... 171

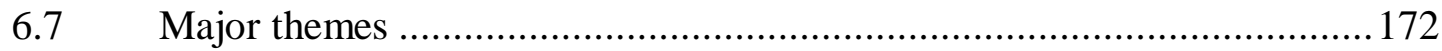

6.8 Theme 1: Communication through a shared understanding of musical style

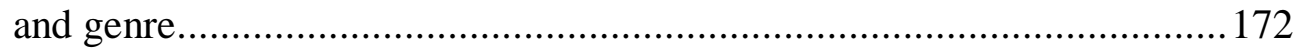

6.8.1 Rationale for back-engineering .......................................... 172

6.8.2 Learning to communicate musically within a stylistic context ....173

6.8.2.1 Balancing challenge and skill requires a safe environment ........ 173

6.8.2.2 Instrumental roles require different levels of challenge and

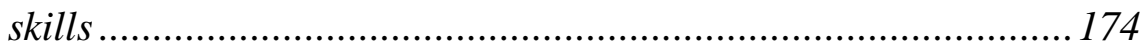

6.8.3 Back-engineering needs to be in familiar styles....................... 175

6.8.4 For transfer of learning, explicit connection needs to be made between the learning and the task............................................ 175

6.8.4.1 Big Group fail to compose a stylistic piece................................ 176

6.8.5 Back-engineering leads to conceptual shifts for students ............ 177

6.9 Theme 1: Communicating through a shared understanding of compositional

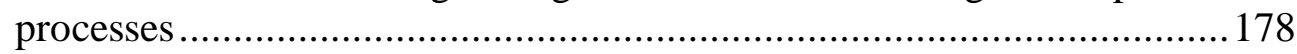

6.9.1 Using the conceptual model ............................................... 178

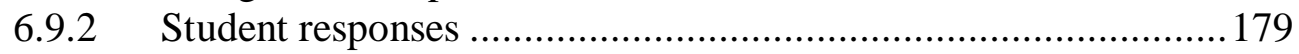

6.9.3 Using the model to give feedback ........................................ 180

6.9.4 David transfers this learning to other aspects of his practice.......180

6.9.4.1 Student progress is more clearly identified and reported............ 181

6.9.5 Verifying and assessing CCP ............................................... 181

6.9.5.1 Using the model to assess rhythm section CCP ....................... 181

6.10 Theme 2: Teacher experience and NCEA assessment practice ................. 182

6.10.1 Conceptions of assessment.................................................... 182

6.10.2 Stress, workload and NCEA assessment requirements ............... 183

6.10.3 Lived experience as a learner of summative assessment ............ 184

6.10.4 Improved NCEA knowledge leads to greater confidence and better practice ...................................................................... 185

6.11 The relationship between task design and valid assessment ....................185

6.11.1 Actual assessment criteria for group composing....................... 186 
6.12 Theme 3: Assessing the CCP of low achieving students ....................... 187

6.12.1 Shared skills and knowledge in group composing .................... 187

6.12.1.1 Validity: Written representation by only one group member ...... 187

6.12.2 Big Group fail to compose a valid piece................................... 188

6.12.2.1 Implications for teacher practice ........................................... 189

6.13 Theme 4: Achievement in group composing, and the NCEA ...................189

6.13.1 Achievement expectancy of the whole class.............................190

6.13.2 Achievement expectancy of the research participants................190

6.13.2.1 Student beliefs about high achievement and group composing ... 191

6.13.3 Achievement and the St Bathan's Collegiate environment .........192

6.13.4 Group composing is about more than just NCEA achievement...192

6.13.4.1 Altruistic motivations: supporting others to achieve...................193

6.13.4.2 Open-mindedness and tolerance of friends' different tastes........ 194

6.13.4.3 Flow ......................................................................................... 195

6.14 The implications of the research for David's practice ............................ 196

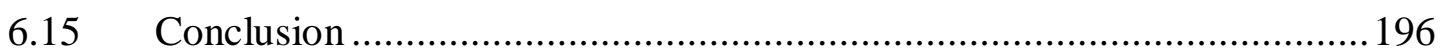

Chapter 7 A valid contribution to social jamming and group composing .......................................................................................... 199

7.1 Social jamming and its relationship to group composing ....................... 199

7.2 Social jamming as an activity system ...............................................200

7.3 NCEA group composing as an activity system ....................................201

7.3.1 Inner contradictions within the NCEA group composing activity

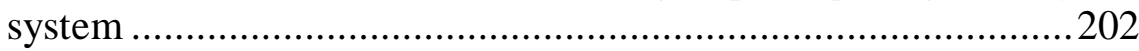

7.3.1.1 Conflicts of values between jamming and group composing .......203

7.3.1.2 Appropriate tools, knowledge and resources are required for group composing ................................................................................. 204

7.3.1.3 Divisions of labour when composing specific musical styles ......205

7.3.1.4 Identity within the community: composer, jammer, or NCEA achiever?

7.4 Third generation analysis of social jamming and NCEA group composing

7.5 Social jamming, group composing and student motivation to achieve in

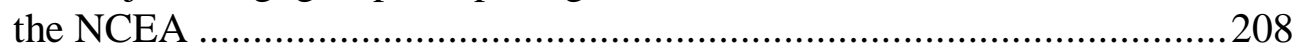

7.5.1 Student motivation to achieve at school ...................................208

7.5.1.1 Achievement expectancy and group composing difficulty are

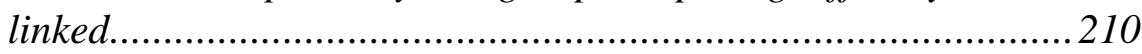

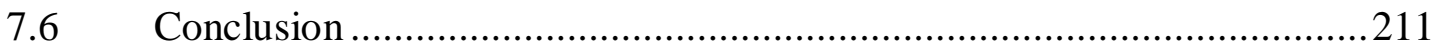

Chapter 8 Teaching and assessment...................................................... 213

8.1 A socio-cultural view of teaching and assessment................................2213

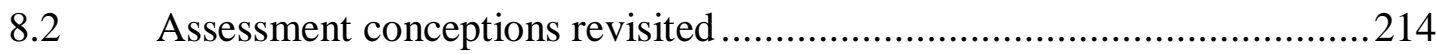

8.2.1 My initial assessment conceptions .......................................2214 
8.2.2 Shifts in assessment conception ...........................................215

8.2.3 Alice and David's conceptions of assessment .........................216

8.3 The implications of group composing for teacher practice ......................217

8.3.1 Divisions of labour: teacher and student.................................218

8.3.1.1 Changing role of the teacher.................................................219

8.3.2 Communities: authentic music making and group composing at

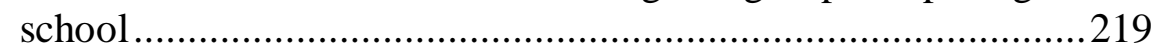

8.3.3 Pedagogical tools ........................................................... 221

8.3.4 Changes in practice lead to changes in pedagogical rules ...........222

8.3.4.1 Back-engineering changes the rules........................................ 222

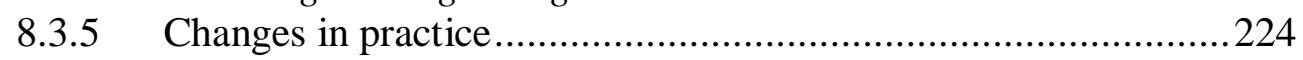

8.4 Assessment's purpose and function for group composing ......................2225

8.4.1 The assessment dimensions of group composing ...........................226

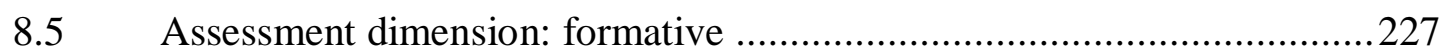

8.5.1 Using a conceptual model for formative assessment.................228

8.5.1.1 Informal-formative discussion...............................................228

8.5.2 Feedback and emotional safety of group composers..................229

8.5.2.1 Ethical concerns about the assessment of low-achieving students'

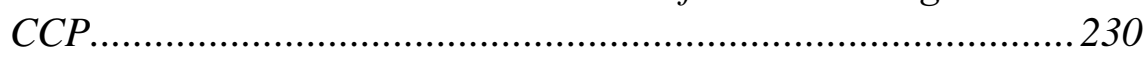

8.5.3 Using stylistic exemplars as assessment models .......................231

8.5.4 Assessment practice changes teaching practice .......................231

8.5.5 Task design and assessment criteria: tensions, contradictions and dilemmas ................................................................................ 233

8.5.5.1 Student responses to the task and to the assessment criteria.......234

8.5.5.2 Popular music sets the benchmark, not AS91092 ......................235

8.5.5.3 If the task is well designed, are written criteria really

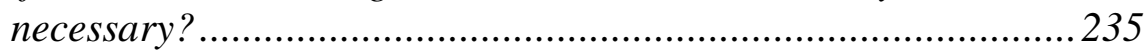

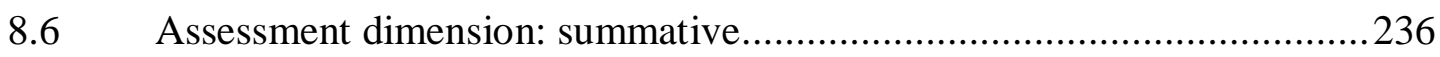

8.6.1 Teacher identity and cognitive domain knowledge when assessing

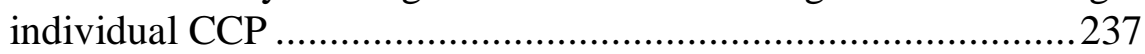

8.6.2 Interpreting assessment criteria ..........................................239

8.6.3 Inhabiting our castles: power relationships when making assessment judgments ........................................................239

8.6.4 Gathering summative CCP data about each student is stressful and demanding in a large class ..................................................2240

8.6.5 CCP and the validity of formal-summative judgments ..............240

8.6.5.1 Plausible rather than accurate ................................................ 242

8.6.5.2 Professional and clinical judgement ......................................... 243

8.6.5.3 The different roles of valid micro and macro CCP .................... 244

8.6.5.4 Assessing the CCP of novice players......................................... 245

8.6.5.5 Validity of group composing grades for novice or low-achieving students 


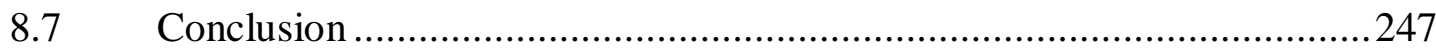

Chapter 9 Conclusion............................................................................. 249

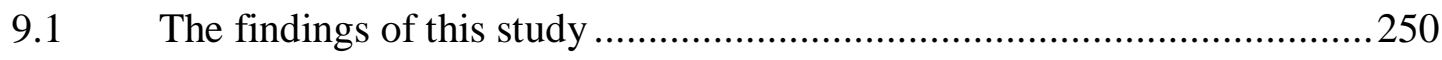

9.1.1 What is a valid contribution when group composing is assessed for a secondary qualification?.....................................................2250

9.1.2 What are the implications for teacher practice when group composing is introduced into an established summative assessment programme?............................................................. 252

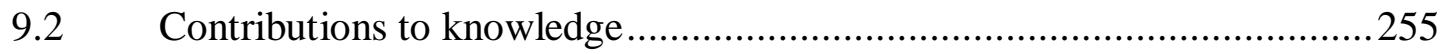

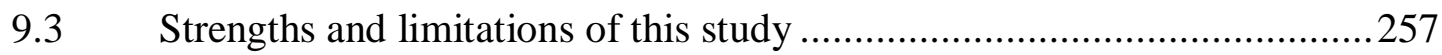

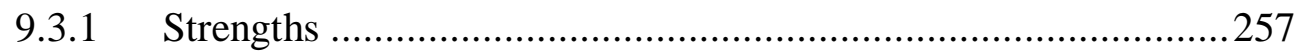

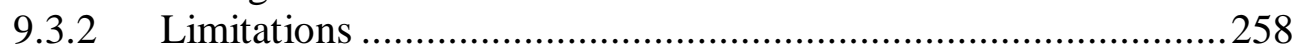

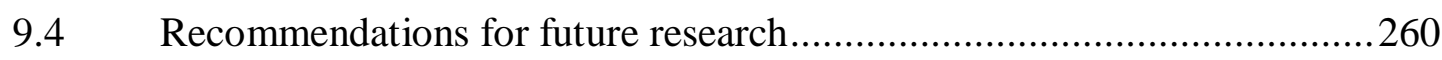

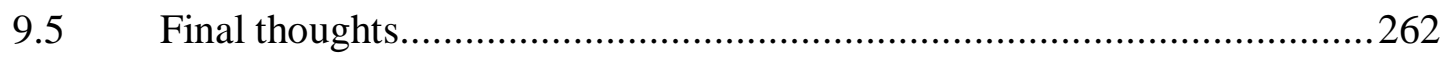

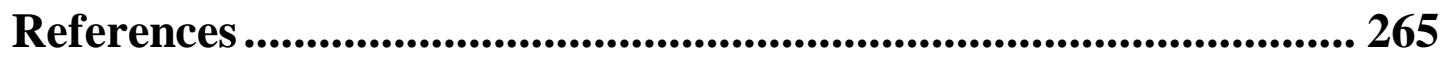

Appendices...................................................................................................... 293

1.1 NCEA Music Achievement Standards in 2011 .....................................294

$1.2 \quad$ Achievement Standard AS91092 _...................................................295

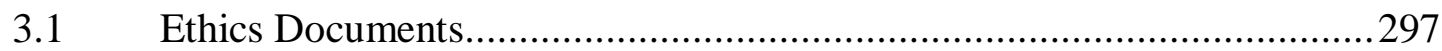

3.2 Indicative examples of interview and discussion questions .....................309

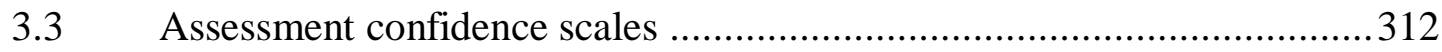

3.4 St Bathan's Collegiate questionnaire .....................................................313

4.1 Pilot Study: Song Writing Task and Assessment Schedule ......................314

5.1 Feedback Sheet (Blues Rock's first piece: Jay).......................................316

6.1 First composition task (St Bathan's Collegiate) .................................... 317

6.2. Assessment schedule for Task 1 based upon exemplar from the TKI website. 


\section{List of Tables}

Table 1.1. Overview of the research project..................................................

Table 2.1. Informal and formal music learning (Green, 2002, as cited in Thorpe, 2008, p.39) ....

Table 2.2. Dimensions of assessment purposes and practices (Harlen, 2012, p.98) 37

Table 3.1. Pilot Timeline

Table 3.2. Pilot study data set .71

Table 3.3. Engeström's four levels of inner contradiction in an activity system (Yamagata-Lynch \& Haudenschild, 2009, p.510)...............................79

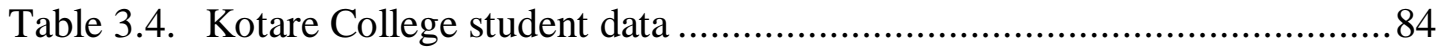

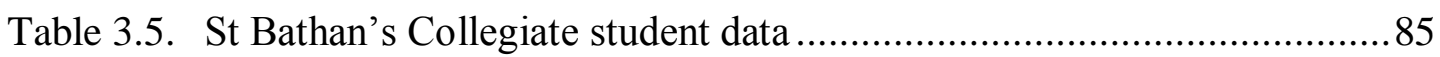

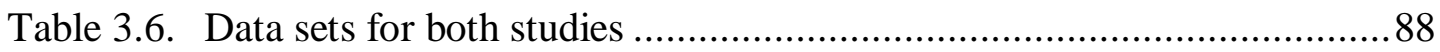

Table 3.7. Analytic memo: St Bathan's data analysis. 3 November 2011 ...............90

Table 5.1. Overview of the research at Kotare ................................................. 121

Table 6.1. Overview of research at St Bathan's Collegiate................................. 158

Table 8.1. The assessment dimensions of group composing (adapted from Harlen, 2012, p.98) 


\section{List of Figures}

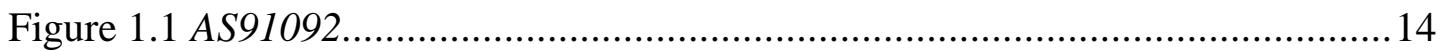

Figure 2.1. Complexity of knowledge in music education .....................................30

Figure 2.2. Balance between challenge and skill..............................................46

Figure 2.3. Webster's (1990, p.23) model of creative thinking in music .................53

Figure 2.4. Distributed composing (Fautley, 2005, p.43) .......................................54

Figure 2.5. The composing process deconstructed ...............................................54

Figure 2.6. Diagram of creative processes (Tobias, 2013, p.236) ..........................55

Figure 2.7. Theoretical model of group composing ..........................................57

Figure 2.8. "Conditions in which flow may occur" ...........................................62

Figure 3.1. Initial design (after Yin, 2009, p.57) ................................................66

Figure 3.2. Dialectical cycle (Mills, 2007, p.20) .................................................77

Figure 3.3. Vygotsky's triangle of mediated action ........................................... 78

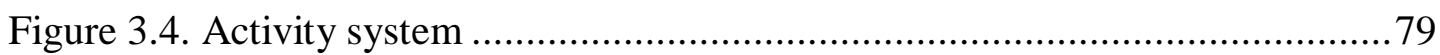

Figure 3.5. Two interacting activity systems as minimal model for the third generation of activity theory. Engeström (2001, p.136) ....................... 80

Figure 3.6. Inner contradictions and tensions example ....................................... 91

Figure 3.7. Nested and adjacent systems (Barab et al., 2002; Engeström, 2001) ......92

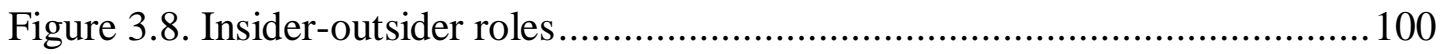

Figure 3.9. Research identities: Alice, David and VT ..................................... 103

Figure 5.1. Handwritten version of the conceptual model .................................. 126

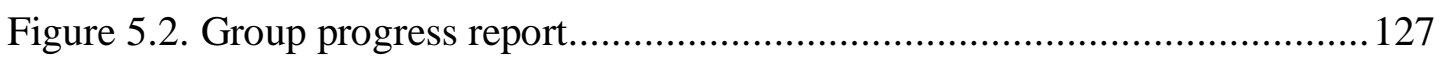

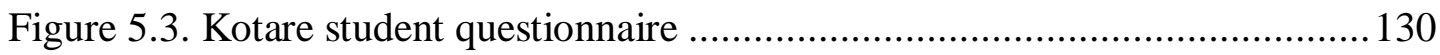

Figure 5.4. Group composing assessment tool: Jimmi ..................................... 140

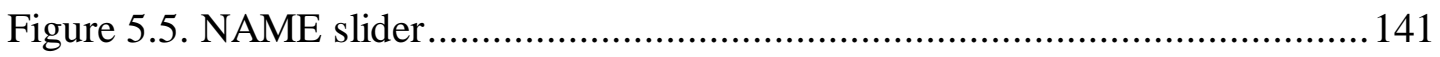

Figure 6.1. Notes framework for back-engineering a style................................. 166

Figure 6.2. Conceptual model: St Bathan's version .......................................... 167

Figure 6.3. Conceptual model of NCEA assessment for composing ...................... 170

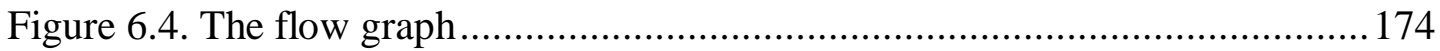

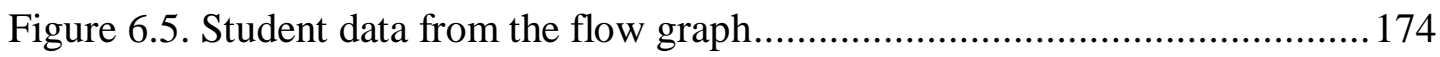

Figure 7.1. Social jamming as an activity system ...........................................201

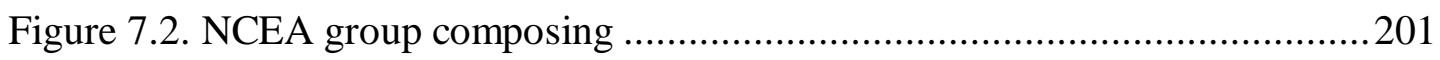

Figure 7.3. Social jamming and group composing as adjacent systems .................207

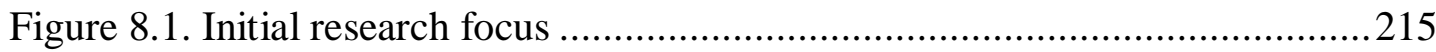




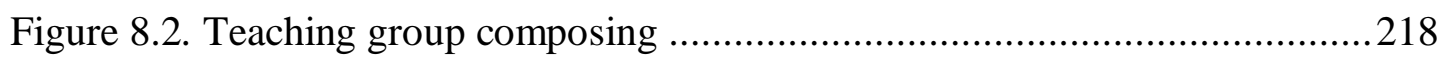

Figure 8.3. Traditional pedagogical model for NCEA composing .........................223

Figure 8.4. Crossing the boundaries of informal and formal practices and knowledge .224

Figure 8.5. Nested activities of professional learning associated with group

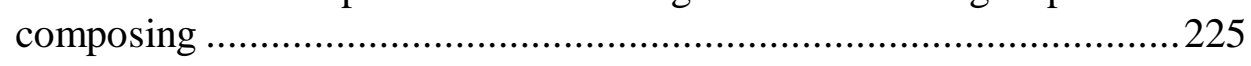

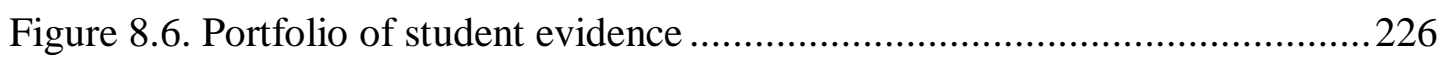

Figure 8.7. Alignment between task design, pedagogy, and assessment criteria .....233 


\section{Terms and abbreviations}

A composition The musical product of composing. Sometimes referred to as $a$ piece.

AS91092:

NCEA Level 1 achievement standard for music "Compose two original pieces of music".

CCP:

An abbreviated version of "contribution to the creative process" as defined by the achievement standard AS91092 explanatory notes, point 5, "Each student's creative contribution to the group composition must be individually assessed" (p.2).

Composing The process of musical creation. Group composing refers to the process of composing music in a group. Solo composing refers to the process of composing music as an individual. To groupcompose is a verb and refers to the act of composing music with others.

Gender: All student participants in the main study are boys. Therefore "he" will sometimes be used as the personal pronoun when referring to students.

Māori: $\quad$ Indigenous New Zealander

NCEA: $\quad$ The National Certificates of Educational Achievement. This is New Zealand's secondary school qualification.

NZQA: $\quad$ The New Zealand Qualifications Authority, the government organisation that administrates the NCEA.

Pākehā: $\quad$ Non-Māori

Palagi: $\quad$ Non-Pacific Islander

Pasifika: $\quad$ Pacific Islanders, or those of Pacific Island decent

Productive The combination of students in a group that leads to the successful grouping completion of a composition. This term is used because group composition is often referred to in literature in terms of the teacher's role in determining the mixture of individuals within a group of students, and is not a musical term. This would be confusing if used that way in this study.

tki:

Te Kete Ipurangi, 'The online knowledge basket,' is a bilingual education portal, administrated by the Ministry of Education. It contains information, resources, and curriculum materials. Artsonline is a section of tki for The Arts curriculum learning areas.

Year 11: $\quad$ The 3rd-last year of secondary schooling, usually students are 15 to16 years. Year 12: the 2nd-last year of secondary schooling, usually students are 16 to 17 years. Year 13: last year of secondary schooling, usually students are 17 to 18 years. 


\section{Chapter 1 Introduction}

This thesis is an investigation of the assessment of group composing in music for New Zealand's secondary school qualification, the National Certificates of Educational Achievement (NCEA). It is a qualitative, ethnographic study, carried out within an interpretivist paradigm (Guba \& Lincoln, 2008) and addresses two research questions:

- What is a valid contribution when group composing is assessed for a secondary qualification?

- What are the implications for teacher practice when group composing is introduced into an established summative assessment programme?

The study views the assessment of group composing through a socio-cultural lens. I make the ontological assumption that musical understanding is acquired by both teachers and students across a number of musical, cultural, and social planes, not just through one school-based experience (Dillon, 2007; Green, 2008; Odena \& Welch 2009; Wiggins, 2007). Group composing is assumed to be a socio-musical activity where learning is something that happens between people, not only inside the heads of individuals. It is an activity mediated by culturally, socially, and historically situated tools (Vygotsky, 1978). I take the epistemological view that, for group composing, music learning occurs both through formal music learning at school and through the informal music experiences within the lives of students (Green, 2008; McPhail, 2012a). I also view group composing as situated practice and in the context of this study, associated with the interrelated practices of teaching and assessment. This thesis addresses the potential divide between formal and informal music knowledge, practices and discourse, and shows how two conceptual models were used in an attempt to bridge this divide.

This chapter identifies the two main research questions and places them in their educational and theoretical context. It explains why these have arisen and why they are important questions to answer. The term validity (meaning credible and rigorous) and its relationship to the practices of composing, teaching and assessment is a key focus in this study (Black, Harrison, Hodgen, Marshall, \& Serret, 2010; McPhail, 2009). Identity as related to these three practices is also a key focus. 
Following this is an outline of how my research was conducted and the methodology used. This includes an account of how cultural historical activity theory (CHAT), is used to illuminate structures and processes embodied in group composing, teaching and assessment (Cole \& Engeström, 1993). It concludes with a summary of how the thesis is structured.

\subsection{Description}

This thesis presents findings from research in three schools. The research was first carried out as a pilot, followed by the main study. The main study was collaborative practitioner research between myself and two secondary teachers. This is not a tidy research methodology (Cook, 2009; Ulichny \& Schoener, 2010). As the findings will show, the research journey included many unexpected events, some serendipitous, some disappointing, and some contradictory. Therefore the study is also a methodological examination of the complexities, tensions and contradictions in university-school research collaboration. It aims to provide new insights into the relationships between identity (teacher and students), practice (pedagogical and musical) and assessment. I will also present several new methods for the assessment of collaborative compositional processes. As the literature review in Chapter 2 will show, this is an aspect of assessment that has not been researched in any depth before.

\section{$1.2 \quad$ Research questions}

My prime research question is "What is a valid contribution when group composing is assessed for a secondary school qualification?". The study focuses upon the validity of contributions of group-composing students, classroom teachers and myself to the common purposes of learning, teaching, and assessment. It examines the impact the assessment of group composing had upon the teachers and students, and what the implications these impacts had for the teachers' practice, including my own as a teacher-educator. This thesis therefore considers a second research question, "What are the implications for teacher practice when group composing is introduced into an established programme of summative assessment?"

\subsection{My research approach}

I am a tertiary music educator and former secondary school music teacher. This study builds on my Master's research (Thorpe, 2008) into the compositional processes 
of young rock and pop bands. It is also informed by my professional experiences and practice as a music teacher, teacher-educator, and national moderator for secondary music assessment in New Zealand, and my practice as a musician.

\subsubsection{Research background}

The initial motivation for this particular research began in 2004 in my work as a music adviser. One teacher with whom I worked was very focused upon the peermediated, informal music learning practices of many of his students. We noticed that most of the students who chose to work in this way were Māori (indigenous New Zealanders) and Pāsifika (Pacific Island) boys, many of whom had been identified by the teacher as generally disengaged from formal music learning, but who were nevertheless highly focused upon playing and composing together. The teacher often expressed disappointment to me that there were few opportunities for these kinds of music-making to be assessed in the newly-instituted NCEA. Our professional discussions about this became the stimulus for my Master's research (Thorpe, 2008).

\subsubsection{Master's research (Thorpe, 2008)}

Initially, I planned to investigate how collaborative composing might be assessed, should group composing ever be incorporated into the NCEA. I soon discovered that, at that time, there was a paucity of research into how young people composed music together in contemporary genres. The focus of the research thus shifted from summative assessment for qualification to the processes of collaborative composing in what is often termed "garage bands" (Thorpe, 2008). An important incident during this research led me to new insight into the complexities of group composing:

A 30-minute car journey to the recording studio was a fairly silent one for me, with each band member listening intently to heavy rock through headphones on their individual MP3 players, pausing occasionally to share headphones and songs with each other. Any conversation involved a highly focused critique of what was being heard and it was clear that the members of Junior shared a common understanding of the music to which they were listening. Junior existed even when its members were not actually playing or song writing together because the band is a knowledge-based social structure that owes its existence to a shared reality amongst its members (p.127)

As will be demonstrated in the next two chapters, other researchers concur that group composing is not simply a technical matter of creating a musical construction, but rather, a highly complex socio-cultural activity. 


\subsubsection{Experiences as a musician}

I am a classically trained musician in piano and voice with a preference for chamber music and accompaniment. On graduation from university, I briefly sang in a rock band, but have mainly played "classical" music in various chamber music ensembles over the years. I have also been a member of, and have directed numerous choirs.

In 2006, my practice as a musician underwent a considerable shake-up when I joined an alt country band as a keyboard player and singer. Between 2006 and 2011 the band played numerous public gigs, where I played without notation, learning (at times painfully) to improvise solo keyboard breaks. Most of the songs performed by the band were original compositions by two of the band's members and I was often involved in the arrangement and re-composition of these songs, as well as playing and singing on the band's subsequent album. These were very challenging and rewarding artistic experiences where I recognised very similar collaborative compositional processes to those that I had observed in my Master's research. Both my professional practice and personal artistic experiences therefore inform this study.

\subsubsection{Changing professional role}

During this period (2005-2010) my role changed from that of Music Adviser, focusing upon teacher professional development in schools, to a position as Lecturer in initial teacher education, specifically primary and secondary music education, at the Victoria University of Wellington's Faculty of Education. While my professional focus remains upon teacher practice and music pedagogy with an interest in composing and assessment, I have developed a broadened and deepened perspective that includes student and beginning teachers as well as established teacher practice. These perspectives influence my research view, leading to a greater emphasis upon the analysis of practice and related philosophies of music education.

\subsubsection{My general stance as a researcher}

Initially, despite espousing group composing as a complex socio-cultural activity, my research approach was founded upon a series of unexamined assumptions. The stance of "non-participant observer" had worked well for my Master's research and I assumed that it would be the same for this study. In the first stages of the research, analysis of the pilot study data soon revealed that non-participation in an exploratory study was not an appropriate position from which to examine the challenges raised by 
the new achievement standard. I needed to develop a much more reflexive position, beginning with a careful examination of the underlying motivation for the choice of doctoral research.

When reviewing and reflecting upon the professional journey that had led me to the outset of this research, I came to the conclusion that my underlying research stance was primarily that of practitioner, that is to say, a music educator. This stance will be examined in greater detail in Chapter 3.

\subsection{Overview of the research}

This research was conducted between 2010 and 2012 and is presented as three case studies set in three New Zealand secondary schools. The research began in 2010 with a pilot study, followed by the main study in the form of two cycles of collaborative practitioner research in two schools. This is summarised in the table below where I refer to myself as "VT".

Table 1.1. Overview of the research project

\begin{tabular}{|l|l|l|l|}
\hline \multicolumn{2}{|c|}{ Overview of the research project } \\
\hline Dates & \multicolumn{1}{|c|}{ School $^{\mathbf{1}}$} & \multicolumn{1}{|c|}{ Participants } & $\begin{array}{c}\text { Type of qualitative research \& } \\
\text { my role in it }\end{array}$ \\
\hline Sept-Nov 2010 & $\begin{array}{l}\text { "Manuka } \\
\text { High School" }\end{array}$ & $\begin{array}{l}1 \text { classroom teacher \& 4 } \\
\text { students (1 group) }\end{array}$ & $\begin{array}{l}\text { Pilot study } \\
\text { Non-interventionist, case study, } \\
\text { VT as non- participant observer }\end{array}$ \\
\hline May-Nov 2011 & $\begin{array}{l}\text { "Kotare } \\
\text { College" }\end{array}$ & $\begin{array}{l}1 \text { classroom teacher, VT, 8 } \\
\text { students (2 groups) }\end{array}$ & $\begin{array}{l}\text { Collaborative practitioner, VT as } \\
\text { participant }\end{array}$ \\
\hline $\begin{array}{l}\text { Nov-2012-Dec } \\
2012\end{array}$ & $\begin{array}{l}\text { "St Bathan's } \\
\text { Collegiate" }\end{array}$ & $\begin{array}{l}1 \text { classroom teacher, VT, 14 } \\
\text { students (4 groups) }\end{array}$ & $\begin{array}{l}\text { Collaborative practitioner, VT as } \\
\text { participant }\end{array}$ \\
\hline
\end{tabular}

\subsection{Educational context}

The past 15 years have seen radical and comprehensive changes to the Music curriculum, the national school curriculum (Ministry of Education, 2007) and secondary school qualifications in New Zealand. The following summary of these changes places the study in its historical and educational context

\subsubsection{Music Education in New Zealand}

In New Zealand, school education is compulsory from the ages of six to 16 , but most children start primary school at age five, moving on to secondary school at 
age 13. Students attend secondary school during Years 9 to 13, where Years 9 and 10 are generally referred to as "junior secondary" (aged approximately 13-15 years), and Years 11, 12 and 13 as "senior secondary" (aged approximately 15-18 years).

Music has been compulsory in the primary school curriculum, and optional at senior secondary school level since 1945 (Braatvedt, 2002). In 2000, Music and Visual Art were joined by Drama and Dance as four disciplines in a new arts curriculum (Ministry of Education, 2000). Then in 2007, the entire school curriculum was superseded, including the new arts curriculum. Music remained a discipline in The Arts learning area but was renamed "Music-Sound Arts" in its ninth iteration as a curriculum subject (Ministry of Education, 2007, p.21). All four arts disciplines remain compulsory, in some form or other, at primary school level. In the first year of secondary school (Year 9), students must study at least two of the four arts disciplines, but these then become "option" subjects from Year 10 onwards.

The current national curriculum (Ministry of Education, 2007) is very broad in its objectives, which are intended to be:

... a framework rather than a detailed plan. Therefore, while every school curriculum must be clearly aligned with the intent of this document, schools have considerable flexibility when determining the detail. In doing this they can draw on a wide range of ideas, resources, and models. (p.37)

Most New Zealand secondary schools employ only one, or possibly two classroom music teachers. McPhail (2012a) notes that, because the curriculum is broad, and teacher skills and knowledge are diverse, music curriculum content may vary widely between schools:

The current national curriculum in New Zealand (Ministry of Education, 2007) has little specified knowledge content and it appears to exert minimal influence over specific music curriculum enactment in the secondary school except by default in that it provides teachers with the opportunity to appropriate their own contents and approaches at a local level. (McPhail, 2012a, p.35).

It is generally acknowledged that the assessment requirements of secondary school qualifications usually underpin and drive teachers' curriculum choices for Music (Hipkins, 2010; Savage \& Fautley, 2011). Therefore, in the context of this research it was hypothesised that teacher contribution to teaching and assessing group composing for the NCEA might also be highly sensitive to local context. 


\subsubsection{Senior secondary school curriculum and assessment in New Zealand} 1945-2002

In the $20^{\text {th }}$ century, school music syllabi reflected New Zealand's history as a British colony. Indeed, the first four teacher-educators in Music in New Zealand were all recently-arrived Englishmen (Sell, 2003). Prior to 1993, the senior music curriculum in New Zealand secondary schools was strongly influenced by university canon. Curriculum content requiring cognitive responses, such as music theory and analysis, was regarded as more academically acceptable, and thus had higher status than practical content such as composing, singing, and playing music (Drummond, 2003). The titles of two of the most senior qualifications, University Entrance and University Bursaries, give a clear indication of the intended purpose and function of these, and in turn the music knowledge privileged by these qualifications reflects this.

During this period, the curricula of both universities and schools were highly influenced by Euro-centric views of music, particularly those in England. In both secondary schools and universities, knowledge of European Art Music and related music theory was valued more highly than applied musical practices in non-European or popular music (Drummond, 2003). For music to be valued as an academic, "serious" school subject, worthy of inclusion in the senior school curriculum, a valid link to university study was imperative. As Drummond wryly observes, "for fifty years the arts have been applying to join the club of traditional 'school subjects' and, as occurs whenever one joins a club, the only way in is to show that you can follow the club rules" (p.54). For example, even in the first qualification undertaken by students, School Certificate, music knowledge was summatively assessed in a three-hour written examination where composition was limited to derivative, short written exercises, bearing a strong resemblance to music theory examinations implemented by external bodies such as the Royal Schools of Music, or Trinity College (Donaldson, 2012).

In the late 1980s, considerable pressure was brought to bear upon the New Zealand Qualifications Authority (NZQA), the organisation responsible for senior secondary music assessment systems. For several years music teachers and teachers' organisations sought to change this situation and in 1993 the assessments for music were substantially revised to make them more relevant and accessible to students (Thorpe, 2008). Composition (individual) and performance (solo and group) were incorporated into the assessment structures of all three secondary school qualifications. 
Students' compositions and performances were assessed by their teacher, and samples from each class were then externally moderated under the auspices of NZQA. ${ }^{2}$

When these changes came into effect, the number of students taking music at senior secondary level tripled almost immediately (Carter, 2003). Many in this new influx of students played and composed in contemporary and pop music genres, leading teachers to consider incorporating these kinds of music into established "classical" programmes of study (Carter, 2003). Many of these students were Māori and Pāsifika students who, thus far, had largely been excluded from senior secondary music programmes (Carter, 2003). Popular genres and their socio-musical conventions are the compositional focus of the students in this study.

\subsubsection{My professional experience of composing and assessment during this period}

In 1995, on my return from teaching in Melbourne, I learned I was now required both to teach and assess composing at senior level. The students' work and my assessment judgments were also subject to national moderation. Like many other teachers in New Zealand, this was new practice for me. During this period Dorothy Buchanan, a nationally-recognised composer and teacher-educator, mentored me in her role as the Wellington secondary music adviser. With Dorothy's professional support, I learned a great deal about how a non-composer like me might teach, foster, support and facilitate my students' composing.

I left secondary teaching to take up the role of Music Adviser in 2000. In that capacity I was invited by NZQA to join the national moderation team to moderate performance assessments for the University Bursaries examination. A team of 24 moderators worked in pairs for one week a year to moderate samples of the performance and composition assessments from every school in the country. I worked in that capacity until the qualification was superseded by the NCEA in 2004. During those intense annual sessions, as a "rookie" assessor in the company of highly experienced experts, I gained a great deal of insight into the extremely diverse range of summative assessment procedures of teachers, and a deep appreciation for the value of the assessment community of practice that was the moderation team. While I did not moderate the composition assessments I learned a lot from the composition

\footnotetext{
${ }^{2}$ Unlike the secondary school curriculum in North America, music performance in choirs, bands and orchestras was (and still is) a mainly co-curricular activity that happens outside the classroom.
} 
moderators about the complexities of ascertaining assessment validity in composition. Lave and Wenger (1991) refer to such learning as legitimate peripheral participation.

At the same time, I acted as the Wellington regional moderator for School Certificate Music composition and performance until it was superseded (in 2002) by the NCEA. Moderation involved facilitating (if not refereeing!) groups of teachers in the collaborative moderation of their performance and composition assessments. These experiences were very enriching to my practice as an educator and led to a continuing interest in the assessment of composing and its relationship to practice.

\subsubsection{Disparity, inequality and cultural inclusivity}

During this period, and subsequently, there was growing evidence of serious inequalities within New Zealand's educational systems, particularly for Māori and Pāsifika students (OECD, 2004). Cultural inclusivity was, and remains, a significant issue in New Zealand schools (Bishop \& Glynn, 1999; Macfarlane, 2004; Savage et al., 2011), and in music education (Henderson, 2003; Rohan, 2011). For example, national studies of secondary school students reveal that Māori are four times more likely to live in neighbourhoods of high deprivation compared to Pākehā /NZ European (Grant, Milfont, Herd, \& Denny, 2010). In line with research from other countries, socio-economic disparity has been identified as being a significant challenge to achieving equitable educational outcomes for New Zealand school students, particularly Māori students (Hynds et al., 2011).

In the late 1990s, amid calls from teachers and community groups for a more inclusive and equitable secondary school education, there was a radical reform of all of New Zealand's secondary school qualifications. Following the disestablishment of the norm-referenced qualifications, the NCEA was phased in from 2002 to 2004. During this period I acted as regional facilitator for NCEA music, running implementation workshops for secondary music teachers in the Wellington region.

\subsubsection{The National Certificates of Educational Achievement}

The NCEA is a modular, outcomes-based, criterion-referenced, national qualification where students study a number of courses or subjects, including music. As Hall (2005) explains:

Criterion-referenced assessment focuses on judging whether students have met pre-specified written criteria in respect of what constitutes acceptable performance in a course or a component of a course. Individuals are not compared with each other but with the written criteria. (p.237) 
In each NCEA subject, skills and knowledge are assessed against a number of achievement standards, each with a set of written criteria. Some of these standards are externally assessed, mainly by written examination, while others are internally assessed by the classroom teacher and subject to external moderation by NZQA. When a student achieves a standard, he or she gains a number of credits that count towards an NCEA certificate. There are three levels of certificate. In general, students work through Levels 1 to 3 during their last three years of school.

High achievement for each standard is recognised by grades of Merit or Excellence. A student does not "pass" a subject, but rather, achieves a series of standards within that subject domain. However, a high level of Merit or Excellence grades within a subject qualifies a student to receive a "subject endorsement" certificate. All NCEA achievement standards are stand-alone, leaving both teachers and students to choose which assessments to complete within subjects. There is an expectation that the students will make a valid contribution to these decisions, particularly in the senior years (Walkey, McClure, Meyer, \& Weir, 2013).

\subsubsection{NCEA Music: then and now}

As explained earlier, the NCEA was introduced not long after the radical revision of senior secondary school assessment for Music. It is not surprising, therefore, that initially the music achievement standards had a very similar structure to those they replaced (McPhail, 2012a).

When designing NCEA music courses, the teacher usually selects a series of achievement standards to suit the specific needs of the students in the class. Typically, this is a mix of solo and group performance, composition, music works and score analysis, and aural perception, and more recently, digital, recording and amplification technologies. ${ }^{3}$ Unlike some countries, the involvement of New Zealand teachers in summative assessment for high stakes is not particularly controversial (Crisp, 2012) and a music teacher may even design NCEA courses that are entirely internally assessed. However, based on my experience in the field, a fairly typical Level 1 NCEA Music assessment programme is usually:

${ }^{3}$ In New Zealand secondary schools, students learn to play an instrument or sing either through statefunded music lessons taught by itinerant teachers at their school, or learn from private teachers. Classroom teachers do not teach instrumental or vocal performance and typically direct ensembles such as choirs in out-of-class time such as the lunch-break or after school. 
- AS91090: Perform two pieces of music as a featured soloist (6 credits)

- AS91091: Demonstrate ensemble skills through performing a piece of music as a member of a group ( 4 credits)

- AS91092: Compose two original pieces of music (6 credits)

- AS91093: Demonstrate aural and theoretical skills through transcription (External examination, 4 credits)

- AS91094: Demonstrate knowledge of conventions used in music scores (External examination, 4 credits)

- AS91095: Demonstrate knowledge of two music works from contrasting contexts (6 credits)

See Appendix 1.1 for a full list of Music achievement standards at the time of the research.

\subsubsection{The problem with NCEA Music and the national curriculum}

Hall (2005) describes the complexities of the teaching and learning environment in which NCEA summative assessment takes place:

The effectiveness of the context [of teaching-learning] in providing a productive learning environment for students is dependent upon a number of factors: the way teachers manage the environment, including their use of a wide range of teaching strategies and their knowledge of how students learn; the expertise of teachers of both their subject and the pedagogy of their subject; the rapport between teachers and students; the attitudes, prior learning and home background (including family encouragement) of the students; other characteristics of the students (e.g. learning, approaches to learning, interests, motivation and so on); and the nature of the subject matter and the ability of the teacher to provide meaningful and relevant activities (in-class and through assessment tasks) so as to engage the student effectively with this content. As is evident, the teaching-learning context demands a lot of teachers in respect of course design, assessment, their understanding of students' learning, and the means by which to motivate students to learn. (pp.241-242)

The implementation of a criterion-referenced, standards-based qualification like the NCEA is underpinned by two assumptions: that teachers, not external examiners, are the most informed and therefore the most appropriate assessors of student achievement; and that assessment is an intrinsic part of learning (Hall, 2005). However, critics of the NCEA, including teacher advocacy organisations, argue that the administrative demands of managing NCEA internal assessments have greatly increased the workload of already hard-pressed teachers, to the potential detriment of teaching and learning (Donaldson, 2012; Hall, 2005; McPhail, 2009). 
While the NCEA seems to have had a positive effect upon the flexibility, curriculum variety and overall accessibility of music education at senior secondary level in New Zealand, this has not been without problems. McPhail (2012b), a former national moderator for NCEA Music, argues that the NCEA creates a technicalinstrumentalist paradigm, where the relationship between traditional bodies of knowledge and the knower has been replaced with the modularisation of that knowledge into "assessment packages" (p.325). He asserts that explicit disciplinary curriculum knowledge about music has been "emptied out" by the NCEA because the achievement standards now act as the unofficial curriculum for teachers (p.324).

Over the past two decades the traditional canon of European music knowledge has been joined by that associated with a multiplicity of world and popular music genres, skills that are often tacitly or informally learned, along with highly diverse and increasingly complex digital technologies. In a study of the music creativities of professional, adult musicians, Burnard (2012a) identified six different forms of musical practice: originals bands, singer-songwriter, DJ cultures, composed music (such as European art music, or "classical"), improvised music (such as jazz), and interactive audio design. Young people are engaged in these practices too, both inside and outside the classroom, resulting in an explosion of musical opportunities for teachers and students alike. However, catering for such broad artistic and cultural diversity remains a considerable challenge for music educators (Burnard, 2012a), carrying with it considerable implications for summative assessment for a school qualification like the NCEA.

Music as a curriculum subject now has an extremely broad knowledge base. Yet, as has been explained earlier, both the achievement standards for music and the New Zealand Curriculum (Ministry of Education, 2007) are very open to, or do not specify, what content should be taught. Such a situation leads to huge variance in curriculum content and delivery between schools, challenging the validity of NCEA music because it is highly sensitive to the specific skills, knowledge and preferences of (usually sole) music teachers. McPhail (2012b) points out that there has been little in the way of guidance for teachers with regards to how they might manage NCEA course content, particularly for composing where very few teachers have had any formal training in either composition, or its teaching. Furthermore, the modularisation of assessment risks knowledge and skills becoming segmented. Opportunities for students to make deep connections between abstract concepts, such as music structure, 
and their practical composing skills could be lost. McPhail (2012b) asserts that "while not promoting a return to overly narrow and Eurocentric prescriptions, I consider that more detail and guidance in terms of knowledge structure and sequence would be beneficial for teachers and students" (p.325).

The Ministry of Education implemented the new national curriculum for New Zealand primary and secondary schools during the first few years of the NCEA (Ministry of Education, 2007). This meant that some NCEA achievement standards were at odds with the requirements of the new curriculum because they referenced the previous curriculum. This necessitated a comprehensive review of the NCEA in 2009 and 2010 to align the qualification with the curriculum. One of the outcomes of this review was a new NCEA assessment for music composition: AS91092 Compose two original pieces of music (Ministry of Education, 2010). This was soon followed by similar achievement standards for the NCEA Music Levels 2 and 3, thus allowing music composition by groups of students to be assessed for a secondary school qualification for the first time in New Zealand education history.

\subsubsection{AS91092 and issues for my research}

My study is about the NCEA assessment of group composing related to an achievement standard, AS91092. All NCEA Achievement standards have the same written format as the example below. Each has a number, a subject reference (in this example, "Music 1.3"), a one-sentence description and a version number. The standards are reviewed every three years. During the research period AS91092 was superseded by a new version with small changes made ${ }^{4}$. The assessment criteria for the grades of Achieved, Merit and Excellence are stated, followed by extensive explanatory notes where the criteria are explained in detail. Although unique, AS91092 bears a strong similarity to the Level 2 and 3 standards for composition. (See Appendix 1.2. for the whole document)

\footnotetext{
${ }^{4}$ In the context of this research, all references to AS91092 mean Version 1 (2010), not Version 2 (2014).
} 
Achievement Standard

\begin{tabular}{|c|c|c|c|c|c|}
\hline \multicolumn{2}{|c|}{ Subject Reference } & \multicolumn{4}{|l|}{ Music 1.3} \\
\hline \multicolumn{2}{|l|}{ Title } & \multicolumn{4}{|c|}{ Compose two original pieces of music } \\
\hline Level & 1 & Credits & 6 & Assessment & Internal \\
\hline Subfield & Music & & & & \\
\hline Domain & Making M & & & & \\
\hline Status & & Registered & & Status date & 17 December 2010 \\
\hline Planned r & view date & 31 Decembe & 2014 & Date version published & 17 December 2010 \\
\hline
\end{tabular}

This achiev ement standard irwolves the individual andior collaborative composition of two original pieces of music.

Achievement Criteria

\begin{tabular}{|l|l|l|}
\hline Achievement & Achievement with Merit & $\begin{array}{l}\text { Achievement with } \\
\text { Excellence }\end{array}$ \\
\hline $\begin{array}{l}\text { * Compose two original } \\
\text { pieces of music. }\end{array}$ & $\begin{array}{l}\text { * Compose two effective } \\
\text { original pieces of } \\
\text { music. }\end{array}$ & $\begin{array}{l}\text { Compose two convincing } \\
\text { original pieces of music. }\end{array}$ \\
\hline
\end{tabular}

Explanatory Notes

Figure 1.1 AS91092

\subsubsection{Issues raised by the inclusion of group composing into the assessment}

When AS91092 was first introduced in 2011, there were no exemplars of assessed group-composed work available for teachers to refer to, nor have there been any subsequently (Thorpe, 2012). Furthermore, as shown above, the assessment criteria were extremely brief.

The NCEA is designed to assess individuals' achievement and yet the explanatory notes in AS91092 state that "each student's creative contribution to the group composition must be individually assessed" (Ministry of Education, 2010, p.2). Unlike solo composing, where the composition itself is deemed sufficient evidence of a student's achievement, the teacher is also required to assess both the groupcomposed product and verify, if not actually assess, the individual's creative contribution to process. How this might be done, or what constitutes validity is not specified in the explanatory notes. This is the central problem addressed by this research. As Fautley (2010) explains: 
Composing is a process, and is one which is undertaken intentionally and deliberately with the aim of producing a piece of music. For educational purposes we need to distinguish between the process of composing, and the compositional product that results from it." (p.135)

It was also not clear whether the teacher was required to grade or just verify an individual student's contribution to the creative process (hereafter referred to as CCP). Furthermore, what an individual student's CCP might or should be was not clearly defined. One of the main concerns of this thesis is therefore how a teacher might reconcile the simultaneous assessment of both compositional process and product because this was not explained.

While composing has been part of the New Zealand secondary school curriculum since 1993, teachers have only been required to assess the music (the product), not the process of composing. Examination of this problem led to the generation of an initial research question, "What are the experiences of participants when group composing is assessed for qualification?" As will be explained in Chapters 3 and 4, the findings of the pilot study revealed that limiting the research to participants' experiences of the assessment meant that the data could not fully account for the complexities and wide range of variables within each case. Therefore, the first research question changed to "What is a valid contribution when group composing is assessed for a secondary school qualification?" The delineation between process and product, and their assessment became a key focus in this study.

At the outset of the research I wondered what the impact might be upon a teacher's established practice. Bearing in mind Hall's (2005) emphasis upon the importance of disciplinary and pedagogical knowledge to NCEA assessment, I also wondered whether teaching and facilitating students' composing in groups required new pedagogical approaches, and whether a non-composing teacher would possess the necessary disciplinary knowledge to do so. The assessment of individuals' composing in groups might prove problematic for teachers. This was subsequently confirmed by the pilot study, leading eventually, to the generation of the second research question: "What are the implications for teacher practice when group composing is introduced into an established summative assessment programme?" 


\subsection{Composing, teaching and assessment as practice}

Practice is more than action; it is a way of carrying out or going about action (Kemmis, 2009; Wenger, 1998). In an educational context, this could be termed pedagogy, or the practice of teaching whereby the teacher shapes curriculum content and disciplinary knowledge to engage and motivate students to learn (McPhail, 2012c). In this study, what disciplinary knowledge might or should be is part of its exploratory nature. Moreover, the study examines the contributions of both the teacher and the students to the assessment of group composing, and the impact this has for teacher practice, and by association, student learning and achievement. Composing is also practice, and both teachers and students are, to a greater or lesser extent, practitioners of music.

\subsubsection{Architectures of practice}

When practice is viewed as being situated (Lave \& Wenger, 1991), a much broader perspective emerges because "pedagogy" refers only to the actions of the teacher. Kemmis (2009) conceptualises practice as densely woven patterns of "sayings", "doings" and "relatings" and characterises these as "practice architectures", mediated by:

- cultural-discursive preconditions, which shape and give content to the 'thinking' and 'saying' that orient and justify practices;

- material-economic preconditions, which shape and give content to the 'doing' of the practice; and

- social-political preconditions, which shape and give content to the 'relatings' involved in the practice. (p.466)

Kemmis asserts that these preconditions both enable and constrain each new interaction, giving familiar practices their characteristic shapes. These concepts are highly pertinent to this study because they allow for the complexity of the context while maintaining a focus upon the actions of both teacher and students. Kemmis' practice architectures are able to account for both intrinsic and extrinsic factors related to the practices of composing, teaching, and assessment. This perspective also enables these practices to be viewed through the lens of activity theory, where practice is mediated socially, culturally, and historically in communities through tools/artefacts, rules and divisions of labour (Engeström, 1996). 


\subsubsection{Practice, identity and community}

Wenger (1998) also asserts that practice and identity are profoundly connected because in order to develop a practice one must be connected to a community. As a member of a community (for example, that of music teachers in Wellington secondary schools), individuals must therefore negotiate who they are in that context. The relationship between practice and identity is an important one in this study. Wenger asserts that practice is intrinsic to learning that he views as a social process of identity and meaning-making, taking place within communities. He observes that as we go about our everyday lives, we are members of several communities of practice and that membership is in a state of constant flux. When the teacher practice under examination in this study is considered from this perspective, it can be seen as a multi-layered concept, individual to each teacher, and interconnected to multiple practice identities (Kemmis, 2009).

Elliot (1995) calls for a praxial philosophy of music education, highlighting the importance such a philosophy places on music as a particular form of action that is purposeful and situated and therefore revealing of one's self and one's relationship with others in a community. There are clear links here to teacher practice and identity. Elliot's (1995) view is that music ought to be understood in relation to the meanings and values evidenced in actual music making and music listening in specific cultural contexts. A praxial orientation extends beyond useful, practical activity to actions that consist of undertakings and behaviours that are selective, critically informed and cognitively guided (Bowman, 2005). This is also a key concept for this study. The teacher is also "committed to the double task of the self-development of the individual learner .... and simultaneously the development of the good for humankind" (Kemmis \& Smith, 2008, p.16). This study therefore recognises the complex, situated, contextual, and moral nature of music teaching.

\subsection{Structure of the thesis}

Chapter 2 Review of literature presents the literature that informs and underpins this thesis. It defines key terms, outlines the theoretical framework of the study and locates key concepts. It begins with an examination of informal music learning literature, followed by literature about the purpose and function of assessment and assessment of learning in groups. One of the key issues in this study is how the contribution of an individual to a collaborative creative process might be assessed for 
qualification. Therefore, the nature of creativity and composing and how they are represented in the literature forms the central section of this chapter. This is followed by an examination of literature on the assessment of composition and composing. It concludes with a summary of the gaps in research and explains how this study aims to address them.

Chapter 3 Methodology presents the methodology of the study. It begins with an examination of the initial paradigm and design of the pilot study. This includes ethics procedures, data collection, and analysis methods, the object of the pilot being to gauge the appropriateness of these prior to the main study. A rationale for a radical shift in research method and stance is explained, followed by the design of the main study as collaborative practitioner research. My stance as both researcher and participant is analysed in relation to this and the research questions are presented. This is followed by background information about the participants and their schools. Trustworthiness and validity, and the methodological and ethical issues that subsequently arose during the research are explained. Data analysis methodology is presented, showing how this led to an expansion of the theoretical framework of the study to include cultural historical activity theory as a framework for the subsequent discussion of the findings.

Chapter 4 Pilot: Manuka High presents the pilot study findings and the implications these had for the main study.

Chapter 5 Kotare College and Chapter 6 St Bathan's Collegiate present the findings from the research from two cycles of collaborative practitioner research. Following an overview of each project, the research cycles are described and explained. Major themes arising from the analysis of the resultant data are then examined in relation to the research questions. The extent to which the research questions have been addressed is analysed in terms of my learning and that of the participant teachers, Alice and David.

Chapter 7 A valid contribution to social jamming and group composing is an analysis of the findings derived from the student participants' responses to the practice of composing. The influence of the activity of social jamming is discussed in relation to the activity of group composing. CHAT is used as a framework for examining two interrelated activities: social jamming and group composing. It explores how these 
activities might be associated with student expectancy and identity in relation to achievement in the NCEA, and group composing.

Chapter 8 Teaching and Assessment revisits the assessment conceptions literature in relation to the findings about the teacher participants' assessment conceptions and the implications these had for practice. Then the activity teaching group composing is discussed in detail, leading to an examination of a new activity, facilitating productive groupings, nested within the activity teaching music. The pedagogical and curriculum implications of these activities are then discussed in relation to the research questions. The purposes of assessment for group composing are discussed and Harlen's (2012) assessment dimensions are reinterpreted for group composing. Teacher identity and the nature of cognitive domain knowledge are examined in relation to the assessment of process.

Chapter 9 Conclusion summarises the findings and concludes the thesis. It considers each of the research questions in turn and shows the extent to which this research was able to address and answer them. The significance of the study is then evaluated in relation to recent research. The strengths and limitations of the findings are critically examined leading on to recommendations for future research. It concludes with personal observations of my experiences whilst undertaking this doctoral study. 


\section{Chapter 2. Review of literature}

This chapter presents an examination of the literature that informs this thesis. It locates the study within its theoretical framework and defines the key terms of the two research questions. It examines literature related to informal music learning and its relationship to curriculum and pedagogy, the purposes and functions of assessment, the assessment of learning in groups, and the assessment of creativity, composing and creative processes.

For many young people, learning happens in non-dedicated or non-regulated contexts, outside of the classroom and outside of the school (Finney, 2007; Green, 2002, 2008; Miell \& Littleton, 2008). Collaborative learning within friendship groups is the predominant way where, inevitably, information and ideas of a formative nature are both consciously and unconsciously exchanged between peers through "enculturation" (Green, 2008, p.5). Friendship groups and shared musical tastes are crucial variables in identity construction and maintenance in adolescence and, for many young people, music is their most important leisure activity (Stållhammer, 2003; Tarrant, North, \& Hargreaves, 2001; Zillman \& Gan, 1997).

In the context of this study, group composers are predominately rock/pop musicians composing in the conventions of what is sometimes referred to as garage band (Jaffurs, 2004, 2006). Most young musicians playing and composing in this way employ skills and knowledge that are informally or tacitly learned (Green, 2002; Jaffurs, 2004). Therefore this review begins with an examination of that literature.

\subsection{Informal and formal music learning}

For nearly two decades music education writers have drawn attention to a gulf between the music young people choose to play, listen to and compose for themselves, and the music of high school music programmes (Allsup, 2003; Burnard, 2012a; Finney, 2007; Folkestad, 2006; North \& Hargreaves, 1999; Sloboda, 2001). There is a tension between unregulated music learning outside of the classroom, and regulated, potentially less authentic music learning in classrooms and schools (Burnard, 2008; Burnard et al., 2008; Evelein, 2006; Finney, 2007; Folkestad, 2006; Jaffurs, 2004; Mellor, 2000; O’Flynn, 2006; Savage, 2003; Sloboda, 2001; Stauffer, 2002). Finney (2007) refers to this as "a curriculum on the edge" (p.11). While he means the music 
making of individuals in digital domains, the same can be also said for informal music learning in rock bands because they can exist both inside and outside of school structures.

\subsubsection{Green's research}

In an extensive analysis, Green (2002) investigated the nature of adult popular musicians' informal learning practices, attitudes and values. Two predominant musiclearning practices were identified. The first was solitary (usually at home) and involved experimenting, playing along with and imitating recordings, improvising, and composing. The second occurred in groups and involved both the conscious direction of peers and unconscious learning (through observing, imitating and talking). Green (2002) found that composition and improvisation were integrated with listening and revolved around music in which the musicians were thoroughly enculturated. Personal qualities such as cooperation, responsibility and commitment were highly valued, with an emphasis placed upon musicality and getting the feel right, as opposed to technical prowess. Most informal music learning processes generally happened in collaborative groups. Green (2002) compared these with traditional music learning practices at school:

Table 2.1. Informal and formal music learning (Green, 2002, as cited in Thorpe, 2008, p.39)

\begin{tabular}{|l|l|}
\hline Formal Music Learning & Informal Music Learning \\
\hline $\begin{array}{l}\text { Listening to new and often } \\
\text { unfamiliar music }\end{array}$ & $\begin{array}{l}\text { Personal choice, familiar music } \\
\text { with whom the listener identifies }\end{array}$ \\
\hline $\begin{array}{l}\text { Learning music transmission } \\
\text { through notated instructions and } \\
\text { exercises }\end{array}$ & $\begin{array}{l}\text { Recorded music as the principal, } \\
\text { aural means of music transmission } \\
\text { and skill acquisition }\end{array}$ \\
\hline $\begin{array}{l}\text { Learning through adult supervision } \\
\text { and guidance, curricula, syllabi or } \\
\text { external assessment }\end{array}$ & $\begin{array}{l}\text { Self-teaching and peer-directed } \\
\text { learning }\end{array}$ \\
\hline $\begin{array}{l}\text { Following a progression from } \\
\text { simple to complex }\end{array}$ & $\begin{array}{l}\text { Assimilating skills and knowledge } \\
\text { in haphazard ways according to } \\
\text { musical preferences }\end{array}$ \\
\hline $\begin{array}{l}\text { Listening, performing, composing } \\
\text { and improvising increasingly } \\
\text { differentiated as skills and } \\
\text { knowledge are acquired }\end{array}$ & $\begin{array}{l}\text { Listening, performing, improvising } \\
\text { and composing integrated into the } \\
\text { learning process as a whole }\end{array}$ \\
\hline
\end{tabular}


Green (2008) then investigated the extent to which the students' tacit or informally acquired musical skills and knowledge might be incorporated into classroom music. She brought informal music learning practices into junior secondary school classrooms as a "new classroom pedagogy" in order to "recognize, foster and reward a range of musical skills and knowledge that have not previously been emphasized in music education" (p.1).

The project, a mixed-methods qualitative study, ran from 2002 to 2006 and involved 21 secondary schools, 32 classroom teachers, and over 1,500 13 to 14-yearolds. It has subsequently become part of a major, national music education programme in England, known as "Musical Futures", which continues to this day.

Informal learning practices derived from her research with adults informed the five underlying principles of the project.

- Student choice in selection of initial learning material

- Learning by ear rather than reading music

- Learning and self-teaching instruments in friendship groups

- No pre-determined sequence of skill development within tasks (learning may appear unstructured and haphazard as students essentially teach themselves the instruments and songs)

- Integration of listening, performing, improvising and composing into holistic student directed activities. (Green, 2008, p.10)

Since the publication of this research and that of others, many music education scholars argue that to acknowledge the essentially self-directed, peer-mediated nature of informal music learning in contemporary popular music contexts necessitates radical shifts from musical experiences at school constrained by "regularities, rituals and formalities" of formal music learning (Finney, 2007, p.11). The intention seems to be to challenge out-dated teacher practice to include a much broader concept of music learning and music knowledge (Folkestad, 2006). These practices have since been widely accepted in music education (Burnard, 2012b).

\subsubsection{Curriculum and assessment implications of informal music learning}

Young (2010) asserts that "students do not come to school to learn what they already know" (p.25). There is a difference between the laudable educational aim of incorporating students' experiences and prior learning in the curriculum in order to make it more relevant and engaging for them, and regarding those experiences and that knowledge as curriculum (Wheelahan, 2010). Some music educators are critical of an 
undue emphasis upon informally or tacitly acquired skills and general knowledge, where the teacher merely acts as a facilitator (McPhail, 2012b).

There is a risk that this might lead to no teaching at all, just irrelevant recreational loafing, devoid of valid learning or achievement (McPhail, 2012b). Music Futures has been subject to such criticism but Green (2008) emphasises that her project was not intended to be a magic bullet for music education, warning that "if school pupils were to follow the project and nothing else, they would be likely to miss out on what most people would agree are some essential aspects of the music curriculum" (p.181).

McPhail (2012a) draws attention to possible scenarios in New Zealand secondary music classrooms, pointing to a lack of informed and skilled teacher practice and specific disciplinary knowledge. McPhail (2012c) examined the ways in which six New Zealand secondary school music teachers managed the relationship between classical and popular music in their elective music programmes. He found that the inclusion of both kinds of music as curriculum content was unproblematic. However, some teachers struggled to accommodate the types of knowledge and ways of knowing associated with each style of music. In particular, there was a gulf between teachers' disciplinary knowledge about popular music practices (associated with socially acquired, informal knowledge), and their disciplinary knowledge of classical music (usually formally and individually acquired).

Teachers' values, decisions and actions had a pivotal role in mediating this divide for their students. Employing Bernstein's (2000) concept of knowledge systems, McPhail (2013) conceptualises this as crossing the boundaries between the vertical discourse of the classical "canon", and the horizontal discourse of informally acquired knowledge and skills. Rather than peripheral, McPhail (2012c) argues that the role of the music teacher in mediating informal and formal learning discourse should be central if students are to reach their full potential as learners and musicians. A shared understanding between teacher and students of relevant conceptual and stylistic knowledge was found to be a crucial variable in achieving such a goal. As Chapters 4-8 will show, this is also one of the key findings of the present study.

Other studies of the intersection of formal and informal music learning practices have also emphasised the central role of the teacher in mediating this learning divide (Allsup, 2003; Cain, 2013; Finney, 2007; Folkestad, 2006; Jaffurs, 2006). Moreover, 
Green (2008) found that participation in the Music Futures project led some teachers to make substantial practice changes in all aspects of their teaching. These findings are of particular relevance to the present study because when informal music learning practices are part of the school curriculum, then they will probably be assessed. This has considerable implications for teacher practice.

\subsection{Theories and conceptions of assessment}

Pajeres (1992) contends that any investigation into research participants' conceptions or beliefs is complex. He also contends that distinguishing knowledge from belief is problematic. This is an important consideration for this study because assessment itself is the representation of the underlying learning theories and conceptions of learning that give rise to it. According to Pajeres (1992):

\footnotetext{
Defining beliefs is at best a game of player's choice. They travel in disguise and often under alias - attitudes, values, judgments, axioms, opinions, ideology, perceptions, conceptions, conceptual systems, preconceptions, dispositions, implicit theories, explicit theories, personal theories, internal mental processes, action strategies, rules of practice, practical principles, perspectives, repertories of understanding, and social strategy, to name but a few that can be found in the literature. (p.309)
}

Indeed, the terms theory, conception, perception and belief seem to be used interchangeably in many studies (Pajeres, 1992) while others do not define it at all (Bishop, Bullock, Martin, \& Thompson, 1999). In the context of the present study, theories, conceptions and beliefs are defined as mental representations of the practices of the assessment of learning, teaching and composing (Kelly, 1991; Thompson, 1992). Composing conceptions are examined later in this chapter.

The terms evaluation and assessment seem to be used interchangeably in the reviewed literature, with evaluation tending to be used more extensively in the American literature. In the context of this study, the term assessment is used in relation to school and qualification structures such as curriculum and the NCEA, and evaluation is used contextually in relation to the participant judgments of particular situations. Wiliam and Black (1996) define the practice of assessment as a cycle involving elicitation of evidence, and this will be used here. Assessment is defined as "deciding, collecting and making judgements about evidence related to the goals of the learning being assessed" (Harlen, 2012, p.87). Other assessment terms, key to the present study, are "formative" and "summative". 
Between the 1960s to the late 1990s there was a radical shift away from functional concerns about the reliability and validity of external testing, towards the purpose of assessment and its role in teaching and learning. Scriven's (1967) examination of assessment theories is a seminal work cited in much subsequent research and is the first significant analysis of assessment purpose and function. Although Scriven's focus is primarily upon the improvement of curriculum through evaluation, Wiliam and Black (1996) note that Scriven was the first to use the terms formative and summative to define contrasting functions of assessment (Black \& Wiliam, 1998, 2009). These terms are now in general use. Summative (assessment of learning) refers to the measurement of achievement. Formative (assessment for learning) means using assessment diagnostically and formatively to inform teacher decision-making. It is also used to give feedback to the learner to help him or her to recognise strengths and weaknesses, where the aim is for students to take an active role in their learning and engage actively in the assessment process (Black \& Wiliam, 1998, 2009).

\subsubsection{Purpose and function of assessment}

Many writers assert that the purpose for which assessment evidence is used defines its function (Black \& Wiliam, 2009; Harlen, 2005; Newton, 2007; Sadler, 1989). Assessment validity and reliability are therefore inextricably linked to the perceived purpose and function of assessment held by these different stakeholders, what they believe constitutes valid learning and how that learning should be measured. What is valid in one context, may not be in another. This is another key concept in this study.

Assessment literature generally addresses three different assessment purposes:

- assessment of learning for some form of certification, such as grades, reports and/or qualification

- assessment for the enhancement of learning (for or as learning)

- assessment for accountability of either the students, or the teachers, or both (Boud, 2009).

As has been explained in Chapter 1, this study focuses upon the first two assessment purposes related to the NCEA and group composing. How assessment is designed and implemented, and the purpose for which its data are used is primarily influenced by assessors' assumptions about what constituted learning and knowledge 
(Boud, 2009). This means that any examination of assessment requires an analysis of the epistemologies that underpin its design, implementation and use, in other words, its perceived purpose and an assessor's assumptions about what constitutes learning and knowledge. The diverse theoretical lenses through which these can be viewed, and which underpin such assumptions, are therefore an important consideration in any analysis of assessment literature.

\subsubsection{Theories of learning and their relationship to assessment}

To understand the complexities associated with the assessment of group composing and its relationship to the NCEA, it is necessary to examine the assumptions about learning that underpin assessment purposes and functions. While there is considerable agreement in the literature that there should be alignment between these, this is not always the case (James, 2012). There is tension between a teacher's professional accountability to external authorities for the validity and reliability of their assessment judgements, and meeting the needs of individual students within the local context (for example, Harlen, 2008; Savage \& Fautley, 2011).

There is also a potential mismatch between contemporary educational theory and assessment structures (Boud, 2000). As James (2012) observes, "while exciting new developments in our understanding of learning unfold, developments in assessment systems ... have lagged behind" (p.189). Therefore, key theories of learning relevant to assessment are examined in the next section.

\subsubsection{Behaviourist}

This theory considers learning as a conditioned response to external stimuli (learning is being taught). Learning is most effective when complex ideas are reduced to a series of achievable steps where the student does not move on to the next step until mastery has been achieved. Knowledge is viewed as a fixed and thus measurable commodity (Inbar-Lourie, 2008). The teacher is in the centre of the learning picture, passing on an established, socio-historical canon to the student (Hofer \& Pintrich, 1997).

While this theory of learning fell out of favour with educators many years ago, behaviourist perspectives nevertheless pervade many assessment structures (James, 2012). As will be revealed in the findings and discussion, this was occasionally so for this study. Behaviourist assessment still exists in some areas of music education, derived from teacher-centred behaviourist views of teaching and learning, often in 
combination with structuralist Piagetian views of human development (Fautley, 2010). The notion of learning by sequential, numbered grades, assessed through performance examinations (such as those administered by the Royal Schools of Music for example) is familiar to many people, and graded "method" books are used widely by teachers across the world. While some scholars challenge the conservatoire to consider the impact of informal, socially constructed learning in music, a behaviourist assumption that assessment means formal testing of sequential and hierarchical skills remains well established in music education, particularly with regard to learning to play a musical instrument (Green, 2008; Lebler, 2008). This is also a widely held assessment view in many communities, often referred to as the "folk" view of assessment (Fautley, 2010, p.3). As the findings will show, this assessment view was (at least initially) held by all of the teacher participants in this study.

\subsubsection{Social-constructivist}

In contrast, social-constructivists consider that learning is constructed between people, mediated by culture and its artefacts, notably language, where a child appropriates knowledge socially through interaction within a socio-historical context (Vygotsky, 1978). Vygotsky's zone of proximal development (ZPD), or each person's range of potential for learning (Smagorinsky, 1995) is a key concept. Vygotsky defines the ZPD as the distance between what a child might achieve alone and what he or she can achieve with adult assistance, or in the company of more capable peers, where there is an assumption that learning is shaped by the cultural and social environment in which it takes place.

This has implications for this study because, while group composers may learn together, their learning will be individually assessed. Therefore, a social constructivist assessment perspective recognises that both knowledge and learning are multi-faceted and highly sensitive to context (Inbar-Lourie, 2008). The learner is placed in the centre of the learning picture, with the teacher alongside to scaffold and support learning (Assessment Reform Group, 2002). Learning is context-bound and intertwined with assessment in a dynamic system of feedback and feed forward, where assessment is for learning, rather than of learning (Black \& Wiliam, 2009). Both product (the learning) and process (how learning occurred) are assessed. 
James (2012) asserts that:

Vygotsky's theory of goal-oriented, tool-mediated activity can encompass learning outcomes associated with notions of learning as acquisition of knowledge and learning as participation in activity (Sfard, 1998). But it also embraces outcomes associated with creativity because it provides a description of how knowledge and practices can be transformed. (p.193)

From the perspective of this study, where informal music making and its creative acts are viewed as evidence of learning, it is possible to connect successful group learning with successful collaborative composing.

\subsubsection{Socio-cognitivist}

Socio-cognitivists theorise learning as individual sense making. The emphasis is upon the development of internal mental models or schema, based upon prior knowledge, to construct understanding (James, 2008). The individual learner is in the centre of the picture, and assessment is of the learner's understanding of concepts and their relationships, as well as their competencies when applying that understanding, rather than a demonstration of what was taught (James, 2012). Central to this theory are cognitive models of mind, where there is an emphasis upon problem-solving, and self-monitoring and self-regulation are important dimensions (Zimmerman \& Schunk, 2008). This is examined later in this chapter in relation to models of the compositional process. Cognitivists view learning as the property of the individual that exists independent of others, within the individual mind. This is very different from that of behaviourists and there are extensive implications for teacher assessment practice necessitating, in some cases, radical shifts in teacher beliefs and assumptions about learning (James \& Pollard, 2011).

Fautley's (2010) representation of the complexity of knowledge in music education reflects a generally social-cognitivist assumption that musical knowledge resides within the minds of both the individual student and the teacher. Musical knowledge is both complex and interrelated, partly constructed between the teacher and the student. This also is generally representative of the NCEA and therefore pertinent to the present study. 


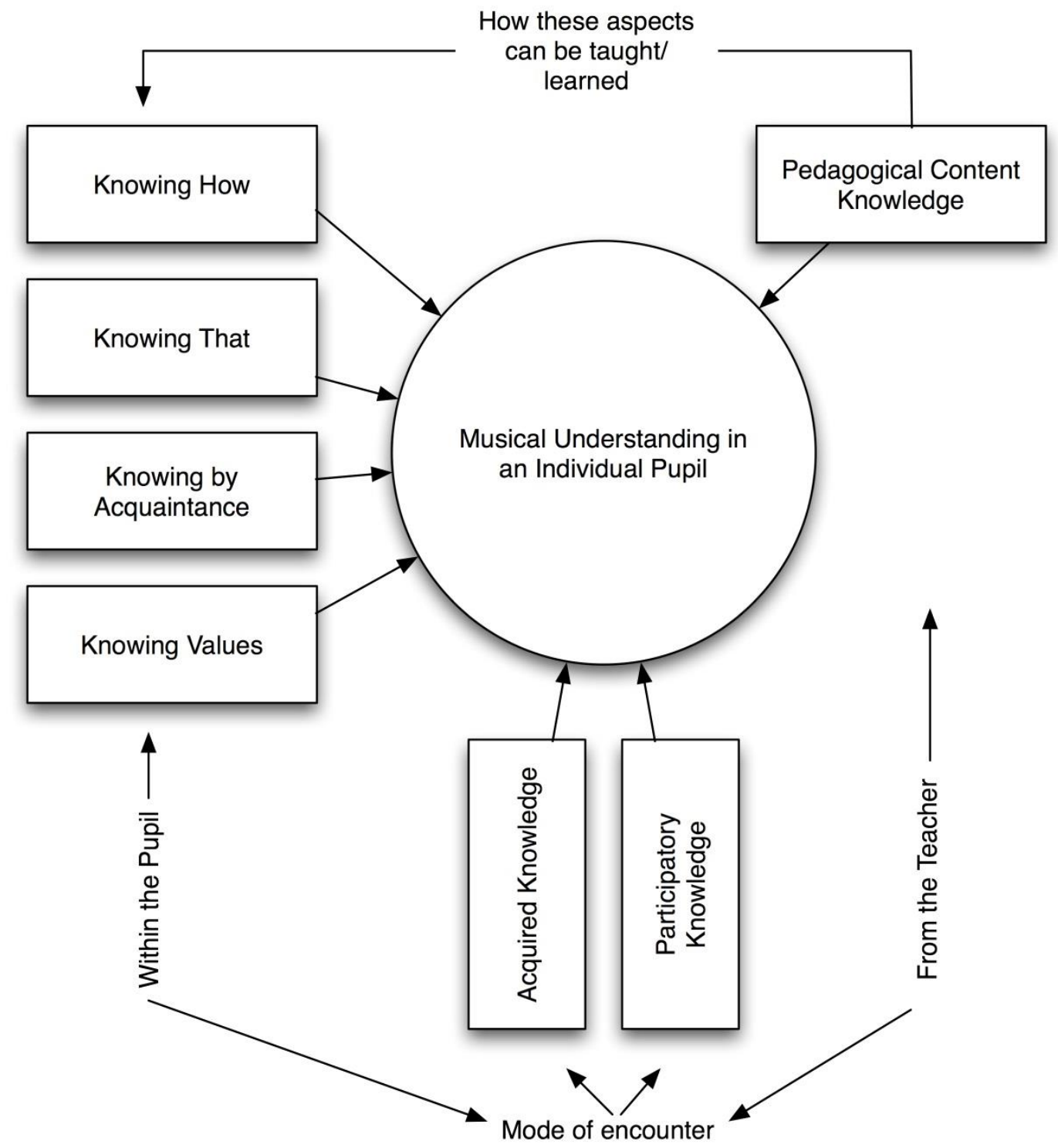

Figure 2.1. Complexity of knowledge in music education (Fautley, 2010, p.56)

Fautley suggests that, at a simplistic level, assessment could consider the four dimensions on the left of the diagram "within the pupil" as a starting point for what to assess in music education, reflecting a combination of behaviourist and sociocognitivist assessment views. While he observes that much musical knowledge and skill is "picked up implicitly due to enculturation" (p.54), where everyone is an expert in their own culture, what this kind of assessment does not consider is that musical skills and knowledge could also be constructed between students through interactions that may or may not take place within educational structures. This implication for the present study is that informal music practices could be problematic for an assessment structure, like the NCEA, which is generally cognitivist in its orientation. 


\subsubsection{Socio-culturalist}

As has been explained in Chapter 1, an examination of the assessment of group composing for qualification is complex and involves multiple perspectives, necessitating a socio-cultural view. Socio-culturalists view learning and its assessment as something that happens between people within their social environment (Allal, 2013; James, 2012). Learning is a mediated activity, where artefacts such as physical resources, but more importantly language, play a crucial role. Socio-culturalists believe that language is central to our capacity to think and that it arises out of relationships between people. This means that social relationships precede learning and that learning could not happen without them (Vygotsky, 1978). Therefore, intellect cannot be separated from "the fullness of life, from the personal need and interests, the inclinations and impulses of the thinker" (Vygotsky, 1986, p. 10).

Key socio-cultural theorists such as Rogoff (1990) and Lave and Wenger (Lave \& Wenger, 1991; Wenger, 1998) regard learning as situated. Lave and Wenger also characterise learning as apprenticeship, taking place within communities of practice where novices learn through participating in the actions of the community alongside more experienced members (Wenger, p.100). Learning is socially mediated through tools, or artefacts, including language (Cole \& Engeström, 1993; Vygotsky, 1978). Given the strongly practice-oriented nature of both group composing and teaching, this is a highly appropriate way in which to examine these complexities.

If the socio-cultural view is that "learning is building knowledge through doing things with others", then the learner is no longer at the centre of the picture, nor is the teacher, but rather both are placed within a complex web of social interaction, mediated by culture and its artefacts (James, 2012, p.192). Expansive learning cycles are created when the individual internalises the group or community's collective knowledge, and then externalises new learning to be subsequently shared and appropriated by others who in turn internalise it (Engeström, 2001). Learning may occur within communities of practice where novices gain legitimate membership of that community and its knowledge through peripheral participation alongside more expert or knowledgeable members (Wenger, 1998). There are clear parallels here with the informal music learning literature examined earlier, and the examination of creativity literature which follows. 
When summative assessment is viewed through the lens of socio-cultural theory, James (2008) concludes that:

- If learning cannot be separated from the actions in which it is embodied, then assessment too must be situated.

- Assessment of group learning is as important as the learning of the individual.

- "In vivo" studies of complex problem solving may be the most appropriate form of assessment to take.

- The focus should be on how well people exercise "agency" in their use of the resources or tools (intellectual, human, material) to formulate problems, work productively and evaluate their efforts.

- Learning outcomes can be captured and reported through various forms of recording, including narrative accounts and audio-visual media. The portfolio has an important role here.

- Evaluation needs to be more holistic and qualitative, not atomised and quantified as in measurement approaches. (p.31)

As the findings will show, these criteria have particular relevance for this study. The question they raise, however, is how these views might be reconciled with grading group composing for the cognitivist assessment orientation of the NCEA. Sociocultural views of learning and collective knowledge pose considerable challenges to externally administered summative assessment and grading systems where the focus is almost always upon that of the achievement of an individual as the property of that individual, not the group (James, 2012).

As Boud (2000) observes, "every act of assessment we devise or have a role in implementing has more than one purpose. If we do not pay attention to these multiple purposes we are in danger of inadvertently sabotaging one or more of them" (p.160). The findings of this study will show that these challenges are highly pertinent to the assessment of group composing for a secondary school qualification and raise considerable issues for teacher practice.

\subsubsection{Assessment conceptions of teachers and students}

Assessment is shaped by the particular socio-political forces within them (Brown, 2011). Teacher and student conceptions of what assessment is for and how it works are crucial variables in any examination of assessment but the contexts of assessment literature are highly diverse. This is because the way assessment is carried out in schools reflects the diverse understandings of different societies and cultures about the nature of learning and achievement. The assessment systems and 
qualification structure under scrutiny here are derived from New Zealand educational values and assumptions about what constitutes knowledge and how learning occurs. These differ from country to country and are derived from specific socio-political structures (Swaffield, 2011). Therefore any examination of assessment must be placed within its particular context.

\subsubsection{Teachers' assessment conceptions}

There are tensions when assessment has multiple purposes, particularly between externally imposed assessment systems (such as national literacy or numeracy standards) and assessment for learning (Brown, 2004; Black, Harrison, Lee, Marshall, \& Wiliam, 2003; Clark, 2005; Crooks, 2002; Hargreaves, 2005; Newton, 2007). Teachers struggle to cope in such scenarios (Brown, 2004, 2011; Brown \& Hirschfeld, 2008; Harlen 2005; Newton, 2007; Peterson \& Irving, 2008).

In a comparison of the assessment conceptions of 473 primary and 504 secondary school teachers in New Zealand, Brown (2011) found that the secondary teachers generally conceive of assessment as being a more formal and summative process than primary teachers, who relate it more to student learning. Brown (2011) observes that there has been very little investigation into assessment conception and its relationship to school context.

In a similar study, Brown (2004) also found that teachers' conceptions of assessment include potentially conflicting beliefs about the relevance, or otherwise, of assessment, its role in improving student learning and whether assessment can make students accountable for their learning. These beliefs about the purposes of assessment can lead to different practices. Consistent with earlier literature, Brown also found that the teachers' espoused assessment beliefs were not necessarily enacted in the classroom (Harlen \& James, 1997).

\subsubsection{Conflicting views of assessment's purposes and functions}

If assessment views are derived from the viewer's understanding of what constitutes valid knowledge and learning, then qualification systems such as the NCEA are themselves representations of these understandings (Gardner, 2012; James, 2012; Swaffield, 2011). As explained in Chapter 1, New Zealand secondary music teachers walk a fine line between target-driven, instrumentalist demands from external groups, such as government and qualification authorities, parents and employers, school management, even their own students, and a professional desire to use assessment 
strategies pedagogically for the enhancement of learning and student engagement (Brown, 2011).

While the former requires valid and reliable assessment judgements that are readily and statistically comparable to national benchmarks of achievement, the latter necessitates a local focus upon the needs of particular students acting in particular school, classroom and musical environments. Lebler (2008) observes that in informal music learning environments, such as group composing in a garage band, "it is normal for learning to be autonomous, self-assessed and intrinsically motivated" (p.194). What is reliable and valid in one context, therefore, may not be the case in another and where the two are combined there may well be a mismatch (Brown, Lake, \& Matters, 2011).

External assessment structures inevitably influence teachers' assessment practice, and, thus their teaching (Harlen, 2004; Savage \& Fautley, 2001). Where there is pressure to prioritise this accountability assessment processes risk becoming teaching and learning instruments in their own right. As such, an instrumentalist view means that the assessment tail sometimes wags the learning dog (Fautley, 2010). Summative assessment then becomes the primary pedagogical focus, often referred to as teaching to the test (Fautley, 2010).

In the context of the present study, summative assessment is carried out by the teacher, not an external authority. In such contexts there is evidence to suggest that the boundaries between formative and summative assessment practices can become pedagogically blurred (Fautley \& Savage, 2011). Furthermore, Harlen and James (1997) found that a teacher's espoused beliefs about learning and assessment are not necessarily enacted. The purposes of assessment can become confused in practice and that as a consequence, assessment can fail to have a truly formative role in learning, particularly with regard to "deep learning" or learning for understanding. Harlen and James contend that the essential differences between summative and formative assessment have been "smothered" (p.365) because their purposes have been confused.

\subsubsection{Students' assessment conceptions}

Relatively few researchers have examined the relationship between students' conceptions of summative assessment systems and their motivation to achieve within 
those systems (Brown \& Hirschfeld, 2008; Meyer, McClure, Walkey, Weir, \& McKenzie, 2009; Peterson \& Irving, 2008).

Peterson and Irving investigated junior secondary students' conceptions of the purpose of assessment and its perceived impact on them, hypothesising that New Zealand secondary students' conceptions of assessment would be in consonant with Brown's (2004) study of teachers' assessment conceptions. Consistent with Brown (2004), students conceived of assessment as being inextricably linked to feedback, as helping them to improve, and that they believed it was a good progress indicator. The authors found that, unlike the teachers in Brown's (2004) study, the students believed that assessment was irrelevant or served no purpose if it was not formally graded or done by teachers (self or peer assessment, for example). Interestingly, most students believed that their good marks were the result of their own hard work but that bad marks were not due to a lack of effort!

Meyer et al. (2009) examined the interrelationships between the beliefs, values and motivation of over 3,000 NCEA candidates, across multiple NCEA subjects, and their actual overall achievement. The authors hypothesised that the high level of choice available to students within the NCEA would impact negatively on students who were motivated to do only just enough to pass, while encouraging others to take an active role in their own learning and achieve their best.

Results suggest that the strongest predictors of academic achievement in the NCEA are student self-ratings for two factors: doing my best, and doing just enough. Doing my best was found to be a fairly strong predicator of higher grades, while those students who rated their approach to the NCEA as doing just enough (to achieve) were much more likely to achieve lower grades. Gender, socio-economic status, and ethnicity were also found to be influential factors. The authors suggest that "students may modify their approach to educational tasks within a personally meaningful conceptual framework" (Meyer et al., 2009, p.288).

In the context of this research, this begs the question as to whether or not students view composing in a band as being an "educational task", and whether they are motivated to compose in order to achieve in the NCEA, or for other reasons. These findings informed the creation of a number of questionnaires used in the present study, where the aim was to gain an understanding of group composers' attitudes to NCEA achievement and composing music. See Chapters 5 and 6. 
Subject choice may be an important variable in students' beliefs about summative assessment. The NCEA gives students the opportunity to choose not only the subjects they will be studying but also which assessments they will complete within subjects, with the expectation that they will take an active role in making decisions about their learning (Meyer et al., 2009). Hipkins and Vaughan (2002, 2004) conducted a longitudinal study of the impact of the implementation of the NCEA between 2002 and 2004. Their findings suggest that there was a strong tendency for students to be quite strategic in their choices of NCEA subjects and that their decisions were influenced both by their perceptions of the NCEA assessment system as a whole and their motivations as learners (Hipkins \& Vaughan, 2005).

\subsubsection{A broad assessment conception is required for group composing}

Much empirical literature applicable to school contexts makes the assumption that the student is an individual learner, and that achievement involves reading, writing and/or talking within formal classroom structures. As shown in the informal music learning literature, this is not necessarily the case for group composing in bands where its outcome, the composition, is subject to constant change, as are the interactions between group members. Furthermore, group composing takes place at the intersection of formal learning at school, and informally acquired knowledge and skills outside of school.

The assessment of group composing therefore requires a very broad assessment view because, in order to assess an individual's contribution fully, it is necessary to consider not only the outcome of learning (the composition), but also the complex socio-musical processes that gave rise to its creation (Fautley, 2010).

Harlen's $(2008,2012)$ assessment perspective aligns with the epistemology of the present study. Harlen (2008) asserts that formative and summative assessment is not a simple dichotomy (for and of learning) but rather, a series of interacting dimensions whose purposes are defined by their intended use. She defines these as: informal-formative, formal-formative, informal-summative and formal-summative (Harlen, 2012). These dimensions reflect different assessment purposes, used in different ways, by different stake-holders, such as the students, the teacher and an external marker, and are represented in Table 2.2. 
Table 2.2. Dimensions of assessment purposes and practices (Harlen, 2012, p.98)

\begin{tabular}{|c|c|c|c|c|}
\hline \multicolumn{5}{|c|}{ Formative $\longleftrightarrow$ Summative } \\
\hline & $\begin{array}{l}\text { Informal } \\
\text { formative }\end{array}$ & $\begin{array}{l}\text { Formal } \\
\text { formative }\end{array}$ & $\begin{array}{l}\text { Informal } \\
\text { summative }\end{array}$ & $\begin{array}{l}\text { Formal } \\
\text { summative }\end{array}$ \\
\hline Major focus & \multicolumn{2}{|c|}{ What are the next steps for learning? } & \multicolumn{2}{|c|}{ What has been achieved to date? } \\
\hline Purpose & $\begin{array}{l}\text { To inform next } \\
\text { steps in learning }\end{array}$ & $\begin{array}{l}\text { To inform next } \\
\text { steps in teaching }\end{array}$ & $\begin{array}{l}\text { To monitor } \\
\text { progress against } \\
\text { plans }\end{array}$ & $\begin{array}{l}\text { To record } \\
\text { achievement of } \\
\text { individuals }\end{array}$ \\
\hline $\begin{array}{l}\text { How } \\
\text { evidence } \\
\text { collected }\end{array}$ & $\begin{array}{l}\text { As normal part of } \\
\text { class work }\end{array}$ & $\begin{array}{l}\text { Introduced as } \\
\text { normal part of } \\
\text { class work }\end{array}$ & $\begin{array}{l}\text { Introduced as } \\
\text { normal part of } \\
\text { class work }\end{array}$ & $\begin{array}{l}\text { Separate task or } \\
\text { test }\end{array}$ \\
\hline $\begin{array}{l}\text { Basis of } \\
\text { judgement }\end{array}$ & $\begin{array}{l}\text { Student and } \\
\text { criterion } \\
\text { referenced }\end{array}$ & $\begin{array}{l}\text { Student and } \\
\text { criterion } \\
\text { referenced }\end{array}$ & $\begin{array}{l}\text { Criterion } \\
\text { referenced }\end{array}$ & $\begin{array}{l}\text { Criterion } \\
\text { referenced }\end{array}$ \\
\hline Judged by & $\begin{array}{l}\text { Student and } \\
\text { teacher }\end{array}$ & $\begin{array}{l}\text { Student and } \\
\text { teacher }\end{array}$ & Teacher & $\begin{array}{l}\text { Teacher or } \\
\text { external marker }\end{array}$ \\
\hline $\begin{array}{l}\text { Action } \\
\text { taken }\end{array}$ & $\begin{array}{l}\text { Feedback to } \\
\text { students and } \\
\text { teacher }\end{array}$ & $\begin{array}{l}\text { Feedback into } \\
\text { teaching plans }\end{array}$ & $\begin{array}{l}\text { Feedback into } \\
\text { teaching plans }\end{array}$ & $\begin{array}{l}\text { Report to student, } \\
\text { teacher, parents, } \\
\text { others etc }\end{array}$ \\
\hline Epithet & $\begin{array}{l}\text { Assessment for } \\
\text { learning }\end{array}$ & Matching & Dipstick & $\begin{array}{l}\text { Assessment of } \\
\text { learning }\end{array}$ \\
\hline
\end{tabular}

The appropriateness of Harlen's assessment model for the present study is that both the teacher and the students are present within it and that there is room for those within the action to move between complex layers of assessment purpose and function. This model is reinterpreted in Chapter 7 .

Boud (2000) takes a similar stance to Harlen, asserting that assessment is "always doing double duty" (p.159). This is because, whether or not they are intended as such, assessments (such as AS91092, for example) have multiple purposes, such as: formative assessment for learning; summative assessment for certification; and the pedagogical requirements of assessment. These entail the teacher focusing on the immediate task and assessing the learning process and the extent of the students' disciplinary knowledge, while keeping in mind the need to equip students for lifelong learning in an unknown future. 
There is considerable evidence in the literature that strategic use of formative assessment, where students are active participants in the evaluation of their learning, leads to a deepening of the teacher-student relationship, and improved learner autonomy (Willis, 2011). While Black, Harrison, Hodgen, Marshall and Serret (2010) contend that the integration of summative assessment into the daily pedagogy of teachers is problematic, they also suggest that teachers may be able to develop strategies to promote such positive interaction between their formative and summative assessment practices. As Chapters 5 to 8 will show, this is a key teacher strategy in the present study.

\subsection{Studies of the assessment of learning in groups}

In an extensive review of literature concerned with the assessment of collaborative learning, van Aalst (2013) identified the following issues, all of which have a bearing upon the present study:

1. If assessment is based on a group product, this it is difficult, if not impossible to ascertain what individual students have learned.

2. If students are assessed individually after learning in a small group, then what they know is measured correctly, but is attributed incorrectly to their personal achievement. A well-functioning group can solve more difficult problems than any single student.

3. Assessment practices treat collaboration as a method for accomplishing learning but it can be argued that it should be seen as a human capability worth assessing in its own right. Collaboration distributes the learning process over students and there is a potentially powerful role for assessment in the development of such practices.

4. Situations in which collaborative learning is most necessary, in the sense that it would be impossible to achieve learning goals without the cognitive benefits of collaboration reference in Issue 2, all involve novelty, problem solving, and creativity. In these situations, there are qualitative differences in the outcomes generated by different teams, rendering objective and reliable assessment difficult. (pp.280-281)

In comparison with the very large body of research into group learning and assessment, there is very little that investigates the assessment of learning in groups, particularly of individuals engaged in collaborative creative activities (van Aalst, 2013).

\subsubsection{Learning within groups}

Many studies of the assessment of learning in groups consider the effect of feedback upon group members and usually take a social-constructivist stance, often incorporating Vygotsky's (1978) ZPD. Such studies seem to have arisen from the cooperative learning movements of the past thirty years, and most seek to ascertain the 
benefits of group learning through the comparison of the assessment of student achievement in groups with that of students working individually (for example, Boud, Cohen, \& Sampson, 1999; Johnson \& Johnson, 2004; Knight 2004; Mello, 1993; Webb, 1997; Webb, Nemer, Chizik, \& Sugrue, 1998). The purpose and intent of studies of this kind are essentially pedagogical and they are strongly influenced by social-constructivist theories of learning discussed earlier. Key foci are the centrality of assessment task design, teachers' and students' understanding of the assessment's purpose, and how a teacher manages the make-up of the groups.

Some writers contend that in the interests of all students, teachers should ensure a mix of abilities and achievement levels in all groups, so that there are high-achieving students in every group (Webb, Farivar, \& Mastergeorge, 2002). Johnson and Johnson (2004) refer to these as "productive groups", a term that will be used extensively in this study (p.23). However, Johnston and Miles (2004) found that organising groups in this way may be disadvantageous to the high-achieving students. Furthermore, there is considerable evidence to suggest that group problem solving involves highly diverse and highly complex processes, sensitive to a myriad of socio-cultural factors, no matter what the abilities of the students (van Aalst, 2013). Barron (2003), in particular, is critical of such instrumentalist views of collaborative learning. Consistent with Webb et al. (2002), Barron's research into the group make-up in 12 triads of sixth-graders indicated that the most effective collaborative learning involves "coordinated coconstruction" and even heterogeneous groups containing high-ability students can be problematic to assess (p.344).

\subsubsection{Grading achievement in groups}

Studies concerned with the "how to" of assigning grades to students learning in groups all grapple with the issues raised by van Aalst (2013). Most studies are situated in tertiary education or the workplace, particularly in medical and health teams, and usually make the assumption that the assessment will be based on the output of the group as a whole, rather than an individual's processes, and that the group's work will be assessed as a single entity. Johnston and Miles (2004) suggest that awarding one grade had little bearing on the validity of the grades for most students, but that this might not be so for high or low achievers. The implication for the present study is that the achievement of novice or expert group composers may be sensitive to the assessment of process. 
Johnston and Miles examined self and peer assessment in an undergraduate social psychology laboratory course in a New Zealand university. Consistent with similar research (Falchikov, 1991; Lejk \& Wyvill, 2001), they found that "converting a given student's contribution to a group into a numeric grade is a complicated task" (p.751). Working in 15 groups, 61 students scored the contribution of themselves and their group members to a variety of tasks within the assignment. The students' contribution ratings were then correlated with performance on individual written assignments about the group's project. While the students took peer-assessment seriously, individuals tended to show self-bias in self-assessment and there was little relationship between self and peer assessment scores. The authors remain unconvinced that self-assessment should not be used in the assessment of group processes however, arguing that its inclusion encouraged individual students to reflect upon their contribution to the group's processes, and so develop critical and reflexive thinking skills. Johnston and Miles also found that peer assessment encouraged students to pull their weight in the group because they knew their individual contributions were going to be assessed by their team members, arguing that this enhanced the learning experience of students and minimised "free riding" (p.766). For most students, their final grades were not substantially moderated by the contribution index. However, peer-assessment was found to be sensitive to the grades of the highest and lowest achieving students and may possibly have exacerbated the high-ness or low-ness of these students' grades.

Although the influences of friendship groups at school upon learning have been extensively studied, much of the literature on group learning does not investigate the influence of students' informal peer learning. Parr and Townsend (2002) found that peer influences and counter-cultures in some groups have potentially negative effects on learning at school. The assessment of group composing may involve learning that is highly influenced by peer culture. While teachers will have some role to play in creating a learning environment within which the students can compose their songs, the music composed may be derived from the very counter-cultures educational researchers have identified as having negative influences upon student learning.

A number of studies provide significant evidence that assessing an individual's achievement within either a group process or of a group product might have a negative effect upon both learning and motivation (Johnson \& Johnson, 2004). Johnson and Johnson found that when an individual is evaluated when working on a new and 
complex task with others, then that person's performance is impaired by increased levels of anxiety, apprehension and distraction and that, conversely, working in a group without individual assessment "creates mild physiological arousal that energizes us to engage in the work" (p.13). I have been unable to locate any studies on the assessment of individuals' achievement in creative groups.

\subsection{Creativity and its relationship to assessment}

Nowhere are the tensions between conflicting concepts of assessment more contested than in the assessment of artistic expression and its processes (Eisner, 2007). The assessment of artistic works themselves is, and has always been, contentious because, as Eisner (2007) observes, "conceptualizing productive idiosyncrasy as an educational goal has much to do with what the arts promote. Such an aspiration frequently flies in the face of the aims of typical assessment programs" (p.425).

Assessment arises out of our propensity to look for and generalise indicators of academic performance, whereas the arts, music in this case, seek "productive idiosyncrasy and individualized distinctiveness" (Eisner, 2007, p.423). Composing is a subjective act, as is a person's response to it (Asmus, 1999; Burnard, 2007; Hickey, 1999, 2003; Murphy \& Espeland, 2007; Wiggins, 2007). The last thing an assessment model (like the NCEA) needs is a surprise, and yet, for creative artists, this is often the goal. The objective assessment of creative products is therefore fraught with difficulty and controversy. Even the idea of declared assessment criteria for creative works is a fairly recent one (Boyce-Tillman, 2003).

Traditionally, the assessment of a composition or musical performance has been the domain of the high-status expert whose recognised expertise confers the right to make a judgment without need for justification (Odam, 2001). Faulkner (2003) challenges this, arguing that this assessment view is a problematic way to address group composing and its processes. As explained in Chapter 1, NCEA group composing assessment includes individual students' contributions to the creative process. Therefore, it is necessary to review creativity literature, with specific focus upon what is known about the nature of creativity and compositional process, and the implications these have for the assessment of group composing.

The term creativity is a complex and vague one (Odena, 2012a). Western educational scholars generally regard creativity as "a thinking style manifested in 
actions", reflecting a generally social-cognitivist view (Odena, 2012a, p.514). Psychological theories of creativity, however, generally focus upon characteristics of individuals related to thinking styles and aspects of personality. Odena's (2012b) review of literature reveals that psychological studies of creativity usually make the assumption that it is a normally distributed trait within the population, and that everyone is creative to a greater or lesser extent.

Consistent with the reviews undertaken by Odena (2012a) and Hickey (2007), four significant areas of research into the nature of musical creativity were revealed by my analysis:

- Theories and conceptions of creativity

- The creative environment

- Studies of creative processes

- Assessment of creativity

\subsubsection{Theories and conceptions of creativity}

If assessment structures and practice are a response to theories and conceptions of what constitutes valid learning and how learning occurs, then the assessment of creative processes must also be sensitive to assessors' theories of conceptions of these.

Two theories of musical creativity are in evidence in the literature. The first is what is often termed the romantic or traditional concept of composing, (Odena, 2001), or sometimes a first generation creativity concept (Houmann \& Sæther, 2014). Boden (1996) calls this historical, or H-creativity, derived from the popular $19^{\text {th }}$-century notion of a great compositional genius (Beethoven, for example) toiling away in solitude, awaiting a flash of (possibly divine) inspiration, where the ideas that are generated are wholly original and new. Odena (2001) develops this idea as the concept of traditional creativity that recognises the creation of new and original ideas that have value within a community, and are usually those of adult artists. Sometimes this is referred to as big- $C$ creativity (Craft, 2005; Kaufman \& Beghetto, 2009a).

The second theoretical view of creativity takes a socio-cultural stance within music education (Burnard, 2012a; Fautley, 2010; Odena, 2001) and is a second generation creativity concept (Houmann \& Sæther, 2014). Often in the music classroom a student or group of students will compose music that is not only highly derivative, but strikingly familiar to the music teacher. This does not mean that the young composers hear their music in this way however. At such moments the idea may 
be completely new to the students and they may well regard their compositions as great achievements (Fautley, 2010).

Boden (1990) calls this psychological creativity, or being P-creative that involves "a surprising, new idea that's new to the person who comes up with it. It doesn't matter how many people have had that idea before" (p.2). This developmental view of creativity has much broader applications within education, particularly schools (Savage \& Fautley, 2007). Sometimes it is referred to as little-c creativity (Kaufman $\&$ Beghetto, 2009b).

Kaufman and Beghetto (2009b) expanded the dual view of creativity into a four-fold model: mini-c, which is transformative learning involving personally meaningful interpretations of experiences, actions and insights; little-c which is everyday problem solving and creative expression; Pro-C, which is the creativity of (adult) professionals who are not necessarily leaders in their fields; and Big-C which is the creativity of those whose influence results in change in the field itself (John Lennon and Paul McCartney, for example). The authors intended this model to be used to evaluate the creativity of individuals, not groups.

Tensions and contradictions arise when differing views of creativity clash, particularly when young people's composing (often P-creativity) is assessed by teachers using H-creativity criteria (Fautley, 2010; Odena \& Welch, 2012; Savage \& Fautley, 2011). As the findings will show, this tension is particularly pertinent to the high-stakes nature of assessment in this study because the creativity conception of the teacher has a bearing upon their assessment practice.

\subsubsection{Creativity as conceptualised in music education}

Creativity is a burgeoning field of research and a recurrent topic in education (Odena \& Welch, 2012). Many studies of creativity focus upon complexity and originality in adults, whereas music education research tends to focus upon the mastery of musical skills in children and young people. Here creativity is viewed as “imagination successfully manifested in a valued pursuit” (Odena, 2012a, p.515). This study is situated in schools where the composers are adolescents, and so this is how creativity is defined in this study. Skills which facilitate creativity include: 
Sensitivity to pinpoint and restate problems in ways that provide new insights; fluency to generate large numbers of relevant ideas; originality to generate unusual ideas; analysis to break down the problem into its constituent parts; and synthesis to see connections between its parts and other areas of experience. (Odena, 2012a, p.514)

In an extensive review of literature, Hickey (2002) found that general psychological models of creativity postulate a U-shaped development: high creativity in early childhood, followed by a gradual slump in adolescence leading to greater levels of more sophisticated creativity in adulthood. Music education research, however, suggests that musical creativity develops progressively and that children move through successive levels of mastery. This is an important concept when considering the learning and achievement of students in groups where there is a diversity of skills and knowledge.

Burnard (2012b) contends that "the unique challenge of musical creativity as it relates to music educational systems is to comprehend the multiplicity of forms, fluid roles and meanings defined in contemporary popular musics" (p.8). She warns that there are huge changes occurring in musical creativity in the $21^{\text {st }}$ century due to the ubiquitous nature of electronic media, and musical forms are highly diverse, occurring in "social and cultural sites and activity systems in which music creativities are increasingly complex" (p.9). She calls for a re-thinking of what is understood to be creativity in music education, believing it to be an urgent issue for music educators because these complexities and multiplicities are not sufficiently recognised by curriculum and assessment systems. The implication this issue has for this study is that if students' responses are as diverse and complex as Burnard contends, then the assessment system that measures their achievement may not necessarily be aligned with this rapid rate of change.

\subsubsection{Creativity conceptions of teachers}

As has been explained earlier, the musical practices adopted by students are closely related to the styles of music they compose (Burnard, 2012b), requiring a rich spectrum of pedagogical approaches on the part of the teacher (Tobias, 2012, 2013). Musical creativity practices are, in turn, influenced by the pedagogical traditions of each country (Odena, 2012a).

In a four-year study of secondary music teachers' perceptions of student creativity, Odena and Welch $(2007,2009)$ found that the teachers' life experiences as 
musicians were also significant factors. Teachers who had wide experience of diverse musical styles, particularly in composing, tended to have more open views about what constituted valuable creative processes, and were more tolerant of divergent student responses to composing, compared with teachers whose personal musical experiences were limited to one kind of musical context.

In this small sample of only six teachers from diverse school contexts, the teachers' professional experiences of learning, and experiences of initial teacher education were not found to influence perceptions of students' composing to any measurable extent. One teacher working in low-socio economic communities believed that her students' family backgrounds had a strong influence upon their creativity, whereas other teachers working in relatively affluent schools did not.

Like much of music education research, this is a small-scale study (Burnard, 2007) but there is an implication that a teacher's lived experiences as musician, rather than teacher, could have a significant impact upon his or her perception (and thus assessment) of students' creativity. Other studies also assert that a teacher's personal experience of life and music affect their teaching (Carlisle, 2013; Craft, 2005; GeorgiiHemming, 2006; Macdonald, Hargreaves, \& Miell, 2009). It follows, therefore, that these experiences might impact upon the creative environment fostered by the teacher (Lewis, 2012). As the findings will show, this was very much the case for both teachers in this study.

\subsubsection{Flow}

Csikszentmihalyi (1999) proposed a systems view of creativity, emphasising socio-cultural factors within what he terms the "domain" and the "field" (Barratt, 2005, p. 180). Creativity exists within the individual, and is distributed between individuals in groups. He described a system where "a set of [external] rules and practices must be transmitted from the domain to the individual. The individual must then produce a novel variation in the content of the domain; the variation must then be selected for inclusion in the domain" (p.315).

An important creativity concept for this study is flow: the effortless involvement in the activities of everyday life when we are totally absorbed in doing things we enjoy. Sheridan and Byrne (2002) list the components of enjoyment resulting in flow: 
- there is no worry of failure

- there are clear goals every step of the way

- there is immediate feedback

- distractions are excluded from consciousness

- there is a balance between challenge and skill

- self-consciousness disappears

- sense of time becomes distorted action and awareness are merged

- the activity becomes autotelic (worth doing for its own sake) (p.140)

Flow is experienced when a there is a balance between challenge and skill. Massimini and Carli (1988) represent this balance thus:

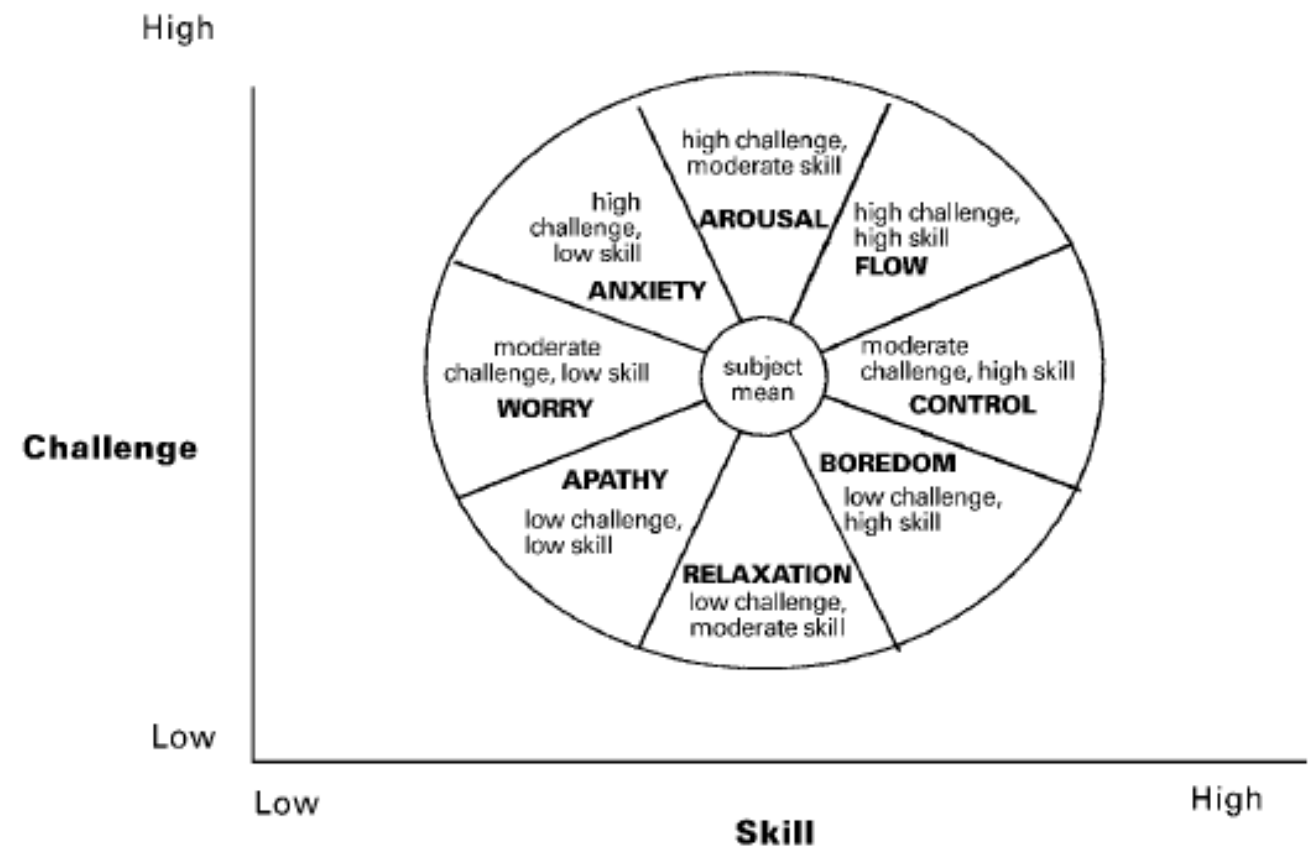

Figure 2.2. Balance between challenge and skill. Massimini \& Carli (1988), as cited in Sheridan \& Byrne (2002)

As asserted by Sheridan and Byrne, and as revealed in the findings of this study, the concept of flow is an important one for the assessment of group composing. Additionally, Massimini and Carli's (1988) graph proved to be a useful conceptual tool for the assessment of group composing.

\subsubsection{Educational theories and their relationship to creativity and assessment}

Early creativity research focuses upon internal psychological states of the solitary individual, reflecting the big-C view. During the 1980s and 1990s however, it was recognised that this was not the whole of the creative picture and some began to 
view creativity through the lenses of social-constructivist and socio-cultural theories of learning (Sawyer \& DeZutter, 2009). It is no coincidence that literature examining the nature of creativity in groups is subsequent to that of constructivist literature. If learning, and therefore cognition, is socially constructed between people, then both the processes and products of creativity are socially constructed artefacts (Cole \& Engeström, 1993). Creativity is therefore a socially embedded process and its products emerge from social networks (Csikszentmihalyi, 1990).

Socio-cultural theorists assert that because they are socially constructed, learning and its associated knowledge are also socially situated, that is, contextually and culturally bound (Folkestad, 2006; Greeno, 1997; Lave \& Wenger, 1991; Rogoff, 1990). Csikszentmihalyi (1999) asserts that "creativity presupposes a community of people who share ways of thinking and acting" where creativity is situated practice. (p.316). This concept is highly pertinent to this investigation of creativity in groups because, as Rogoff (1995) explains, "it is incomplete to focus only on the relationship of individual development and social interaction without concern for the cultural activity in which personal and interpersonal actions take place” (p.141).

Rogoff (1995) describes interpersonal activity in collaborative groups as existing on three planes: apprenticeship, where less experienced members are able to participate alongside more experienced members (referred to as legitimate peripheral participation by Lave and Wenger, 1991); guided participation where "communication and coordination occur in the course of participation in shared endeavours, as people attempt to accomplish something" (p.148); and participatory appropriation, which is the means by which group members transform their understanding through taking part in the activity of the group. Socio-cultural theorists refer to a collaborative group as a community of practice which is a group of people who "share a concern, a set of problems, or a passion about a topic" and who "deepen their knowledge and expertise in this area by interacting on an on-going basis" (Wenger, 1998, p.133).

This is a very apt description of any collaboratively creative group working on the production of art works, particularly a group-composing rock band (Thorpe, 2009). 


\subsubsection{Distributed creativity}

A socio-cognitive theory relevant to an examination of creativity in groups is that of distributed cognition (Cole, 1996; Cole \& Engeström, 1993; Salomon, 1993). Creativity is viewed as a form of thinking and problem solving, and so is the result of cognitive processing among people. Cognition is a complex social phenomenon and within creative groups it is "distributed - stretched over, not divided among - mind, body, activity and culturally organised settings" (Lave, 1988, p.1). Thus, when groups of people work together in a community of practice to create something, then thinking is distributed across the group in meaningful ways (Bell \& Winn, 2000). This leads to a joint ownership of process, referred to as an artefact (Saloman, 1993).

While the socio-cognitive view of creativity regards the individual and the social as separate units (Glăveanu, 2011), socio-cultural theorists are critical of this separation, arguing that this is a reductionist view that cannot account for what occurs among and between people when they create together (Wenger, 1998). The sociocultural view is that creativity is social in nature and therefore "located in the space "in between' self and others", in other words, the social is both inside and outside of the person (Glăveanu, 2011, p.480). Both views of creativity, often existing side by side as separate views, are termed distributed creativity (Glăveanu, 2014; Sawyer \& DeZutter, 2009). Glăveanu views creativity from a Vygotskian, socio-cultural perspective, asserting that creativity is distributed between people, objects and places. While gaining popularity in literature and research in digital industries, theatre and the adult workplace, this relatively new theoretical concept has not yet been examined within educational settings.

Glăveanu contends that "if creativity is a distributed, dynamic, socio-cultural and developmental phenomenon then it makes no sense to discuss it in terms of fixed borders and static domains" (p.1). As such, collaborative creativity is viewed as being a mixture of materially, socially and temporally distributed processes that involve creating, using and developing external artefacts.

In the context of the present research, this concept raises some questions for the assessment of such processes by an external assessor (the teacher) who has not had the experience of distributed creativity and yet assesses its product. Creative distribution might prove problematic for teachers working within the "fixed borders and static domains" of a secondary school qualification system (p.1). 


\subsection{Creative Environments}

There is considerable evidence within the literature that the social-emotional climate of the creative environment is a crucial variable (Carlisle, 2013; Odena, 2012a; Waters, Cross \& Shaw, 2010). Social and cultural interactions between people (in other words their relationships with each other) are key elements (Allsup, 2003; Burnard \& Younker, 2002, 2004, 2008; Macdonald \& Miell, 2000; Wiggins, 2007).

Friendship and shared musical tastes are crucial variables in group-composing by young people (Allsup, 2003; Campbell, 1995; Davis, 2005; Miell \& Littleton, 2008; Thorpe, 2008), where informal, peer-mediated music learning is central to their acquisition of knowledge and skills (Burnard, 2008; Burnard, Dillon, Rusinek, \& Sæther, 2008; Green, 2002; Lebler, 2008). Purposeful, enjoyable, peer-mediated activities with friends (such as group composing) can foster and maintain engagement in the classroom, and in school generally (Fredricks, Blumenfeld, \& Paris, 2004; Li, Doyle, Kalvin, Liu, \& Lerner, 2011; Parr \& Townsend, 2002). There may therefore be a link between engagement at school and in class, and playing in bands. This is proved to be the case for this study and is explored in Chapters 5, 6 and 7.

\subsubsection{Physical environment: quiet, space and enough time}

Some music education researchers have identified that the physical aspects of the environment are important factors when examining composing in schools (Odena, 2012b; Savage \& Fautley, 2007). Houmann and Sæther (2014) and Kennedy (2002) found that students needed periods of quiet contemplation to compose, often in the evenings or late at night. Lack of quiet time and space, combined with academic pressure and stress, placed significant constraints upon young composers (Houmann \& Sæther, 2014). Young composers report that listening to music alone in their bedrooms is a crucial aspect of the creative process and the place where many do most of their solo composing in both acoustic and digital domains (Kennedy, 2002; Tobias, 2012). Tobias (2012) found that group composers then bring their ideas to school to be worked on by others.

These studies suggest that students from affluent homes who have their own space to work in may be significantly advantaged as composers over students from crowded and/or less well-resourced environments. Certainly, the physical resourcing of the music departments in the present study are diverse and, as the findings will 
show, access, or otherwise, to appropriate spaces and resources seemed to have a considerable impact upon group composing.

Odena (2012a) asserts that "teaching that encourages children to be creative may flourish, whatever the physical resources", implying that a good teacher will somehow cope no matter what the circumstances (p.516). Lewis (2012) found this to be the case when she collaborated with a professional composer in her classroom. Lewis believed that the composer's "make it work" professional attitude to overcoming a lack of resources for composing helped her to set aside her negative, cynical attitudes to these limitations.

Other than research into composing using digital media (largely outside the bounds of this investigation), there is a significant paucity of research into what kinds of physical resources support effective composing in groups. Much music education research is situated in quite affluent, well-equipped schools and there seems to be a paucity of research into the impact of the availability (or scarcity) of instruments and multiple spaces for collaborative composing.

In any case, Allsup (2003), Burnard (2012b) and Tobias (2012) present persuasive evidence for a re-examination of the nature of the music classroom, asserting that multiple modalities of musical practices in the $21^{\text {st }}$ century require new, hybrid spaces for music learning, both in terms of teacher practice and physical resourcing, where students can work creatively. The teacher's role in creating such spaces is a crucial variable.

\subsubsection{Safety}

Kratus (2012) emphasises the importance of emotional safety within the creative environment when he observes that it is:

... an environment in which students can give free rein to their imaginations without fear or ridicule ... What is necessary is the establishment of a community of composers, a group in which students collaborate and learn from each other. In such a learning environment students are more likely to help each other than criticize each other. (p.382)

The teacher has a significant role to play in the construction and maintenance of that environment because such a creative environment requires that the teacher's role be that of guide, facilitator and cultural manager, rather than the sole constructor of music (Cabedo-Mas \& Diaz-Gomez, 2013; Carlisle, 2013; Dillon, 2007; Welch, 2012; Wiggins, 2007). 


\subsection{Studies of creative processes in composing}

Music is more than the sum of its parts and so simplifying its complexities through assessment risks the music becoming "denatured" and meaningless (Mandolini, 2012, p.351). I described this as "pulling the wings off a butterfly in order to find out how it flies" (Thorpe 2008, p. 144). This is a significant tension for this study, particularly with regard to the assessment of group processes, about which little is known (van Aalst, 2013). Therefore, any examination of the assessment of process must first examine the ways in which creative process has been interpreted and defined in music education. As Hammershøj (2014) observes, any examination of creative processes is underpinned by conceptual assumptions:

Few concepts have proven to be as resistant to conceptualization as creativity. This is, however, not due to a lack of research or consensus on the subject. In the literature there is consensus on how to define the creative product, on which traits and abilities are characteristic of creative persons, on where creative processes usually occur, and even on how to nurture creativity... but a consensus on how to define and conceptualize the process of creativity remains elusive. (p.168)

It follows, therefore, that unless the creative process is understood by teachers, then it is neither effectively taught, nor assessed, either formatively or summatively (Byrne, McDonald, \& Carleton, 2003). As the findings and discussion will show, this is one of the central concerns of this thesis.

Much of the literature makes the assumption that composing is a cognitive act, a form of creative thinking, usually drawing upon Wallas' (1926) four-stage theory of creative thinking. This involves: preparation, where ideas are investigated and explored; incubation, where ideas are not thought about but are nevertheless subconsciously developed; illumination, where ideas are generated, often seeming to appear from nowhere; and verification where ideas are consciously worked upon through logical processing.

\subsubsection{Models of creative musical processes}

As will be demonstrated in the findings, a conceptual model of composing plays a key role in this study. A number of scholars have sought to represent and explain creative thinking in music (Emmerson, 1989; Hargreaves, 1986; Sloboda, 1985, for example). These earlier studies view composing as a cognitive, problemsolving process, assuming that composing is an individual, not a collaborative act. More recently, collaborative compositional processes have been studied (Allsup, 2003; 
Biasutti, 2012; Fautley, 2005; McGillen \& McMillan, 2005; Tobias, 2012, 2013). Many of the examinations of creative processes in the literature represent these processes graphically, usually in the form of conceptual models.

One of the most often-cited conceptual models of composing is by Webster (1990, 2002). Wallas' (1926) four-fold theory is central to Webster's model, which draws together musical and psycho-social elements to explain the multiplicities and complexities of creative processes. This conceptualisation of the creative process, therefore, acknowledges the importance of environment as well as the subconscious. Personality and motivation are included as enabling conditions for creativity.

Creativity is viewed as a cognitive process because the model incorporates the concepts of convergent and divergent thinking. These are derived from Guildford's (1950) and Torrance's (1988) studies, where convergent tasks have a single correct answer and divergent tasks have multiple solutions. These are key concepts.

Webster's model (1990, 2002) has an almost industrial orientation, beginning with the intention to create a "product" which then runs through a sort of assembly line of cognitive processes, resulting in the finished product. The outcomes of musical creativity are not limited to composing or improvising, but also include playing and analysing, which presumably includes listening. 


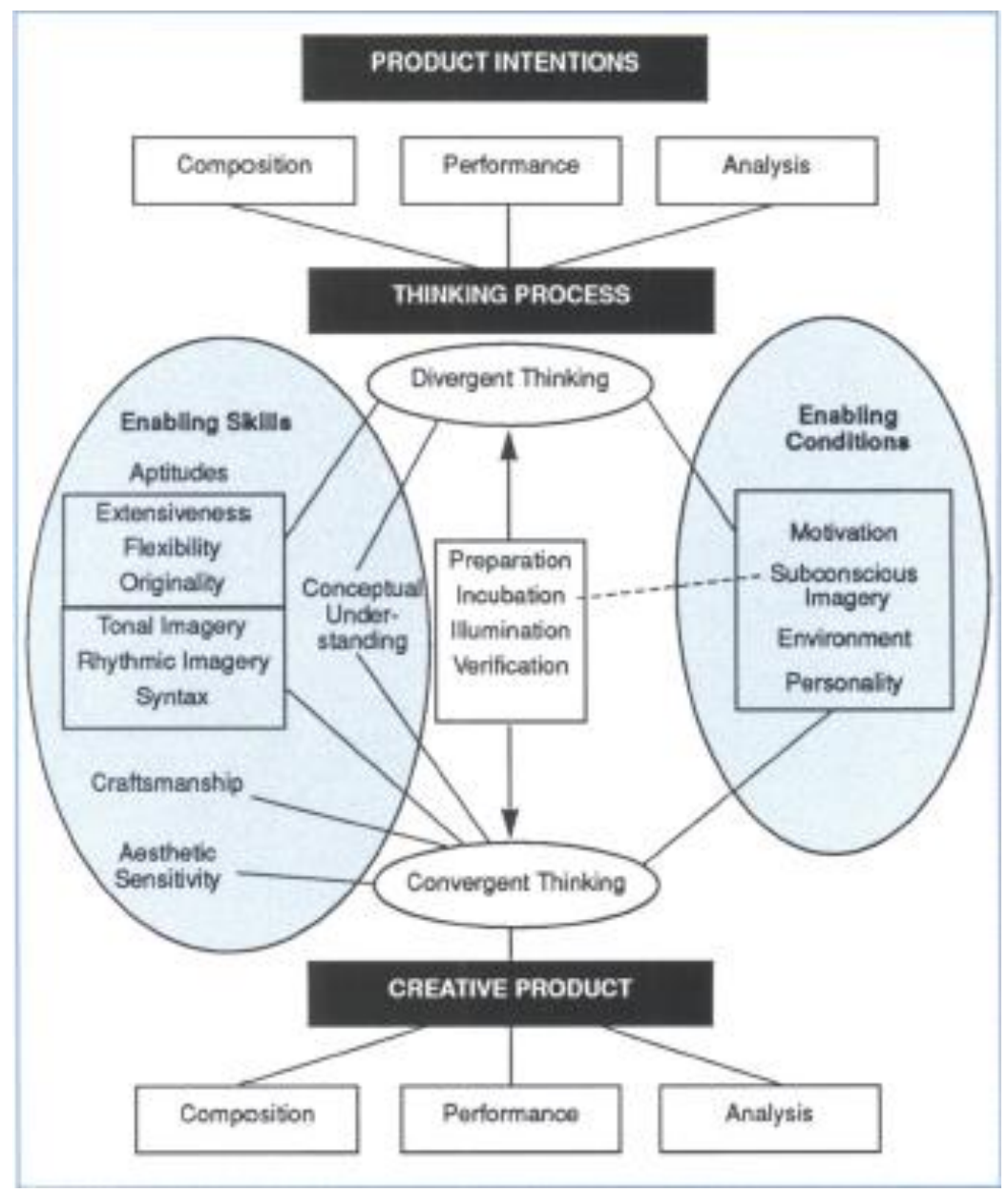

Figure 2.3. Webster's (1990, p.23) model of creative thinking in music

Burnard and Younker, $(2002,2004)$ studied the compositional pathways of young composers in terms of problem solving and creative thinking. Like Webster (1990, 2002), the authors represented creative thinking in music heuristically as a model, incorporating Wallas's (1926) four stages. Fautley $(2005,2010)$ also represents composing as a process of creative thinking. His study is of a small group of 14-yearold girls composing a "happy/sad" piece using classroom instruments. While smallscale, this study was the first to view group composing as a process of distributed cognition. 


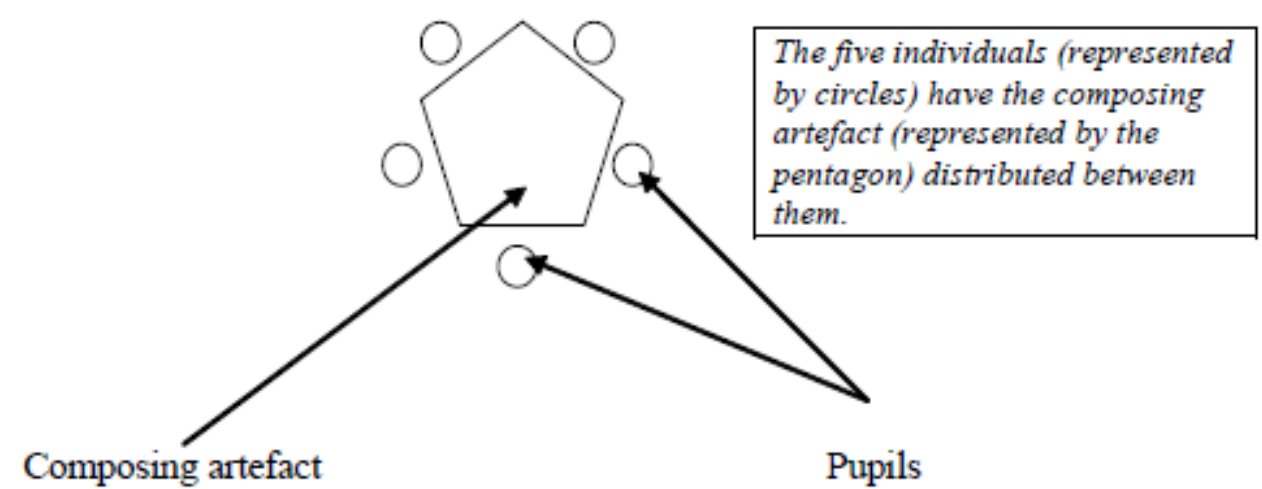

Figure 2.4. Distributed composing (Fautley, 2005, p.43)

Fautley (2005) observed that Wallas' (1926) four-stage theory does not describe or explain what goes on within each of these stages, and goes on to summarise models of musical creativity in terms of expert composing by (presumably) adults, and novice composing by (presumably) children and young people. Fautley (2010) then refined his (2005) model as a pedagogical tool for teachers. As the next section will show, it has also proved a very useful tool for this music education researcher.

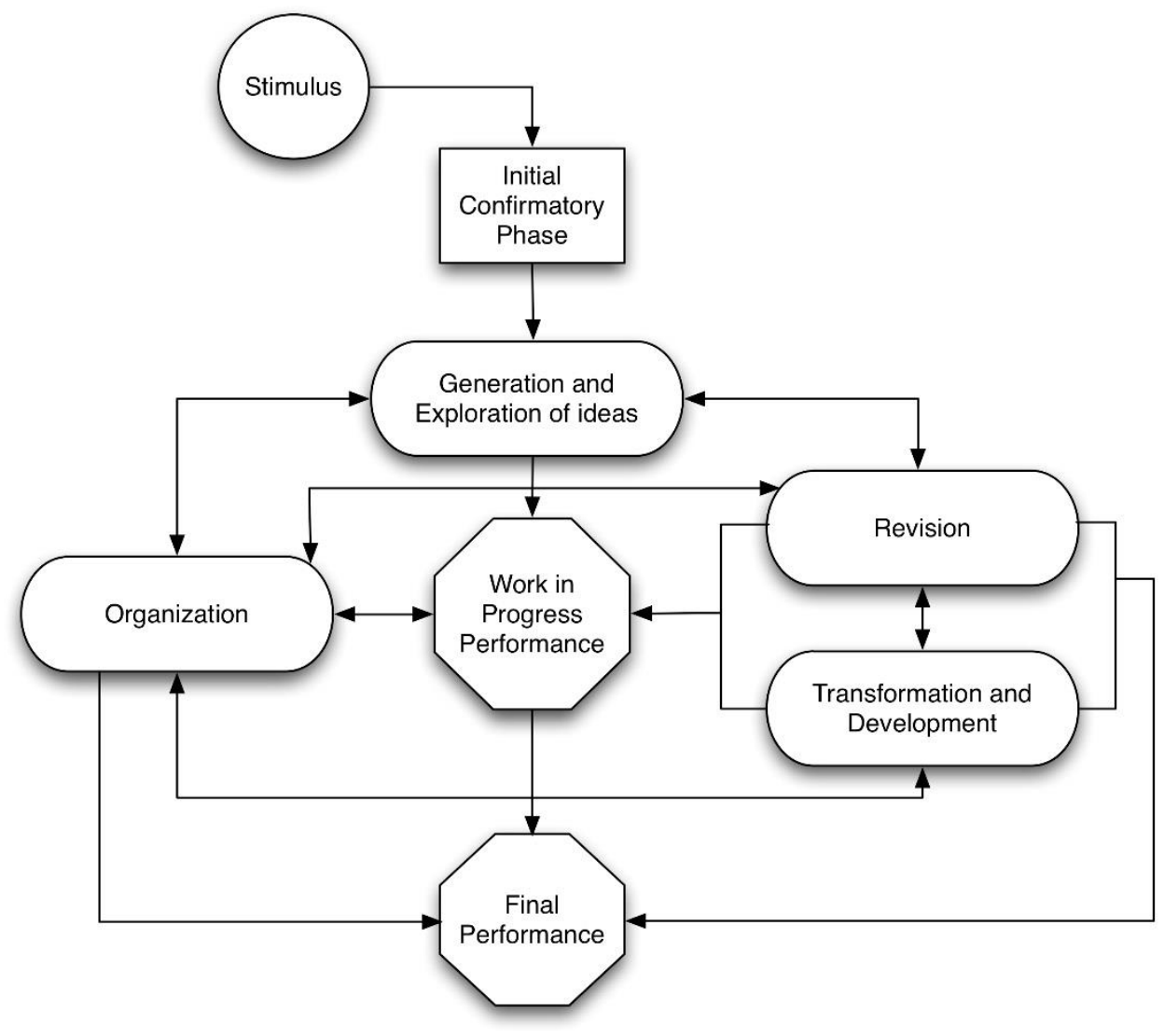

Figure 2.5. The composing process deconstructed

(Fautley, 2010, p.139) 
Tobias (2013) examined the creative practices of several young people working across a number of musical domains. These included song writing in bands, composing using digital media (such as Pro Tools), recording, editing, mixing and producing their music. While some collaborative creative processes are considerably different to those examined above, Tobias presents a model that suggests that one group of boys compose in very similar ways. As can be seen in Figure 2.6, jamming was an important creative tool, particularly in the early stages of composition, and, consistent with my model, group composers moved into more convergent, focused practices as the music neared completion. Jamming and its relationship to group composing was found to be an important variable in the present study.

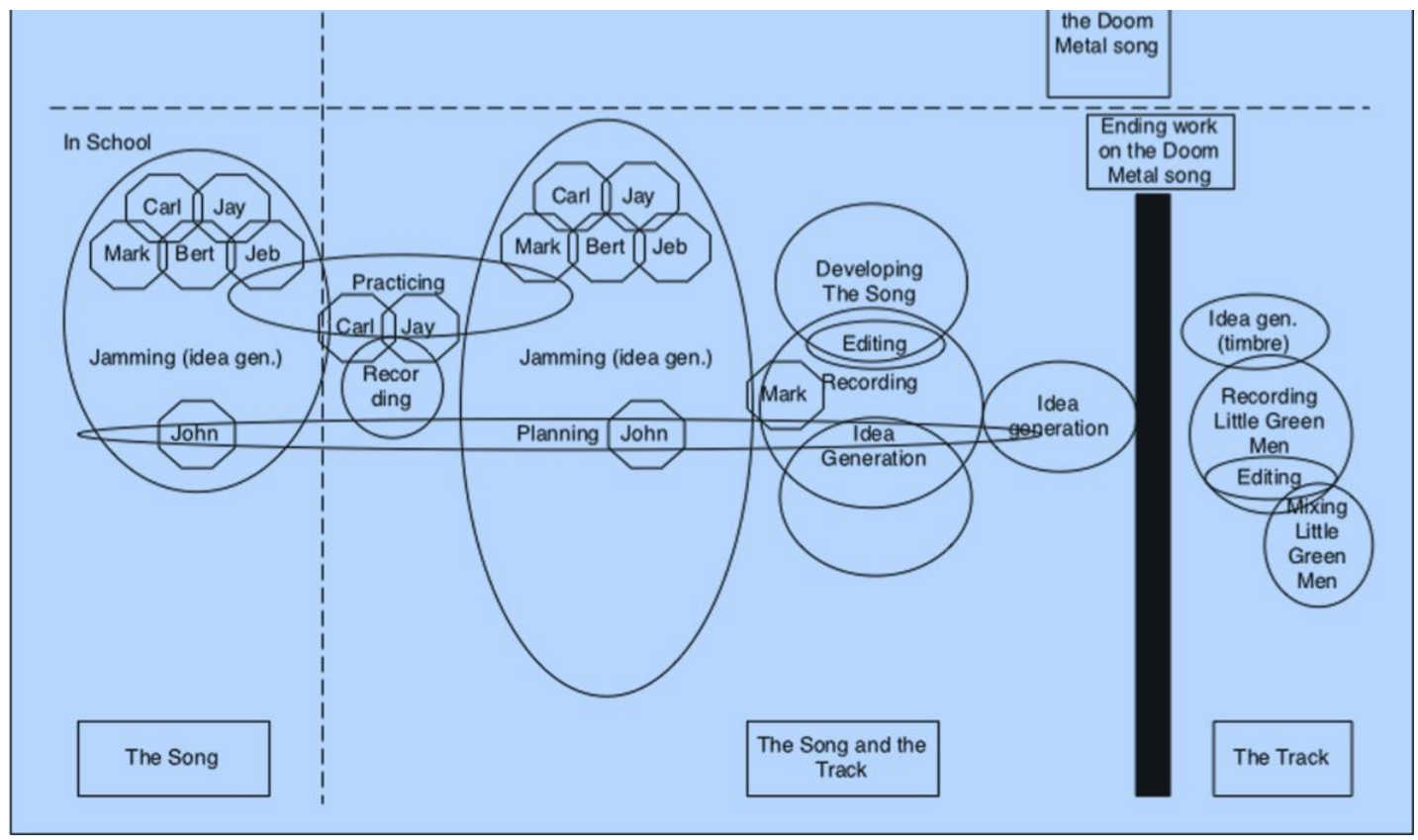

Figure 2.6. Diagram of creative processes (Tobias, 2013, p.236)

The potential of Tobias' model for further research is discussed in the final chapter of this thesis.

\subsubsection{Collaborative creative processes in bands}

Biasutti (2012) notes in her literature review that "few researchers have analysed how pop or rock musicians compose within groups (p.345). One reason for this could be that there is already considerable alignment between the findings of existing studies of composing in bands. Campbell (1995), Jaffurs (2004, 2006), Davis (2005), Miell and Littleton (2008), and Thorpe (2008) examined creative music practices in teenage garage/ heavy rock bands and have similar findings. 
While each study had a slightly different focus, all also had findings consistent with those of Green's (2002) study of adults' informal learning practices. Although Lassig (2013) suggests that adolescents might engage in creative processes differently from children or adults, there is some evidence in the literature to suggest that group composing in rock or pop styles may be the quite similar for young people and adults where the variables are the levels of musical skill and knowledge, not the ages of the composers. Whether or not this is the case is outside the bounds of this study but is nevertheless a current gap in research. This is discussed in the final chapter.

Campbell (1995) found that novice players tend to focus on learning to play covers, whereas the more experienced band members regarded composing original songs as integral to their emerging band identity. The older boys defined their group through the practice of collective composition, even though they rarely composed together. The guitarist or keyboard player wrote his songs at home and brought them to band practice when deemed ready for group input. This entailed teaching the song to the others by singing it repeatedly while the others watched and listened until all were able to play along ("song-getting"). The process was one of experimentation and improvisation, often incorporating a standard repertoire of formulas and patterns. Individuals then refined their parts over the course of repeated playings.

Jaffurs (2004) describes the robust musical processes of a garage band:

During both rehearsals many small, often inarticulate comments were communicated back and forth between the group members. Body language, as well as musical communications, conveyed a certain way that one guitarist wanted the other guitarist to play a section, or a chord played loudly meant that everyone in the group should stop playing. Although there were many more occurrences of peer critique, which at times just appeared to be arguing, 'peer' learning was often subtle and hard to recognize. A glance from one member of the band to another to verify notes or chords can be easy to miss. Arguing, or yelling at another member that the note or tempo was wrong was more obvious. (p.196)

Jaffurs makes it clear that such socio-musical processes are hard to interpret for an outside observer, which, in the context of the present study, raises potential issues for their assessment. Davis (2005) observed similar processes that she describes as the "relentless pursuit of music passion" (p.2).

A conceptual model of group composing, based on my Master's research proved to be highly significant (Thorpe, 2008). This described, analysed and interpreted the collaborative compositional processes of three teenage rock bands. I 
adapted Fautley's (2005) model of group composing, using it as an analytical tool to investigate collaborative song-writing processes. Consistent with Fautley (2005, 2010), and the other studies examined above, analysis revealed that the bands worked in similar ways to generate ideas and construct their songs.

Group composers seemed to work in two different phases: exploratory and divergent; and focused and convergent. I incorporated these two phases into the model to help me to interpret and analyse the complex creative processes within the bands.

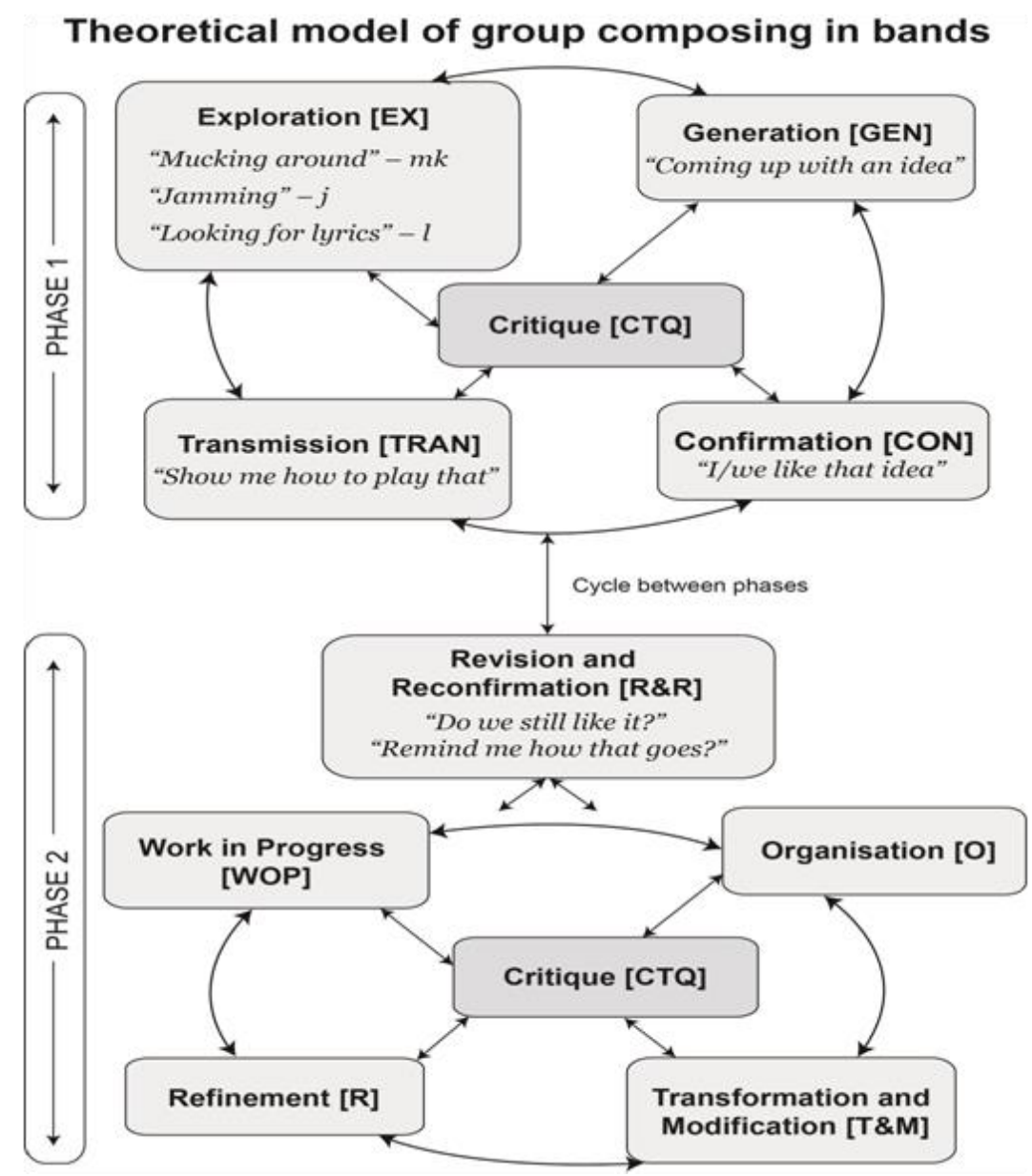

Figure 2.7. Theoretical model of group composing (Thorpe, 2008, p.73)

All of the literature above emphasises that playing and composing in garage and rock bands are meaningful experiences where significant informal music learning takes place between band members. The five elements of effective successful group learning identified by Johnson and Johnson (2004) were observable in two of the three bands I studied: 
1. Positive interdependence, where group members perceive that they are linked with others so that one cannot succeed without the others, and that achievement is mutually beneficial.

2. Accountability, where both individuals and the group as a whole are accountable for the group's outcomes.

3. Promotive interaction, where group members share resources, help each other and give each other personal support, particularly when problemsolving.

4. Social skills, particularly the interpersonal skills required to function as a member of a team.

5. Group processing, where group members are able to monitor, discuss and critique their achievement whilst maintaining effective group relationships. (p.32)

\subsection{Assessment practices in music education}

As shown earlier in this chapter, summative assessment practices are subject to the cultural, socio-political and educational environments in which they take place and reflect the learning and knowledge conceptions of those who design and implement the assessment. To illustrate this, a comparison of music teachers' assessment practices in three countries is presented.

\subsubsection{Assessment practices of American primary and secondary music teachers}

Russell and Austin (2010) present a very bleak assessment picture indeed. In their study of the assessment practices of 4,889 primary and secondary music teachers in south-western USA, the authors found that assessment practice was idiosyncratic, ad hoc and highly diverse. Although there are national standards for music, it was found that these were rarely incorporated into formal assessment practice and often teachers were discouraged from assessing by school management because the assessment of music was thought unnecessary. When teachers did assess, the methods they used were developed in isolation, with few, if any, opportunities for consultation or moderation with colleagues from other schools or regions. Throughout the study there is an assumption that assessment is summative and that its function is to test and grade students.

Russell and Austin found a widespread emphasis upon the summative assessment of students" "attendance and attitude", with scant regard for actual music learning (p.39). The music assessment practices revealed by this study were mostly related to aspects of instrumental or vocal performance, and reflected for the most part the behaviourist assessment views described earlier. There is no evidence in this study that teachers viewed assessment as intrinsic to good teaching practice or related to effective student 
learning, although this may be a reflection of the kinds of questions they were asked. Surprisingly, for a recent study of assessment in schools, Russell and Austin did not refer to any of the current formative assessment literature examined earlier in this chapter and seemed to use the terms assessing, grading and testing interchangeably.

\subsubsection{Assessment practice of English and Scottish secondary music teachers}

Savage and Fautley's (2011) study of secondary music teachers' assessment of composition in England provides evidence of more sophisticated and knowledgeable practices. This could be attributable to national secondary school curriculum and qualification structures because, unlike the teachers in the previous study, the teachers in this study were directly accountable to national examination boards for their assessment. In addition, the English secondary school music curriculum is taught holistically and, unlike the USA, ensemble performance is usually part of the cocurriculum, not classroom teaching. Like New Zealand, composition has been part of the senior secondary curriculum for many years. Holistic music curricula require teachers to teach and assess across a number of musical domains, not just instrumental or vocal performance, thus necessitating diverse practices.

The study, part of a wider investigation, surveyed 94 teachers twice, asking them about how they organised and assessed composing at Key Stage 4 level (14-16 year-olds) for senior secondary school diplomas. The authors then followed up with 11 teacher interviews. Teachers assessed compositions (not composing) according to set criteria and, for one qualification, within set musical and stylistic parameters. Teachers reported that once students had gained confidence in group composition tasks, most chose to compose individually. There was no teacher support for the assessment of compositional process, with some teachers commenting that the workload would be prohibitive. The authors explained that, "at Key Stage 4, the assessment criteria published by the examination boards form the backbone of what teachers do with regards to assessment of composing" (p.142). Eighty-six percent of the teachers surveyed found it easy to assess compositions using the criteria. Some teachers, particularly those in urban schools with large numbers of guitarists and drummers who composed in popular styles, found that the prescriptive nature of the assessment requirements, particularly specified musical styles and forms, stifled creativity and disadvantaged such students. Despite reservations expressed by both the teachers and the authors regarding some aspects of the assessment of composition at Key Stage 4, there remained a critical awareness on the part of both the authors and 
the teachers interviewed of how assessment might foster or discourage learning and achievement in composing.

Sheridan and Byrne (2002) presented an assessment scenario for Scotland that is at the other end of the assessment scale to that of Russell and Austin's (2010) study. The authors describe a situation where the examination system dominated music teaching and learning at secondary school level, where tightly controlled and specified assessment criteria stifled the very creativity the examination system purported to assess.

Music education researchers have noted that this has occurred in a number of educational settings, often in relation to standardised national testing, where many music educationalists believe that assessment accountability and political expediency rather than curriculum are the educational drivers (Hickey, 1999; Sheridan \& Byrne, 2002; Wiggins, 1999). This resonates with the research into assessment perception discussed earlier where teachers perceived assessment as an unwelcome intrusion into teaching and learning (Brown, 2004; Harlen, 2005; Newton, 2007).

The three studies examined above reveal that it is necessary to examine the socio-political, cultural and educational context of summative assessment for qualification because these structures have a direct bearing upon how teacher practice is enacted. With the variance in summative assessment systems and practices in evidence here, the present study can be viewed as a search for a sort of "Goldilocks" summative assessment zone - neither tight nor loose, neither prescriptive nor laissez faire.

Some scholars have investigated other ways in which this might be achieved for composing.

\subsubsection{Using taxonomies and rubrics}

Colwell (2002) suggests using taxonomies such as those by Bloom (1956), Hauenstein (1998) and Marzano (2001) to assess compositions, but notes that the emphasis these place upon writing and talking are not helpful for music educators. He points out that writing and talking are not usually appropriate ways to assess music learning and offers some suggested responses to Marzano (2001) that could be used when assessing playing or composing. 
Hickey (1999) proposes the use of highly structured, standards-based assessment using rubrics as they "help teachers to understand and measure students' achievements". Eisner (2007) warns, however, that without consensus, rubrics do not provide the objectivity and reliability they seem to offer. This is of crucial importance for a national qualification assessment system such as the NCEA because AS91092 is basically a very brief rubric with explanatory notes attached and teachers are expected to develop their own more detailed rubrics. There has not been any research conducted into the use of rubrics for NCEA music assessment in New Zealand.

When summative assessment uses rubrics that are too prescriptive, then the outcome might be a "factory model of educational performance" (Eisner, 2007, p.425), where formal assessment procedures dominate at the expense of curriculum, and creativity is stifled (Black, Harrison, Hodgen, Marshall, \& Serret 2011). Like many others associated with summative assessment, this issue is highly sensitive to the socio-political climate in which these educational structures are situated.

\subsubsection{Using consensual assessment technique (CAT)}

Amabile (1996) argued that it is impossible to articulate clear, objective criteria when assessing creative products and proposed that the most valid form of summative assessment is carried out by groups of experts who subjectively rate the creativity of those products, reaching a valid assessment through consensus. There have been several subsequent investigations into Amabile's consensual assessment technique for compositions, three of which are examined here.

Hickey (2001) compared the consensual assessment of 12 pieces of music composed by $4^{\text {th }}$ and $5^{\text {th }}$-graders, carried out by five highly diverse groups: 17 music teachers of varied experience, four music theory professors, three professional composers, $147^{\text {th- }}$ graders, and $242^{\text {nd- }}$ graders. The study's purpose was to test the reliability of CAT and to investigate which might be the most reliable group of experts to judge the creativity of children's musical compositions.

These kinds of studies are relevant to the present study, not because assessment was carried out through teacher consensus or moderation, but because a socio-cultural view of assessment regards both students and their teacher as participants in the activity of assessment. If learning is viewed as something that happens between group composers, then the assessment of this learning needs to take into account group 
composers' self and peer assessments of their composing, which raises the question whether or not young learners are valid assessors of composing.

Hickey (2001) found that while CAT was found to be was a moderately reliable technique for measuring the creativity of children's compositions by most groups of judges, the professional composers were the least consistent group. Music teachers, music theorists, and $7^{\text {th }}$-grade children showed agreement within their respective groups, but the most reliable judges were the music teachers who taught the children. The implication for the present study is that, in the context of assessing student compositions, the term "expert" might mean being knowledgeable about music teaching and the students who composed the music, but not necessarily about composing.

Byrne et al. (2003), and Stefanic and Randles (2014) also investigated the validity of CAT as a summative assessment technique for levels of creativity in composition. Like Hickey's study, both found CAT to be a valid assessment method. Byrne et al. (2003) designed a composing task that aimed to foster the following three conditions of flow: "there were clear goals every step of the way .... there was immediate feedback ..... there was a balance between challenge and skill” (p.282). Byrne et al. then asked individual student composers to rate their psychological states using a simplified version of Csikszentmihalyi’s (1988) Experience Sampling Form.

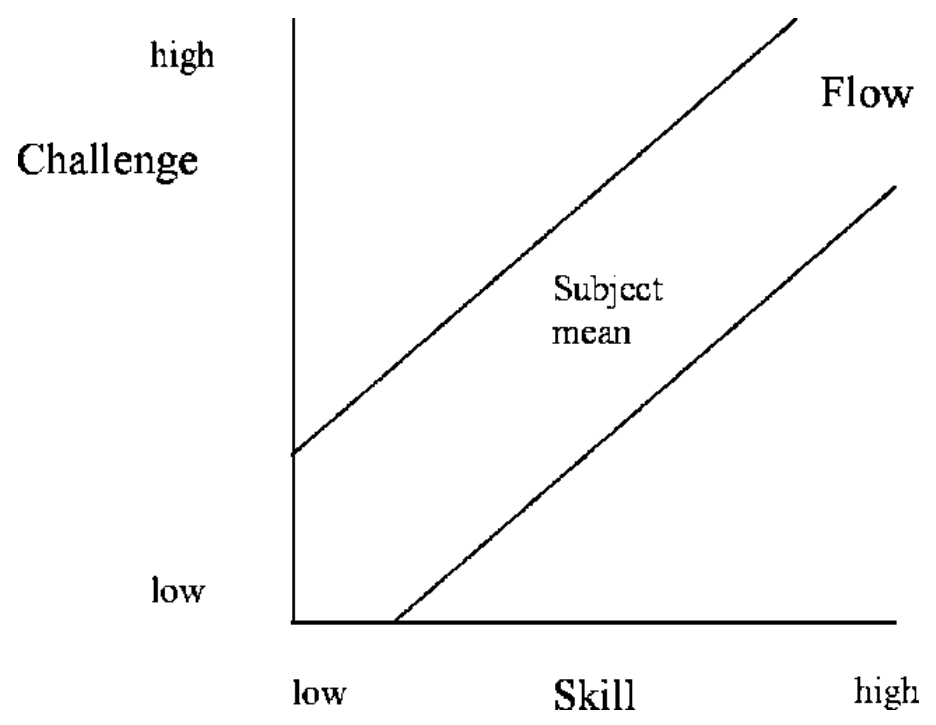

Figure 2.8. "Conditions in which flow may occur" from Byrne, McDonald \& Carleton (2003, p.283) 
The authors found that the concept of flow has potential for making a connection between the experiences of composing and the assessment of the overall quality of the music. However, while all three studies make several recommendations for teaching and assessing composing in secondary schools, none was actually carried out in that context.

\subsubsection{Using peer assessment}

Major (2008) is one of the very few researchers who has investigated the relationship between the assessment of compositional process and its product. She identified six categories of talk related to a variety of activities in her classroom, including solo and group composing: exploration, description, opinion, affective response, evaluation, and problem solving. The categories bear a strong resemblance to the descriptors in the process models examined earlier. Major emphasises the importance of the affective domains of collaborative composing, arguing that composing is not just a cognitive process. She found that problem solving involved "mature, analytical responses" by students who had sufficient music knowledge, experience and skill to be able to evaluate their composing in an informed way (p.312).

In the context of the present study, this implies that peer assessment may not be a valid assessment method for the compositional processes of novice composers with low levels of musical skills and/or knowledge because they may not know enough about what they are doing. The implication for teacher practice is that the more group composers know about the processes in which they are engaged, and the music that they are composing, the more likely they are to be able to discuss and effectively evaluate their compositional processes.

\subsection{Concluding thoughts}

An analysis of the assessment literature examined in this review reveals that the contexts of the research are mainly either in primary schools or in tertiary education, with a strong emphasis upon English literacy, Science and Mathematics. Relatively few studies are situated in high schools. There are very few studies of the assessment of music learning in groups (Blom \& Encarnacao, 2012).

Furthermore, Sadler (1998) notes that "in non-convergent learning environments, [making qualitative judgments] automatically exposes teachers to the variety of ways in which students approach problem solving, and how they argue, 
evaluate, create, analyse and synthesise" (p.81). Black and Wiliam (2009) found that a teacher's feedback "needs to be constructed in the light of some insight into the mental life that lies behind the student's utterances" (p.13). They note the significance of Hattie and Temperley's [sic] (2007) study of how teacher feedback influences learning but consistent with Winne and Hadwin (1998), also that note that:

Neither pays serious attention to the world of classroom discourse and indeed much of what they present can be interpreted as dealing with transactions in which a teacher is interacting with the individual student about a piece of written work. (p.24)

Other than music education research, the assessment literature in this review makes the assumption that a teacher has set a task requiring written and verbal responses. In the context of this study, the assessed work is predominately musical rather than verbal or written. The teacher might not have set the task if a groupcomposing band has been formed independently of school and may even create post hoc composition tasks to cover just such eventualities (Savage \& Fautley, 2011).

This review has revealed that the summative assessment of peer-mediated, non-written, practical or informal learning for qualification is highly problematic for teachers, requiring complex practice responses and sophisticated assessment knowledge. This has not sufficiently been investigated. Given the complexity of sociomusical and creative processes, this review has shown that a much broader assessment view than that of most of the review literature is needed for the present study. The summative assessment of group composing for a secondary school qualification seems to be unique to New Zealand. It is therefore not surprising that I could not locate any literature or research about this and the present study seems to be the first of its kind. The next chapter presents the methodology of the research. 


\section{Chapter 3 Methodology}

This chapter presents the design and methodologies of this study. It introduces the research settings Manuka High (the pilot study school), Kotare College and St Bathan's Collegiate, three secondary music teachers, Sarah, Alice and David, and 30 student participants. How the data were collected, ethics procedures, and data analysis methodologies are described and explained.

\subsection{Limitations of the research}

This thesis examines group composing as it relates to composing assessed for the NCEA. While this might have included ensembles formed outside of school, such as teenage garage bands, the frame of this study remains within school structures and the music department. Increasingly, music education and creativity research focuses upon collaborative composing in digital domains. This study does not examine composing of this kind, although it is referred to, and is limited to group composing by students playing acoustic and amplified instruments, usually as rock or pop bands. The study presents data from three school sites, located within New Zealand secondary school and qualification systems.

\subsection{Initial research paradigm}

At the outset of the research, the new NCEA achievement standard was in draft form only and not yet in use. This was a new situation within secondary school music education in New Zealand and so it seemed logical to design the investigation as an exploratory, naturalistic inquiry (Stake, 1995). I chose a constructivist-interpretivist paradigm, based on the assumption that reality and its associated knowledge are socially constructed through interactions between people (Denzin \& Lincoln, 2005). The aim was to investigate the experiences of teachers and students within the unique context of a school. It was not an intervention and I was going to be a non-participant observer (Bailey, 2007).

At this point in the research I was unaware that the assessment of group composing involved complex and sometimes conflicting interactions between multiple, stake-holding communities. The initial design was based on my simplistic assumption that the teacher and group composers were one and the same community. 
The initial research question, derived from my first reading of the literature, was "What are the students' and teachers' experiences of the assessment of group composing?"

\subsubsection{Initial design}

The initial research design was multiple case study in five diverse secondary schools, carried out over one school year. The aim was to gain an in-depth understanding of each holistic case (Yin, 2009), resulting in intensive, "thick" descriptions of five, separate and bounded systems (Stake, 2003). See Figure 3.1.

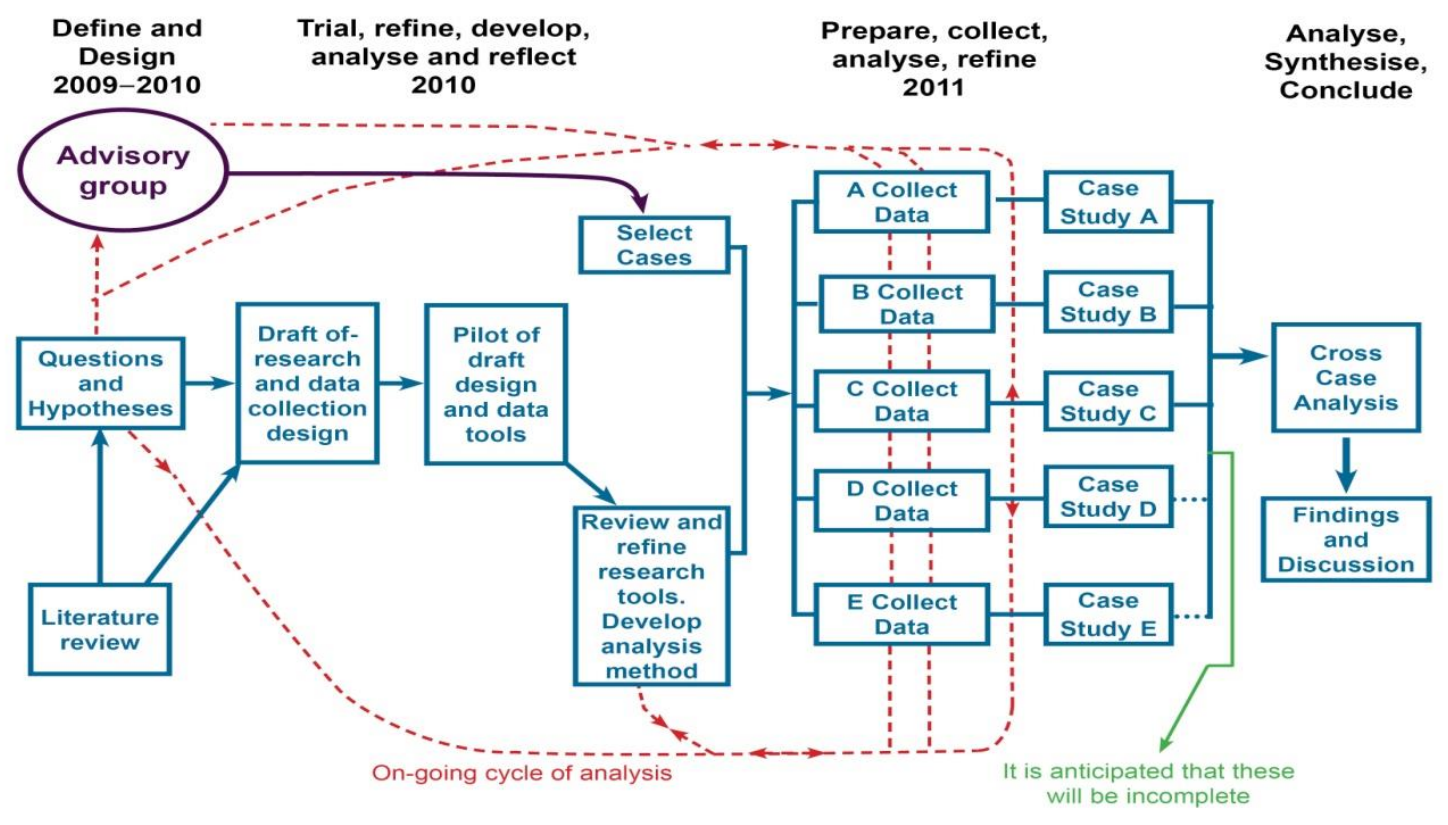

Figure 3.1. Initial design (after Yin, 2009, p.57)

Stake (1995) states that research design and case selection should maximise what can be learned at a particular site. As I became more familiar with the literature, I became less convinced that focusing upon participant experience as a non-participant observer was an appropriate course of action. Therefore, I trialled this paradigm, design and questions in a pilot study.

\subsection{Pilot Study ${ }^{5}$}

In July 2010, I approached a teacher to carry out the study with her and her Year 10 Music (pre-NCEA) class. "Sarah" agreed to trial the draft, yet-to-be-registered achievement standard with her class of 27, Year 10 (pre-NCEA) students. "Manuka

\footnotetext{
${ }^{5}$ The pilot and its findings are published in Thorpe, V. E. (2012). Assessment rocks? The assessment of group composing for qualification. Music Education Research, 14(4), pp.417-429.
} 
High" is a medium-size co-educational school of about 1200 students, in a mediumto-high socio-economic area.

I had worked with Sarah on a number of occasions in my capacity as an advisor, and over the years we had performed together in various ensembles. Some of my students had recently taken their teaching practicum at Manuka High and had been mentored by her. As such, I was familiar with the music department, and Sarah was familiar with me. I knew that she successfully incorporated group composing into her junior programmes and so it was highly likely that her Year 10 students would be composing together. Furthermore, she was "hospitable" to my inquiry (Stake, 1995, p.4).

The New Zealand school year runs from February to December and the new achievement standard was likely to be registered late in 2010, so I needed to complete the pilot as soon as possible. The relative ease of access enabled me to test my research design and analyse the data within a relatively short timeframe.

\subsubsection{Reflexivity}

The reasons for choosing Sarah and her school were quite pragmatic and there was a potential threat to data validity because of the relatively unexamined state of our relationships. The pilot study data needed to be subjectively valid, not only in and for itself, but also to inform my subsequent actions and decisions regarding the main study, so I needed a rigorous form of reflexivity to intentionally examine my assumptions (Guba \& Lincoln, 2008).

Throughout the pilot, and all of the main study, I kept detailed memos of my thoughts and experiences, looking for biases, surprises, paradoxes, inconsistencies and challenges to my preconceptions and assumptions. Much of this is in several handwritten A4 notebooks, and in digital form using NVivo software. This practice helped me to examine the potential subjectivity of my experiences, and led to a change in the research questions and the design of the main study. It also helped me to navigate the considerable methodological and ethical challenges in the main study.

\subsubsection{Ethics}

Before proceeding, I obtained ethics approval for the pilot and main study, as initially proposed, from the Victoria University of Wellington Faculty of Education Ethics Committee. (See Appendix 3.1 for all documents associated with ethics.) 
Ethical procedures and issues related to the main study will be discussed later in this chapter.

I met with the principal of Manuka High and received permission to approach the students and their parents to take part in the study. All of the participants were recruited by invitation, although Sarah suggested the group, chosen because she believed that they were a truly collaborative group, and "all reasonably capable ... you've got a pianist, and a singer, and a guitarist and they're getting on pretty well with the task."

The students were Eva, Anna, Bella and Luke (pseudonyms chosen by the students). All are Pākehā (white, non-indigenous New Zealanders) and were either 14 or 15 years old at the time. I met them informally and asked them if they would be interested in taking part and they all agreed. I phoned their parents to introduce myself, and to explain what the study was about. All expressed positive support for their children's participation. Sarah, the principal, the students and their parents received an information sheet about the project. I informed them that they could withdraw from the project at any time during the data collection. All, including parents, signed consent forms prior before the research started.

I considered that engaging in new practice, particularly the assessment of collaborative and creative student achievement, might make Sarah professionally vulnerable and so her identity, and that of her students and her school were protected (Wiles, Crow, Heath, \& Charles, 2008). The students were also assured that what they said in interviews would not be shared with Sarah because I wanted to encourage as open response as possible from them and to ensure that this information was handled ethically. I informed Sarah of this too and received her agreement. These data were kept separate because at this point I did not appreciate the importance triangulating conversations between teacher, researcher and students had for this study.

The pilot study, while not anonymous, is confidential. All people and written documents are referred to using pseudonyms and the school was referred to as "Pilot" in all documents. The data were stored on a computer in password-protected files and digital recordings were deleted after transcribing and coding. 


\subsubsection{Data Collection}

Table 3.1. Pilot Timeline

\begin{tabular}{|l|l|}
\hline \multicolumn{1}{|c|}{$\mathbf{2 0 1 0}$} & \multicolumn{1}{c|}{ Procedure and data sources } \\
\hline September & $\begin{array}{l}\text { Negotiated access, collect ethics documents } \\
1 \text { semi-structured interview with Sarah. }\end{array}$ \\
\hline $\begin{array}{l}\text { October } \\
\text { Prior to summative } \\
\text { assessment, when composing } \\
\text { nearly complete }\end{array}$ & $\begin{array}{l}1 \text { semi-structured student group interview } \\
\text { semi-structured teacher interviews. Video of } \\
\text { students performing their composition to the class }\end{array}$ \\
\hline $\begin{array}{l}\text { November } \\
\text { Post-summative assessment } \\
\text { once students had received } \\
\text { their grades }\end{array}$ & $\begin{array}{l}\text { Structured student interviews (individual \& group) } \\
\text { Final semi-structured teacher interview } \\
\text { Assessment documentation collected }\end{array}$ \\
\hline
\end{tabular}

\subsubsection{Interview methodology}

I aimed to use five kinds of interview questions (Wengraf, 2001).

1. Chronological: For example, "When was ...?" "And then what happened ...?" "What was the first thing you did?", as well as predictive questions such as "When do you think that ...?"

2. Detail: "That's really interesting. Tell me more about ..." "Could you explain a little more about ...?"

3. Clarification: "I don't quite understand"... "Do you mean that ...?"

4. Explanation: "Why...?

5. Devil's advocate: "Some people might say... What do you think ...?"

All but one of the interviews was semi-structured. The structured interview is discussed in the next section. Refreshments were provided, such as coffee (teachers), juice (students) and chocolate biscuits (everyone). I created an interview schedule of questions related directly to the research questions, or which had arisen from the initial data analysis. (See Appendix 3.2 for an indicative list of interview and discussion questions for the whole project). When possible, I emailed the interview questions to Sarah. The students read the interview questions before each interview. I also asked many more questions, allowing the interviews to take a natural, conversational course within the scheduled questions.

Immediately following each interview I wrote down my impressions, usually in the staffroom or car. I followed this up with several, careful listenings, making notes and memos. I also examined my interview technique and found that I tended to repeat questions, and reworded them before allowing the interviewees to respond. I 
subsequently strove to keep my questions short and to the point, although this was a tendency throughout the research.

All interviews were audio and/or video recorded, transcribed, uploaded into NVivo and subjected to on-going deductive and inductive analysis through the process of constant comparison (Merriam, 1998). During this process, interview questions arose from the data analysis and were incorporated into the next interview. Transcriptions were emailed to the participants for checking (Stake, 1995). None responded to these. The following nomenclature is used: $P=$ Pilot, $P T I=$ Teacher Interview, $P S G I=$ Student group interview, $P S I L \& B=$ Interview with Luke and Bella, $P S I E=$ Interview with Eva, PSIEA = Interview with Anna. Eva, Bella Anna and Luke were interviewed twice, initially as a group when they had just started working on a composition, and then after they had performed their piece to the class, prior to receiving their grades. I did not observe the students composing but videoed them performing their composition to the class.

I conducted four semi-structured interviews with Sarah aiming to gather, over time, data about her experiences of the assessment of group composing (Fontana \& Frey, 2005). This was more often than originally anticipated because it took her several weeks to come to grips with the assessment of compositional process. This was a surprise to her, and to some extent to me. I continued to interview Sarah until I had reached data saturation, that is, I was not learning anything new and the data were beginning to repeat themselves (Charmaz, 2006). In the final interview, Sarah and I viewed the video of the students performing their composition and I asked her to "think aloud" the assessment of the final product as she watched. The "think aloud" responses yielded rich data.

All student interviews took place during music class, sometimes running into a lunch hour, and were audio recorded. I read out and gave the students copies of a "ways of working” protocol:

- I talk a little, you talk a lot

- It's a discussion, rather than an interview

- Everyone gets a say

- Feel free to discuss things with each other. I'm just as interested in discussions as individual answers. I'll bring you back to the questions if I need to.

- It's OK to say “I don't know, or "I haven't thought about that before" - that's useful info for me too. 


\subsubsection{Documents}

I asked the students to indicate on a 1-10 scale about how confident they were that Sarah knew what each of them had contributed to compositional process and final composition: 1-my teacher has no idea what I contributed to the composition, to 10my teacher completely understands what my contribution was to the composition. Sarah also completed a similar one: 1- I have no idea what individual students contributed to the composition to 10- I completely understand what each individual student contributed to the composition.

I also collected copies of the compositional task, the assessment criteria, and the assessed student compositions, including a score.

\subsubsection{Pilot Study data set}

Table 3.2. Pilot study data set

\begin{tabular}{|l|l|}
\hline \multicolumn{2}{|l|}{ Pilot study data set } \\
\hline Interviews & Sarah: PTI1, PTI2, PTI3, PTI4 \\
& Whole group: PSGI1, PSGI2 \\
& Luke \& Bella: PSIL\&B \\
& Anna: PSIA \\
& Eva: PSIE \\
\hline Video & Students perform their composition \\
\hline $1-10$ confidence estimations scale & Each student, and Sarah \\
\hline Documents & Written score of the composition \\
& Written composition task \\
& AS91092 (2010 draft) \\
& AS91092 (2005 version, solo composing only) \\
\hline Memos & 9 reflective memos \\
& 11 memos related to data analysis and constant \\
& comparison. \\
\hline
\end{tabular}

\subsubsection{Data analysis methodology}

As the data were gathered and transcribed, I read through the hard copy many times, annotating and highlighting as I read, creating layers of reflection and analysis. I also wrote analytical memos while doing this. The data were then uploaded for analysis with NVivo software. I used constant comparison until the data began to repeat themselves, indicating data saturation (Charmaz, 2006).

While comparison and data saturation are grounded theory terms, it is important to note that this study is not grounded-theory research. While exploratory, my thesis is based on some pre-existing theoretical assumptions. Moreover, the qualitative design of this research is evolving and inductive (Robson, 2011). 


\subsubsection{Coding}

I started with open coding where the data were fragmented and sorted into indicators leading to broad categories (Miles \& Huberman, 1994). This was followed by axial coding, where categories were abstracted into preliminary models (Creswell, 2009). Then, using conceptual and theoretical memos, I constructed a narrative that described the relationships amongst the categories (Grbich, 2007). This generated new interview questions. The cycle continued until data saturation was achieved. To ensure that the findings were referentially adequate I frequently compared them with the raw data (Guba \& Lincoln, 2005).

Following data collection, I made two more analytical passes through the data. This was followed by more conceptual and theoretical coding, leading to a finergrained analysis, resulting in two core categories related to the research questions: learning when composing collaboratively; and assessing group composing.

\subsection{Implications of the pilot study findings}

I asked Sarah a number of questions about why she chose to encourage her students to compose in a group, believing I was investigating her beliefs about assessment and its relationship to group composing. Two other categories containing a large amount of data arose from coding the data: composing pedagogies and teacher philosophies of practice.

On careful examination, these were less closely aligned to the research question than the codes about assessment, or group learning. While Sarah talked at length about her philosophies of teaching and learning, and told me how she taught composition, none of these data referred specifically to teaching group composing. Mostly the data were related to teaching the whole class about how to compose and, because I did not observe Sarah teaching, I could not triangulate these data with other sources (Merriam, 1998).

Although the study purported to investigate the summative assessment of group composing, analysis revealed that the pilot study had generated few data about it, and raised more questions than it answered. As the review of literature indicates, the summative assessment of complex group processes requires knowledgeable input from all participants, at all stages (James, 2012). Sarah did not seem to know very much about the collaborative compositional processes in which the students were 
engaged, nor did any of the participants seem to have many ideas about how these might be assessed. Clearly, there were flaws in the research design because questions raised during coding could not be answered by the data.

\subsubsection{Should I participate in the research?}

I brought to the pilot study ideas and knowledge about the assessment of process, but my status as a non-participant meant that I was unable to discuss these with Sarah and her students, nor was I able to find out about how effective these ideas might be. I reflected upon this.

Perhaps if the students and Sarah had had the opportunity to develop a shared understanding of the nature of collaborative compositional processes, then they all might have been better able to discuss how the music was created. Perhaps Sarah might have been able to give the students more targeted feedback, more efficiently. What might have happened if I had shared a conceptual model of group composing with Sarah? What if she and I had shared this with the students? What might have happened if Sarah and I had worked together on the development of assessment practice?

It seemed ironic to me that in the process of investigating collaboration I observed her struggle to implement new assessment practice while possessing knowledge that might have helped her, and her students. This felt unethical and unprofessional. It was also possible that if I focused only on the participants' experiences of the assessment of group composing, then I might merely generate five replications of the pilot. Not only was the research design inadequate, so was the research question. I needed questions that addressed both the assessment of group composing, and its associated teacher practice but was, at this point, unsure what these might be. An overarching interim question was developed: What are the praxial implications when group composing is assessed for qualification? Bowman's (2005) definition of praxial seemed to provide me with enough room to develop more focussed questions as analysis progressed. It was not until I had gone deeply into the analysis of the study as a whole that the two research questions were finally established. This is explained in Chapters 7 and 8 . The research questions that emerged from this analysis are: "What is a valid contribution when group composing is assessed for a secondary qualification? and "What are the implications for teacher practice when group composing is introduced into an established summative assessment programme?" 


\subsection{A shift in approach}

By March 2011, despite many attempts over six months, using all of my extensive contacts and networks throughout the music education community in New Zealand, I had had no luck engaging participants in the main study.

I reflected upon the pilot study data and findings. Sarah said she felt irritated and anxious about being accountable to NZQA moderators and her school management for her NCEA assessment judgments and that NCEA assessment procedures were time-consuming and challenging. Why would a busy secondary school music teacher invite me to observe him or her trying something both new and complex, while at the same time being publically accountable to students, parents, school management and NZQA for NCEA internal assessment? I could think of no reason.

\subsubsection{Research subjectivity and validity}

In my $\mathrm{PhD}$ research proposal, I acknowledged some subjectivities or threats to internal research validity (Merriam, 1998). I stated that I viewed the summative assessment of group composing as potentially problematic for both teachers and group composers. I also stated that I believed there was a risk that if I conducted research with teachers with whom I had already worked as an adviser, then we might revert to previous ways of working together. Furthermore, my role as an adviser was also that of advocate, teacher-educator and critical friend to secondary school music teachers, and the teachers might still see me in that role when in fact this was not the case. There were also ethical risks when it came to reporting the findings.

I reflected on these issues, asking myself, "Is having an opinion about the assessment of group composing a threat to research validity? This is one of the valid consequences of my learning about this complex process. How might this (potentially) subjective view be accounted for in the research? What would happen if I discussed my opinions and ideas with a teacher who planned to assess group composing for the first time? Generating new learning is the point of research, and collaboration might lead us to that. What if we tried these ideas out together?" Could collaborative research within an established professional relationship, where I was already welcome in the classroom, be a valid research inquiry into group composing and its assessment? How might the identified potential threats to theoretical and methodological validity be managed or accounted for? 
The literature review has revealed that a multiplicity of contextual factors need to be accounted for when group composing is assessed for qualification and some of these cannot be externally perceived. Teachers and their students in this study are actors within a highly complex situation, subject to external conditions such as NCEA structures, NZQA requirements and procedures, school and community cultures, timetabling, and resourcing. Assessment is integral to teaching and learning, and is highly sensitive to the context, and the life experience, identity and practice of those involved. The pilot study findings indicated that if I was to learn more about group composing and its assessment for the NCEA, then I needed to participate. This decision aligns with practitioner research literature where it is asserted that nonparticipant observation removes the researcher from the complexities of practice (Carr \& Kemmis, 1986; Lincoln, 1995; Whitehead \& McNiff, 2006).

\subsubsection{Educational action research}

Educational action research is appropriate to use when a particular problem involving people, tasks and procedures needs a solution, or where some change could lead to better outcomes (Cohen, Manion, \& Morrison, 2007). In the present study, the "problem" is that the assessment of group composing for the NCEA was new, little was known about the assessment of individuals in creative groups, and that teachers might be unsure about how to go about doing it.

This kind of research combines diagnosis, action and reflection, focusing on a practical problem that has been identified as such by the actors (Elliot, 1991). It has to do with action (improving practice) and research (creating knowledge about practice) in a real-life setting, where practice is that of the researcher and other participants (McNiff \& Whitehead, 2010). If this study was to be practitioner research, then it needed to be an investigation of practice, namely, composing, teaching, and assessment.

Educational practitioner research is often collaborative and involves systematic procedures carried out in the classroom by teachers or other educational professionals (Cresswell, 2009). It addresses local problems of practice within specific educational contexts (Mills, 2007). On this basis I redesigned the main study as practitioner research, in collaboration with secondary school music teachers. 


\subsubsection{Positioning myself in the research}

Unlike other forms of qualitative research, where the researcher usually adopts an outsider or spectator role, an action researcher is part of the action. Caution is needed when an outside researcher collaborates with an insider-practitioner because unequal power relationships can lead to research being done to, rather than done with the teacher (Cresswell, 2009). Theory and practice are situated within the action and so cannot be carried out by someone who is not part of the institution or environment in which the action takes place (McNiff \& Whitehead, 2010).

I reflected that, although I am not a school teacher any more, I am a tertiary educator concerned with secondary music education in New Zealand. If, as an educator, I wanted to know more about teaching and assessing NCEA group composing, and the teachers I worked with did too, then, perhaps, I could be inside the action (Elliott, 1994). Nevertheless, if I conducted practitioner research in a secondary school it would need to be as a practitioner, working in collaboration with other practitioners on a problem both of us wanted to solve.

\subsubsection{Research models}

While there are many kinds of action research (practical/practitioner, participatory, emancipatory, critical, for example), they all involve rigorous, responsive data collection and a high level of reflexivity (Cohen, Manion, \& Morrison, 2007; Somekh, 1995). Whether or not this study is practical action research or qualitative collaborative practitioner research remains contestable because both terms are used in a variety of ways in the literature (see McNiff \& Whitehead (2010) and Rusinek (2012) for example). All emphasise rigorous reflexivity however, along with a consistent intention to effect practice change, and an explicit awareness of roles and power relationships.

The main study was a series of dialectic action research spirals (Mills, 2007), derived from Lewin's (1947) cyclical process of planning, execution and reconnaissance and Zuber-Skerrit's (1996) cycle of observing, planning, acting and reflecting. These are not discrete stages but are a representation of a complex, dynamic process in its entirety (Somekh, 1994). 


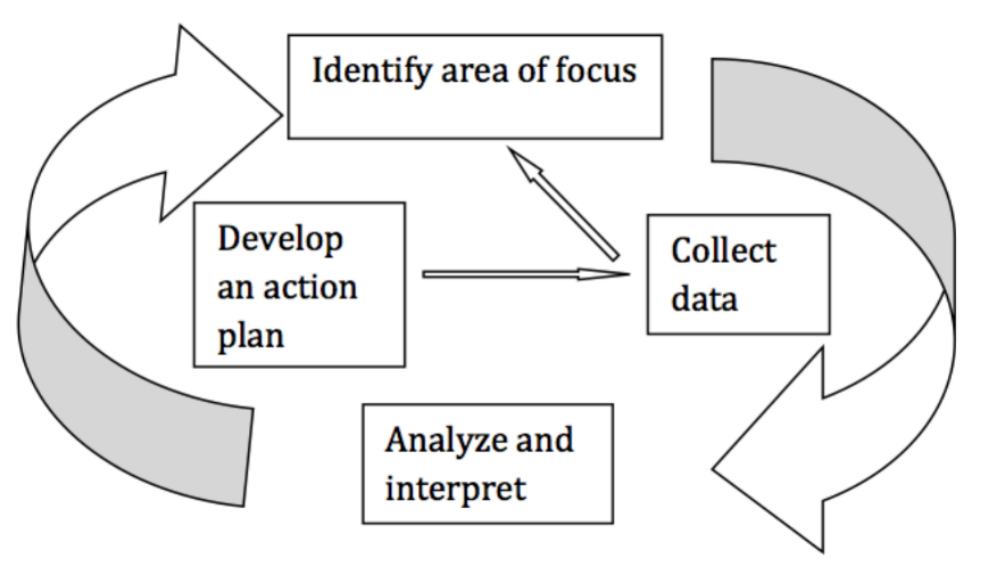

Figure 3.2. Dialectical cycle (Mills, 2007, p.20)

The similarities between this cycle and the models of the creative process examined in Chapter 2 are striking. Both involve cycles of exploration, generation, refinement and synthesis, moving reflexively between the known and the unknown. This idea is reflected upon in Chapter 9.

\subsection{Activity theory}

As the research progressed, analysis revealed a significant number of tensions and contradictions within and between multiple, interacting activities associated with group composing, teaching and assessment. When viewed through the lens of sociocultural theory, the complexity and multiplicities of human activity (such as groupcomposing, learning, teaching and assessing) are mediated through physical, social, psychological and cognitive domains (Hakkarainen, Paavola, Kangas, \& SeitamaaHakkarainen, 2013). CHAT is a means by which these complexities can be interpreted (Engeström, 1993). While activity theory has not been used extensively in music education research to date, Odena (2012b) and Fautley (2010) observe that it is emerging in the literature as an analytical tool to examine and explain such complexities (Burnard \& Younker, 2008; Soares, 2012; Welch, 2007). Once I had "zoomed in" to explore the data through action research, I then used CHAT to "zoom out" and engage in more systematic analysis, (Somekh \& Nissen, 2011, p.96).

\subsubsection{First generation activity theory}

Activity theory is derived from the work of Vygotsky (1978, 1986) who asserted that human development occurs through a series of interactions among mediating artefacts and the individual, and that these artefacts are culturally and historically situated. Vygotsky believed that signs were the impressions made upon 
individuals by their interactions with tools or artefacts, and that it is these impressions and artefacts that mediate human action.

This theory, often referred to as first generation activity theory, is usually represented as a triangle where the subject is the individual engaged in the action, the object is the goal of the activity, mediated by the artefact which could be a tool, instrument and/or sign (Cole \& Engeström, 1993). (See Figure 3.3 below.)

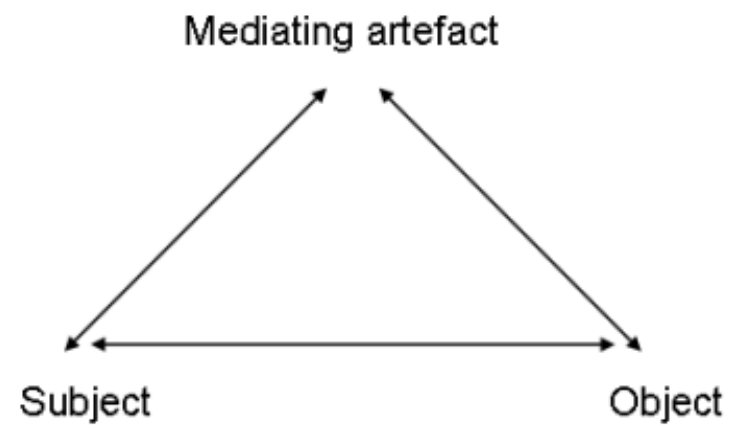

Figure 3.3. Vygotsky's triangle of mediated action (adapted from Cole, 1996)

\subsubsection{Cultural historical activity theory}

This idea was further expanded upon by Leont'ev and Luria to incorporate societal, historical and cultural dimensions (Leont'ev, 1981). In the West, Engeström (1987) and Cole (Cole \& Engeström, 1993) represented this as second generation activity theory. (See Figure 3.4). Vygotsky's triangle of mediated action can be viewed as the "tip of the iceberg" of collective rather than individual activity. Engeström (1987) asserts that activity takes place within communities that generate culturally and historically derived rules and divisions of labour. The object of the activity is the goal of the subjects (those taking part in the activity), mediated by culturally and historically derived artefacts and leading to an outcome. 


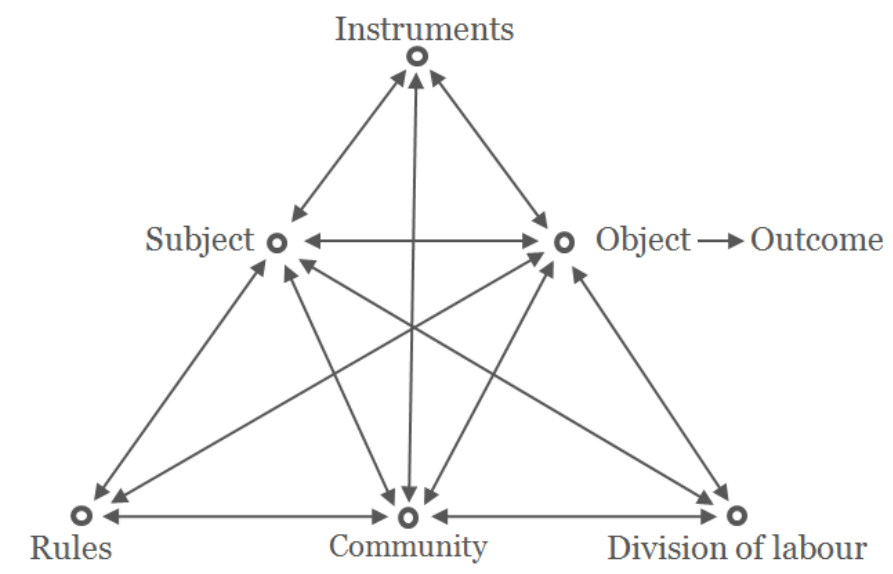

Figure 3.4. Activity system (adapted from Engeström, 1987)

\subsubsection{Contradictions within activity systems}

Engeström's core ontological assumption is that activity is dynamic in nature and that change within a system is inevitable (Engeström, 1987). He identifies four levels of inner contradiction. See Table 3.3.

Table 3.3. Engeström's four levels of inner contradiction in an activity system (Yamagata-Lynch \& Haudenschild, 2009, p.510)

\begin{tabular}{|l|l|}
\hline Contradiction level & \multicolumn{1}{c|}{ Engeström's definition (1987) } \\
\hline Primary & $\begin{array}{l}\text { When activity subjects encounter more than one value system attached to } \\
\text { an element within an activity that brings about conflict. }\end{array}$ \\
\hline Secondary & $\begin{array}{l}\text { When activity subjects encounter a new element of an activity, and that } \\
\text { process for assimilating the new element into the activity brings about } \\
\text { conflict. }\end{array}$ \\
\hline Tertiary & $\begin{array}{l}\text { When activity subjects face conflicting situations by adopting what is } \\
\text { believed to be a newly advanced method of achieving the object. }\end{array}$ \\
\hline Quaternary & $\begin{array}{l}\text { When activity subjects encounter changes to an activity that result in } \\
\text { creating conflict between adjacent activities. }\end{array}$ \\
\hline
\end{tabular}

Engeström (2001) expanded the heuristic to represent the third generation of activity theory where the interactions between adjacent systems lead to a third object and its associated outcome. See Figure 3.5 


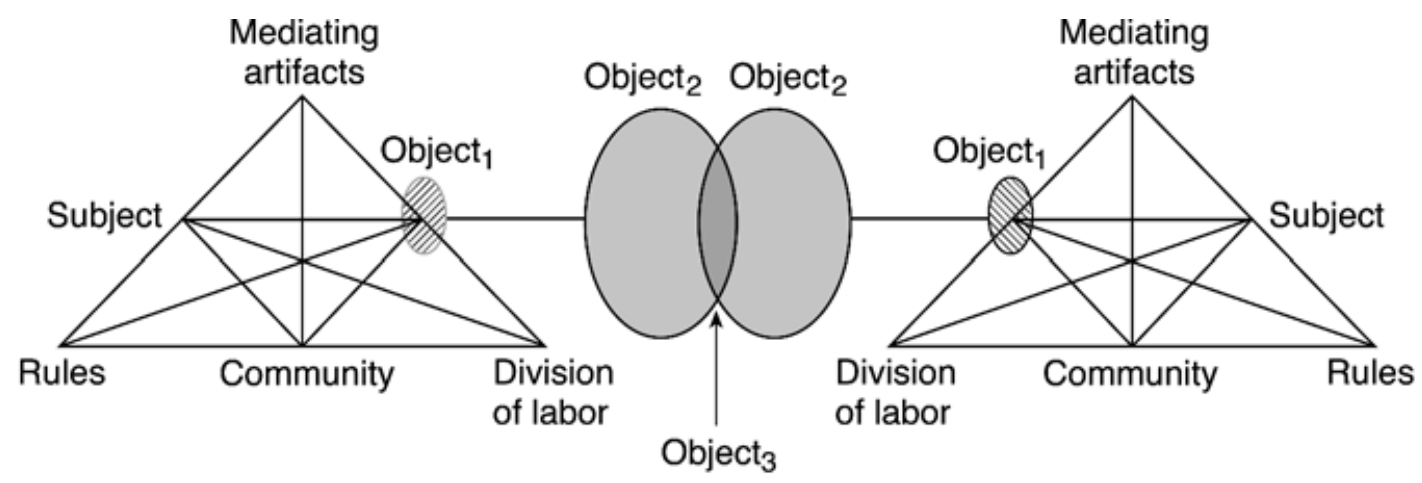

Figure 3.5. Two interacting activity systems as minimal model for the third generation of activity theory. Engeström (2001, p.136)

\subsubsection{How activity theory is used in this study}

Each of the two research questions in this study examines the contradictions and tensions among and between multiple, interacting activities.

For Question One (what is a valid contribution when group composing is assessed for qualification?), these activities might be socio-musical, such as composing, playing, and singing, or pedagogical, such as teaching or planning, or those associated with assessment.

For Question Two (what are the implications for teacher practice when group composing is introduced into an established summative assessment programme?), these might be the activities associated with teaching, such as giving feedback, or grading, or examining or in modifying practice.

Activity theory is used in this study to uncover some of what occurs in these activities, as well as illuminating the contradictions and tensions both within and between them. As explained in Chapters 7 and 8, activity theory provided me with a framework to gain deeper insights into the assessment of group composing and its impact upon teacher practice.

While this study uses socio-cultural theory as its framework, the research methodology and design is that of practitioner inquiry. In this study, CHAT is employed as a conceptual framework to analyse and discuss the multiple levels of activity within the study's findings, but was not used during data collection. This is partly because, early in the study, I did not fully appreciate its relevance to the research, but mainly because it was not until I had analysed the data and thought very deeply about it, that I gained sufficient insight into what had happened, and thus was able to recognise which activities were significant. 


\subsection{The main study}

In April 2011, I emailed secondary classroom music teachers via the regional subject association list-serve, inviting them to express interest in working in partnership with me to find out more about NCEA assessment and group composing. Two teachers replied within five minutes! By the end of the week, six teachers had expressed strong interest in taking part. Two withdrew because their Year 11 students all elected to solo compose. One teacher was a personal friend and we agreed that this was inappropriate for a professional/academic inquiry. Another teacher was in her first year of practice and I decided that, as a beginning teacher, she would probably not be professionally ready to undertake action research. This left the two teachers who had originally expressed interest with such alacrity. I invited them to participate in the project and they both immediately accepted.

\subsubsection{Alice and David}

Alice is the sole music teacher in a low-decile, co-educational school, Kotare College ${ }^{6}$. Alice has a degree in performance on her instrument and works regularly as a session musician. She describes her instrument as "the love of my life" and practices daily. Some of her teaching career has been spent outside of the classroom as a private instrumental teacher, and also in schools as an itinerant teacher of her instrument.

Alice had not yet begun teaching composition to her Year 11 class and, as this was at the end of Term 1, was keen to get started as soon as possible. She said she was unhappy with the low level of NCEA achievement in solo composing over the years (usually only $10 \%$ of the class). Some of her current Year 11 students, particularly Māori and Pāsifika boys, spent a lot of time jamming together and Alice believed that these students would have a better chance of achievement through group composing rather than alone.

David has a specialist degree in Music Education with a background in concert/jazz bands and classical music. In 2009, he came to New Zealand to take up the post of Director of Music at St Bathan's Collegiate, a private boys' school. Not long after he arrived in New Zealand, David approached me through the local subject association for some advice about getting to know the New Zealand education system.

\footnotetext{
${ }^{6}$ Decile is a government rating of the level of socio-economic affluence within a school's community. Low decile indicates low affluence.
} 
In April 2011, David's class of eight Year 11 NCEA music students was already well advanced in composing, including one group of three students. The Year 11 music class for 2012 (20 students) was to be the largest he had ever taught at senior level. David also thought it likely that some boys would opt to group-compose and, as a recent arrival to New Zealand, was unsure how to manage NCEA internal assessment, particularly for so many students. David believed he needed to make changes to his practice when incorporating group composing into his Year 11 programme and expressed particular interest in doing so.

\subsubsection{Ethics}

The original ethics proposal was amended and resubmitted to the Ethics Committee for further approval. However, ethics procedures at the beginning of each project were the same as those of the pilot. The Ethics Committee pointed out that recordings of student compositions might be identifiable and so the titles of some pieces were changed.

Once the two studies were concluded I tested the anonymity of the research sites. I confidentially checked the descriptions of the schools with a colleague who is very familiar with the teachers and secondary school music departments in the region. She could not identify Kotare College, but certain details about St Bathan's Collegiate, such as the lavish new facilities, were not so easy to disguise because they are integral to the findings. I immediately raised the possibility of identification with the school's principal, and with David. Neither could see a problem with this and, on the contrary, were happy for the school to be identified, although we agreed to keep this information as confidential as we could because it was important that individual students could not be identified under any circumstances. We also agreed that should David and I present any research together, as we have subsequently done, then individual student data would only be used with specific parental permission.

As the data analysis progressed, a number of personal issues related to David's practice were revealed. I invited him to read what I had written about these issues, and any references to these are published with his express permission. As with the pilot, I used participant checking. On one occasion after reading an interview transcript, Alice felt that her comments did not accurately represent her thinking and wrote a paragraph which she believed more clearly represented what she wanted to say. With her approval, I added this to the transcript as an addendum. 
I interviewed Alice and David at the end of data collection. In these interviews I shared the emergent findings with them and asked for their opinions, observations and thoughts. David in particular has been very involved in this process as part of our on-going professional and research relationship. While both teachers and I regularly discussed the students, student interview data were only shared with the teacher following participant checking, and I did not name specific students but instead shared the overall interview content.

Throughout the research at Kotare, and subsequently, there has been an ongoing ethical concern about how to present the Kotare findings honestly because some findings do not show Alice's practice in a favourable light. Anonymity is of great importance here and so details about Kotare College, Alice and her students have either been omitted or changed to ensure that they cannot be identified.

\subsubsection{Timeframe}

Alice wanted to start right away (May 2011), and David wanted to begin planning the research at the end of 2011 once his senior classes had concluded. Data collection ran from May to December 2011 at Kotare College, and from October 2011 to December 2012 at St Bathan's Collegiate.

\subsubsection{Kotare College}

Kotare College is a medium-sized, co-educational state secondary school in a mid-to-low socio-economic community. The teaching spaces consist of one classroom and two practice rooms. None of these rooms is soundproofed. The classroom and one practice room contain a piano, a drum-kit and amplifiers for guitars; the other room contains a piano. Instrumental and vocal tutors also teach in the two practice rooms and come and go throughout the week. The IT consists of a TV, a Stereo, a DVD player and two elderly, non-networked PCs located in the storage room. There are class sets of guitars and keyboards.

\subsubsection{Kotare student participants}

The class consisted of 15 boys (eleven Pākehā, two Māori, one Tongan, one Tuvaluan) and five girls (two Pākehā, two Tongan, one Māori). There were fewer girls and Māori students in the class than in the Kotare College population as a whole. 
Table 3.4. Kotare College student data

\begin{tabular}{|l|l|}
\hline \multicolumn{1}{|c|}{ Kotare College } & \multicolumn{1}{c|}{ Year 11 Music } \\
\hline $40 \%$ Māori & $25 \%$ Māori \\
\hline $40 \%$ Pākehā & $55 \%$ Pākehā \\
\hline $12 \%$ Pasifika & $20 \%$ Pasifika \\
\hline $4 \%$ Asian & $0 \%$ Asian \\
\hline $4 \%$ other ethnicities & $0 \%$ other ethnicities \\
\hline $51 \%$ boys & $75 \%$ boys \\
\hline $49 \%$ girls & $25 \%$ girls \\
\hline
\end{tabular}

Eight student participants from two collaboratively composing groups participated in the project. Blues Rock were Jimmi (Māori, lead guitar), Rāwiri (Māori, drummer), Jay (Pākehā, bass guitar/rhythm guitar), and Aaron (Māori, rhythm guitar). Heavy Rock (all Pākehā) were Jason (vocalist), Zach (drummer), Liam (bass), and Damien (guitar).

\subsubsection{St Bathan's Collegiate}

St Bathan's Collegiate is a Year 1-13 private boys' school for both day and boarding students. In January 2012, a multi-million dollar, state-of-the-art performing arts complex was completed and the Music Department moved from a two-classroomno-practice-rooms set-up, to an entire floor in the new building. There are two large classrooms/rehearsal spaces, multiple soundproofed practice rooms containing drum kits, amplifiers and/or pianos, and a professional recording studio with a full-time technician. Class sets of guitars and keyboards are stored in rooms adjacent to the classrooms. Each classroom contains eight new Macintosh computers (on-line), orchestral percussion instruments, a piano, drum kit and an on-line data projector. Teachers have laptops as well as desktop computers. During the research period David was one of two classroom music teachers and had sole responsibility for secondary music.

\subsubsection{St Bathan's student participants}

In 2012, the Year 11 music class consisted of 20 boys. The ethnicities were generally representative of the school as a whole. All but one boy, an international student recently arrived from China, had studied music with David in 2011. 
Table 3.5. St Bathan's Collegiate student data

\begin{tabular}{|l|l|}
\hline St Bathan's Collegiate & Year 11 Music \\
\hline $68 \%$ Pākehā & $85 \%$ Pākehā \\
\hline $7 \%$ Chinese & $5 \%$ Chinese \\
\hline $7 \%$ Indian & $5 \%$ Indian \\
\hline $5 \%$ Māori & $5 \%$ Māori \\
\hline $14 \%$ other ethnicities & None \\
\hline
\end{tabular}

There were ten student participants from four groups. All of the students are Pākehā except Chris who is Māori.

- Pikachu: Jake, Shin, Tom (from the 2011 class)

- Action Movies: Fraser, Rob, and Angus

- Indie Rock: Callum, Alex and Oliver

- Big Group: Richard (plus Chris, Mike, Josh, and Luke who were not interviewed)

Late in 2011, I interviewed the Pikachu boys who had collaboratively composed a piece for $A S 91092$ that year.

\subsubsection{Data collection}

The pilot data collection methodologies explained earlier in this chapter were employed in the main study. I also added a student questionnaire. Practitioner research means that collecting student data is directly linked to pedagogical and assessment processes in which teachers and I engaged. Some data collection methods, such as observation, did "double duty", as assessments, or opportunities for reflection on new ways of teaching, as well as data for the present study (Boud, 2000, p.160). Many of these were developed as the research progressed and will be explained in the context of the findings.

\subsubsection{Interview}

I conducted two semi-structured interviews with both Alice and David, one at the beginning and one at the end of the research (Fontana \& Frey, 2005). The aim was to gather data about what they thought about group composing, the current context, the problems they wished to solve, their subsequent learning from the research, and whether or not they believed they had been successful in achieving their goals. Some of these questions were derived from interviews carried out in the pilot study. 
For the first interview I used the same questions with both teachers with the aim of gathering comparable baseline data. All planning and discussion sessions with the teachers were audio recorded. At times these consisted of un-structured interviews, while others consisted of mutual discussion about practice.

I conducted semi-structured interviews with five groups of students and one individual student (19 students in total). I interviewed one group of Kotare College students twice but did not need to do so at St Bathan's. This was because the teacherstudent interactions at St Bathan's were different from Kotare and I learned more from the students during classroom interactions.

Before each student interview I read out and gave the students copies of the "ways of working" protocol from the pilot, as well as the 1-10 assessment confidence scale. I gave a similar scale to Alice and David. (See Appendix 3.3) I gave the Kotare students a four-question $4 \mathrm{x}$ Likert scale questionnaire about their attitudes to NCEA and composing. Following analysis of the Kotare data I added four more motivational questions to the St Bathan's questionnaire. (See Appendix 3.4.)

As in the pilot study, I employed constant comparison and interviewed Alice or David and the students until I had reached data saturation, indicating that a particular research cycle was coming to a close. I audio-recorded all discussions and meetings.

\subsubsection{Observation as a participant}

I observed Alice and David teaching as part of our collaborations, and also to triangulate interview, document and reflection data (Robson, 2011). I took notes where I aimed to gather as much detail as possible. I also videoed some parts of lessons, as did both teachers. Whenever possible in the busy school day, I discussed what happened with Alice or David immediately after each observation and wrote memos immediately afterwards. I also annotated my observation notes.

Here is a transcribed example:

\section{Observation 9}

David starts with revision "Explain to me as if I was a Year 9 student what we learned yesterday". Boys gradually offer answers. They learned about strong chords (I, IV, V to home) and weak chords (II, III, vi - an infinite cycle that doesn't go anywhere) and then learned to join up the chord notes using passing notes to make a melody. 
David has identified the weaknesses in their composing and is addressing this. I think that this is in part due to our discussions where I identified harmony and melody writing as being weak, and also what he has observed from the boys' compositions so far.

Then he asks students to give a show of hands who "gets it"?. 75\% of them don't get it. Then he asks them to give him feedback as to why not.

What great practice. This is "assessment as learning" in action. However this kind of technique can only work in environments of complete trust where students are happy to say they don't get it, or don't understand the task. Must ask him what he thinks about this.

Although I was present in many of Alice's lessons, I formally observed her teaching only five times because I found that I did not learn very much from observation. All lesson observations were subsequent to our reflection and planning sessions, where the aim was to put our new learning into practice. Alice did not take up my offers to discuss these data however. I asked Alice to observe me teaching, and while she verified and commented upon student engagement, her observations were generally limited to descriptions of what I did. It soon became clear that we were not going to learn very much through this data collection method.

I observed David teaching ten times until data saturation. David was always keen to find out what I had observed, particularly when implementing new teaching and assessment practices. This proved to be a very effective means of gathering rich data with which we both subsequently engaged.

\subsubsection{Documents}

I collected documents relating to the project including student assessment records, recordings of student compositions, lead sheets of the compositions, teaching resources, David's external moderation submission to NZQA, and Alice's journal. In collaboration with David, I also developed a number of data collection tools.

\subsubsection{Data sets}

I retained the pilot nomenclature system:

- $\mathrm{K}=$ Kotare College

- $\quad$ B = St Bathan's College

- $\mathrm{OB}=$ Observation

- $\mathrm{TI}=$ Teacher interview

- $\mathrm{TD}=$ Teacher discussion

- $\mathrm{SI}=$ Student interview 
The participant groups are named:

- $\quad \mathrm{HR}=$ Heavy Rock

- $\quad \mathrm{BR}=$ Blues Rock

- $\quad \mathrm{IR}=$ Indie Rock

- $\mathrm{AC}=$ Action Movies

- $\mathrm{BG}=$ Big Group

- $\mathrm{P}=$ Pikachu

Table 3.6. Data sets for both studies

\begin{tabular}{|c|c|c|}
\hline \multicolumn{3}{|c|}{ Data sets: main study } \\
\hline Data & Kotare College & St Bathan's Collegiate \\
\hline $\begin{array}{l}\text { Semi- } \\
\text { structured interview }\end{array}$ & $\begin{array}{l}2 \text { with Alice, } 2 \text { with Blues Rock, } \\
1 \text { with Heavy Rock }\end{array}$ & $\begin{array}{l}6 \text { with David, } 1 \text { each with } \\
\text { Pikachu, Action Movies, Indie } \\
\text { Rock, and Richard from Big } \\
\text { Group }\end{array}$ \\
\hline $\begin{array}{l}\text { Discussion, } \\
\text { planning \& } \\
\text { assessment sessions }\end{array}$ & 5 with Alice & 9 with David \\
\hline $\begin{array}{l}\text { Observations } \quad \& \\
\text { field notes }\end{array}$ & $\begin{array}{l}4 \text { of Alice teaching } \\
\text { On-going observations/field } \\
\text { notes of the groups as they } \\
\text { worked together }\end{array}$ & $\begin{array}{l}10 \text { of David teaching } \\
\text { On-going observations/field } \\
\text { notes of the groups as they } \\
\text { worked together }\end{array}$ \\
\hline Video & $\begin{array}{l}2 \text { recordings of Blues Rock's } \\
\text { performances of their } \\
\text { compositions } \\
1 \text { recording of Alice using the } \\
\text { assessment tools }\end{array}$ & $\begin{array}{l}5 \text { recordings of students } \\
\text { performing their compositions } \\
1 \text { recording of VT \& David } \\
\text { interviewing Big Group }\end{array}$ \\
\hline Documents & $\begin{array}{l}8 \text { student questionnaires: Blues } \\
\text { Rock \& Heavy Rock } \\
9 \text { assessment confidence sheets: } \\
\text { Blues Rock \& Heavy Rock, } \\
\text { Alice } \\
\text { Planning, teaching \& assessment } \\
\text { materials: VT's \& Alice's } \\
\text { Student assessment data, } \\
\text { including } 2 \text { chord charts of } \\
\text { Blues Rock's compositions } \\
\text { Relevant NZQA documents } \\
12 \text { emails } \\
\text { Alice's journal }\end{array}$ & $\begin{array}{l}1 \text { class set of student } \\
\text { questionnaires (19) } \\
7 \text { student questionnaires: Indie } \\
\text { Rock, Action Movies, Richard } \\
\text { from Big Group } \\
12 \text { assessment confidence } \\
\text { sheets: Pikachu, Indie Rock, } \\
\text { Action Movies, Richard from } \\
\text { Big Group, David } \\
\text { "Flow diagram" data } \\
\text { Planning, teaching \& assessment } \\
\text { materials: VT's \& David's } \\
\text { Assessment tasks \& assessment } \\
\text { schedule (rubric) }\end{array}$ \\
\hline
\end{tabular}




\begin{tabular}{|l|l|l|}
\hline \multicolumn{2}{|c|}{ Data sets: main study } \\
\hline & & $\begin{array}{l}\text { Student assessment data, } \\
\text { including written representations } \\
\text { of compositions } \\
\text { St Bathan's Collegiate 2011 \& } \\
\text { 2012 submission to NZQA } \\
\text { music moderator, \& moderator's } \\
\text { responses } \\
\end{array}$ \\
& & $\begin{array}{l}\text { 45 emails } \\
\text { Research materials }\end{array}$ \\
& $\begin{array}{l}29 \text { memos } \\
\text { VT's journals }\end{array}$ & $\begin{array}{l}35 \text { memos } \\
\text { VT's journals }\end{array}$ \\
\hline
\end{tabular}

\subsubsection{Data analysis during data collection}

Initially, my findings from the literature review and the pilot study data informed my initial discussions with Alice, the initial interview questions, and the gathering of baseline data. The same data analysis methodology was used as the pilot (see 3.3.3).

The first cycle of analysis revealed a strong focus upon Alice's and my practice, and the subsequent student responses to our teaching. However, as more data were collected, analysis revealed this focus was not productive. A second analytical pass across the emerging data examined student responses in more detail, focusing upon what I was learning about group composing and its assessment, but with less focus upon Alice's practice. The reasons for this will be explained later in this chapter.

Near the end of data collection at Kotare, I began a third cycle of analysis using the methodology described earlier, moving through three analytical cycles from open to axial coding followed by two more coding passes through all of the Kotare data, and 170 codes were reduced to 55 (Charmaz, 2006). I wrote a lot of analytical and reflective memos, annotating these both electronically with NVivo, and by hand on the hard copy.

Once the coding began to stabilise and consolidate, I created a tentative frame for the analysis of the St Bathan's data:

- New pedagogies in response to group composing

- Managing group composing

- Assessing group composing 
- Student learning and group composing

- Group learning

- NCEA and being assessed (students)

- Teacher philosophies about teaching and assessment

- Teacher lived experience

- Practice enacted/not enacted

I tried to stay as flexible as possible, modifying the framework in response to the data, allowing the data to tell me what needed to be done. The same methodology as Kotare was used for the St Bathan's data. After each coding cycle I wrote a specific analytic memo for each data item. (See Table 3.7):

Table 3.7. Analytic memo: St Bathan's data analysis. 3 November 2011

\begin{tabular}{|c|c|c|c|c|}
\hline \multicolumn{5}{|c|}{ Analytic memo: St Bathan's Collegiate } \\
\hline Date & Item & $1^{\text {st }}$ pass coding & $\begin{array}{c}\text { Emerging themes } \\
3 / 91^{\text {st }} \text { pass } \\
\end{array}$ & $\begin{array}{l}\text { Thoughts, surprises, } \\
\text { outliers }\end{array}$ \\
\hline $\begin{array}{l}3 \\
\text { Nov } \\
2011\end{array}$ & $\begin{array}{l}\text { BSTI } \\
\text { Yr11 } \\
2011 \\
\text { (student } \\
\text { interview) }\end{array}$ & $\begin{array}{l}\text { Deep shared understanding } \\
\text { of genre } \\
\text { ZPD } \\
\text { Mutual support \& sharing of } \\
\text { ideas } \\
\text { Instrumental skills } \\
\text { Fun } \\
\text { Relaxed learning } \\
\text { Doesn't feel like school work } \\
\text { Freedom \&choice } \\
\text { Need variety of instruments } \\
\text { Group vs individual } \\
\text { composing } \\
\text { Jamming } \\
\text { Articulating process } \\
\text { Articulating assessment } \\
\text { criteria } \\
\text { Novices } \\
\text { Confidence } \\
\text { Pop music is the benchmark } \\
\text { Fairness \& honesty } \\
\text { Teacher feedback } \\
\text { NCEA \& being assessed }\end{array}$ & $\begin{array}{l}\text { Level of student's } \\
\text { instrumental skills, and } \\
\text { type of instrument played } \\
\text { are important } \\
\text { Familiarity with, \& } \\
\text { understanding of genre is } \\
\text { important } \\
\text { Novices, or less confident } \\
\text { students are lifted up by } \\
\text { more confident \& able } \\
\text { peers. There is safety in } \\
\text { numbers. GC1st time, solo } \\
\text { compose next time. } \\
\text { Pop music is a benchmark } \\
\text { \& students aren't very } \\
\text { interested in NCEA criteria. } \\
\text { GC refreshing, fun change } \\
\text { from most activities at } \\
\text { school, involving a high } \\
\text { degree of freedom of } \\
\text { choice. }\end{array}$ & $\begin{array}{l}\text { Despite the profound socio- } \\
\text { economic disparity with } \\
\text { Kotare, kids seem to be } \\
\text { saying very similar things } \\
\text { here. } \\
\text { Compare with pilot \& Masters } \\
\text { - maybe do a theoretical, } \\
\text { deductive sweep of all data } \\
\text { for this when doing cross case } \\
\text { analysis? } \\
\text { What about coding some } \\
\text { pertinent literature to see if } \\
\text { similar themes emerge? }\end{array}$ \\
\hline
\end{tabular}

\subsubsection{Data analysis following data collection}

Following the second pass through both data sets, I extracted emerging themes, allowing these to indicate the ways in which a new cycle of inductive, theoretical coding of both data sets was to proceed (Miles \&Huberman, 1994). I created more graphic concept maps using NVivo and returned to the literature review, which was in turn added to in response to the analysis. 
When writing up the findings, new insights emerged (motivation to succeed, for example) and I returned to the data analysis to investigate these further. I made new hard copies of the data and made a series of hand-written annotations as I read and re-read these. As new insights emerged, I also used Queries in NVivo to interrogate the data more deeply. This was followed by a cross-analysis where I compared the themes of the two data sets. The three practices that are the foundation of this study began to emerge as significant and the final stages of data analysis were therefore constructed around the conception of practice architectures explained in Chapter 1, where composing, teaching and assessment are practice. These are interpreted through the meta-practice of qualitative practitioner research (Kemmis \& Grootenboer, 2008).

\subsubsection{CHAT as a conceptual framework for analysis}

CHAT was the conceptual framework for analysing the findings. Firstly, the socio-cultural aspects of activity (such as tools, communities, divisions of labour) were identified, analysed and discussed. Then I used CHAT to interrogate the questions arising from the findings analyses. Specific activities were examined in terms of Engeström's triangular diagram, with a particular focus upon contradictions and tensions, which are represented in Figure 3.6 by dotted lines and numbers.

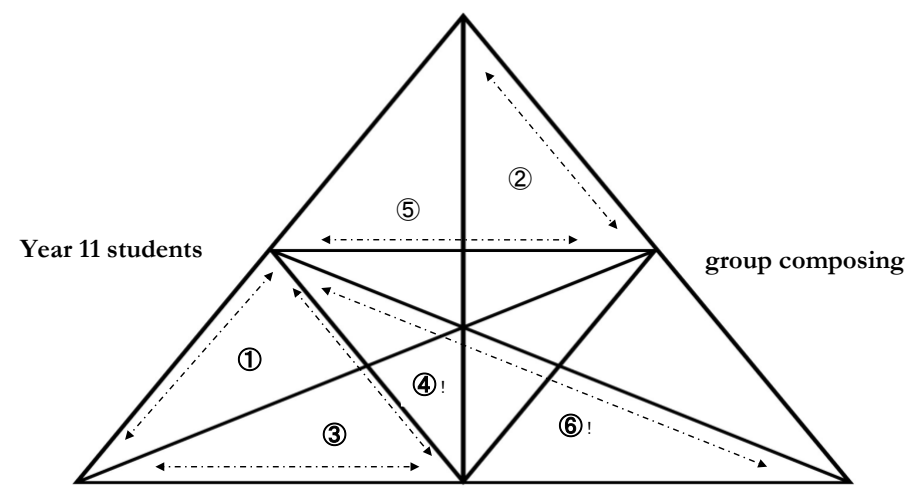

Figure 3.6. Inner contradictions and tensions example

I also examined the relationship between activities nested within, or adjacent to, other systems (Barab, Barnet, Yamagata-Lynch, Squire, \& Keating, 2002; Engeström, 2001). See Figure 3.7. 

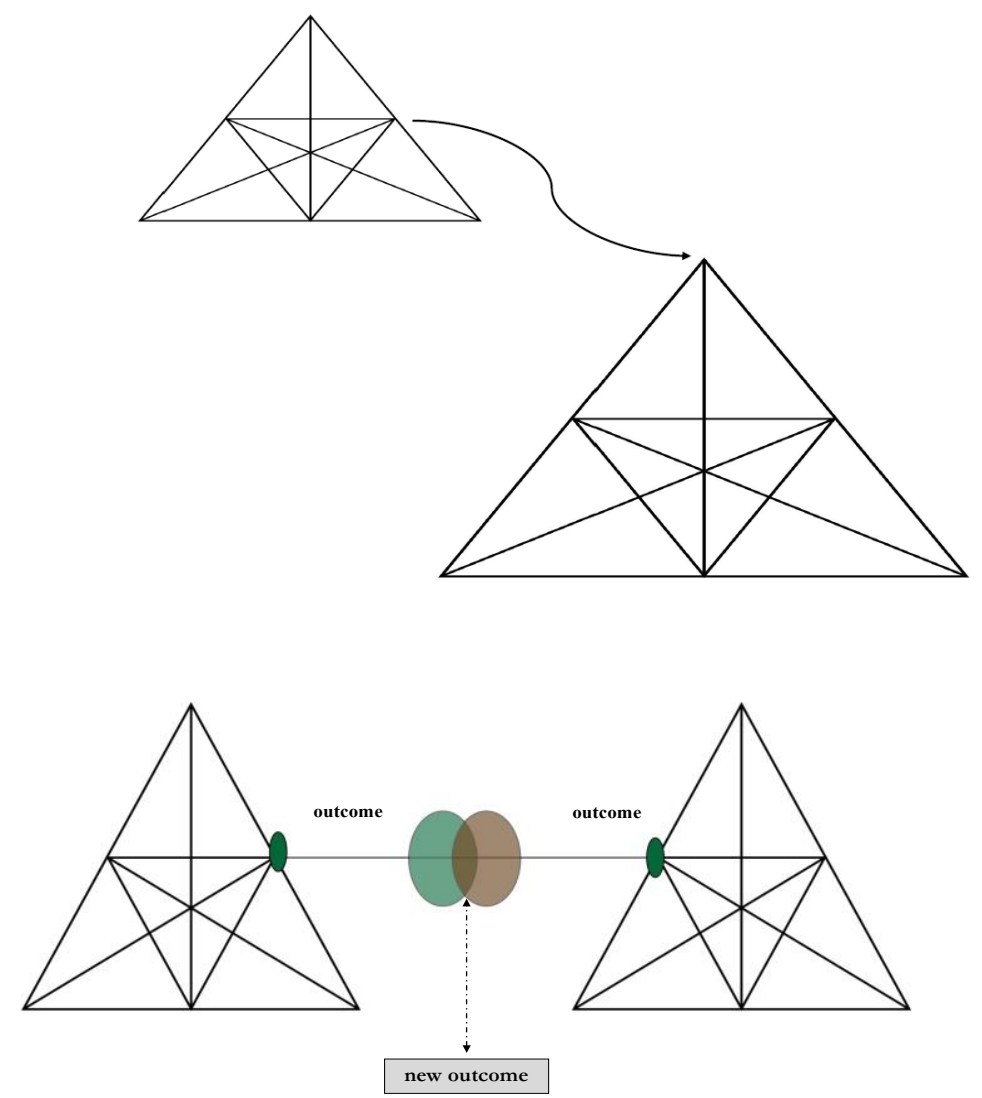

Figure 3.7. Nested and adjacent systems (Barab et al., 2002; Engeström, 2001)

It was at this point that the two research questions were identified and integrated into the writing.

\subsection{Limitations within the practice setting}

Research in practice settings is limited by a multiplicity of external and internal factors associated with the setting itself.

\subsubsection{Limitations for VT}

Throughout most of the data collection I was also teaching at the University. This meant that occasionally visits to the schools needed to be fitted around my own teaching timetable. It also meant that I no doubt missed significant moments.

During the research, three of my students were placed in the research schools on teaching practicum (one at Kotare, two at St Bathan's). These placements coincided with breaks in the research when Alice or David taught other aspects of the curriculum. I continued to come and go for interviews and to share my emerging findings with David or Alice. The student teachers signed confidentiality agreements. When I visited the school to assess them, it was as a visiting teacher-educator, not a researcher. 


\subsubsection{Limitations: Alice and David}

The teachers' participation in the research was entirely voluntary. The extent of my access to their classrooms and their students was up to them and they had control over when this happened. While both teachers were unfailingly hospitable and positive regarding the research and my presence, the multiplicity of demands of secondary music teaching meant that they were not always available (Somekh, 1994).

Initially, both teachers agreed to keep reflective journals. While Alice did so very diligently, what she recorded was not very reflective and consisted mainly of descriptions of her actions and mine. As the research progressed, low student achievement and its relationship to Alice's practice began to be revealed by the data. This may have affected Alice's professional confidence and her willingness to candidly record her reflections in written form.

While David was highly reflective and said he was keen to examine his practice "warts and all", he did not keep a reflective journal, having indicated at the beginning of the research that he would struggle to do so. Emails, phone calls, text messages, interviews and regular meetings helped to keep us both engaged in the reflexive cycle, but this limitation had consequences which are discussed in Chapter 6.

Composing is only a part of the Year 11 curriculum and so Alice and David were limited by the classroom time available. Although subject to negotiation within the research partnership, this was mainly determined by them. Re-connecting after a break was sometimes difficult as both teachers were engrossed in other aspects of their work. Rehearsals and performances for music groups and a school production took up a lot of both teachers' time and energy. It was hard to find time to meet. We negotiated a communication protocol where we agreed to a 24-hour communication turnaround on emails, the preferred means of communication when I was not on site.

David also set aside a two-hour slot in his timetable where we met as teachers to examine student data and plan next steps with the students. We also met once a fortnight out of school hours in a cafe to "put on our white coats", as David put it, as researchers and examine the data from that perspective. These arrangements helped us both to define our roles.

Teacher workload, stress and accompanying illness, enduring issues for secondary music teachers, were significant limitations (Donaldson, 2012). Unlike the 
teacher-researchers in much of the literature about such collaborations, this research was not part of a professional development programme, neither teacher was working towards post-graduate qualifications, nor in some teacher-education relationship with the University. Neither received any time allowance to take part in the research. On a number of occasions planned work was postponed because either Alice or David was overwhelmed by work, or ill, or stressed-out, or (usually) all three.

\subsubsection{Limitations: students}

At Kotare College, student absences affected the ability of groups to work together. Some students left the school or were "stood down" temporarily from the school for bad behaviour, bringing group composing to a halt. As the findings will show, generally low student expectation of success or achievement in music proved to be a significant limitation.

Group composers needed regular access to separate sound-proofed spaces in which to work, and access to drum kits and amplifiers. St Bathan's students had access to these but the Kotare students did not. These limitations are examined in detail in Chapter 5.

\subsubsection{Limitations: School and NZQA structures}

Both teachers suspended the research whilst directing a musical production. There were interruptions due to sports fixtures, school photos, field trips, end-of-term events, competitions, and visiting groups or speakers.

At Kotare College, Alice was obliged to teach one Year 11 Music lesson in a science lab on the last spell of every second Friday because of a timetable glitch. The research timeframe was limited by the school year and NZQA requirements, such as when moderation submissions were due, internal moderation procedures, and AS91092 assessment criteria.

\subsection{Credibility, trustworthiness and validity in practitioner research}

Merriam (1998) recommends six basic strategies to enhance internal validity in qualitative research: long term observation at the site, triangulation, participant checking, peer examination, collaboration, and the explicit examination of research bias. 
Observation was long term because data collection for this entire study, including the pilot, took 26 months. Triangulation and participant checking are discussed in the next two sections. Procedures, issues and responses related to peer examination, collaboration and researcher bias in the main study are related to interpretive validity in what Guba and Lincoln (2008) refer to as "new paradigm" research (p.255).

\subsubsection{Triangulation}

Triangulation refers to the stability of the data where multiple sources and a range of methods are used to confirm emergent findings (Guba \& Lincoln, 2008). As the data set summaries above show, the data were in many different forms, and thus, triangulated.

Several methods of data collection were needed so that weaknesses in one method could be compensated for by strengths in another. Where one method of data collection was found to be insufficient to provide insights into what was happening, for example observation at Kotare, I used another.

\subsubsection{Participant checking}

The data associated with Alice and David were subject to on-going checking throughout the study. Transcripts were emailed to both teachers for comment and their responses to these integrated into the collaborative research process, although more so for David than Alice. I also returned to both schools after data collection to check and re-check my findings with both teachers, although, again, David engaged in more indepth discussion about these than Alice.

Participant checking of the student data was a less rigorous process. I emailed interview transcripts to the students, but none commented so I do not know what they thought about them. Two students, Jason and Aaron, left school before I could send them the transcripts so I did not have the opportunity to check their data. As will be explained in Chapter 5, data associated with Aaron were significant, leaving some unknowns in the Kotare findings.

\subsubsection{Democratic validity}

Democratic validity means that the perspectives of all participants (the students', the teachers,' and my own) are accurately represented. Authentic research is fair, in that it reflects all stakeholders' views, voices and perspectives, and where 
there is a deliberate attempt to avoid marginalisation (Lincoln, 1995). The study was collaborative and so the teachers' perspectives are integral to the study. David, Alice (to some extent), and I gathered data about student responses on an on-going basis and so, as far as possible, the reflexive nature of the research ensured that every effort was made to represent the student perspective as accurately as possible.

\subsubsection{Catalytic validity}

This is achieved when the research generates learning that prompts (or catalyses) the researcher/s, and other participants to take action leading to change (Guba \& Lincoln, 2008). This indicates that that the outcomes of the research are valid within the practice setting itself. For example, David and I often returned to our original (individual and shared) aims and success criteria, examining the emerging data and modifying what we were doing in order to give ourselves the best chances of success. David's focus was centred on making changes to his practice.

Practitioner research is messy and unpredictable and reflexivity was not a priority for the teachers involved (Cook, 2009). However, catalytic validity assumes that actors have complete control over all of the variables impacting on research however, and in the real world of practical action research this is not the case. External factors, often beyond the control of a researcher, are significant limitations and can have a major bearing on research outcomes. This was a source of on-going concern for me throughout the project, particularly at Kotare College. While I aimed for "win-win" research partnerships, the research at Kotare College nevertheless raised a number of ethical, methodological, and moral issues. These are examined in 3.10.1.1.

\subsubsection{Interpretive validity and research "selves"}

Data need to be made subjectively valid by intentionally revealing underlying assumptions and biases (Guba \& Lincoln, 2008). Throughout the study I critically reflected upon the self as the research instrument, including what I brought to the research and also what was created in the field (Somekh, 2009).

From a socio-cultural perspective, I viewed the research selves as being related to the requirements of the project: brought selves as social, historical and professional identities; and situational selves, as those created in response to the context (Reinharz, 1997, 2011). Interpretive validity for this study depended upon the extent to which I was aware of this while in the field, and subsequently during interpretation of the data. 
This is a significant validity issue for all qualitative research, but particularly for this project because it is intentionally subjective.

I strove to write down thoughts, assumptions, questions, musings, conflicts and ideas as soon as possible after the fact so that I did not rely upon my memory. I repeatedly and critically read my journals, annotating them with new ideas and using them to inform my subsequent actions. I frequently asked myself "are we addressing the problem for this teacher, these students?" I might ask "am I learning more about the pedagogical implications when group composing is assessed? Or, as a former advisor, am I drifting into a familiar professional development role and focusing on other less relevant aspects of teacher practice?"

Four "selves" emerged from this reflexive process:

1. Lead researcher

2. Co-researcher

3. Music teacher

4. Musician

At various points in the research I was also a critical friend, teacher educator and research facilitator. While I often took the leading role, this was not always the case.

\subsection{Power, position and identity in this research}

The overall aim of this research is to learn more about what is a valid contribution when group composing is assessed for the NCEA, thus creating new, potentially useful professional knowledge for music teachers. However, there were pitfalls to be aware of when doing so because in practitioner research, methodology and ethics are inextricably linked (Lock, Alcorn, \& O’Neill, 2013; Mockler, 2007).

First, Elliot (1994) is critical of the university researcher who adopts a romantic stance when collaborating with teachers, believing herself to be the "big sister" mouthpiece of an "oppressed profession" (p.136). He argues that the paradigm of a study, such as this one, renders such a stance methodologically invalid and ethically dubious. I kept this in mind.

Secondly, insider-outsider relationships within practitioner research, particularly those between university-based teacher-educators and classroom teachers 
are key variables in the overall validity of practitioner research (Herr \& Anderson, 2005; Somekh, 1994). Elliott (1988) describes these partnerships as "first-order" and "second-order" research, where the teacher does all the teaching and inquiring (first order), and the teacher-educator investigates problems associated with the teacher's learning (second order) (p.164). In this study, insider-outsider relationships at Kotare were particularly problematic.

\subsubsection{Kotare: insider-outsider roles and relationships}

At the outset of our collaboration, I assumed that if I taught Alice's students, it would be as a teacher-educator. I thought perhaps we might teach together as part of a reciprocal cycle of professional learning (first order for both of us, second order for me), or that I might teach the class with Alice observing, using new practices we had devised together (first order for both of us, second order for me), or I might observe Alice doing the same (first order for Alice, second order for me). I assumed these actions would be followed by in-depth, highly reflective professional discussions. In the first meeting, Alice and I talked this through and agreed that this is how our collaboration would proceed.

I suggested that Alice read Schmuck (2008), chosen because of its clear, readable style and focus upon practical classroom teaching, and also Fautley's (2010) book about assessment in music education. Alice appeared very enthusiastic about the project and started a journal. She was unfailingly kind, hospitable and welcoming throughout the project, introducing me warmly to her students and always very keen to observe me teaching and working with them.

The data soon indicated that we needed to approach teaching composing in new ways. Alice identified positive aspects in my practice when I taught her students, often noting subsequent improvement in student engagement. Alice made several observations about how she might do things differently, but did not act upon these during the period of the research. I observed Alice teaching on several occasions and her practice tended to follow the same procedure: 10-30 minutes of showing-andtelling, followed by unstructured group work. Alice rarely commented on her actual practice and I was not invited to do so. Often, with Alice's encouragement, my role was classroom teacher. I learned a great deal in this first order research role. However, this was not second-order action research; this was not my classroom, and these were not my students. 
Excerpts from memos I wrote during this period illustrate this role dilemma:

23 June 2011 It's becoming an issue. I try out the different teaching strategies we've planned because I want to empower her, motivate her to change her practice, not hold up a mirror. I can already see that we are going to need to do things differently for group composing but she doesn't seem very interested in trying anything new although she is very appreciative when I do it. It's an ethical issue too - I don't want to be critical of her when she is so welcoming and kind, and anyway, she might say "hey I've had enough of this!" We are both encountering her reluctance - her eyes shift away from me whenever I ask her if she would like feedback on how it went after seeing her teach and she changes the subject. She keeps handing me the power - and I keep handing it back! Then nothing happens. Maybe I could try a more structured observational tool? Maybe support her to give me feedback on what she sees? Maybe be more low-key in the classroom?

Alice conscientiously used the tools I developed, and worked with group composers when I was not on site, but overall her practice did not seem to change. While this is not an unequivocal judgment that Alice's practice was unaffected by the research, during the period of the data collection, I did not observe changes in practice.

\subsubsection{Ethics when working with Alice and her students}

The literature abounds with cautionary tales of researchers doing research to teachers, where unequal power relationships render the research findings invalid and ethically unsound (Avgitidou, 2009). Alice did not ask me for feedback and, unless invited, it was not ethical for me to give any (Kelly, 2005). I asked her if she felt compelled to participate in the research but she always replied that she was only too pleased to have me in the classroom. She said that she welcomed the opportunity to share the teaching and that our work helped to relieve her anxiety about low student achievement. She clearly trusted me and I did not want to betray that trust. There was a host of logistical, cultural and educational barriers to student achievement in composing at Kotare College, but one group of students appeared to be working very well together. The extra attention seemed to provide them with the confidence to continue composing. I did not want to let them or Alice down.

\subsubsection{Should I stay or should I go?}

I considered ending the research at Kotare, with the ethical aim of continuing to provide informal professional support to Alice and the boys until the end of the year. When I reflected upon whether the project had addressed the two new research questions however, the data clearly indicated that, for me at least, it had. 
Herr and Anderson (2005) reassure novice researchers, such as myself, that practitioner research:

... does not automatically mean that there was a successful change in effort to document with a happy ending - although it might. Rather, our goal as researchers is the documentation of working to understand and initiate change in the contexts being studied ... These 'failed attempts' are important to document in terms of increasing our understanding of the complexity of the change process. (pp.127-128)

The inquiry at Kotare may not have been collaborative action research in the truest sense, but it was leading me to new praxial understandings. Mess, the uncomfortable "punctum" where the perceivable, but as yet unexplainable, exists, was beginning to crystallise into reified knowledge (Cross, 2009, p.280). I considered Herr and Anderson's (2005) models of "positionality" in action research to help me reexamine my position at Kotare. These are conflated into four diagrams below: reciprocal, collaborative, insider, and outsider. (See Figure 3.8)

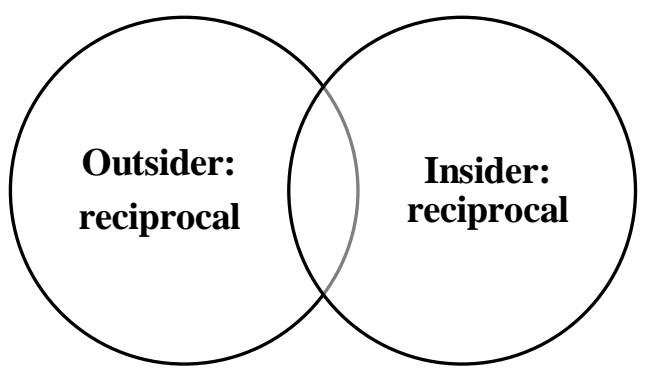

Diagram 1: Reciprocal

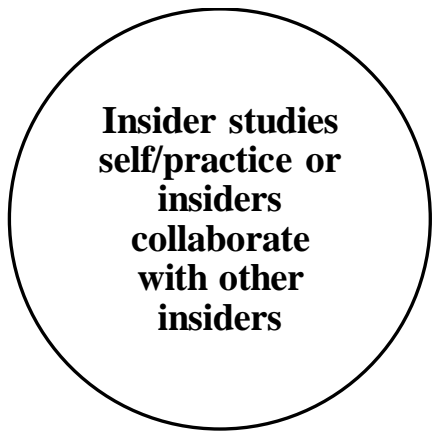

Diagram 3 Insiders study insiders

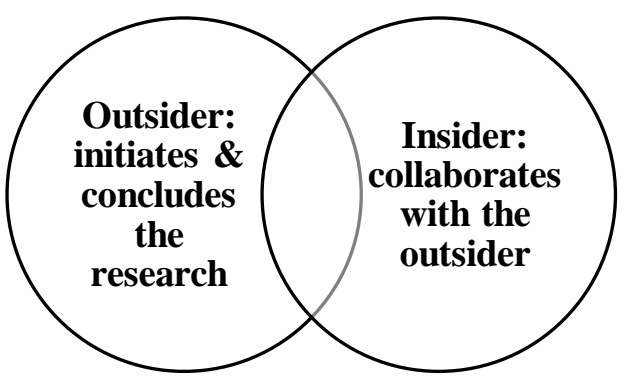

Diagram 2: Collaborative

Figure 3.8. Insider-outsider roles (derived from Herr \& Anderson, 2005, p.41) 
When considering myself as an outsider conducting second-order research at Kotare, then Diagram Four seems to apply. Unlike the other research positions represented here, outsider studies insider research does not lead to improved, critiqued or transformed practice for the insider. This is irrelevant to action research because it is the outsider stance adopted by more traditional forms of applied social science research (Herr \& Anderson, 2005). Even so, Herr and Anderson argue that "this end of the continuum does contain some gradations of insider-outsider collaborations" (p.41) and these can lead to the generation of new practice knowledge. This seemed to be the case at Kotare and, at this point, I hoped that this new knowledge might inform the next cycle at St Bathan's Collegiate. Also, as a music educator I was still an insider studying my own practice and so Diagram Three also applies. On those grounds I decided to continue at Kotare.

At the end of the project I shared the diagrams of insider-outsider roles with Alice and she chose outsider studies insider as being most representative of our partnership. In contrast, David chose reciprocal and collaborative. David mostly saw himself as the insider and me as the outsider, but not always. For example, when we examined assessment theory or discussed scholarly literature, David who, like most classroom teachers, finds academic writing quite inaccessible, observed that our roles were reversed. David has subsequently gone on to carry out research projects of his own. This change in research role is discussed in the concluding chapter of this thesis.

\subsubsection{Practice identity}

Further reflection on the difficulties at Kotare led to a flash of insight. I asked Alice about her professional identity:

$V T: \quad$ Sometimes you could describe a music teacher as a "teacher who is also a musician", or you could say a "musician who's also a teacher". Which one would you say you are?

Alice: I'd like to think I was a musician first. That's where my love is, yeah.

$V T: \quad$ So if you were made up of only these two things, what percentage of each would you be?

Alice: I'd be a musician without a doubt.

$V T: \quad$ So is that where you are coming from in terms of being a teacher?

Alice: Oh certainly. The reality is that I need to be a teacher to pay the bills but if someone offered me a full time gig with guarantees then I'd be out the door.

$V T: \quad$ So teaching is just a means to an end? 
Alice: Yes, but I really believe that it's the way music teachers should be. Because, you know I've worked with music teachers who don't even play anymore. I think "so why do it?" I always tease the Maths teachers and say "I go home and practice for hours. Do you go home with your Bunsen burner or whatever?" It's different. Music is different, all the arts are. You have to live it to be a musician. You can't go home and watch telly and read books. You have to go home and do your practice and rush out to perform or something. I reckon if you are like that then you can stand in front of the kids, the kids who really matter, the ones who are really into it.

I emailed these comments to Alice, reminding her that she could remove them from the transcript if she wished. She emailed back that she was happy for me to retain them but added the following:

I certainly would rather be playing music than teaching but I do become very caring about the kids that I teach. I think I put a lot of myself into teaching. I'm certainly not just in it for the money.

Perhaps I had made an error in selecting Alice as a participant in practitioner research about being a music teacher? I speculated that if she had been engaged in research into practice as a musician, then her response might have been different. Alice's apparent disinclination to change her teaching practice made sense when viewed from this perspective. I then asked David the same question:

$V T: \quad$ Sometimes you could describe a music teacher as a "teacher who is also a musician", or you could say a "musician who's also a teacher". Which one would you say you are?

David: Oh that's easy. An educator who's a musician.

$V T: \quad$ So that's your first priority?

David [emphatically]: Yep.

$V T: \quad$ So ... a teacher first, a musician second?

David: Oh yes, definitely. That was from when I started doing my undergraduate degree. I knew then, and I was so excited to be doing it. So yeah, I'm a career music educator.

When viewed alongside my research identities, the differences are clear as Figure 3.9 shows. 
Alice

David

VT

Music educator Teacher educator

Figure 3.9. Research identities: Alice, David and VT

\subsubsection{Practitioner research or teacher professional development?}

Analysis of David's discourse reveals that he generally worked in a nearconstant state of professional reflexivity, with a strong focus upon student engagement and achievement:

I'm really concerned about my own professional practice. If I'm not doing well by my students and maybe I don't know that, and then it comes out that I am [not doing well by my students] then I'm going to do whatever it takes to change [my practice] so that my students are getting the best out of the situation.

Although he kept notes about the achievement of each of the group-composing students, David did not keep a reflective journal or log book about his practice. His observations, actions, and reflections were based on day-to-day experiences, and usually focused upon the students' rather than himself.

David and I share some similar philosophies about music teaching and learning. I also believed our teaching styles and manner in the classroom are similar and during the project our thoughts often ran along similar lines. It was not unusual for me to arrive at school ready to propose a possible solution to a particular pedagogical problem we had encountered, to find that David had thought of the same thing, and was already doing it! We arrived at these shared conclusions via different means: through data analysis, written and informal reflection (for me), and through on-going observation of student learning and achievement and informal reflection (for David). While these "snap!" moments were gratifying, we acknowledged that this ease of professional communication and its accompanying assumptions might make us complacent about our collaboration.

During the first two research cycles, the collaboration remained focused and dynamic. In August 2012, however, David's practice was challenged by a major issue and, without the supporting structures of systematic practice inquiry, his research 
process foundered. It became difficult to maintain contact with him and he "went to ground" until, eventually he asked for my help. During this period, our roles shifted from co-researchers, to teacher and teacher-educator. Once the issue (related to NCEA summative assessment) was successfully resolved, the collaboration resumed, although for me, it had never really ceased because during this period I learned a great deal about teacher practice and the NCEA.

David continues to conduct first order practitioner research, pursuing questions arising from our project. Our professional dialogue and research collaboration is also on-going. This is discussed in the concluding chapter of the thesis.

\subsection{Generalisability}

It is not the aim of this research that its findings are generalisable. It is contextbound, where the goal was to gain insight into practical problems within specific situations (Mills, 2007).

The present study seeks to generate new knowledge about a practical problem currently existing within the wider educational setting of secondary school music in New Zealand. It was carried out in two very different schools with two very different teachers, over two academic years, and involved the collection of a large amount of detailed data. Its cyclical and reflexive nature generated multiple opportunities to find out if knowledge about the assessment of group composing created in one context (Kotare College) might be transferred and generalised to another (St Bathan's Collegiate). Whether these findings are transferable to other settings is speculated upon in the last chapter of this thesis. They are intended to be useful to teachers. As this is practitioner research it has the potential to create accessible and useful theories of practice (Elliot, 1991). While the pilot study findings were not generalised, they did subsequently inform the main study.

\subsection{Conclusion}

Throughout this study there are strong parallels and symmetries between group composing, qualitative social research, and teaching. Each involves the application of practice-related skills and knowledge to complex human situations, and each aims for outcomes that are both predictable and unpredictable. All involve, to a greater or lesser 
extent, a creative response to particular problems or tasks and are thus different ways of engaging in a creative process.

Professional identities, roles in the research, and the extent to which I was an insider or an outsider to practice are central methodological questions in this study because it is a socio-cultural examination of the practice architectures of composing, teaching, and assessment. When I first began the project I expected to learn a lot about group composing and its assessment. What I did not anticipate is that some of the most significant learning would be methodological and that this learning would be the pathway to the knowledge I was seeking. 


\section{Chapter 4 Pilot study: Manuka High}

As explained in Chapter 3, the pilot study sought answers to the initial research question, “What are students' and teachers' experiences of the assessment of group composing?" This chapter presents the findings of this that subsequently informed the design and research approach of the main study. It explains the students' reasons for choosing group rather than individual composing, and why Sarah chose to include it in her Year 10 programme. This is followed by a discussion of the task that the students engaged in and how the composing proceeded. How and why the assessment of CCP foundered, and why Sarah abandoned the new achievement standard in favour of the old one, is explored. The students' and Sarah's responses to the resulting assessment challenges are then discussed. The chapter concludes with a summary of these findings presented within the practice architecture of composing, teaching, and assessment.

\subsection{Choosing group rather than individual composing}

The students had several reasons for choosing to compose in a group rather than individually, all of which are related to confidence and safety. As will be shown below, there is some evidence of learning within two zones of proximal development: composing, and notating music. The learning they valued the most was how to work productively with others.

\subsubsection{Lack of knowledge and skills}

Luke was regarded as the expert songwriter in the group:

$V T: \quad$ So have any of you written songs yourselves, by yourselves, before?

Luke: Yes, I do it all the time.

$V T: \quad$ Okay, so would the rest of you say that Luke is probably the more experienced songwriter?

Anna: Oh yes! [Laughter from the other girls]

Luke: [mock-long-suffering groan, more laughter]

The girls had invited Luke to join them because, as beginner composers, they needed the benefit of his greater experience. However, as an informal music learner, Luke said he did not know much about music theory and notation. He said he joined 
the group to get help from the more theoretically knowledgeable girls when notating the composition using unfamiliar Sibelius software.

\subsubsection{Safety and confidence in a group}

Luke, Bella, Evan and Anna also chose to compose together rather than alone because it provided them with opportunities to test their ideas through peer critique and verification:

Anna: And if you were the only person who thought it sounded good.

Eva: Yeah, and people's opinions, as well.

There was safety in numbers because they could take collective responsibility for the composition when it was performed under the potentially critical gaze of the whole class:

Luke: Yeah, lyrics are real personal, cos they tell stories. Not that our song in particular portrays my life, and I doubt anyone else's life in our group, but yeah, they can be real personal.

Bella: It was kind of daunting to be up there by yourself.

Composing in a group gave novice group composers confidence and the collaborative process helped them to develop their ideas:

Eva: I've never really written a song on my own before. Like I've tried, but I found it a lot harder on my own. In the group, just being able to kind of bounce ideas off other people was a lot better. Just the confidence of knowing I didn't have to get up and perform it on my own made it a lot easier.

\subsubsection{Social learning}

The students told me many times that composing in a group was much more fun than composing alone:

Bella: With a group, you know ... fun [laughs].

Luke: I enjoy working as a group. It's real fun. These guys are awesome.

However, Luke, the relatively experienced member of the group, found group composing more difficult than solo composing because he had to accommodate the ideas and needs of the others:

Luke: I learned that working in a group is really hard. Each person brings their own unique thing to the group but then it's being able to utilise each person's own unique thing to create something. 
The students believed that their most significant learning was social, rather than musical and that this occurred during the collaborative creative process:

Anna: I've learned how to give my opinion to other people and stuff without forcing it on them or anything. [PSIA]

Luke: There are certain moments when people don't want to work with other people and then nothing gets done. And then you don't get any progress. It was a learning experience for me.

Bella: You need to be able to know how they [the others in the group] work and then you know how to work with them. How they structure. [PSIL\&B]

\subsubsection{Sarah's beliefs about why students chose group composing}

Sarah regarded group composing as less challenging and more accessible than individual composing. She also thought that it provided some students with opportunities for learning:

There's always going to be kids who are going to be swept on along with it, who really didn't do much. But then I sort of think, well, what's the purpose of running a group assessment? It's to try and encourage those kids to be involved and to pick it up and learn something.

She encouraged some students to compose in groups because she believed that this suited their learning styles:

It's becoming a very, very verbal culture in that kids work out things, they create things together much more than they used to. You know when you think about when we were in music classes, it was a whole pile of structured individuals. These days we've got a whole pile of people who really start firing on all cylinders when they're talking to someone. Or when they're listening to something. What we would consider multi-tasking or intruding interruptions, they consider kind of part of the process, part of the inspiration, part of the creation. For them it's very unusual to sit down by yourself and create something all by yourself. They see it around them all the time, that people work together to create things.

Like Bella, Eva, Anna and Luke, Sarah also believed that less confident, and/or less able students would be more likely to take risks and try something as challenging as composing when they had the support of their peers.

\subsection{Composing in response to a written task}

The students had been given guidelines by Sarah and knew what they had to do. (See Appendix 4.1.)

Bella: Write a song, and do it in groups.

Anna: Lyrics and melody and chords. 
Luke: Yeah. It had to have at least one verse, and one chorus. It had to be at least 30 seconds long and up to four minutes long and it had to have lyrics.

The students could also explain to me what they had previously learned in class about composing:

Eva: We'd done a few activities beforehand, like before we started this composition, about, writing lyrics and writing melodies, just kind of little short things that took a couple of spells.

Bella: To get a main idea and then, some brainstorming, writing starting sentences and stuff.

\subsubsection{Notation and performance disrupt the creative process}

Luke, Bella, Anna and Eva reported that they stopped composing before their piece was finished in order to have time to notate and rehearse it. They reported that they spent more time doing this than actually composing together:

$V T$ : You said you were "right down to the wire". Why was that?

Luke: That was just really all the practising, that aspect of it, and then the kind of fine-tuning of nuts and bolts and things. But ...

Eva: We sort of, got side-tracked by...

Bella: Trying to write it out on Sibelius, to write it all down. We were like, "Oh, wait - we haven't even finished this." So we had to go and ...

Anna: We were quite new to Sibelius I think, so, yeah we took a bit of a while to get it into the computer.

$V T$ : So you started notating the piece before you'd finished composing it? Is that correct?

Bella: Yeah.

Luke: Yeah, it hadn't been completed, yeah.

The students all said that they were all nervous about playing their piece in front of the class and devoted considerable time to rehearsal. It is interesting to note that the cohesion of the group was such that they answered the question above as one person, finishing each other's sentences.

\subsection{Assumptions of competence}

Luke, Bella, Anna and Eva were competent musicians and able, diligent students. All of the participants believed that because of this, the group did not need much help from Sarah with their composing: 
Anna: Because she knew we could actually do it, you know?

Bella: Yeah, she sort of trusted us.

Luke: Yeah, because she realises that we all have a certain amount of musical ability, so ...

Anna: She trusted us to actually do something.

Bella: She knew that we were working.

The students reported that Sarah spent most of her time with novice composers or disengaged students. Other than help with the notation software, the participant group received almost no feedback:

Luke: [Miss S] came around occasionally, but she was kinda more preoccupied, like, with the other groups I think.

Sarah's class was large and highly diverse. She too reported that she spent almost all of her time with the beginner composers or off-task students and that it was a struggle to meet the needs of all 27 students, spread across multiple spaces. She believed that the participant group was getting along fine and did not need much help. The students believed that this was entirely appropriate, given that there were so many other students in the class needing more help than they. Later, these assumptions of competence had a considerable impact when it came time to grade the group's composing, and composition.

\subsection{Gathering evidence of $\mathrm{CCP}$}

Initially, Sarah had a number of ideas about how she might gather evidence of a student's CCP required by the new achievement standard. She considered making a series of written notes about each student based on multiple observations:

I'd like my sort of written log which is just very brief statements, so I can build up a mental progression in my head, because that's the way, you know. I can see it as a kind of bullet-point statement and then I can build up a picture.

Sarah also considered using a checklist for group composers to self-assess:

They include all the information, like who the piece is by, "What compositional devices did you include? What structural devices?" I could create a sheet like that for every student, but the tick sheet would include things like, "I participated in this aspect" tick. "Were you involved in lyrics?" tick. "Were you involved in creating a chord pattern?" "What special thing did you bring to your group?" tick. I could craft a page that basically they have to sign off and say, "these are the things that I can say that I did well and contributed to the 
group." That's mainly how I see I could do it, in combination with a written teacher log, a pupil log, a copy of the performance.

The students were not given any qualitative assessment criteria and Luke expressed some frustration that they had not seen an assessment schedule prior to composing:

I think [Miss S] should tell us how she is going to assess it because she hasn't told us how she is assessing it, other than that she is assessing how we did it and then what we do. And I think that [Miss S] should tell us what we're being assessed on. Not even guidance, just information. What is she looking for?

\subsubsection{Novices are at risk when CCP is summatively assessed}

When developing these data collection tools, Sarah began to have some professional qualms. She reported that she was very concerned that grading a student's contribution to a group composition might have a negative impact upon the confidence and motivation of the musical novices in the class. This was a class of junior students, many of whom had not composed before, and some who would not be going on to study Music for the NCEA the following year. Sarah was concerned that if these students lost confidence through receiving negative feedback about the extent of their $\mathrm{CCP}$, they might opt out of composing altogether:

I've been working my way through this process and now I can totally see that for some students you sort of feel, gee, they're probably not taking music next year. They are just really a beginner. I want them to be creative. I don't want to be too hard on them. And you feel a group mark would be more appropriate for those students.

At this point, a few weeks into the research, Sarah decided she needed to support these novice students and abandoned the draft standard in favour of the old achievement standard, intended for the assessment of solo-composed, notated music.

Sarah then used the old criteria to grade the actual composition, and awarded one grade to the whole group for this.

\subsubsection{Verification rather than assessment of CCP}

Sarah decided to award another grade to individual students based on their participation in, rather than contribution to, the creative process. This was based on one summative self-assessment where the students were asked to write one or two sentences about what they did. 
The criteria for verifying participation were: make some contribution to the process, notate the composition in full score using Sibelius software, and perform the work in front of the class.

Sarah explained how she intended this to work:

There are two different layers of stuff going on there together so I think they need to show that they've fully participated in the process, in those three steps. Then on top of that, and it's more really looking at it then as a group, that second bit, the composition, is more a mark that's going to be delivered to the group, because the piece either works or it doesn't. That's more difficult to pull apart; who was responsible for structure.

However, it seemed to me unlikely that a single self-assessment could provide Sarah with sufficient evidence to verify participation in the creative process.

\subsection{Assessing CCP}

Data analysis revealed that, even if she had wanted to, Sarah would not have been able to validly assess the creative contribution of the individual students. This was because she had not had the opportunity to engage with them when they were composing together. Sarah saw that Bella, Luke, Eva and Anna seemed focused on the task so she left them to get on with it.

Sarah indicated on a 1 to 10 scale that she was $75 \%$ confident that she understood what each of the students had contributed. However, when I asked her to explain to me what each member of the group had contributed to the composition, she seemed to have only a vague idea:

Well, I can't say specifically who wrote the lyrics. But I do know that I walked in and I asked them and they were like "Oh, Luke has just joined our group" because originally he was on his own. "Oh he's been really helpful, we've been doing X, Y and Z" and "Oh we were just working on the lyrics at the moment". I couldn't say specifically who, you know, apart from knowing what instruments everyone plays. I know that there's an attachment of responsibility that you see in the end product. Like Anna was playing the piano and umm ... oh, was it Anna playing the piano? And I know that she had a big part to play. Actually who is the other pianist in that group? Umm ... Is it Bella? Oh no, she's playing the guitar ...

Sarah made the logical assumption that what a student plays is his own work. This is not a valid assessment assumption, however, because, as I found in my Master's study with the band Boys, a student may play what another student has composed for them. 
At this point I reflected "does it really matter who does what, if the group has had a valid, experience of composing together?" As a music educator I did not think it did at the Year 10 level because I believed that picking apart the creative processes of novice composers might do more harm than good. From the perspective of assessor for a secondary school qualification, however, it might matter a great deal. As anticipated by my initial analysis of assessment literature, here were significant tensions associated with the valid assessment of compositional process.

\subsubsection{Assessing CCP is too difficult}

When asked about how they thought CCP should be assessed, the students believed that assessing individuals' contributions to the creative process was an unfair expectation of teachers because it was an impossible task:

Bella: You'd have to be pretty confident to actually know everything that I've just seen. She'd need to know everything that those specific people have actually done. I can't see that it could be simply done.

Luke: I think that it's unreasonable that a teacher should have to do that because it's just not do-able. I don't think it's fair on the teachers to try.

The challenge of how to account for individuals in a group was closely associated with concerns regarding fairness:

Luke: Cos she's not gonna like, be able to stand over your shoulder and watch you every day with, like ... cos also, sometimes people just don't have ideas at the certain time, as well. So then it wouldn't be fair that they don't get a good grade just because, maybe, say for the verse they didn't have as many ideas as say, one person else did. It would be a really, really hard thing to assess.

The students believed that assessing CCP was unnecessary because performing a completed, notated piece was sufficient evidence to verify that they had all made a valid contribution to process:

Bella: Because we did it, she must have known that we actually worked. She must have known that we composed it, or we wouldn't have had a song at the end.

The students indicated on the 1-10 scale that they were between $30 \%$ and $60 \%$ confident that Sarah understood what each of them had individually contributed to the creative process, reiterating that they did not see how Sarah could be expected to know what each of them had achieved.

Sarah also believed that this was not an easy thing to do, maybe even impossible: 
I mean I can't actually figure that one out ... You can't nut that one out. That's why I'm saying, "the final product" because that's what often happens in a band. Once the piece is written it might only be two members of the band who really wrote the piece. But everyone in the band performs the piece and makes the final product happen and has made a contribution at some point, but it's not always clear.

Provided that individual participation was verified, Sarah deemed the composition itself sufficient evidence that the creative process had been collectively successful for all group members.

\subsection{Arriving at a summative grade}

Sarah decided that an individual student's participation in at least two of the specified aspects qualified him or her to share the grade given to the final product. If the piece was an Excellence, then a student who participated in all three aspects, as indicated on the self-assessment sheet, was also awarded an Excellence. If he or she had participated in two of these aspects (for example, participated in the composing and performance but did not notate the piece), then he or she received a Merit, or an Achieved, depending upon the grade awarded to the final product.

\subsubsection{The students grade themselves}

The students believed that they each had an equal role to play in the creation of their song and said that, if they had a choice, they preferred a group rather than individual grade:

Bella: I'd prefer a group grade, because you know how Luke sang and he played the guitar as well? Does that mean he would get a higher grade? Because we all came up with the lyrics and we all came up with everything ... we all came up with it and worked together to do it.

In a group discussion they agreed to award themselves Excellence for their participation and Merit for their composition, the same grades subsequently awarded to the group by Sarah.

Despite arriving at the same grades as Sarah, when assessing the music itself, the students seemed to work from a different set of benchmarks, where popular music set the assessment criteria:

Eva: I reckon I might just say, Merit.

Anna: Yeah, I was thinking Merit.

Eva: Because it wasn't bad or anything. 
Luke: It wasn't bad.

Anna: It's not like it's, yeah, I mean I'm not expecting to hear it on the radio or anything.

\subsubsection{Individual versus group grades}

The students expressed some unease about the prospect of individual grades. Memos written at the time showed that the strong sense of camaraderie and mutual support I perceived within the group seemed to dissipate when I asked them about this.

At no point in the research did any of the participants suggest that anyone in the group should get a different grade. However, Anna believed that, if it were possible to do fairly, that individual grades might work.

I think there would be some groups who would have, like, a main person who did most of the work and that it might be a bit unfair to give an Excellence grade out to someone who didn't do as much work. The people you work with does affect everything because you've got to feel comfortable with showing your ideas and comfortable with saying, with critiquing their ideas and I think you need a pretty good group dynamic. You need a good leader, someone who doesn't do everything, but someone who does help out. So I think if the group was really well organised then it [individual grades] would probably work quite well. I mean I think our group was really well selected and that's why it worked so well. I don't know what it would be like to be in a bad group, with people I didn't know as well.

Anna implies here that a teacher would need to have a deep understanding of the interpersonal relationships within the group, not just knowledge about "who did what" musically when awarding individual grades. She also demonstrates a perceptive understanding of the group process, presumably acquired through working with Luke, Bella and Eva.

All of the participants, including Sarah, expressed disquiet at the prospect of some students getting a "free ride" and then being awarded high grades for group compositions they had not contributed very much to. This was all speculation or hearsay however, and all believed that the participant group deserved equal credit for the group's achievement.

\subsubsection{Factors influencing Sarah's assessment judgement}

There is some evidence to suggest that the students' diligence, musicianship skills and ability to work successfully together influenced Sarah in her assessment of the composition itself. At first she believed that the students should receive an Excellence grade for both process and product: 
For that group, I am going to give them an Excellence mark, because I feel that for a Year 10 assignment, that they completed all the criteria, that they worked together, that they truly were successful with the creative process, that they really did work as a group, and that they all contributed.

After viewing the video of the students' performance of their piece however, Sarah expressed surprise that the composition was not as good as she had anticipated:

I saw really solid evidence that they worked in an excellent manner. I feel that they can reflect, and comment fully, and make valid connections about the work that they have achieved. [reads the criteria for the old standard] "Compose music that shows character, skilful development and structuring of ideas, and is represented through clear and detailed notation". I just feel it's maybe not quite there, not quite at that Excellence level.

She decided to award the students two group grades: an Excellence for their participation and ability to reflect on the process, and a Merit grade for the actual music. When I asked her how she might reconcile the two grades into one, she commented that she was still wondering how she might do it:

Well, this makes it very interesting as to how I would actually give a final mark. This is the bit that I haven't quite got to, that I haven't quite figured out in my head how you would separate out those.

\subsection{Implications for the main study}

During the course of the pilot study it seemed that the summative assessment of group composing was as complex as the literature had indicated it might be (van Aalst, 2013). The following main pilot study findings informed the re-design of the main study and my actions during both the Kotare and St Bathan's studies. They are presented here within the practice architecture design of the main study: practice as composing, teaching, and assessment.

\subsubsection{Composing}

Students' reasons for choosing to compose in a group may be associated with pragmatic decisions about relevant skills and knowledge. On the other hand, students may place a higher value upon social learning than musical learning when group composing. Group composing may be more fun for some students than composing alone. Group composing may also be perceived as easier than composing alone, and may be more accessible for novices, or students who lack confidence. 


\subsubsection{Teaching}

There are tensions between giving the students enough time to compose, and having time to complete task requirements for the performance of the piece or notating the score. A shared understanding of collaborative creative processes between teacher and students may be helpful. The students in the pilot study did not learn about the collaborative process prior to composing and it seemed that none of the participants possessed a shared, explicit understanding of the compositional process in which the students were engaged.

The teacher needs to spend considerable time with the students and some form of conferencing of on-going dialogue is probably required. The pilot study showed that leaving a group to get on with composing meant that their CCP could not be verified. Diligent, knowledgeable and/or skilled students may be perceived as needing less help than less able students, and so may miss out on the teacher's attention they need for composing, and the teacher needs to summatively assess their work. There was some evidence to suggest that conferencing between the teacher and the group, or with individual students may also lead to a clearer understanding of how the group members went about composing together. This subsequently became a key finding in this thesis, with considerable implications for the main study.

\subsubsection{Assessment}

Gathering CCP data might be time consuming for the teacher, and requires methodical collection and thoughtful interpretation. Unless a teacher is prepared to make changes in practice to accommodate these requirements then it is unlikely that group composing can be validly assessed.

Sarah struggled with the complexities of assessing individual contributions to the creative process in a large and diverse class. Assessing CCP may be difficult in such circumstances. There were inconsistencies between what Sarah thought she knew about each student's contribution to compositional process $(75 \%)$, and what the students thought she knew (30-60\%). Whether or not this disparity is significant in terms of assessment validity is not known, but it does show that Sarah and her students had not talked about their grades. What is intriguing is that, despite this, the students and Sarah made the same assessment judgements for CCP and the composition.

Sarah's prior beliefs about the students' capability, such as diligence, may have had an impact upon overall assessment judgements. Unless the teacher knows the 
students and their composing processes very well, verifying participation only is probably "hit and miss" assessment practice. Whether CCP should be assessed remains a vexed question because there is evidence to suggest that it might be unsafe for some students.

Students in high-functioning groups may prefer group grades to individual but consider such assessment practice as potentially unfair when not all group members participate fully. How summative CCP grades for individuals and the grade for the music itself might be reconciled, or even if they should, remains unknown.

\subsection{Conclusion}

As explained in Chapter 3, the pilot study findings led me to make a radical change to both the research method and the overall design of the main study. This was because they were not sufficient to address the intent of the study, which is to learn more about group composing and its assessment for qualification. However, as the summary of the pilot study findings above shows, it nevertheless did lead to significant new knowledge, and this knowledge was used to inform the new design. These findings also acted as a point of comparison for the main study with Alice, David and the students at Kotare College and St Bathan's Collegiate. The next chapter presents the findings from the Kotare study. 


\section{Chapter 5 Kotare College}

This chapter presents a discussion and analysis of findings from collaborative practitioner research at Kotare College in 2011. Following an overview of the project, three research cycles are described and explained. Four major themes arising from an analysis of the resultant data are then examined in relation to the two research questions:

1. Communication. This theme is examined in two sections: communication when group composing; and assessment as communication

2. Students' reasons for group composing

3. Teacher and student expectations of success and achievement in the NCEA

4. Assessment validity and its relationship to group processes.

\subsection{Overview}

The research at Kotare was in three broad cycles. Cycle One involved preparing the students for composing and mainly addressed composing and teaching practice. Cycle Two involved facilitating the students' work as they composed and giving them feedback. The third cycle involved the assessment of group composing processes and products. These two cycles mainly addressed all three practices.

Table 5.1. Overview of the research at Kotare

\begin{tabular}{|l|l|l|}
\hline \multicolumn{3}{|c|}{ Overview of research at Kotare College: May-Nov 2011 } \\
\hline \multicolumn{1}{|c|}{ Cycle } & \multicolumn{2}{|c|}{ Composing \& Teaching $\stackrel{\text { Assessment }}{\longrightarrow}$} \\
\hline $\begin{array}{l}\text { Cycle 1 } \\
\text { 25 May- } \\
\text { 18 July }\end{array}$ & $\begin{array}{l}\text { Barriers to achievement identified \& a } \\
\text { sequence of teaching and learning } \\
\text { planned and implemented. }\end{array}$ & $\begin{array}{l}\text { VT interviews Alice about her perceptions } \\
\text { of assessment }\end{array}$ \\
$\begin{array}{l}\text { Preparing } \\
\text { students for } \\
\text { group } \\
\text { composing }\end{array}$ & $\begin{array}{l}\text { VT teaches Year 11 \& Alice observes: } \\
\text { Concept of composing }\end{array}$ & $\begin{array}{l}\text { Diagnostic: on-going data gathering about } \\
\text { the students' prior knowledge/skills }\end{array}$ \\
& $\begin{array}{l}\text { Composperiences of music } \\
\text { Composing a process }\end{array}$ & $\begin{array}{l}\text { Musical structure. } \\
\text { Theoretical model used to help make CCP } \\
\text { explicit for Alice \& students }\end{array}$ \\
& $\begin{array}{l}\text { VT \& Alice facilitate solo/group } \\
\text { composing. Three groups: Reggae, } \\
\text { Heavy Rock, Blues Rock. }\end{array}$ & $\begin{array}{l}\text { Students introduced to AS91092 \& NZQA } \\
\text { exemplars. }\end{array}$ \\
\hline
\end{tabular}




\begin{tabular}{|c|c|c|}
\hline $\begin{array}{l}\text { Cycle 2 } \\
2 \text { Aug- } \\
20 \text { Sept } \\
\text { Group } \\
\text { composing }\end{array}$ & $\begin{array}{l}\text { Sequence of shared teaching planned \& } \\
\text { implemented, informed by Cycle } 1 \text { data } \\
\text { analysis. } \\
\text { - Revisiting the model of composing } \\
\text { - Creating a song structure } \\
\text { - Composing riffs and melodic ideas } \\
\text { - Harmonic progressions. } \\
\text { Alice teaches other parts of the course } \\
12 \text { Aug-20 Sept. } \\
\text { Reggae \& Heavy Rock disintegrate. } \\
\text { Blues Rock continues. }\end{array}$ & $\begin{array}{l}\text { Students receive on-going feedback \& } \\
\text { feed forward on CCP } \\
\text { Data gathering tool used to record group } \\
\text { composers' CCP Aug-Sept. } \\
\text { VT interviews Blues Rock \& Heavy Rock } \\
\text { about NCEA assessment \& group } \\
\text { composing perceptions. } \\
\text { VT \& Alice interpret the assessment } \\
\text { criteria for AS91092. } \\
\text { Alice creates a classroom poster of } \\
\text { AS91092 achievement criteria. }\end{array}$ \\
\hline $\begin{array}{l}\text { Cycle } 3 \\
20 \text { Oct- } \\
16 \text { Nov } \\
\text { Assessment } \\
\text { of group } \\
\text { composing }\end{array}$ & $\begin{array}{l}\text { VT \& Alice examine student data, \& } \\
\text { VT's analysis of the effectiveness of } \\
\text { the teaching in Cycle } 2 \text {. } \\
\text { VT compiles a list of strategies for } \\
\text { future action with group composers. } \\
\text { Working with Year } 10 \text { students is } \\
\text { investigated but not fully implemented. }\end{array}$ & $\begin{array}{l}\text { VT \& Alice grade Blues Rock's } 1^{\text {st }} \\
\text { composition, evaluate each student's CCP } \\
\text { \& write “next steps" feedback for Blues } \\
\text { Rock boys. } \\
\text { VT \& Alice grade Blues Rock's } 2^{\text {nd }} \\
\text { composition, \& evaluate then grade each } \\
\text { student's CCP. } \\
\text { VT \& Alice reconcile composition \& } \\
\text { individual CCP grades. Each Blues Rock } \\
\text { student awarded individual grades. }\end{array}$ \\
\hline
\end{tabular}

\subsection{Cycle 1: Learning about composing}

This cycle largely focused upon supporting the students to move from social jamming to generating structured musical ideas. Alice wanted to observe me teaching her class and so I taught the first four lessons, which we planned together. The review of literature suggested to me that the students would probably choose to compose in musical styles they enjoyed. Therefore I asked all of the students in the class to list the songs they liked, or were listening to right now, and then viewed these on Youtube. Alice said that she thought that her students had very little knowledge about musical styles and structures, so I was surprised by the diversity and sophistication in their music. When I shared these with Alice, she also expressed surprise and commented that she did not know very much about the musical tastes of her students.

One seemingly disengaged student, Aaron, enjoyed loop-based remixes of Madonna songs. With Finney (2007) in mind, I thought he needed access to software such as Acid, Garageband or Mixcraft to help him engage his interest and prior knowledge and compose similar kinds of music. When I asked Alice about whether 
we might try to access such software, she was pessimistic. Despite many conversations about how this might be achieved, this was not acted upon.

\subsubsection{Connecting the concept of composing to the achievement standard}

The first lesson that I taught aimed to help the students connect the practice of jamming for fun, to the practice of composing. I asked the students to brainstorm in groups about "what makes a good piece of music" and "how is music put together?" Five students used the terms verse, chorus, intro and bridge, revealing some prior knowledge. Alice later identified these five students as good or competent instrumental players. During this lesson I noticed that the students whom Alice had identified as having little or no experience of music as players (about half the class) rarely took part in the discussion. The concept of music as a structure seemed unfamiliar to them. I also noticed that writing was generally unpopular, particularly for the boys whom Alice identified as potential group composers.

As a class we examined AS91092 and listened to some of the NZQA exemplars of solo piano compositions I had downloaded from the NZQA website. Most students seemed familiar with examining NCEA documents. Some commented that they disliked listening to the "lame" midi-piano pieces because they did not sound like "real music" and I had to agree. Later, I reflected that if the students could not relate to these as music then they might not be able to make the connection between AS91092 and their own compositions, or music they liked.

\subsubsection{Making connections to students' music}

I followed with a more structured approach to learning about composing, aiming to make connections between the kind of composing required by the achievement standard, the students' own music, and popular music I thought they might enjoy.

In consultation with Alice, I selected the New Zealand Music Commission's (2004) Making Music DVD featuring Wellington band, The Black Seeds, talking about how they compose their songs. Although the DVD had been published some years earlier, The Black Seeds remained a popular Wellington band. As we viewed the video, I invited students to write their ideas on the board for the rest of the class to read. Unfortunately, the AV set-up in the classroom made this quite difficult as there was no data screen in the classroom and everyone had to cluster around a television. 
Chatting with the students, questioning them during class discussion, observing them in group work, and reading what they had written revealed that none seemed familiar with the concept of popular music analysis. From the literature, I also knew that students who were informed, knowledgeable and/or experienced in listening to and/or playing diverse musical styles would be better able to engage with learning how to compose than musical novices (Burnard, 2007, 2012b). I discussed this with Alice and we agreed that in order to successfully reflect upon and refine their compositions, group composers needed to learn how to analyse music. This was the point where I really began to understand the importance of the links between musical literacy, in its widest sense, critical listening and composing.

Observational data revealed that the most engaged students were the same five students whom I had previously identified as saying the most in class discussion. Alice told me that each of these students had a particular passion for composing or playing: Jimmi (electric guitar); Alisa (a singer songwriter); Danny (electronica, composed on his computer at home); Zach and Rāwiri (drummers). It seemed likely to me that these students were already engaged in musical practice and that class discussions about composing were, for them, discussions about it. Given that half the class either did not play an instrument, or were beginners, I began to see why Alice's achievement rates for composing were so low.

\subsubsection{Noise, space and resourcing prove to be significant problems}

Once the students began to explore ideas for a composition and negotiate their groups, one group of boys began jamming loudly. I discovered that the room was not sound proofed because there was a singing lesson going on in the next room and the singing teacher asked that the boys stop because she could not hear anything else! The two other practice rooms I planned to use were not available either, because teachers in adjacent classrooms also objected to the noise. This meant that groups were not able to explore ideas because, outside of the single classroom, there was no access to soundproofed rooms. Furthermore there were no computers or jam-hubs in the classroom where they could explore ideas quietly. When a group jammed in the classroom it was too noisy for the solo composers. This was a major issue.

I suggested that two groups work acoustically on guitars in the practice rooms while waiting for access to instruments and space. Some of the more experienced players were able to adapt their skills to this scenario but the classroom was still very 
noisy. Discussion became shouting and the less experienced students rapidly went off task. Eventually, Alice devised a group composers' roster for the band room and classroom, with solo composers working in the practice rooms and corridors. This worked quite well but did not provide quiet, space and time needed for creativity indicated by the literature review as being necessary.

\subsubsection{Using a theoretical model to make the process explicit}

As the students began to experiment and jam, 12 boys formed three groups, referred to here as Heavy Rock, Blues Rock, and Reggae after the styles they were emulating. As explained in Chapter 2, a conceptual model had accounted for much of what I, as a non-participant, had observed during band rehearsals, helping me to conceptualise, analyse and articulate some of the complexities inherent in collaborative composing (Thorpe, 2008). It also helped me to discuss process with group composers. I wondered whether this model might help the students in the present study to locate themselves in compositional process, and (crucially), support Alice and me to give them feedback about how to move out of the jamming phase and into more structured composing. I wondered if the model's descriptors might also facilitate formative assessment discussions with the students, as well act as a useful conceptual tool for planning and assessment. Moreover, the pilot study findings suggested that if students were able to conceptualise the process in which they were engaged, then they might be more able to discuss these processes with each other, and with their teacher.

When I showed my model to Alice, she said she recognised her own processes as a musician and composer. We decided to teach this model to the students.

\subsubsection{Modifying the model to make it more student-friendly}

I modified the model to make it more student-friendly. There was a lack of AV technology in the classroom and Alice's teaching style generally involved quite a lot of "talk and chalk". Therefore I explained the model to the whole class, drawing it on the whiteboard while they copied it into their composing journals (small exercise books Alice had given them). Below is a facsimile of the handwritten, student-friendly version I used: 


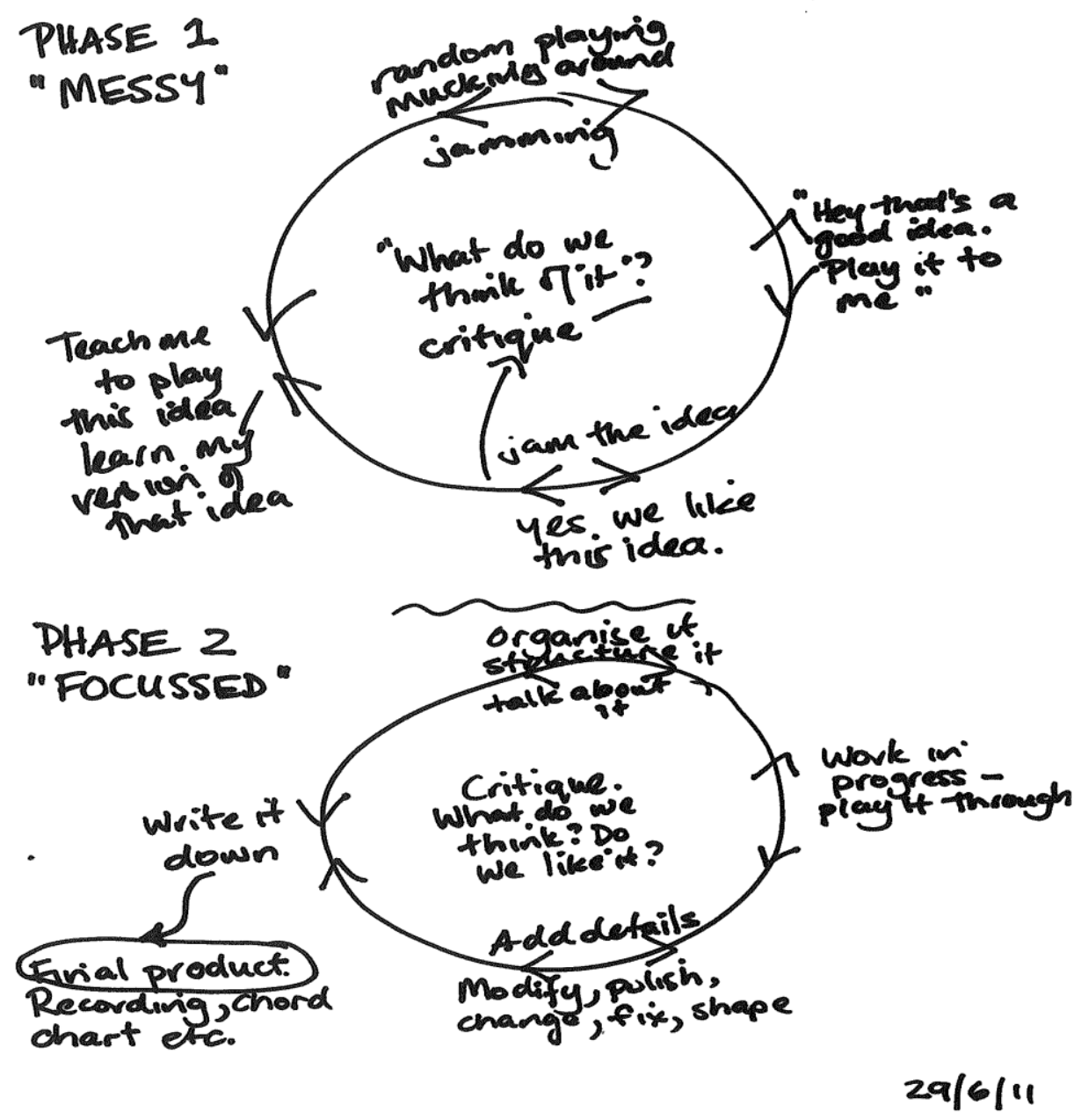

Figure 5.1. Handwritten version of the conceptual model

This was the only thing the students wrote down with any significant engagement throughout my time at Kotare College. The usually restless, noisy classroom appeared quiet, focused and intense. Alice said that she thought that everyone in the class seemed fully engaged throughout this thirty-minute session and I thought so too. The students seemed fascinated by it.

\subsubsection{Gathering CCP data using the theoretical model.}

Once the students began composing, Alice and I considered how we might gather CCP data required by $A S 91092$. It was unclear to us if this contribution merely needed to be verified, or whether qualitative assessment judgments of CCP were needed. The pilot study had shown me that even verification of participation had its pitfalls and was not easily perceived. While we needed data to verify participation in process, if we were to give each student informed feedback on their CCP we also needed data about what each student had contributed. We decided that our judgments would be based upon written and video data collected during teacher-student 
discussion. From the pilot study and literature review, I knew that self-assessment might provide questionable data so we also included peer assessment. We decided that we would triangulate these data with informal observation and our notes.

I created a data collection tool based on the model. Fautley (2010) suggests a "simplistic threefold grading criteria", (- = ), or working towards (-), working at (=) and working beyond (+) to record individual students' CCP (p.192). Fautley also suggests that work in progress and organisation are good points in the process for "straightforward peer assessment" (p.191).

With these in mind, I designed a data collection tool based on these and my conceptual model, where the $(-=+)$ grading system gathered a mixture of teacher, self and peer assessed data over time. I added organisation to the first phase part of the table. This was because, if the originator of the idea had already moved on to structuring an idea while the others were still exploring, thus crossing the phases, then it was possible that these kinds of discussions might start earlier in the compositional process. Alice added another section for notes and this proved invaluable.

\section{Group progress report}

$-($ none or not much $),=($ did some of it $),+($ did most of it $)$

\begin{tabular}{|c|c|c|c|c|c|c|c|c|}
\hline Date & $\begin{array}{l}\text { Come } \\
\text { up } \\
\text { with } \\
\text { new } \\
\text { ideas }\end{array}$ & $\begin{array}{l}\text { Your } \\
\text { opinion } \\
\text { and } \\
\text { ideas: } \\
\text { accept, } \\
\text { change } \\
\text { or reject } \\
\text { ideas }\end{array}$ & $\begin{array}{l}\text { Organise, } \\
\text { structure, } \\
\text { shape }\end{array}$ & $\begin{array}{l}\text { Change, } \\
\text { modify, } \\
\text { improve } \\
\text { ideas }\end{array}$ & $\begin{array}{l}\text { Your } \\
\text { opinion } \\
\text { and } \\
\text { ideas: } \\
\text { accept, } \\
\text { change } \\
\text { or reject } \\
\text { ideas }\end{array}$ & $\begin{array}{l}\text { Organise, } \\
\text { structure, } \\
\text { shape }\end{array}$ & $\begin{array}{l}\text { Refine, } \\
\text { polish, } \\
\text { complete } \\
\text { it }\end{array}$ & $\begin{array}{l}\text { Notate } \\
\text { or } \\
\text { write } \\
\text { down } \\
\text { and } \\
\text { record }\end{array}$ \\
\hline $3 / 8$ & + & - & $=$ etc & & & & & \\
\hline & & & & & & & & \\
\hline
\end{tabular}

Figure 5.2. Group progress report

I videoed Alice talking with Blues Rock whilst she and the boys used the assessment tool. I also asked her to ensure that they had their instruments with them so that they could show as well as tell her what they were doing. Alice used the table to record what the boys told and played her, supplementing these data with written notes and observations of her own on the back of the sheet. 
By early August, observational data and my field notes indicated that the three groups were generally spending less time jamming and more time shaping their compositional ideas. Alice and I agreed that we had come to the end of a teaching and learning cycle. It was time to review our data and plan next steps.

\subsection{Cycle 2: Student achievement in group composing}

Alice and I reviewed progress and examined the CCP data gathered to date, my field notes and Alice's day-to-day observations of student progress recorded in her journal. We found that, while the "group progress report" presented above had verified participation over time, it did not contain much useful information because $(-=+)$ tended to atomise the data. I realised that this was because these were intended for making qualitative judgments against a curriculum objective, and this was not what we were doing.

Alice had gathered data using the descriptors as a framework for discussing with each boy his CCP, and made notes in the anecdotal records section. The descriptors at the top of the table proved to be a stimulus for rich conversations. The students were finding it difficult to come up with coherent ideas and it seemed there was a general tailing off in engagement. Given the general lack of knowledge and skills, as well as the noise and space issues, this was not very surprising to us. We planned a series of lessons focusing on musical knowledge (how to use chord sequences and how to create a song structure, for example) that the data indicated the students needed.

Alice explained to the class about riffs and chord sequences and, using music with which she was familiar, showed the whole class how these could be used in a composition. Using examples of popular music in styles the students had told me they liked, I taught three more lessons on musical structure that included collaborative, practical tasks. While some of the more able players were able to utilise this learning, novices seemed less engaged. As I anticipated in Cycle 1, low-level playing skills and a lack of knowledge about musical style, in combination with noise and space issues, meant that students struggled to express their ideas.

\subsubsection{Making the assessment criteria explicit}

Despite discussing AS91092 with them, no student could tell me what he needed to do to achieve AS91092, other than "compose two songs". Alice and I 
downloaded the Ministry of Education's Internal Assessment resource "Compose Music" from the Ministry's website. ${ }^{7}$ This resource provides suggested written guidelines for teachers to use with their students.

On examining the written student instructions for Achieved, we agreed that the wording was too complex for the students. We reflected on what the criteria meant for our group-composing boys. Following this discussion, Alice devised a simple poster of the bare minimum for Achievement and put it up on the classroom wall.

To get the composing standard you need:

- 2-3 good ideas that are developed in some way

- A musical structure (e.g. verse, chorus, bridge)

- A recording

- Written down (e.g. a chart)

Student interview data reveal that the poster was very successful because when I asked each boy what he needed to do to achieve the standard, he used the criteria from the poster in his explanation. However, neither Alice nor I helped the students to define what "good idea" might mean in the context of the styles in which they composed. This was a missed opportunity.

When I asked Alice if we might include some of the criteria for Merit and Excellence, she said that she did not think that this was necessary. While I did not agree with this decision, it was hers to make. The implications of this are examined later in this chapter, and in Chapters 7 and 8.

\subsubsection{Heavy Rock and Blues Rock}

The Reggae boys were frequently absent and made no appreciable progress because they were almost never all at school at the same time. For these reasons I interviewed the only two groups still working well together, Blues Rock and Heavy Rock.

Blues Rock was Jimmi (Māori, lead guitar), Rāwiri (Māori, drummer), Jay (Pākehā, bass guitar) and Aaron (Māori, rhythm guitar). Alice told me that Jimmi was a recent convert to blues/heavy rock guitar solos and had become a very good

\footnotetext{
${ }^{7}$ http://ncea.tki.org.nz/Resources-for-Internally-Assessed-Achievement-Standards/Thearts/Music/Level-1-Music
} 
improviser in the style of Jimmi Hendrix (hence his choice of pseudonym). Alice regarded Rāwiri as one of the best drummers in the school and asked him to play in the band for the annual musical production. Jay was a competent rhythm guitarist, but a beginner on the bass guitar. Aaron was also a competent rhythm guitarist although his overall disengagement and frequent absences from school made it difficult to ascertain his musical skills and knowledge.

The Heavy Rock boys (all were Pākehā) were: Jason (vocalist), Zach (drummer), Liam (bass) and Damien (guitar). Zach and Damien were both fairly competent players, while Liam and Jason were novice musicians.

The pilot study findings revealed that students' motivation to group-compose were potentially significant variables and so the first interview focused on the boys' motivations to compose together. I could see that they gained confidence when together and so interviewed them in groups. I asked each boy to fill out the 1-10 confidence scale described in Chapter 3 and a Likert scale questionnaire about his attitudes to composing and the NCEA (see below). I was particularly interested to find out whether they saw a difference between "writing a really good song" and achieving AS91092.

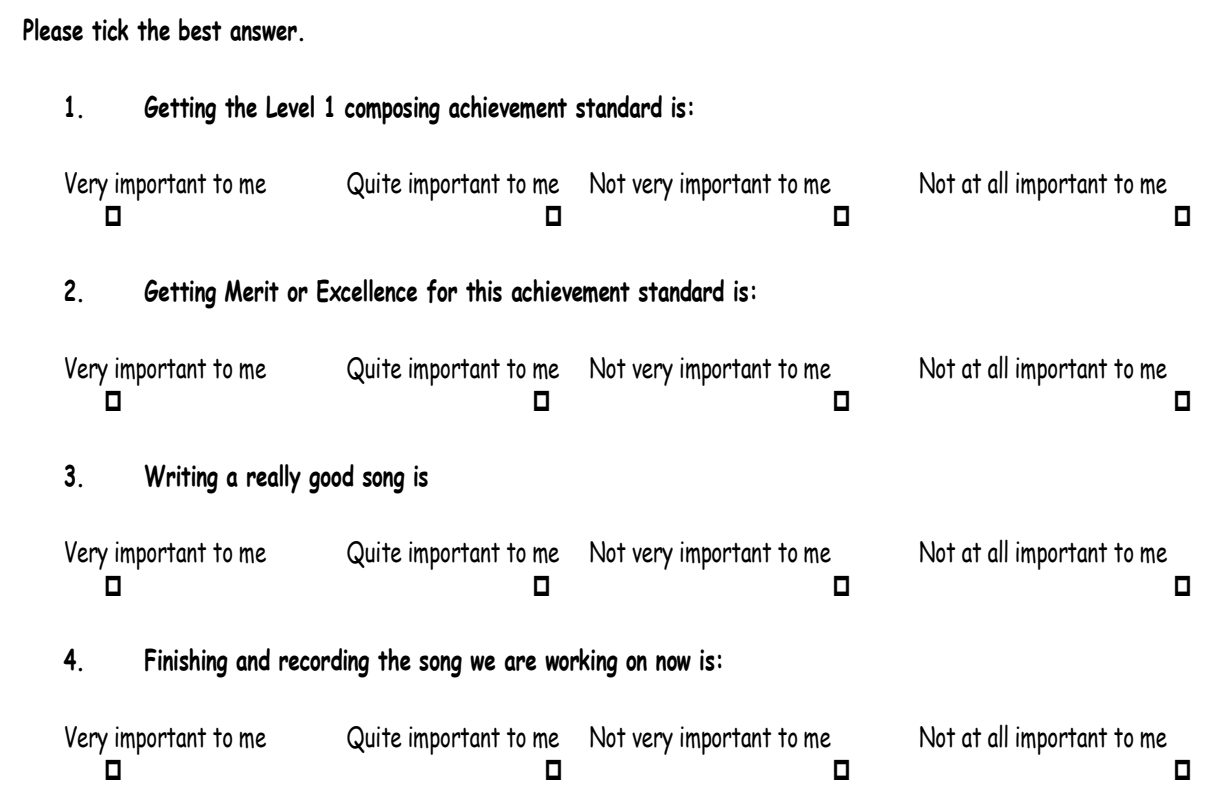

Figure 5.3. Kotare student questionnaire

\subsubsection{Low achievement}

Alice and I focused upon giving feedback about stylistic feel and structure, and discussed with the boys what they might do next. By the end of Cycle 2, some students 
had made some progress towards composing but not as much as we had hoped. All were still in the "messy phase", and only one solo composer had created anything at all.

I reflected that we might have supported the group composing better if we had given more attention to style-specific roles within a musical structure. Perhaps we could have worked with individual students on, for example, how to play bass in a reggae song? While these looked like promising lines of inquiry, we had already spent nearly three months on the project. Alice needed time to prepare the students for other aspects of their NCEA programme but agreed to set aside some time each week for the students to continue working on their compositions. The project was then suspended for six weeks.

\subsection{Cycle 3. Summatively assessing the compositions}

On my return, I was disappointed to learn that Reggae and Heavy Rock had disintegrated and that Jason of Heavy Rock, and Aaron of Blues Rock, had left school without achieving their NCEA Level 1.

\subsubsection{Gathering CCP data and grading Blues Rock's first composition}

Alice created individual folders for each student and kept very methodical records of her observations of the group and each individual or group interview. She reported that she had found this time-consuming, and stressful, however, because she could not focus on her other students:

I was looking at my record book and it's quite sparse. For some kids I've only got eight to ten entries. I think that with group composing ... Two things; one, it's quite time-consuming for the teacher; and two, it's the space issue. It's been really hard with twenty kids in Year 11, for example. It's just mayhem.

Often, while she focused on assessing the CCP of one group, other students damaged gear because Alice was not there to supervise them. This was also stressful:

You have to let them into the back room and just say, "Please don't let [student] smash those leads," you know? You have to push it a step further, and that's pretty hard ... Little things get broken, like the plug or the tiling and it's a bugger every time that happens. I've soldered countless ones up this year, but it takes time and it knocks one band out, so you've got to be showing your face all the time and saying, "Watch those leads guys".

Alice and I assessed Jimmi's, Rāwiri's and Jay's CCP, and graded their composition. We wrote feedback for each student, including "next steps" for their next composition. 


\subsubsection{Next steps}

Together we summed up what we had learned about teaching group composing thus far, and discussed how Alice might go about teaching it in the future. I also made some suggestions for how she might deal with the noise and space issues. We discussed the informal learning pedagogies, such as those of the Musical Futures project.

Informed by this discussion, we compiled a list of the future actions that our data indicated were needed to support effective group composing and task completion:

- Find out what the students are listening to.

- Teach the concept of musical style and genre through focused listening of music familiar to the students.

- Invite the students to choose a piece that everyone in their group knows well. Using classroom and band room instruments, get them to replicate music that they like (similar to the Musical Futures approach).

- Unpack the role each instrument has to play in these chosen styles.

- Develop resources for students to explore playing in a specific genre, prior to composing (possibly use the Musical Futures resources?).

- Overcome the noise and room problems by planning 3-4 lesson cycles, with some groups doing focused listening to specific genres, while others use the classroom and practice rooms to replicate music they like and know. Approach senior Kotare College management to circumvent the school's rule forbidding phones in class so that the students could use them to listen to music and record their work.

- Use the composing model to support students' understanding of the process in which they are engaged.

Alice suggested that we trial these ideas with her current Year 10 Music class, with the intention of preparing them for composing in Year 11. However, it soon became apparent that Alice was reluctant to try these strategies herself and she asked me to do all of the teaching. Without her support I could not make progress and so, by mutual agreement, this work was discontinued. 
By then the Blues Rock boys had completed their second composition. I also interviewed them as a group for a second time because I noticed that the boys were more articulate when talking about their composing together rather than they were by themselves.

After Alice and I had assessed and graded the boys' work, the project was concluded on 3 November, 2011. Three solo composers had completed two compositions each, which meant that six students out of 20 in the class (about 30\%) had achieved AS91092. While not ideal, this was still an improvement on the $10 \%$ achievement in composing the year before.

\subsection{Major themes}

This section presents four major themes arising from analysis of the Kotare data. It explains how these relate to the three interrelated practices of group composing, teaching and assessment, and discusses what constitutes a valid contribution to these:

1. Communication. This is in two sections: communication when group composing; and assessment as communication.

2. Students' reasons for group composing.

3. Teacher and student expectations of success and achievement in the NCEA.

4. Assessment validity and its relationship to group processes.

\subsection{Theme 1: Communication when group composing}

As explained in the review of literature in Chapter 2, valid collaboration requires effective communication between group members. There needs to be a shared understanding of the context of the collaboration, and shared knowledge about the process in which group members are engaged. In order to communicate effectively, group members also need social skills to work together.

\subsubsection{Communicating through shared stylistic knowledge}

In order to make a valid contribution to the composition, group composers needed to be able to communicate their creative intentions clearly to one another. To do this they required a working knowledge about the stylistic context in which they composed. They also needed to be able to use appropriate language (musical and verbal) to communicate this to each other. All of the students group-composed in 
familiar popular styles, rather than any styles they had learned about in class, but this informally or tacitly acquired knowledge needed to be shared by everyone for successful creative and musical collaboration. Without a shared concept of the music they were composing, they could not communicate with each other.

This was clearly demonstrated when I observed Reggae. Two Pāsifika boys (Tongan and Tuvaluan) showed a good understanding of the island reggae style they were jamming. They soon came up with some guitar riffs and a rough musical structure, linked to a few chord progressions. However, the bass player and drummer (both Palagi) were novices who could not play in reggae style. The drummer belted out a standard 4/4 rock beat without a reggae feel. They could not provide a rhythmic platform while the Pāsifika boys looked for melodic ideas. However, there was no-one else available to play the instruments needed for a reggae style composition. The mismatched quartet struggled to communicate musically with each other because they spoke different musical languages.

Blues Rock was a vehicle for Jimmi's virtuosity, but Jay, bass player, did not seem familiar with Jimmi's music. Alice's records showed that Jay made a minimal contribution to $\mathrm{CCP}$ in the first composition and seemed unsure of his role in the musical texture. Rāwiri, on the other hand, confidently laid down a stylistically accurate rhythmic feel for Jimmi to improvise over:

Alice: Without Rāwiri's skills it would have been a much lesser band. He brought a hell of a lot to the band.

$V T: \quad$ What did he bring?

Alice: A whole dynamic thing. And the skills that he brought. That's why I asked him to play in the show. I knew that he wasn't going to give me much of a problem with organising. I wrote out a book and said "this one's shuffle" etc. ... Rāwiri was always onto it. He just had that musicianship thing.

Jimmi's composing, and thus that of Blues Rock, was influenced by the style of music that he liked and had taught himself to play. Alice told me that Jimmi had learned informally from a gifted Year 10 student, Mario:

What Jimmi has achieved, skills-wise, has been amazing. He's learnt it all off Mario. He's absorbed a lot of the stuff that Mario was doing and he learned by just making a nuisance of himself really. He just hung on to Mario and they've become friends. And he spends most nights round at Mario's place. He just absorbs. He's really into the overdrive thing and he's playing very fast blues licks. They're very controlled and sound good. It's all in one key though. 
Jimmi's instrumental skills were situated within style-specific knowledge he had learned from Mario and from listening to songs he liked. He used this knowledge to address specific musical challenges and problems when composing:

Jimmi: I was playing "Cocaine" and I liked the sound of the riff.

$V T: \quad$ So you were playing around in that [hums the "Cocaine" riff]. Then what happened?

Jimmi: Then I was listening to a song by Firehouse and one of their riffs has got, like, pinched harmonics so I tried to add that in.

Jimmi and Rāwiri knew how the music was supposed to sound but Jay was not familiar with "Cocaine" or the Firehouse song. He could not explain how his bass playing fitted into the overall structure;

$V T: \quad$ So you came up with a riff or a tune that you liked and then what happened? [Silence] Rāwiri did you start drumming to it?

Rāwiri: I made one main tune and just played that.

$V T: \quad$ Like the original, like "Cocaine", or was it your own idea?

Rāwiri: It was my own idea.

$V T$ : What about you Jay? What were you doing at that stage?

Jay: I was listening and um ...

[Silence]

VT: You'd want to pick up the chords wouldn't you?

Jay: Uh, yeah pick up the chords ... um ... [Silence]

The Blues Rock boys took nearly three months to compose their first piece, but only two weeks to compose their second. Jay in particular made much more CCP as he became more familiar over time with the style of music Jimmi was playing. The boys also told me that what they had learned in class about compositional process and musical structure enabled them to communicate more effectively with each other:

$V T: \quad$ Have you learned anything from [Alice] or from me?

Jimmi: Like that thing about composing, messy and focused. And how like, repetition and stuff and A section and B section. I would have just stuck to an A section for about three minutes in the song.

Rāwiri: And the structure, solos and stuff. This time, it's a bit easier coz ...

Jay: We're talking about it more.

$V T: \quad$ What sort of stuff are you saying? 
Jay: When different ideas come in.

Rāwiri: How the song's gonna start. Whether it's gonna start on drums or guitar.

At the end of the project, Jimmi, Rāwiri and Jay were still unable to explain to me how they composed their pieces:

$V T: \quad$ Can you tell me the story of how you composed your piece? [Silence]

Jimmi: I don't know how to explain it.

VT: Is it hard to explain how you put your song together?

Jay: Yeah, coz I don't know.

On the other hand, while they could not verbally articulate how they composed together, they had composed, represented and recorded two reasonably coherent compositions showing a degree of stylistic control. Observational data reveal that the boys generally constructed and shaped the music within their tacitly agreed stylistic structure by communicating musically, but not verbally. For example:

Räwiri indicated with fills etc. when a particular harmonic sequence came to an end, or where the texture needed filling out. Without saying anything, Jay followed him, while at the same time Rāwiri and Jimmi were responding to each other's ideas. [Observation 8 August, 2011]

I reflected that, in my Master's study, the young group composers of loud rock music often communicated their ideas to each other through music and gesture, rather than words and that Davis (2005) and Jaffurs (2004) had observed the same thing. Boud's (2000) assertion about tacit learning that "we know more than we can tell" resonated here (and I wondered if he had teenage boys in mind!)

I made the following entry in my reflective diary about the implications of this for teacher practice:

9/8/11. Some of the students have made contributions, like Aaron, but don't have the words to articulate what they've done because they don't seem to know enough about music to do so. In group composing it's all about process so the kids need musical language in order to communicate with us and with each other... And they often work at a musical, not a verbal level so they can't or won't talk about it. Students need to know lots about the style in which they are composing, and it needs to be shared so that everyone in the group knows what they are doing. Jay is struggling with this.

\subsubsection{Appropriate resourcing is needed for effective communication}

Analysis revealed that group composers could not make valid contributions when they could not hear each other, or were frequently interrupted. At Kotare, the dire lack of sound-proofed practice rooms impeded students' learning and 
engagement. When a group had sole use of the music classroom or band room, significantly more progress was made, but in Cycles 1 and 2, bands rarely had more than 40 minutes per week each to work in this way.

In the first interview, Rāwiri explained that he regarded a lack of time as being the hardest thing about composing in a group:

$V T$ : What's been the hardest thing about composing in a group?

Jay: Having to make something up.

Rāwiri: And having time.

Aaron: Getting it all in exactly the same time.

Rāwiri: No! I mean doing it.

Aaron: Getting our part, like, learning our part.

Rāwiri: No! I mean we don't get enough time to do it.

$V T$ : Rāwiri you said "time". What did you mean?

Rāwiri: Getting the time to play. Just time in class!

Aaron: We have at the moment.

Rāwiri: Yeah, twice.

I reflected that perhaps one of the reasons why the Blues Rock boys were able to complete two compositions was because, as the last remaining group of composers in their class, they did not have to compete for rehearsal space. The implication for teacher practice is that multiple, soundproofed spaces are needed for valid contributions to group composing.

\subsubsection{Low musical skill impedes communication}

Few students in the class could play their instruments with any degree of fluency, and some did not sing or play at all. There is compelling evidence in the literature that without access to music technology, such students do not have the skills to express their creative musical intentions and so are unable to make a valid contribution to composing (Finney, 2007).

Some band members struggled to communicate their intentions to each other because they did not have access to the instrumental combinations appropriate to the styles they played. For example, no one in the class played the bass competently and, unlike Rāwiri, few drummers had the skills and knowledge to play in a variety of styles. As has been discussed earlier, the boys in Reggae struggled to compose a 
melodic line when the rhythm section boys could not play in style. Jay played bass for the first composition with minimal skills because the Blues Rock style needed a bass line. While the boys managed to compose a coherent second piece with two guitars and no bass, the composition lacked the stylistic assurance that a good bass line might have given it. Furthermore, the style in which they composed generally requires a vocal line but Jimmi, Rāwiri and Jay believed that singing was far too scary and unsafe to do in public, even with the support of the others. The exception was Aaron who hinted that he might have liked to sing:

Jay: And singing is a bit different. You just don't sing at all.

[They all giggle and shuffle uncomfortably]

$V T$ : I reckon you guys would be just fine singing.

Aaron: Jimmi was playing a song I liked so I sang too.

$V T$ : So why is singing in front of people kinda scary?

Aaron: It's not like a guitar, or a bass guitar where you can pick the wrong string. In singing you can pick the wrong note.

Jay: And you know everyone's laughing at you.

$V T: \quad$ Is that because you're the instrument?

Aaron: Yeah, exactly.

Jay: $\quad$ Not fun.

Jimmi: Yeah. All eyes on you.

All agreed that a lack of vocal confidence meant that they avoided song writing and that singing was what was missing in their compositions. Given that singing was a common feature of the musical styles in which the boys composed, this affected the validity of their contributions. The implication for teacher practice is that students composing in styles requiring a vocal line might need support to sing confidently.

\subsection{Theme 1: Assessment as communication}

Data analysis reveals that the valid assessment of group processes required good communication between and among group composers, between students and Alice, and between Alice and myself.

\subsubsection{Conceptualising group composing to communicate about achievement}

The model proved to be an effective assessment tool to evaluate CCP in discussion with the students. Both Alice and the students used it as a framework to 
explain what was happening in the band. "Moving out of messy into focused" became a common phrase used by Alice, and occasionally the boys, during discussions about their progress. These concepts seemed to help them to know where to go next, and to identify what might be a valid contribution on their part. Whether group composers used the model to communicate with each other while composing, however, is unknown because neither Alice nor I observed them doing so.

\subsubsection{Micro and macro CCP}

The model helped Alice and me to interpret the validity of each student's CCP. In Blues Rock's first composition, CCP seemed to occur on at least two levels. Jimmi and Rāwiri shaped and refined the piece as a whole (macro CCP) as well as composing their own parts (micro CCP). However, Jay only shaped and refined a bass line in response to Jimmi and Rāwiri's structure (micro CCP).

During a discussion about his CCP, Alice showed Jay her records of what he had achieved over time. The model descriptors (organise, structure, shape, for example) were a framework for Alice to give Jay both feedback and feed-forward. Following this feedback, Jay seemed to realise that if he was to make a valid contribution, then he needed to take a larger role in process. Alice reported that he subsequently asked her several times what he could do to make more of a contribution and "pass".

To ensure that Jay achieved the NCEA achievement standard, Jimmi reported that he specifically asked Jay to compose a chord progression for the verses of their second composition. This implies that, for Jimmi, a valid group composing process was one that ensured that everyone in the group achieved AS91092. Jay also told me that he played guitar for the second composition because he knew he had more skills to contribute on a macro level when playing that instrument. The data indicate that it is unlikely that either boy would have been aware of this if Alice had not communicated to them the need for every member of the group to contribute to process.

\subsubsection{Using the model to grade the first Blues Rock composition}

The conceptual model supported a change in assessment practice for Alice because she used the model to gather data about all of the boys' $\mathrm{CCP}$ and then to communicate this to them. For example, here is an electronic version of an excerpt of Alice's handwritten records for Jimmi. (See Figure 5.4). 


\begin{tabular}{|c|c|c|c|c|c|c|c|c|}
\hline Date & $\begin{array}{l}\text { Come } \\
\text { up } \\
\text { with } \\
\text { new } \\
\text { ideas }\end{array}$ & $\begin{array}{c}\text { Your } \\
\text { opinion } \\
\text { and } \\
\text { ideas: } \\
\text { accept, } \\
\text { change } \\
\text { or } \\
\text { reject } \\
\text { ideas }\end{array}$ & $\begin{array}{c}\text { Organise } \\
\text { structure } \\
\text { shape }\end{array}$ & $\begin{array}{c}\text { Change, } \\
\text { modify, } \\
\text { improve } \\
\text { ideas }\end{array}$ & $\begin{array}{c}\text { Your } \\
\text { opinion } \\
\text { and } \\
\text { ideas: } \\
\text { accept, } \\
\text { change } \\
\text { or } \\
\text { reject } \\
\text { ideas }\end{array}$ & $\begin{array}{c}\text { Organise, } \\
\text { structure, } \\
\text { shape }\end{array}$ & $\begin{array}{l}\text { Refine, } \\
\text { polish, } \\
\text { complete }\end{array}$ & $\begin{array}{c}\text { Notate } \\
\text { write } \\
\text { down } \\
\text { and } \\
\text { record }\end{array}$ \\
\hline 9/8 & + & + & + & & & & & \\
\hline 23/8 & & + & + & & & & & \\
\hline 6/9 & & & & & & + & + & + \\
\hline 22/9 & & & & + & & + & + & \\
\hline \multicolumn{9}{|c|}{ Handwritten notes the other side of the page made while talking to Jimmi. } \\
\hline 9/8 & \multicolumn{8}{|c|}{ Completed chord progression. Added A and B section. } \\
\hline $23 / 8$ & \multicolumn{8}{|c|}{ Practicing scales and solos } \\
\hline 6/9 & \multicolumn{8}{|c|}{ Leading. + ve ideas and playing. } \\
\hline 22/9 & \multicolumn{8}{|c|}{ Song sounding ready to record. Leader and soloist. } \\
\hline $27 / 9$ & \multicolumn{8}{|c|}{ "I wrote the chart and came up with some of the chords. I structured it" } \\
\hline
\end{tabular}

Figure 5.4. Group composing assessment tool: Jimmi

The model then acted as a framework for summatively assessing CCP. This was new practice for both of us. Alice and I examined the collected data and decided that Jimmi received a Merit grade for the first piece because he had made the most significant CCP at both micro and macro levels across all aspects of the compositional process.

Initially, Alice believed that Rāwiri's CCP was at the Achieved level while I thought that, as a drummer, he had contributed a lot in terms of style, feel and overall structural integrity. Eventually, after much discussion, Alice decided to give Rāwiri the benefit of the doubt and we gave him a Merit.

We were doubtful about whether to award Achieved to Jay because his bass part was a simple rendering of Jimmi's harmonic sequence. Furthermore, Jay had made no macro CCP to the first piece, although the observation data indicated that he was becoming more proactive about participating in the process as a whole. Alice and I agreed that we did not want to discourage a novice composer and so awarded a formative grade of (just) Achieved. However, Alice and I agreed that if Jay did not make CCP on a macro level in the next piece we would not have enough evidence of a valid contribution to group composing. 


\subsubsection{Limitations of written feedback}

Alice and I gave written feedback to the Blues Rock boys using the kind of feedback sheet commonly used by teachers. (See Appendix 5.1.) In the past, Alice had avoided giving written feedback because she said that the students did not usually read it but I wanted to see for myself whether or not this was the case and so, together, we wrote feedback for each boy. Here is an excerpt of written feedback to Rāwiri:

Next steps: You made a good contribution to your first group composition because your drumming was an important ingredient in making the piece work. You were very aware of the form, which is great. Your next challenge is to be more involved in the overall composition process. Maybe you might decide to write a drum piece? Your challenge could be to organise the form. Remember that you need to start with 2 or 3 good ideas - these could be rhythmic.

I also included a sliding scale in order to give the students, particularly Jay, an indication of how close they were to the next NCEA achievement standard grade. We called it the "NAME slider".

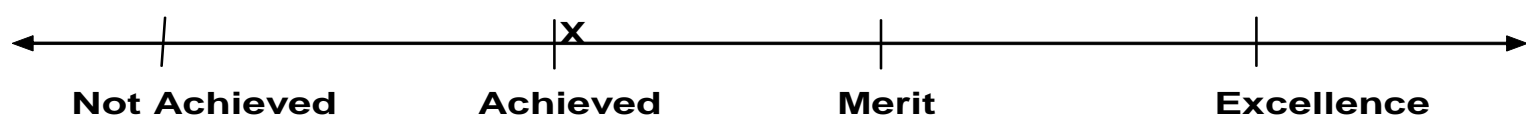

Figure 5.5. NAME slider

As Alice had predicted, the boys ignored most of the written feedback:

$V T: \quad$ What about the feedback that you got from [Mrs A] about your first composition. Did you read that stuff?

Jimmi: Nah, I didn't even see it. I think I saw the mark and handed it back and she told me to take it home.

$V T: \quad$ She gave you a whole lot of bullet points about how to make your next composition better. Did you take any of that on board?

Jimmi: Nah, I didn't even see it.

On reflection I realised that my reasons for giving written feedback were more about teacher accountability to the NZQA moderator and part of my established practice, rather than being useful for the boys.

However, one kind of written feedback was effective. The Blues Rock boys all said they wanted to "get the credits" and so read the NAME slider: 
Jimmi: That time-line looking thing?

Rāwiri: I got just above Merit.

Jay: I got just above Achieved.

$V T: \quad$ How about you Jimmi?

Jimmi: I got halfway between Merit and Excellence.

\subsubsection{Articulating the assessment criteria}

Like most sole music secondary music teachers, Alice did not usually have the opportunity to check the validity of her assessment judgements through collegial discussion (Donaldson, 2012). As revealed in this excerpt, assessing student work together helped us both to develop a valid, shared understanding of the AS91092 assessment criteria:

Alice: The standard, on there [gestures to the screen], doesn't tell us much does it?

$V T$ : Well it does say it needs to be "coherent". "Stylistic control" I guess means that it has an identifiable style.

Alice: OK. Say it's a blues piece. Yeah, if it's got blues stuff in it you might be looking at .... um ... and if you can see that a guy has put a fair bit of thought into it you're going to be thinking it's going to be a Merit, aren't you?

$V T: \quad$ So that's what you'd mean by "stylistic control"? So ... hmmm ... if they've done those three basic things, even if the music's well ... just, um ... alright ... then if they can do that, then that's an Achieved? Whereas, with Merit it's got to sound like something?

Alice: Yes.

During these conversations we agreed that a valid Achieved composition is a completed piece with some structure and represented adequately enough for someone else to reproduce or play it. We then decided that for a valid Merit, "stylistically controlled" means that the students were able to demonstrate their understanding of a style through their composition. Once we had communicated these ideas to each other, and agreed on them, grading the compositions was straightforward.

However, more often than not, I found myself leading the discussion and interpreting the assessment criteria.

Alice: Someone said to me once, that, like, a Level 2 Achieved is like a Level 1 Excellent. I don't know if that's true but it sort of stuck in my mind as a rough guide. 
$V T: \quad$ Is it really like that though? I would have thought that maybe Excellence is something different from Achieved, where Achieved is meeting certain criteria and kind of "doing the job" and Excellence has a bit of polish on it.

Alice: Oh yes definitely. I was just saying I've thought about it that way.

$V T: \quad$ So, coming back to the issue ... um ... Merit and Excellence at Level 1 isn't the same as Achieved at Level 2 is it? ... [pause] ... Or is it, perhaps?

Alice: Yes, you're right.

VT: $\quad$ Merit and Excellence are about the quality of the work, aren't they?

Alice: Yes, you're right. Someone just said that and it stuck in my mind. I'd never work that way.

Alice and I assessed the second composition together using the CCP data, the recording and the chord chart as evidence for summative judgments. The "next steps" written feedback from the first composition, largely ignored by Jimmi, Rāwiri and Jay, acted as helpful benchmarks against which we evaluated the progress made by each student. Jimmi and Rāwiri achieved Merit for both pieces and a Merit overall for the achievement standard because they had composed consistently. The data revealed that Jay had been improving steadily. His CCP for the second composition was securely at Achieved at both macro and micro levels. Jay clearly had a valid trajectory of achievement and so we awarded him an Achieved grade overall.

\subsubsection{Conceptions of creativity influence its assessment}

Data analysis revealed that commercial music and adult musical practice dominated Alice's discourse about what she regarded as valid achievement with Excellence:

Alice: I certainly wouldn't give it Excellence.

$V T: \quad$ Why not?

Alice: Because I don't see stuff happening that is pretty original or that turns it from merely a jam piece to something that stands out. If you heard that on the radio, if you didn't know what it was, it would sound like a jam piece of music. And like with any blues, it's not a blues form, but any rock-bluesy sort of tune. It wouldn't stack up. Whereas if you heard [sings a well known heavy rock riff] straightaway you'd recognise the tune. Technically it doesn't really need to be a song, but it needs to have, you know, the holistic thing. Imagine that on the radio or something. This one's more like a jam than a proper song.

Alice believed that a composition had to be highly original to be an Excellence even though originality is not one of the assessment criteria. I inclined towards Boden's (1990) contention that a student's experience of even a clichéd musical idea 
might be original, and thus valid, if he had not experienced or heard the idea before. I reasoned that if the composition was stylistically assured (which is a criterion for Excellence), then this was evidence that the composers had manipulated the specific elements of a musical style to compose coherent, stylistic and interesting music. Provided it was not directly derivative, I did not think that an Excellence piece at NCEA Level 1 had to be original in the H or Pro-C sense of the word (Boden, 1990; Kaufman \& Beghetto, 2009b). Alice was adamant that without originality, the piece could not be an Excellence. These were Alice's students and she had overall responsibility for making the professional judgment and so I deferred to her. Blues Rock's first piece was graded a Merit.

\subsection{Theme 2: Students' reasons for group composing}

Analysis of the students' interview data reveals that the students' reported reasons for group composing were closely linked to their expectations of achievement at school, and in music class. As will be shown in Chapter 7, these motivations seemed related to their beliefs about what constituted a valid contribution to group composing.

\subsubsection{Practical, real world considerations make group composing a valid activity}

All of the Blues Rock and Heavy Rock boys indicated on the questionnaire that "getting the composing standard" was either "very important", or "quite important" to him. Zach recognised that a lack of achievement in the NCEA had future ramifications for him:

Zach: NCEA is for getting your life sorted out. If we didn't get credits or anything then who's going to hire us? For jobs in the future and that. If you've got nothing then people are gonna think that you're a loser.

Rāwiri and Damien knew that NCEA achievement could get them access to tertiary training, or employment:

Rāwiri: If you want to go to Weltech or something they can let you in straight away coz you've done the hard work at school. [KSIIBR]

Damien: You can just search up the first three letters of a name and you've got all their credits and their papers and go "oh yeah, he's got this and this and this". [KSIIHR]

Liam also observed that NCEA acted as a form of social control to keep them in school: 
Liam: It's to keep us in line at school because if you want to achieve, you just turn up and get credits but if you just want to fluff-ass around and just don't turn up, probably go and get stoned or something ... well ...

All said that they would not have group-composed if it were not for the NCEA achievement standard:

Rāwiri: We probably wouldn't be making songs up if it wasn't for NCEA.

Jimmi: We'd probably be doing covers.

Aaron: We just want to jam all the time.

None of Heavy Rock boys completed a composition and so did not achieve AS91092. Nevertheless, some members of this group said that they valued group composing because they saw it as an opportunity to develop real-world skills they needed in their adult lives:

Jason: Like there's nothing better for your NCEA. Like, there's nothing better than getting the experience of working in a group. I'm being serious. I'm not even kidding. You get the experience of working with musical instruments and harmony. And later on if you get to join a band professionally you get the experience.

$V T$ It sounds to me that, not only are you guys learning how to compose, you're also learning how to work together.

Zach: Yeah, it's going to help later on.

VT: In what way help later on?

Zach: [passionately waving his arms] Help with ... LIFE! It will be a lot easier. You won't want to ... like ... hit them.

$V T$ When you are working with other people?

Zach: Even with strangers and stuff.

\subsubsection{Musical reasons for choosing group not solo composing}

None of student participants interviewed believed that he could achieve AS91092 on his own. This was for several reasons.

Jimmi only played in one musical style, one that showcased his florid improvisatory skills. He reported that he could not compose a valid blues rock piece by himself because this style required a rhythm section, commenting that "if you want to solo on your guitar you have to have someone else backing you up." Similarly, because, drums and bass are not solo instruments and thus difficult to compose for without a high level of compositional skills and knowledge, Rāwiri, Zach and Damien 
all believed that they needed to group-compose and could not compose a solo piece for drumkit.

Alice and I agreed that without significantly more skills or prior knowledge, novices Jay and Liam would probably have struggled to compose a valid solo piece. In any case, given Aaron's and Jason's overall disengagement with school, it seems unlikely that either would have been motivated to compose by himself. Aaron listened to loop-based dub-step, so he might have been motivated to compose solo if he had had access to digital media and software. This remains an unknown and one of many missed opportunities for student achievement during the research at Kotare.

\subsubsection{Intrinsic rewards}

Consistent with the findings of the pilot study, composing in a group gave the Kotare boys confidence to tackle a challenging task like composing a piece of music and performing it. It also made them feel good about themselves. They valued the feedback they received from each other and it gave them the confidence to be creative:

Zach: It gives us more confidence in what we do so it's a better outcome. It's like a self-esteem issue as well. Like if you've got mates to support you then you're not going to get as nervous and if you're more relaxed then you can do your work a lot better. [KSIIHR]

Jay: If you have to do it in front of people then you have to play it by yourself. It's awkward. You've got support if you play it in a group.

Aaron: It builds up your confidence. You get to see what other people think about how you're playing and everything. [KSIIBR]

Like the pilot study students, the boys also believed that group composing was easier to do than solo composing because they could share each other's ideas:

Jay: I reckon it's better in a group.

$V T$ : Why is it better in a group?

Jay: Coz you can get good ideas and use them.

Jimmi: Solo composing is hard. It's easier with a group.

Rāwiri: You're not by yourself. You get other people's ideas.

All of the boys indicated in the questionnaire that "writing a really good song" and completing the piece they were currently working on was "important". Aaron and the Heavy Rock boys said that they did not care very much about whether they achieved at Merit or Excellence level. Creating something that they liked seemed to have more validity for them than NCEA grades: 
Jason: Is it a bad thing to tick that getting Merit or Excellence isn't that important?

$V T$ No. I want your real opinion on this.

Jason: Coz in my opinion it isn't about whether you get Merit or Excellence in this.

Zach: Writing a really good song isn't that important. I mean as long as you've got a song that you can actually listen to. Not everyone has to like it.

These boys believed that group composing gave them a lot more freedom and choice compared to other NCEA subjects:

Zach: You're not told to "do it this way, do it that way" [makes a straight-ahead gesture]. You can decide "I'm going to do this, then go over there" [points in different directions] and no one's going to go "well that's wrong".

When asked "how does group composing compare with work you do for other NCEA standards and in other subjects?" all of the boys interviewed said that they preferred working collaboratively.

Aaron: [In other subjects] you don't get to do group stuff or play with your mates. Other stuff is pretty boring.

Jay: It's very fun. It's way funner, um, if that's a word. [Laughter]

Aaron: Coz you get to make your own stuff.

Alice speculated that even the highly focused Jimmi was more motivated by a desire to play his guitar well than achieving in NCEA composing because he was very reluctant to complete the written representation required of the group to achieve the standard:

Alice: Jimmi seems to be reluctant to put the final nail in.

$V T$ Why do you think he doesn't want to finally submit the work and say "it's done"?

Alice: Because he feels pretty proud of his playing. I say lots of positive stuff to him. I think what he's doing is pretty neat. I think maybe he's more into it for the music. He heard Mario play and he wanted to play like that. And he's pulled it off. The old saying "fun gives its own reward". He probably feels quite fulfilled [by his playing] and doesn't need it.

Alice reported that Jimmi needed a lot of encouragement and "nagging" before he finally submitted written chord charts of the two compositions on the last day of the school year, even though the pieces could not be assessed without these.

Unlike the other boys, Jimmi, Rāwiri and Jay ticked "very important" for all the questions in the questionnaire. Significantly, these three students were the only 
ones to complete two pieces and thus achieve AS91092. The implication for teacher practice is that there may be a correlation between having expectations of NCEA success and completing two compositions. This is explored in the next section.

\subsubsection{Assessing lower-achievement students' CCP}

When Alice asked Aaron what he had contributed to the piece he seemed uncomfortable. Like Jay, Aaron, had been playing along in a fairly basic fashion, following Jimmi's and Rāwiri's lead. This CCP conversation (recorded on video) seemed to disengage him further:

Aaron is strumming along to Jimmi's spectacular blues guitar improvisation. He is sits close to Jimmi, smiling encouragingly and seems to be admiring Jimmi's playing. He faces Jimmi, watching his playing closely and sometimes he tries playing Jimmi's ideas. Alice asks them to stop playing.

Alice: Aaron, what did you come up with there?

Aaron: [his face falls and he looks sulky] Nothing. [He looks away]

Alice: So is it fair to say that you've made no contribution so far? Other than just playing along?

Aaron: [still looking away] Nah.

Alice: OK. [She notes this down] So ... guys ... It's just a chord progression so far. Is it going to be a song? Can anyone sing?

Aaron [turns towards Alice]: I can. [His face lights up for a fraction of a second, then he looks embarrassed as the others loudly claim they can't/won't sing]

Alice: So will you sing Aaron?

Aaron: No. [He turns away again]

Aaron seemed to me to be resentful that school and NCEA structures had interfered with the clearly enjoyable social experience of jamming with his friends. When Rāwiri referred to this conversation in an interview, Aaron dismissed it, saying "I didn't even listen to what she was saying" although it is clear from the video that he was listening because he goes on to say that "I need to make something up for me".

Aaron's low attendance and disengagement at school meant that he made very few contributions to the group's composition. Alice reported that, just as Blues Rock were about to record their first composition, Aaron stormed out and refused to 
participate, and the other boys recorded their composition without him. Alice was unable to find out what had sparked what she thought was an uncharacteristic reaction from Aaron because he left school very soon after this episode.

\subsection{Theme 3: Teacher and student expectations of success and achievement in the NCEA}

Data analysis revealed that Alice's and her students' expectations in Year 11 Music were key variables in the low level of achievement.

\subsubsection{Alice's expectations}

Analysis of Alice's discourse reveals that she had low expectations of success for her students. These were usually justified through deficit theorising about the students' backgrounds, or prior knowledge:

That's what I see all the time here. There are so many kids who have got the goods but they are either too lazy, or too unmotivated or don't know how to get the best of it. [KTD3]

Liam knows nothing really. He's been in and out of school a lot too. [KTD2]

When I suggested to Alice that she create posters for Merit and Excellence in composing as well as one for Achievement, she did not believe that this was necessary:

VT: $\quad$ So what about Merit and Excellence? Did you talk to them very much about what Merit and Excellence would involve?

Alice: Probably not. It was just getting to the Achieved. I mean, if you read what it says there at the top, to get a Merit you've got to write an effective piece of music don't you?

This implied to me that Alice did not expect any of her students to compose an effective piece. Analysis of all of the interview and discussion data reveals that Alice mentioned Excellence three times in relation to her students' achievement, and then only to say that she did not think that the work was at Excellence level.

\subsubsection{Student expectation of success}

The students' expectations were also low. Aaron, for example, was disengaged from school generally:

Aaron: All my subjects are optional. It's just if I feel like turning up to them ... I didn't pick music. I got kicked out of computers and music was in the same [timetable] line. 
The students only mentioned Excellence four times in the interviews, and not in relation to their own work. Even Jimmi, a highly talented student, was surprised when he received a Merit:

$V T: \quad$ Jimmi, what do you think about the grade you got?

Jimmi: Well, I wasn't expecting it.

$V T: \quad$ What were you expecting?

Jimmi: Probably not over Achieved.

$V T: \quad$ But you wrote out the chart though. Don't you think you should get credit for writing out the chart? And you came up with most of the ideas.

Jimmi: I have no idea.

\subsection{Theme 4: Assessment validity and its relationship to group processes}

The Kotare findings suggest that students who might not have been able to achieve as solo composers (novices, unconfident students, drummers, bass players) were able to do so as group composers. This raises some questions about the validity of the assessment if everyone in the group is awarded the AS91092 NCEA credits.

For example, the Heavy Rock boys may have used the conceptual model terms to protect Liam who did not seem to make a valid contribution to process:

Jason: He's the manager. [Gestures to Liam]

$V T: \quad$ What does the manager do? What's your role Liam?

Jason: Basically, what Liam does is ... he gets credits for doing nothing! [They all laugh uproariously. Is he joking ... or not? I can't tell]

Damien: He makes sure it's all integrated and it sounds right.

Jason: Yeah, he makes sure he rolls all the smokes.

Liam may have taken on the role of "critiquer", but it is also possible that the others were covering for him. Alice believed Liam had minimal skills and knowledge as a musician and thus did not have the ability to give the others feedback on the music. Nevertheless, the boys go on to say:

Zach: Yeah, that's Liam. In the band room there's a couple of staves on the board and what Liam does is he gets a couple of the notes written down.

Jason: Yeah, makes sure that everything's basically sorted out.

Zach: He's got the intro on one stave and then above it he's got the verse. 
Jason: He's like our ear outside the band you know what I mean? He makes sure everything sounds all $\mathrm{OK}$. Coz, I mean when you play, something it sounds different from what you are hearing. So he hears things and if anything sounds like crap, he says it's crap, and that it's time to do something friggin' properly.

Heavy Rock disintegrated soon after that interview and so it is not possible to know if Liam really did give the others objective feedback during group composing. What is clear is that the other boys in his group were motivated to ensure that Liam, the least knowledgeable and skilled member of the group, was not excluded from the discussion about the band's compositional processes.

\subsubsection{Teacher identity and conceptions of valid assessment}

As explained in Chapter 3, Alice's teaching seemed primarily driven by her experience as a practicing musician. She frequently drew on this experience during discussions about the validity of drummers' and bass players' $\mathrm{CCP}$.

Sometimes I wonder if the whole four-person band group-composing thing is really pushing the limit. I've been in lots of situations where someone is doing a recording and I'm a session player. I might invent a line and they might like what I invent and it might get used on the recording but I still don't really feel that I was a co-writer in that song. I'm using my playing skills to make their song sound as good as I can. Studio musicians do that all the time ... The thing that has challenged me has been the idea of a bass player and a drummer being part of a compositional process.

While Alice's example from her own experience involved supporting a solo composer to realise his or her ideas, rather than a true collaboration, she continued to express these doubts. When it came to awarding final grades to Rāwiri and Jay though, she decided to overlook her misgivings because she believed that the overall learning benefit for both boys outweighed any potential weakness in assessment validity:

Alice: The things that have challenged me are two things. One has been the idea of a bass player and a drummer being part of a compositional process.

$V T$ : Could you just expand on that? Why is that challenging?

Alice: Because, for me, traditionally, a group composition, Lennon and McCartney sort of thing, is one guy doing the tune, one guy doing the words. I know on records you see sometimes everyone credited with the song, where a band's sat down and worked it up. But the part that challenges me would be what the drummer contributed to the composition. I'm happy to overlook that concern because of the fact that it's doing a lot more good than bad in respect that Rāwiri wouldn't have done his composition and Jay wouldn't have done his composition. They probably have learned a whole lot more about composing actually doing it than they would have done with me going on about the form and stuff, because they got to experience it. 


\subsubsection{Grade validity and CCP}

Alice and I were unsure whether a student could be awarded the standard if he had not contributed to the written representation required by AS91092. The chord charts were entirely Jimmi's work and, while Rāwiri engaged with the piece structurally, he had not done so melodically or harmonically. Jay clearly did not have the harmonic knowledge to write out a chart but "representation" was one of the requirements for a valid Achieved, Merit or Excellence grade.

Alice considered Rāwiri's CCP, once more drawing upon her experience as a session musician:

And maybe in the real world we just don't give enough credit to the contribution of the musicians in a song. I did a recording the other day playing [my instrument] and I made some pretty important decisions, one being "keep it as simple as you can". You're having a huge influence on whether it's going to work or not and you're reading the other person's mind. It makes the recording work.

While Rāwiri had made a contribution to the whole piece (macro CCP), Jay had not. Nevertheless, the recordings and the chord chart did represent the creative intentions of all three students. Their skills and knowledge were distributed across the creation of the music and the piece could not have been composed without Jay's input and so, on that basis we decided to award AS91092 to all three boys. Nevertheless, with regard to Jay, the validity of that decision is questionable.

\subsection{Summary and implications for the St Bathan's research}

Although I strove to avoid deficit theorising, some of what I learned at Kotare College was about how low levels of knowledge, skills and resources, coupled with low expectations of success, affected achievement when group composing. It is one thing to identify negative factors influencing student outcomes but quite another to do something about it. I asked myself, "what are the key points in the Kotare findings that might influence my decision making if I were to teach and assess group composing in another school, or work alongside another teacher?"

\subsubsection{Musical skills and knowledge are crucial}

Skilled or competent players were able to realise their ideas when composing but beginner players often struggled to contribute to process, as did those who chose to play on an unfamiliar instrument in order to make a valid stylistic contribution. 
The implication here for teacher practice is that students without adequate instrumental or vocal skills need either access to digital media, which to some extent can play the music for them, or have access to some form of tuition. Sometimes these skills are informally acquired and so the conditions where this kind of learning takes place need to be both acknowledged and supported by the teacher.

The new facilities for music at St Bathan's Collegiate were going to be lavish. What might be the implications for group composing and its assessment if less knowledgeable or skilled students had access to plenty of ICT and multiple practice rooms?

\subsubsection{Specific stylistic knowledge is crucial}

Without specific stylistic knowledge, some group composers faltered because they were not able to clearly express their creative intentions to one another. They also needed an understanding of the underlying theoretical concepts of musical structure in order to do so.

When considering this finding in relation to teacher practice, I wondered if learning about the concepts of specific disciplinary knowledge could be incorporated holistically into all aspects of a Year 11 programme. Perhaps students could acquire both stylistic and theoretical musical knowledge as and when they needed it.

\subsubsection{The conceptual model acted as a framework for both learning and assessment}

The conceptual model had proved to be a very useful and effective assessment tool at Kotare. It enabled Alice to give valid and effective feedback/forward and it had enriched teacher-student conversations. It also enabled us to gather complex CCP data and use it effectively to uncover process.

I was interested in finding out whether David and his students could find the model similarly useful. I also did not know if the Kotare students had used the model when composing. I wondered if this might have been because the students did not have much prior knowledge about composing in the first place, or were not aware they were using it, or that it simply was not that relevant to them. I was interested in finding out more about how compositional and stylistic concepts could be employed as assessment and learning tools. 


\subsubsection{Group composing seems to have positive psycho-social outcomes}

Like the students in the pilot study, the Kotare students found group composing really fun, relishing the freedom and autonomy that came with it. Composing in a group with their peers gave the Kotare boys the confidence to tackle a challenging task that involved performing in front of other people. They valued the feedback they got from each other and believed that it was easier to compose in a group than alone.

There was considerable evidence to show that a less knowledgeable and skilled student, who might have struggled to compose by himself, was able to achieve with the support of his group. Some of the Kotare boys said that they regarded group composing as an authentic, real world activity where they could acquire skills they might need in their adult lives. The students at St Bathan's might have had very different life experiences, and I knew that the school community was generally representative of a very different socio-economic community. Would the St Bathan's boys experience group composing in this way?

While all of the student participants at Kotare said they valued group composing, their expectations of actual achievement in NCEA music were very low. One student seemed to view jamming as a social activity unrelated to NCEA achievement. I was interested in finding out more about student motivation to achieve in group composing and how it was valued in quite a different school community.

\subsubsection{Group composing grades may not be as valid as those for solo composing}

There are questions of fairness and assessment validity if students who cannot achieve by themselves are awarded the same achievement standard as those who can. I wanted to find out more about the learning and achievement of group composing novices and to explore the assessment validity issues this raised.

\subsubsection{Professional isolation may affect assessment validity and teacher confidence}

Alice and I learned a lot together through exploring what CCP meant and how we might gather valid data about it. The assessment of a student's CCP had proved to be quite a complex task, requiring methodical data collection and careful consideration. We had rich professional discussions when grading the students' work. Alice seemed professionally isolated and often commented that she did not usually have professional conversations about music assessment. Was David similarly isolated? If so, did this impact upon his confidence or efficacy when carrying out NCEA assessments? 


\subsection{Conclusion}

Participation as a practitioner at Kotare College led me to significant learning about valid contribution to the assessment of group composing, and the implications for teacher practice of its assessment. While there is some evidence of raised student achievement in composing, and possibly some learning about music in a broader sense, the research at Kotare College was nevertheless problematic, characterised by many missed opportunities for student achievement. The next chapter presents the findings of the subsequent study at St Bathan's Collegiate, informed by the work at Kotare College. 


\section{Chapter 6 St Bathan's Collegiate}

This chapter presents a discussion and analysis of findings arising from collaborative practitioner research at St Bathan's College from October 2011 to December 2012.

Following an overview of the project, three research cycles are described and explained. The four major themes arising from data analysis are then examined in relation to the two research questions:

Theme 1: Shared understanding between teacher and group composers about valid stylistic contributions to group composing processes.

Theme 2: Teacher experience and assessment practice.

Theme 3: The relationship between group composing and AS91092 criteria.

Theme 4: Achievement in group composing, and the NCEA.

The chapter concludes with an examination of the impact of the research upon David's practice and the extent to which his collaboration in the research was catalytic.

\subsection{Overview}

The research at St Bathan's Collegiate was in three broad cycles. Like the Kotare study, these cycles began with a focus upon the practices of composing and teaching, and ended with summative assessment and its associated NCEA structures.

- Cycle 1: Teaching and learning to compose

- Cycle 2: Group composing in a specific style

- Cycle 3: Summative assessment of group composing for the NCEA 
Table 6.1. Overview of research at St Bathan's Collegiate

\begin{tabular}{|c|c|c|}
\hline \multicolumn{3}{|c|}{ Overview of research at St Bathan's College: Oct 2011 - Dec 2012} \\
\hline & \multicolumn{2}{|c|}{ Composing \& Teaching $\longleftrightarrow$ Assessment } \\
\hline $\begin{array}{l}\text { Cycle 1 } \\
12 \text { Jan- } \\
23 \mathrm{Feb} \\
\text { Preparing } \\
\text { the students } \\
\text { for group } \\
\text { composing }\end{array}$ & $\begin{array}{l}\text { David \& VT plan a new } \\
\text { pedagogical approach to } \\
\text { composing. } \\
\text { David teaches, with VT } \\
\text { observing/ facilitating group } \\
\text { work: } \\
\text { - "Back-engineering" a musical } \\
\text { style. } \\
\text { - Analysing music in terms of its } \\
\text { - } \text { stylistic constituents } \\
\text { - Concepts of flow \& mastery } \\
\text { - proup work: composing short } \\
\text { piecesific styles }\end{array}$ & $\begin{array}{l}\text { VT \& David write first draft of an } \\
\text { assessment task for composing. }\end{array}$ \\
\hline $\begin{array}{l}\mathbf{2}^{\text {nd }} \text { cycle } \\
24 \text { Feb- } \\
18 \text { April } \\
\text { Group } \\
\text { composing } \\
\text { in a specific } \\
\text { style }\end{array}$ & $\begin{array}{l}\text { VT teaches conceptual model. } \\
\text { Students browse style examples, } \\
\text { form groups \& negotiate } \\
\text { composing style. } \\
\text { David teaches compositional } \\
\text { concepts, as \& when needed such } \\
\text { as: } \\
\text { - Hook lines \& riffs } \\
\text { - Harmonic sequencing } \\
\text { - Melody writing } \\
\text { Students compose } 1^{\text {st }} \text { pieces. } \\
\text { VT \& David discover } \\
\text { disconnection between task and } \\
\text { student response }\end{array}$ & $\begin{array}{l}\text { VT completes Task } 1 \& \text { introduces } \\
\text { students to AS91092. } \\
\text { On-going verbal feedback to students } \\
\text { using conceptual model. } \\
\text { Students asked to self /peer assess } \\
\text { CCP on an on-going basis using } \\
(-=+) \text {. }\end{array}$ \\
\hline & $\begin{array}{l}\text { David clarifies connection } \\
\text { between back engineering \& } 2^{\text {nd }} \\
\text { composition task. Four new styles } \\
\text { introduced. } \\
\text { On-going group \& solo } \\
\text { composing of } 2^{\text {nd }} \text { or } 3^{\text {rd }} \text { piece, } \\
\text { based on } 2^{\text {nd }} \text { task. }\end{array}$ & $\begin{array}{l}\text { David writes Task } 2 \text { It's all about Style } \\
\text { (revised version of Task 1). } \\
\text { Students self /peer assess CCP on an } \\
\text { on-going basis. }\end{array}$ \\
\hline $\begin{array}{l}\mathbf{3}^{\text {rd }} \text { cycle } \\
8 \text { Aug-6 Dec } \\
\text { Summative } \\
\text { assessment } \\
\text { of group } \\
\text { composing }\end{array}$ & $\begin{array}{l}\text { On-going group \& solo } \\
\text { composing of } 2^{\text {nd }} / 3^{\text {rd }} \text { piece, in } \\
\text { response to } 2^{\text {nd }} \text { task. }\end{array}$ & $\begin{array}{l}\text { David has a crisis of NCEA } \\
\text { confidence. VT works with him on } \\
\text { NCEA assessment concepts \& } \\
\text { documentation processes. } \\
\text { VT writes assessment schedules for } \\
\text { Tasks } 1 \& 2 \text {. } \\
\text { David collates achievement evidence, } \\
\text { assesses the compositions \& arrives at } \\
\text { summative grades. VT moderates these } \\
\text { with David. } \\
\text { David \& VT prepare documentation } \\
\text { for external moderation. }\end{array}$ \\
\hline
\end{tabular}




\begin{tabular}{|l|l|l|}
\hline \multirow{2}{*}{} & & $\begin{array}{l}\text { NZQA moderator accepts all } \\
\text { judgments and processes for group } \\
\text { composing. }\end{array}$ \\
& $\begin{array}{l}\text { David creates exemplar montage of } \\
\text { student compositions, viewed by all } \\
\text { students Years 7-13. } \\
\text { David puts exemplar scores of students } \\
\text { work \& NAME poster on classroom } \\
\text { wall. }\end{array}$ \\
\hline $\mathbf{2 0 1 3 - 1 4 - 1 5}$ & $\begin{array}{l}\text { Follow-up interview with David 13 March 2013. Professional discussions } \\
\text { are on-going. }\end{array}$ \\
\hline
\end{tabular}

\subsection{David's beliefs and professional knowledge about group composing}

Prior to our collaboration, I analysed the data from an initial interview and discussion with David about his beliefs about group composing and five main findings emerged.

\section{Students need instrumental skills and musical knowledge to communicate effectively when group composing}

David believed that his students needed to be able to play their instrument with at least some fluency as well as have a working knowledge of other instruments in their groups if they were to be able to compose successfully together. He thought that they also needed these skills to give useful feedback and make workable suggestions to others. With this in mind, he had created a "super music circuit" with the aim of preparing his (2011) Year 10 students for group composing in Year 11. The students rotated around a number of stations, learning the basics of some instruments, and were tutored by their peers whom David identified as being "experts" in playing their instruments. Some of these students became our research participants in 2012.

\section{Novices who do not yet have the skills or confidence to compose solo are supported in group composing}

David believed that group composing supported novices to participate and gain confidence through collaborating with more skilled students, before going on to solocompose. David often referred to Tom, a member of the 2011 group Pikachu, to illustrate this. 


\section{Students need a shared knowledge of the style in which they are composing}

David believed that boys with similar music preferences were more likely to work productively than groups with diverse tastes. He illustrated this with what he had observed of Pikachu:

This group did Pikachu which is from Pokemon, an animé and came up with a really good, catchy song that they all played on, all sang, all contributed to the construction of the song. They agreed they were going to do this animé, they all liked this animé, they all knew it.

Based on this observation, David organised his Year 10 students into matching musical taste rather than friendship groups, with the aim of supporting more efficient group compositional processes.

\section{Group composing may be motivating for disengaged students}

From his experiences teaching secondary school music in a low socioeconomic community in London, David believed that group music-making could be very motivating for disengaged students:

It was such a difficult school and you could not teach there traditionally, there's no way. Music was seen as a joke subject, a blood subject. I found from Day One there that the kids were hostile to learning, to teachers, to each other and none of the stuff that I was used to teaching in [my country] was going to work ... So I came up with a task, I guess similar to this, where I had them working in groups. Once they'd got that though, you couldn't stop them. It was really productive and music lessons became really fun and really happy and not "me against them" anymore.

\section{Group composing needs multiple, sound-proof spaces}

David had found that group composing required multiple, soundproofed spaces:

To make it work you have to be resourced and have a lot of different spaces ... really, to teach music effectively, rather than having one big room, I need lots of small rooms.

David's 2011 class comprised eight students and so group composing in two small classrooms was quite manageable. The new facility has multiple spaces and in 2012 there was going to be plenty of room for the much larger Year 11 class. 


\subsection{Findings from the Pikachu interview}

Before the research began, I interviewed David's current Year 11 students, Jake, Shin and Tom because they had composed one piece together for AS91092. Analysis reveals seven major findings that, along with the Kotare and Pilot findings, informed my subsequent planning with David. There were considerable alignments with both of these.

1. Confidence. All three said that composing in the group gave them confidence and helped them to feel good at school. Each had reasons to be less than confident at St Bathan's. Jake was new to the school in Year 11, having come from a small rural secondary school with few skilled musicians and quite a different school culture. Shin, a Japanese international student, was new to St Bathan's and not yet fluent in English. Whilst Jake and Shin were experienced and knowledgeable musicians, Tom had only started learning to play his instrument in 2010, and had not studied Music as a school subject before. As Tom explains, "when we made the group it took some pressure off my shoulders."

2. Group composing is fun. All three told me that group composing was a lot of fun. They also relished the freedom and autonomy of composing their own music:

Jake: It's just got the freedom. You can make what you want of it. So that's a thing I like about it.

Tom: It's less structured and just opens you up to having fun.

3. Group composing is a different way of learning. All three boys said they appreciated the opportunity for more active, hands-on activity in a less structured environment than they usually had in their other classes:

Tom: It's not as analytical for me. It's the one subject that is partially relaxed, you can chill in, but you still learn. Don't have to go through three workbooks a year.

Shin: Don't have to take out a calculator.

\section{Group composing is easier and quicker than composing solo because you can}

share skills and knowledge. The boys said they valued each other's skills and believed sharing these meant that group composing was easier than composing alone.

Shin: Well, I could have write by myself, but it just take time. Me and Jake are quite like. Jake is quite good at guitar and we made up chord sequence and it just easier to make. 
Jake: It's good working with this man right here [gestures to Shin] because he's a very, very good musician ... Everyone has their own way of thinking in terms of musical sense. So with a group composition you can have everyone's input. So it's not just you writing the guitar, the bass, the vocals and everything. You get a mixture and you become this concoction of musical greatness.

5. You can communicate through music not words. Although all three boys seemed to be confident speakers, Shin struggled with English. However, Shin was a fine guitarist and the boys were able to communicate musically:

Jake: English, obviously, is not his [Shin's] first language. You can communicate with him in music. That sounds really clichéd but you can. It's an international language.

\section{Novice composers and less skilled or knowledgeable students are supported}

by the group process. Tom was a novice player and composer. Jake makes it clear that he and Shin enjoyed helping Tom and that Tom learned from the other two boys:

Tom: It was probably better for me to be working in a group for the first one, just because I'd learn some stuff that I wouldn't normally know.

Jake: $\quad$ For Tom, there was a lot of encouragement going on ... You can actually help each other out as well.

\section{The students were not very interested in $A S 91092$ requirements and its}

assessment criteria. There was a copy of AS91092 in their Year 11 Music handbook but the boys did not seem very interested in it:

[VT gives them a copy of AS91092.]

$V T$ : Did you guys get one of these? It says here "ideas have been developed coherently, structured coherently". Does that sound familiar to you at all?

Tom: It sounds familiar, but well ... don't want to be blunt, but whether or not it actually means anything ... [Others: Yeah]

Like the Kotare boys, Jacob, Tom and Shin could not tell me what they had needed to do to achieve AS91092. Jake believed that not focusing on the NCEA requirements for composition gave them the freedom to create better songs:

Jake: NCEA [Music] is really relaxed in what you can do. We needed to write a song, we didn't know how many credits we were going to get out of it, we didn't know really what the criteria was either. We just knew that we had to write a song that was original and based upon a movie or game ... you weren't thinking about it. It's not like opening your book to study. We just need to write a song. 
The Pikachu boys all indicated on the 1-10 scale chart that they were very confident that David had a good understanding of their individual CCP, between $70 \%$ and $80 \%$. Given that they were the only group composers in a class of eight, this is unsurprising. David had assessed their piece as an Excellence, giving them all the same grade. Each boy had then composed a solo piece.

\subsection{Cycle 1. Preparing the students for group composing}

David and I met in January 2012 during the school holidays for a whole-day workshop to plan our collaboration. Earlier, I had lent David my copies of Schmuck (2008), Mills (2007), and Fautley (2010), suggesting he might like to read about practitioner research, and music education assessment. When we met at January he had already read them and purchased his own copies.

We began with sharing our interpretations of the AS91092 assessment criteria. David believed that, based on the overall achievement of the students in the previous year, all of his Year 11 students had the potential to reach at least Achieved standard for their compositions, and so wanted to focus upon Merit and Excellence criteria. We theorised that if students' compositions needed to have stylistic assurance and control to reach Merit or Excellence standard, then group-composing students needed to be able to communicate effectively within a shared stylistic context. We also thought that without this shared knowledge, students might even struggle to compose a piece at Achieved level.

We then planned our first cycle of collaborative teaching and research. I recalled artist model pedagogies I had seen in secondary art classes, where the students were required to paint in the specific style of a certain artist:

What do they do in art? Everyone comes out looking like they've painted a Shane Cotton, because they've taken apart a Shane Cotton painting. If they are working in heavy rock, or funk, or gaming music, or, say, musical theatre, "So you want to sound like Sondheim? Well let's go and take apart some Sondheim and find out why it sounds like it does, get the feel for it". What is that particular flavour? It's almost like cooking something. How do you know it's going to taste that way?

David liked this idea and we discussed the similarities this had to the Musical Futures project, where students were asked to replicate music they liked. David sometimes asked his students to deconstruct a musical style in order to understand how 
it worked, likening it to taking a complex machine apart, or "reverse", or "back engineering”. We speculated that back-engineering might work for us:

$V T: \quad$ What came through really strongly in the research last year was that kids found it quite difficult to articulate how they are doing in their composition if they are unaware of musical structure. So I could imagine in the first few weeks quite a lot of content in terms of style, in terms of structure.

David: I would like to do my musical reverse engineering of songs. We'll reverse engineer a couple of songs.

Back-engineering is a key term in this research. It refers to a pedagogical approach that David and I used throughout our collaboration. This is explained below.

Our shared goal was for the students to gain sufficient understanding of stylistic and musical context and vocabulary to be able to clearly communicate with one another when composing. We believed that if they did so then they would compose stylistically controlled or assured music, and thus achieve at Merit or Excellence level. We rejected the more traditional pedagogical approach of beginning with basic musical concepts and scaffolding the learning towards complexity, prior to composing. Instead, we decided to "throw the students in at the deep end", as David put it, and get them composing from the first day in class.

In the first week of Term 1 we decided that the students would compose in a specific style we chose for them, while encouraging them to acquire compositional tools, concepts and techniques, as and when they needed them.

\subsubsection{Back-engineering}

David and I developed the "back-engineering" pedagogy over three short teaching cycles in the first three weeks of Term 1 . The first two cycles involved the deconstruction of two styles chosen by David: Dixieland or trad. jazz, and 1950's rock n' roll. David used the same teaching strategy for both styles. The aim was to give the students a concept with which they could then "back-engineer" a chosen style, prior to composing in that style. My first observation illustrates the teaching strategies David used for whole-class instruction: 
7 February 2012. David introduces the concept of "back-engineering" a piece of music in order to get some tools for 'making' a piece. Uses example of taking a clarinet apart, then tells story of taking his father's watch apart as a kid and then trying to put it back together again (the boys laugh and say "I bet you got into trouble").

He then links taking apart an object to the concept of a style of genre. This is followed by a q\&a session with students about what is their concept of style or genre.

Plays two listening examples with q\&a after each to deconstruct the pieces: Dixie; chamber music; rock \& roll; swing jazz; pop/latin; pop (Michael Jackson); and r\&b. *suggest to [David] -maybe ask them about the 'feel' of the music? Also the context of the music, what was it for etc?

David has a jokey relaxed style where he uses a robust q\&a technique to get the kids to throw ideas around. Kids seem happy to throw out ridiculous or "out there" ideas about the music (lots of laughing) and David throws it back to them with a humorous comment, until someone in the class gets what he's after. After deconstructing the trad-jazz/Dixie piece some boys are keen to find out more about the banjo.

Gradually he introduces musical terms and signs such as 4/4, tempo words, instrumentation and then starts to create a rough score of the piece on the board. All of the students seem really engaged in deconstructing the form of the pieces, an intense, focused atmosphere.*Will suggest to David that he relates this back to the style that the boys may be choosing.

David arranged the students in groups with at least one melodic, one harmonic instrument and one rhythm section player in each. He asked each group to compose a short piece that replicated as closely as possible the trad. jazz sound, using the structure they had copied down while listening to examples.

Following the trad. jazz exercise (three lessons), David went on to deconstruct 1950 's rock ' $\mathrm{n}$ roll with the students, with the intention of following this with several other styles we had chosen. By then observational data revealed that all of the students (to a greater or lesser extent, depending on their knowledge and skills) were able to generate musical ideas together that sounded something like the style they were emulating, as my observation notes reveal: 
10 February 2012. Boys are all working on their trad. jazz ideas. Some groups are finding that the melodic players have the hardest task, while the rhythm-section gets bored. A few boys are asking others how to play chords. One group has totally nailed it - mainly because the rhythm section boys are disciplined and supportive. Also one boy, [Isaac], who plays jazz trombone very well indeed, has taken a leadership role in structuring the piece and is directing the others. He's doing quite a lot of musical leadership and is quite influential. Boys performed their pieces to the rest of the class. One group (Isaac's) managed a quite good trad jazz piece. [Isaac] acted as bandleader he's clearly had a lot of experience of this kind of music because his body language was spot-on for a jazz bandleader. The others boys in this group seemed very knowledgeable too.

The striking thing about the other performances was that, although many were very tentative and some were frankly struggling with improvisation, all gave it a go. A very safe atmosphere where, clearly, students felt safe to make mistakes and give something a go.

Observational data revealed that the students were also able talk to us, and each other, about the stylistic features of the music they back engineered. David reported that several students asked him when they could compose in styles they had chosen for themselves. These data indicated to us that the students had grasped the concept of back-engineering and so we decided that they were ready to do so.

David gave the students a range of CDs in a wide variety of styles and attached these to a listening post. The students then formed their own groups and chose a style to replicate, using the listening post and their own music as stylistic examples.

By 24 February the boys were group-composing short pieces in specific styles. David and I agreed that this indicated that our first cycle of research was drawing to a close. It was now time to focus upon developing and implementing the first groupcomposing task.

\subsubsection{Written analysis of the chosen style for back-engineering}

The students were required to make notes using the same framework David had used for the first two styles.

\begin{tabular}{|c|c|}
\hline Compositional devices & Form \\
\hline & \\
\hline Terms and Signs & Chords \\
\hline & \\
\hline
\end{tabular}

Figure 6.1. Notes framework for back-engineering a style 
When we collected these, we noticed that some groups had made only minimal notes about their stylistic decisions. We did not follow this up however, believing that to do so would demotivate the boys who, like the Kotare boys, seemed reluctant to write anything about their composing. This decision had considerable ramifications for the first compositions because some groups did not compose in a specified style. This is examined in detail in 6.8.2.

\subsection{Cycle 2. Group composing in a specific style}

We decided to investigate whether or not learning about the compositional process would prove beneficial for David's students. In line with David's usual practice, I formatted the hand-written Kotare version of the model as two studentfriendly power point slides and a hand-out sheet.

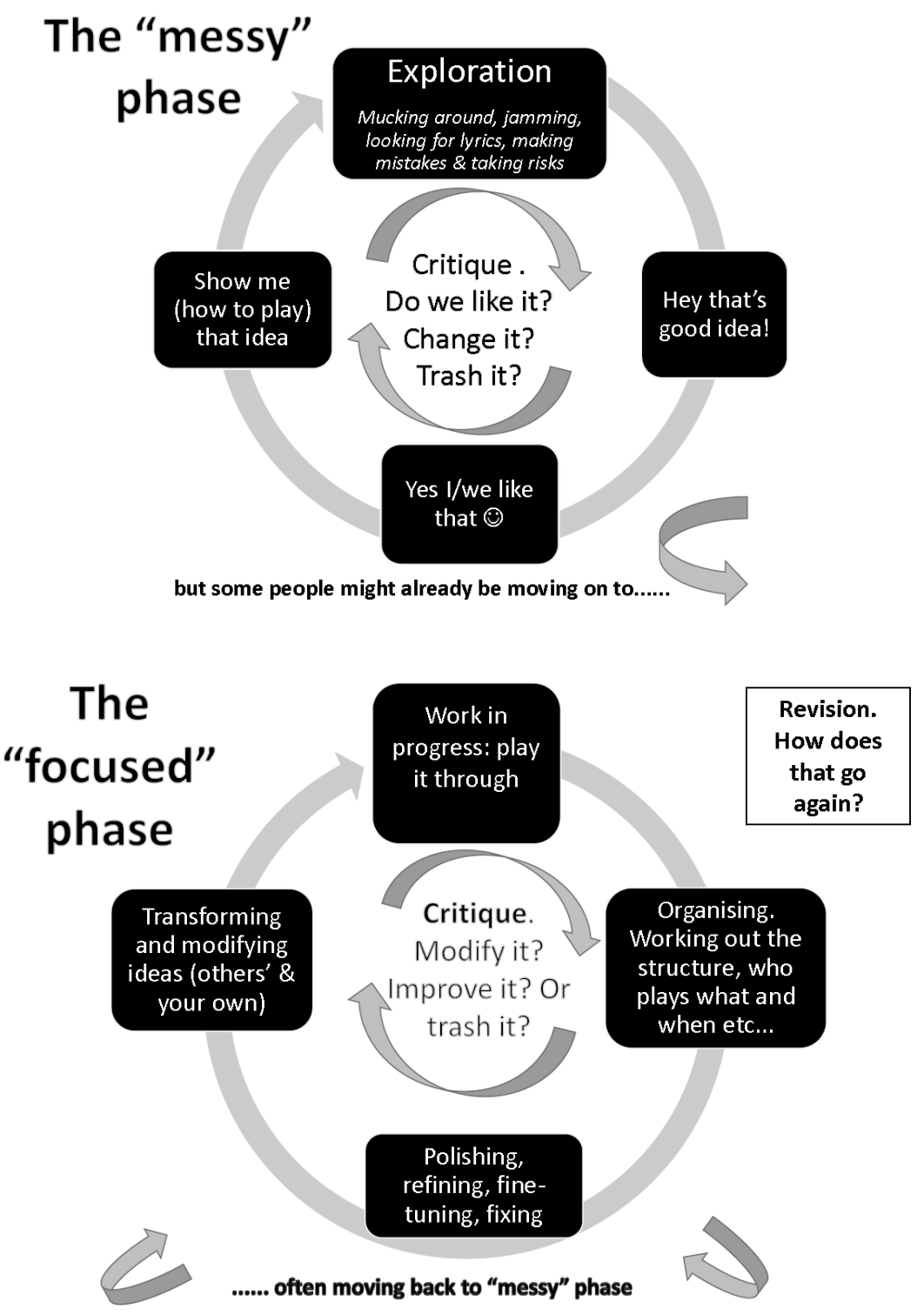

Figure 6.2. Conceptual model: St Bathan's version 
Like the Kotare students, the whole class seemed very interested when I explained the model to them. I had modified the task David and I had written earlier to align it more closely with back-engineering. (See Appendix 6.1.) We read it through as a class and then in small groups and discussed how the requirements of the task aligned with AS91092. The task included assessment criteria based on the Achieved poster Alice and I had developed but also included "sound like the style you have chosen" to encourage the students to compose at Merit and Excellence level:

- Your piece needs to have:

- A clear structure that the listener can hear

- Two or three good ideas that have been developed in some way

- Sound like the style you have chosen

- Be recorded (audio or video)

- Be written down in a form so that other people could play

The $(-=+)$ assessment sheet was already published in the class handbook and so, despite its limited usefulness, we looked at that as well, linking it to the model. David explained that everyone had to fill the sheet in once a week in consultation with other group members.

Eleven students chose to group-compose: Action movies (Rob, Fraser and Angus), Indie-rock (Oliver, Alex and Callum), and Big Group (Richard, Chris, Mike, Josh and Luke). David and I collaborated to facilitate the groups. By the end of Term 1 (29 March, 2012), all of the students in the class had completed either a solo or group-composed piece.

In Term 2, during a second cycle of back-engineering based on film music genres (action, horror, fantasy, and western), David gave the class a slightly modified version of Task 1 . In this task the students were required to clearly specify the film music genre or chosen style they were composing in.

By the end of Term 2 (29 June, 2012), all students in the class had completed at least two compositions, although most had not yet submitted their recordings and written representations. David interviewed the group composing boys about their CCP using the model, and collected their self/peer $(-=+)$ assessment data. During this period, I interviewed the boys in Action Movies and Indie Rock, and also Richard from Big Group. 


\subsection{Cycle 3. Summative assessment}

By the middle of Term 3 (August, 2012), all the students were in the process of completing their written representations. The focus of our research shifted away from composing and teaching to the summative assessment of group composing.

\subsubsection{Assessment practice issue for David}

Although we met on three occasions to grade the compositions, each time David did not have all of the CCP data and recordings to hand, and was reluctant to proceed. My interviews with the students indicated that they might have benefitted from seeing a detailed assessment schedule as soon as they started composing. I raised this with David each time we met but he remained resistant. He seemed very anxious about this. He said that during this period he was very busy, had struggled to find the time to gather written CCP data and did not have many written records of individual student achievement. He also said that he did not regard gathering written data as a priority because he could see that the students were working productively together. I was concerned about the validity of his assessment practice but this was David's decision to make, not mine. I could not give David assessment schedules if he did not want them. Furthermore, if I created them myself there would be no professional learning for him and I would have been doing research "for" rather than "with" him.

David requested that group composition assessments be externally moderated (they were not required that year) and NZQA had agreed to do so. The time for the external moderation submission was looming but David and I had not made any summative judgements. By early August 2012, David was under a lot of pressure from school management to upload his assessments and, like the year before, extremely stressed about it. He seemed very anxious about any form of written material associated with assessment.

While David's paperwork from previous years seemed to indicate that he knew what he was doing, analysis of our discussions revealed that he had been "flying blind" as an NCEA assessor for three years. I was shocked by my assumptions about what David already knew. During Cycles One and Two, our focus had been mainly pedagogical where we had collaborated as teacher-researchers, examining our practice related to student learning and achievement. Furthermore, the collegial ease with which we worked led me to assume he knew more about the NCEA than he actually did. It was I, and not David, who had incorporated NCEA summative assessment 
structures into our work with the students. On reflection I realised that David had avoided engagement with the NCEA whenever he could.

Following a series of crisis talks, we decided to go back to basics with the NCEA before attempting to assess the students' work. David responded positively to the conceptual model so I created one about NCEA assessment structures.

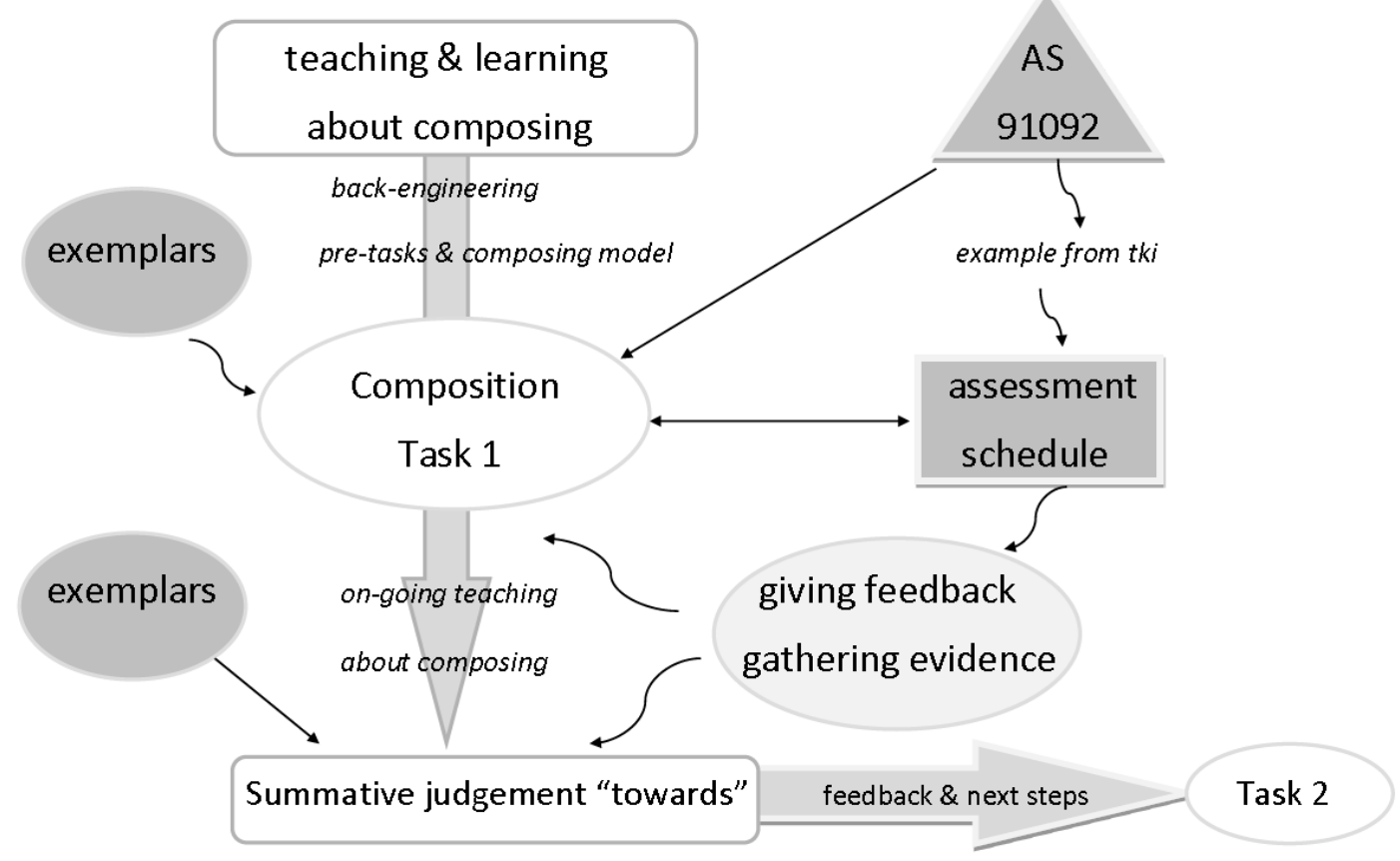

Figure 6.3. Conceptual model of NCEA assessment for composing

David said that this structure was easy to understand because it was connected to the project. He also reported that NCEA internal assessment structures and procedures were now clearer and more real for him. I then showed him how I had adapted some of the exemplar documents available on line to write an assessment schedule for Tasks 1 and 2.

David did not want a teacher version and a student version because he believed that the assessment process needed to be so clear that anyone could follow it. I agreed but kept in mind Fautley and Savage's (2011) caution that simplifying assessment criteria can lead to them becoming meaningless. Therefore I wrote the schedule in accessible language that both he and the students could use, although it was really too late for the students to use it at this stage in the school year. It took careful thought to maintain the validity of the assessment criteria while at the same time wording the schedule in a way that was accessible and clear for the students (see Appendix 6.2). 


\subsubsection{Grading the compositions}

Once David and I had addressed his assessment practice issue, data indicated that his confidence and knowledge of NCEA internal assessment procedures were greatly improved. He graded the compositions and we moderated them together, including his assessment of each boy's CCP. The achievement criteria for composing were embedded in the back-engineering strategy, which was in turn linked to the task. Therefore, we found assessing the compositions very straightforward and were in agreement for all grades because the task and the assessment were already so closely aligned.

The Action Movies and Indie Rock groups composed two pieces each, while two boys from Big Group, Josh and Luke, composed one rap piece together. Josh and Luke, and the Action Movies boys all achieved with Excellence, while all of the Indie Rock boys achieved with Merit.

All of the group-composed works, the composition tasks, all CCP data, the assessment schedules and formative assessment data were submitted to the NZQA national moderator for Music. David included a rationale for why the two assessment tasks were so similar, explaining that the students had not achieved the task very well the first time. He justified this because the single task was open enough for a wide variety of responses over more than one composition. When the assessments came back from NZQA, the task design, judgements and assessment processes were all confirmed as being completely valid.

The moderator wrote:

Overview: The student evidence displays engagement in and commitment to completing the assessment activities. Teacher judgments display a clear understanding of the requirements of the standard. I am highly confident in the assessor's ability to make assessment judgments at the national standard for the sample of student work supplied.

Commentary: The collaborative process for student group compositions has been very well organised by the assessors. Students are made aware from the start of how their compositions will be monitored and assessed. It appears that the resulting compositions have benefitted from these clear assessor expectations. (NZQA, 2012)

I interviewed David about our project and we officially concluded it in December 2012. 


\subsection{Major themes}

As explained at the beginning of this chapter, analysis of the data revealed four major themes. These themes address the two research questions and the three practices of composing, teaching and assessment. Each concerns a central concept arising from the research and related to these questions:

1. Shared understanding between teacher and group composers about valid stylistic contributions to group composing processes: communication through shared understanding of style and genre; and communication through a shared understanding of compositional processes.

2. Teacher lived experience and NCEA assessment practice.

3. Assessing the CCP of low achieving students.

4. Achievement in group composing, and the NCEA.

\subsection{Theme 1: Communication through a shared understanding of musical style and genre}

This theme addresses both research questions and is related to the practices of teaching and composing. This section examines the data associated with the backengineering pedagogy. Its central concept is communication between teacher and students about what is a valid contribution to group composing, in terms of stylistic coherence or assurance.

\subsubsection{Rationale for back-engineering}

As discussed at the opening of this chapter, David's experiences and beliefs about teaching group composing aligned closely to my findings at Kotare. This had led us to conclude that a shared understanding and knowledge of stylistic context might help the students to communicate effectively with each other while group composing. Furthermore, AS91092 required that the students compose stylistically controlled or assured pieces if they were to achieve at Merit or Excellence. The back engineering strategy aimed to enhance effective communication between group composers through a shared knowledge and understanding of musical styles. What follows is an analysis of data related to this theme. 


\subsubsection{Learning to communicate musically within a stylistic context}

Replicating trad jazz was challenging for many, and required intense problem solving for all students. Some found that they were short of melodic instruments such as clarinets to achieve the trad jazz sound they were after. I observed a group of boys discussing their lack of a bass player in their group and how "lame" their trad jazz piece sounded without it. All groups engaged in intense discussions about instrumentation, structure and harmonic sequence. A deputation of students even requested that David purchase a banjo so that they could get the sound they wanted!

\subsubsection{Balancing challenge and skill requires a safe environment}

Melodic players (mainly piano, sax and violin) struggled with improvisation but the classroom environment meant that it was safe for them to experiment and make mistakes:

Observation 9 Feb: Pianist is now improvising on the piano. From the sound of it he hasn't done this before and it's a process of trial and error. Interesting that he's quite comfortable making mistakes and sounding tentative in the public space of the classroom. No one comments - they are all working on their own stuff. He has a friend sitting with him giving advice and feedback (violinist who doesn't have his instrument today). Quite soon you can hear something just recognisable as jazz improv starting to emerge.

David and I wanted to find out more about how the students experienced communicating musically within the context of an unfamiliar style. We wondered if the instrument the students played might have an impact upon these experiences. I developed a data collection tool informed by Byrne et al.'s (2003) use of Csikszentmihalyi's (1988) flow concept (see Figure 6.4). 


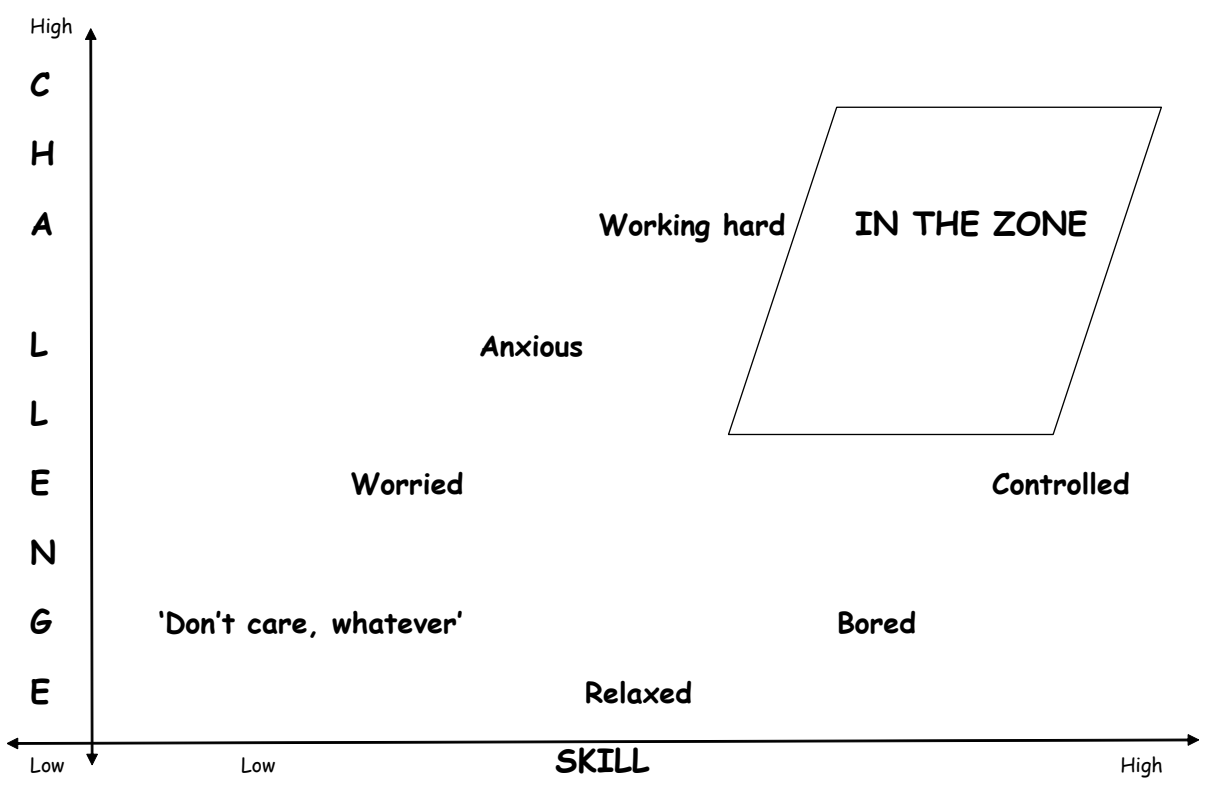

Figure 6.4. The flow graph

Each student in the class was given a copy of this and asked to place himself on the graph (see Figure 6.5).

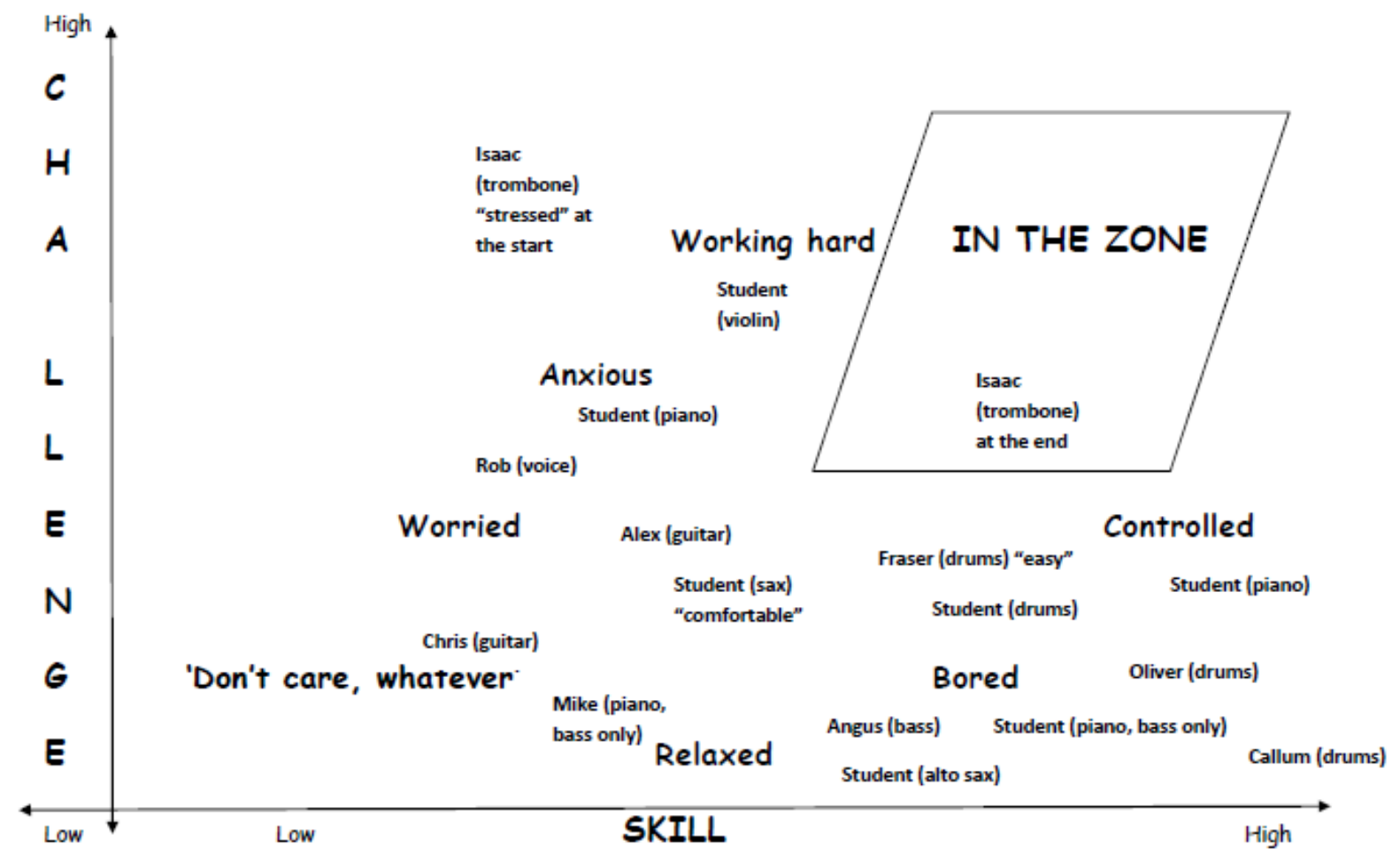

Figure 6.5. Student data from the flow graph

\subsubsection{Instrumental roles require different levels of challenge and skills}

The collated data confirmed what we had observed that, once the drummers and bass players had established the groove or feel, they often became bored while the 
melodic players struggled to improvise. Most harmonic players, guitarists and some keyboard players sat in the middle of this, controlled but a little bored too. Melodic players were the ones who reported that they felt anxious and worried but skilled melodic players who played in the school jazz band were most likely to indicate that they were "working hard" or even, for one student (Isaac), "in the zone". However, students who did not play in the jazz band often reverted to playing in more familiar styles:

Observation. 9 February 2012. One boy plays a heavy rock chord. David calls out "Hey! Off the topic!" and they go back to jazz.

\subsubsection{Back-engineering needs to be in familiar styles}

David reported that most students told him they found the second backengineering task easier than the first because they knew how 50's rock ' $n$ roll was supposed to sound. Our decision to begin with "simple styles" was grounded in our historical assumptions about starting points, derived from musicological studies in our music degrees. While trad. jazz and rock 'n roll represented simple accessible music to $u s$, these styles meant nothing to the students who were not familiar with them, and might as well have been any kind of music:

$V T: \quad$ If you did this again, what would you do differently?

David: I think I would start off with something that they all know and work out how it's put together. Then, for example, the rock band group whatever they decide on we need to look at what they're doing and back-engineer that style. The same with the vocal group, the same with the re-mix-ers.

\subsubsection{For transfer of learning, explicit connection needs to be made between the learning and the task}

When David and I examined the emerging compositions we saw that some students had not transferred their learning about the concept of deconstructing a style to composing in a style of their choice. During an interview later in the year, Callum confirmed this misconception:

It [the first composition task] was easier with the other one because we didn't have to put it in a style. We could decide what the style was afterwards.

David and I agreed that we had not worked explicitly enough with the students when back-engineering in a chosen style. 


\subsubsection{Big Group fail to compose a stylistic piece}

Big Group, had not composed music in a specific style and were very dissatisfied with their piece. David and I videoed Big Group playing it, gathered self/peer CCP data and interviewed the boys about how they came to compose the piece.

The boys had already informally assessed their music because they all told us that their classroom percussion piece did not meet the bullet-point assessment criteria of the task. They thought it was too simplistic and not in any particular style. On viewing the video, David and I could see that the music's lack of stylistic focus and simplicity did not provide enough opportunity for each member of the group to make a significant $\mathrm{CCP}$ :

$V T: \quad$ They hadn't made a connection to a style had they? [No] You have to be so explicit don't you?

David: I thought I'd been explicit enough with that group, but I wasn't. Next time if I see a group still floundering around after two lessons maybe then I have to say "OK let's sit down, let's decide on a style right now and work out what we are going to do" rather than let them go.

We reflected that, while all of the Big Group boys could explain to us the process of back-engineering music, they had not transferred this learning to their composing. We considered why this might be, and listed the reasons:

- The Big Group students were not reminded often enough about the requirements of the task they were working on

- They had not had enough on-going input from either of us when they started to go off task

- The members of this group had diverse style preferences and so could not agree on what style to compose in

- We had underestimated how much help they needed to make this decision

- Some played the same classroom percussion instruments as each other and this did not allow them to extend themselves either as composers or players.

Richard later explained that his newfound understanding of the nature of musical style gave him the insight into why Big Group had failed to compose a successful piece and why he decided to compose by himself: 
They needed me for the piano and so we kind of worked out a song, but we found out afterwards that everyone in the group liked different styles. Chris liked reggae, I was more into maybe ... pop, and the drummer was more into classical. So it didn't really work. There was just something wrong with it because we were trying to incorporate these different styles into this one thing so I just decided that I'd rather make a song in the style that I liked.

We continued with back-engineering for another term so that David could reemphasise the importance of connecting a style back to the composing task. We also paid particular attention to getting the Big Group boys back on track to composing two valid pieces and thus achieving the standard.

\subsubsection{Back-engineering leads to conceptual shifts for students}

Observation revealed that students engaged in an intense, collaborative process of musical problem solving and stylistic exploration when back-engineering in class. We needed to know whether this approach led to better outcomes for group composing and so I asked Action Movies and Indie Rock about this. At first it seemed that they thought it had not been helpful:

Rob: I personally didn't find much benefit out of it because of the fact it didn't appeal to me in terms of the music we did.

$V T: \quad$ The trad. jazz, and the rock and roll?

Rob: Yeah, because when we start doing trad. jazz and we also backengineered music styles, the only one which really appeals for my instrument, like, in my playing style, was the western genre. So I found it not very beneficial because I didn't get much out of it for my instrument.

When I asked them if they were now listening to music in a different way however, the response changed. All of the 2012 participants reported that backengineering led them to hear music in terms of its stylistic constituents and to then apply this knowledge to their composing:

Fraser: Actually, it did teach you about music.

Angus: I'm kind of new to some instruments. I've been playing drums for five years and guitar for one year, so I'm not actually that well versed in that kind of thing but it's really helped me to understand it a bit more, how to compose different styles and what the difference between different styles are and that kind of thing.

Rob: It teaches you what goes together and how to kind of influence a song to be a typical, a specific genre. It was the main thing because usually I'd play something and I'd just kind of think, well that's rock because it sounds like another song or that's pop because it sounds like another 
song, but now you can actually identify all the things and say it's actually a completely different thing.

Fraser: Yeah and like how you can layer certain things. A few years ago I'd probably have thought violin was classical, straight off. Or if I listened to westerns, "there's no way that's a violin, it can't be", whereas now you can listen to it and be like, "that's a violin, that's this, that's this" [pointing] and with those you can create something. With a string quartet you can make a horror song or whatever. It doesn't have to be some slow piece.

It also influenced how they listened to music in their daily lives:

Angus: One thing I did find quite interesting about the back-engineering thing is that now I sit in the car listening to music and I kind of make it a mission, if you hear a song over and over again on the radio, I make it my mission to identify all the different parts of it. I'm trying to figure out all the different instruments, which I never used to do because I always used to be like, "this song is horrible, I want to zone out and go to sleep". [BSIAM]

Richard: Coz now I kind of listen to those things that make it the genre. I was watching a horror movie the other day and I was just listening to those semitones and thinking "oh yeah, that works really well". [BSIR]

Rob believed that it also gave him the tools to be a more critical listener:

Rob: I'm so much more critical of music now and it's ridiculous. I can now tell, that's auto tuned, that's obviously auto tuned, that's made by a computer. It's like you're thinking about it, it kind of ruins music for you in a way, but it makes it better at the same time because if you find a song that you really like you can appreciate it more.

\subsection{Theme 1: Communicating through a shared understanding of compositional processes}

In this section, the second aspect of Theme 1 is examined in relation to data associated with the conceptual model. The concept of communication between teacher and students about CCP is linked to valid assessment practice on the part of both teacher and students.

\subsubsection{Using the conceptual model}

The Kotare data suggests that a shared understanding of a conceptual model of composing provided a framework for group composers and their teacher to discuss the nature of valid contributions to group composing and its assessment. This was also the case for the St Bathan's analysis. There is evidence to suggest that the model was also a self-assessment tool for students, creating conceptual pathways to achievement. There is also some evidence that at least one solo composer found it useful too. 
Interview and observational data reveal more complex student responses to the model at St Bathan's. This does not mean that the Kotare boys' responses were not complex, merely that the St Bathan's students were generally more articulate about their experiences of learning and could tell me more about them. It also may be that I was now more familiar with how the model might be used, and asked more of the right questions.

\subsubsection{Student responses}

The students said they liked the model because it gave them permission to muck around, be messy, unfocused and seemingly without direction, while reassuring them that they were still on the path to achievement. It also helped them to identify where they were in the compositional process so that they were able to know where to go next. It provided them with a platform on which to build their song as well as a shared understanding of structure within which they all could work:

Angus: Because it kind of put less stress on you because you knew that what you were doing was actually working towards something. Because usually you sit there and you start jamming and you think "I'm not coming up with anything, I've got a composition due in a month, it's for my NCEA mark, if we fail it we lose these credits and it's a big amount of credits". With that [model] you can say, "Well we're in the messy phase, we're getting ideas, we are getting somewhere" and you can build on that. Also you kind of know where to go from there, so you can follow a cycle and you know what steps you're actually in and what to do next and build on. So it kind of gives you a schedule of writing a song. [BSIAM]

Callum: It showed us what we were doing. And how close we were from getting it right.

Oliver: You know, how to get there, on the right path. [BSIIR]

These data also suggest that Callum, Oliver and Angus believed that the model reassured them that they were engaged in a process leading to composition completion. The notion of divergent and convergent processes seems to have been particularly useful once the initial ideas had been generated and the piece started to sound good. It also seems likely that the students used the model terms while they were composing together:

Fraser: We were struggling to figure something out. So he started playing that riff again and it was, "hang on, we could use that" and that clicked it into the end of the messy phase. [BSIAM] 
Alex: When we were jamming we were really quite messy but in the other room we were focused - writing it out and stuff. Yeah, we generated all our ideas probably in the practice room, not the classroom.

Oliver: I refined Alex's riff.

Alex: $\quad$ Yep, he critiques it. [BSIIR]

Angus seemed to associate the "focused phase" with NCEA achievement:

The focus phase is kind of when you think, "Oh, we've got something here". Then you can go on because that's when you know that this is something you actually want to build on and you actually want to focus on and do it more for fun than just getting an Excellence, and that's when you hit the focus phase.

Richard from Big Group said that he found the model useful for solo composing:

Richard: Like I know where I am now. I can work out where I am with my songs.

$V T: \quad$ How does that help you?

Richard: I know what I need to do to make it to the next step.

\subsubsection{Using the model to give feedback}

Like Alice, the model reassured David that messy and unstructured student work was a valid contribution to creative processes and not time wasting. He also said that the model allowed the students to explain to him what they were doing:

Now that they know that jamming is part of the process, it gave them permission to do it and they were able to tell me exactly where they were in their task.

The model helped David to interpret the complexities of CCP within a group to give targeted feedback:

Some of them would say "we're almost out of messy, we're almost at the point of getting focused now". Or two of them would be getting into focused but one part would still be in messy because they are still trying to work it out. So that gave me a very clear idea of where they were at and them too, which meant that my feedback could be a lot clearer and a lot quicker and a lot more tailored to exactly what they each needed to do to achieve. They knew all the way along how they were going.

\subsubsection{David transfers this learning to other aspects of his practice}

David found sharing the conceptual model with students so effective as an aid to effective self, peer and teacher assessment and goal setting that he then transferred the idea to other parts of the curriculum: 
I'm trying now to put this into all my other parts of my teaching because, if a boy can say to me, "I'm at this stage of this and I'm at this stage of that", then they're thinking about what they're doing and their process and they're not just floating along with no idea. It spills over into group performance and that's going to be spilling over into my ensemble, conducting as well, because I can say, "OK guys, we're at the building stage with this piece. We're learning the notes, we're learning the rhythms. We're at the interpretive stage with this piece and we're at the performance stage with this piece. So what do we need to get from here, to here, to here?"

\subsubsection{Student progress is more clearly identified and reported}

David found that using the model gave him a much clearer idea about student progress generally, relieving his anxiety when communicating with parents and school management about student achievement:

I got to the end of last term [Term 1, 2012] with a sense of relief, but not relief of "thank god it's over" but a sense of "wow, that worked really well!" Everything worked really well. I actually felt really comfortable with where we were at and not "oh my god, next term we've got to do all of this". It's across the board, because I've been incorporating bits and pieces of this into all of my NCEA teaching. I got to the end of last term with a sense of satisfaction and a sense of comfort and not panic. Since I got to this country I haven't felt this comfortable going into a new term. Parent/teacher interviews with those Year $11 \mathrm{~s}$ were fantastic because I was able to, for most of them, say, "Well, look your son is at this level. He's composing at an Excellence level at the moment and he's just had his mock [performance] exam and alright he got an Achieved, but this is exactly why". To have the parents and the boys go away feeling happy about that was a first for me at this school.

\subsubsection{Verifying and assessing $\mathrm{CCP}$}

The students filled in their $(-=+)$ sheet regularly and, like Alice, David found these data useful for verifying participation, but not for assessing CCP. On-going discussion and verbal feedback using the model generated much more meaningful CCP data. David video-interviewed each group about their CCP for each composition, asking them to "tell me the story of how you composed your piece".

\subsubsection{Using the model to assess rhythm section CCP}

David reported that the model proved very useful for assessing the CCP of Callum, the Indie-rock drummer. Initially, the boys told David that Alex and Oliver had contributed the most to the composition, casting doubt on the validity of Callum's CCP. Using the model, David discussed this with the boys:

David: When I explored this further they actually realised that at the very beginning Callum wasn't contributing but he contributed later on in the process. So at first it was like "Oh yeah we did most of the work", and then, when we explored the process and went down into the perfecting stage, they realised that Callum had put quite a lot in but it just came later. 
$V T: \quad$ Because he's the drummer?

David: He's the drummer! Yes. Exactly. The model was very useful because if we hadn't had it, if I had just said to them "OK, what was the process of your composing? How did you start off?" it would have begun and ended with that initial conversation and Callum would have ended up looking and feeling like he didn't do anything, like he hadn't achieved. But when I talked about the model, and we went past the jamming phase into the polishing stage, then that's when Callum realised that was when he was doing the work and the focus changed within the group. That's really helped because we would have missed that.

Therefore there is considerable evidence to indicate that conceptualising composing as a model has potential as a tool for helping students and teachers identify valid CCP within specific group composing contexts.

\subsection{Theme 2: Teacher experience and NCEA assessment practice}

This theme addresses the second research question and the practice of assessment. Its central concept is that a teacher's life experiences can influence and shape assessment practice. It examines data on how David's experiences of assessment as a learner influenced his teaching and assessment of group composing.

\subsubsection{Conceptions of assessment}

When asked to bring an object symbolising composing and assessment to the first interview, David brought a flower inside a cardboard box:

That is creating, and that's what composing means to me. It's an act of creation. It's one of the best things you can do, creating something, and that's what composing is. I guess that's why I have such a philosophical issue with marking creation because I could mark this flower. There's a few imperfections on it, and it's not exactly perfect, so that's probably, like, a "7 out of 10 flower", you know what I mean? But you can't do that! It's a flower and the same with composing in my mind.

David's assessment symbol was the (now empty) cardboard box. For him, assessment meant the act of summative evaluation and grading. He believed that it was wrong to grade the product of a creative act like composing:

Assessing composition is like an empty box. I don't think you can actually assess something that's creative like that. I think it's the process that we should be focusing on, the actual journey and not the end result, because the end result is so subjective ... you can't assess the final product. I just don't believe you can and that's my philosophical dilemma every time I mark a composition.

David believed that grading the CCP and compositions of novices might have a negative impact upon self- belief and the motivation to compose: 
When you assess a creative process at the end of it, the end result, you run the risk of affecting the creator's self-esteem and the creator's ability to create. They might have created something that's wonderful, but it may have a few technical things and, because that's the final assessment, they might get a low mark, because there's some technical things wrong. Instantly they think, "Oh, well, I'm a terrible composer." And yet in the longer journey, they've probably learned a hell of a lot and they may actually come up with something that's really good.

When I asked him if he viewed assessment as part of the learning process, David conceded that assessment might have a part to play in learning but was still uncomfortable with the notion of grading compositions against a benchmark, believing that a student's grades should reflect the amount of progress he had made within that specific context, rather than how well he performed against a standard. This had brought David into conflict with school management on a number of occasions, including during a recent professional appraisal:

When my lesson was observed, I had a boy in the class who has been learning clarinet privately all year and was playing some really lovely stuff. Another boy had only just taken up keyboard for the first time, and had just learned to play two hands, a very simple song, but there was a huge progression. I marked him with the same mark as the clarinet player. That's where I got in trouble. I actually got told off for doing that and he said that, "You can't do that! Obviously there's favouritism in your classroom," and I said, "Well, it's not

that at all. I'm marking them individually by what they've done, not compared to anybody else."

During the workshop in January, David and I created a draft composition task based on the requirements of the achievement standard. Once the students were composing pieces for AS91092 however, David seemed reluctant to give the written assessment task to the students, or even share the achievement standard with them. While he agreed that I could do so, he seemed very anxious about it. He also told me that he did not want the students to see a formal assessment schedule because he was concerned that they might just work towards the task and that this would inhibit their learning:

Sometimes when you open the black box up and show them what they need to do then that's all they work towards. They don't actually go any further.

When I commented that assessments for qualification, such as the NCEA, exist to meet the needs of society as well as individuals, David conceded that this was a fact of life but continued to avoid summative assessment.

\subsubsection{Stress, workload and NCEA assessment requirements}

As the research proceeded, I became increasingly perplexed by David's avoidance of summative assessment, particularly when it came to written records. 
Between March and June 2012 David's workload and stress increased dramatically when he hosted an international youth orchestra and an independent schools' conference, directed the school show, dealt with problems with the new building, and unexpectedly stepped into the role of Head of Performing Arts, often while battling the 'flu.

By early August 2012 it was quite difficult to make contact with David and he cancelled a number of meetings. I concluded that he had "gone to ground". After several requests from school management for the grades and assessment materials, these issues became too urgent for David to ignore and he contacted me, asking for help. As explained earlier, we were soon able to ameliorate this situation and move on.

I reflected, "why is such a skilled and highly reflective teacher avoiding these aspects of his practice?" I suspected that there might be deeper reasons other than being stressed, or disliking paperwork, or even, as he had said, being philosophically opposed to summative assessment. I returned to the data for possible insights into this.

\title{
6.10.3 Lived experience as a learner of summative assessment
}

During an interview about experiences and beliefs about assessment, David told me about being tested as a young boy.

\begin{abstract}
When I was in Grade 7 my parents wanted me to sit a scholarship exam to go to a private school in the UK. So they got in a tutor who tutored me specifically for this exam and so we spent ages and ages just doing practice exam papers. So I knew exactly what was in the exam, and I passed the exam really well. But that was all I could do. When I got to the school I didn't have the other skills around it. All I could do was pass that exam. I got $99 \%$ and a full scholarship but when I got there I was floundering.
\end{abstract}

I asked him whether he thought that this experience might have left him with negative feelings and associations toward summative assessment. He gave this some thought and came to the conclusion that it significantly influenced his feelings about testing and grading.

I'd never even thought that it resonated through my whole life until we started doing this whole process. Till I started reflecting back, looking at my attitudes and the way I viewed things. And, well yeah, it definitely, definitely has rippled on through my life.

It seems likely, therefore, that David masked his anxieties with his practice philosophies. Moreover, unlike teachers in larger departments at St Bathan's Collegiate, David had no colleagues to talk to about NCEA assessment in music 
because the other music teacher only taught juniors. David had few opportunities to meet with other music teachers to moderate his assessment and this meant that he could usually hide his lack of NCEA knowledge.

\subsubsection{Improved NCEA knowledge leads to greater confidence and better practice}

Once David had gained some insight into reasons why he found summative assessment problematic, he quickly addressed the shortfall in his NCEA knowledge. While his overall assessment philosophy has not changed, from this point onwards his confidence and ability to address NCEA requirements was greatly improved, not only for NCEA Level 1 composing, but for all of his NCEA internal assessments.

His belief that written feedback was unhelpful has changed too because, in a discussion in June 2013, David reported that he now routinely gives his students written feedback on their compositions, based upon the AS91092 assessment schedule I devised. He now uses this schedule as a template for all of his NCEA programmes:

I feel a lot better about it [NCEA assessment] this year because I'll be able to provide a really clear step-by-step process to the moderator so they can see exactly how things have gone. I'll be able to justify the marks I've given, much clearer, because they'll be able to see, this is Excellence. Why is it an Excellence? Because they've done this, this and this. Unpacking the standards, actually, physically doing the assessment marking I feel more confident about using the criteria, I understand it better now. It's definitely not as scary. I don't necessarily like it though. I think there are better ways.

The implication for practice here is that music teachers like David are often very isolated and so do not always have access to professional support that they need for valid assessment practice. Alice too was isolated. This professional issue is discussed in Chapters 8 and 9.

\subsection{The relationship between task design and valid assessment}

When asked about $A$ S91092, all student participants told me that, in order to "get the credits", they needed to record two compositions and create some kind of written representation. All knew that without high quality written representation they could not achieve an Excellence because these criteria were specified in their two composing tasks:

Angus: You've got to have your written music, recording and pretty much you can hand in, well those are the two things you definitely need. But what you do within those brackets is up to you. Like, for our first piece 
we could have written down the lyrics, just have the chords above it and handed it in and that would have been fine but not necessarily would get us Excellence.

However, no one could tell me what a Merit or Excellence composition was like because they had never heard one. Nor had they seen the assessment schedule at this point:

$V T: \quad$ If you all had to give yourself a grade, what would it be?

All: $\quad$ Excellence! [laughter]

$V T: \quad$ Yeah, but honestly now, not joking ... what would you give yourself?

Alex: I don't know what to mark it against coz I don't know. This was my first composition ever so I don't know what good is.

When I asked them if they would have liked to have assessment criteria, like Blues Rock and Pikachu, they did not seem very interested. Most commented that the phrases like "coherently develop and structure musical ideas" had no meaning for them.

\subsubsection{Actual assessment criteria for group composing}

The NZQA moderator made the assumption that the assessment schedule, submitted for external moderation, had been shared with the group composers from the beginning of the year, when in fact they had only seen it late in Term 3. I asked David that, if the boys had been given an assessment schedule and had heard some examples of previous work (Pikachu, for example) earlier in the year, might they have been more interested in engaging with AS91092?

David reminded me that if the group composed in a specific style, then the style itself would act as their exemplar. After all, this was the rationale for our backengineering pedagogy and we had ample evidence to suggest that it had supported the group composers to create stylistically controlled and/or assured music. He pointed out that the students had not needed an assessment schedule to successfully compose two pieces because the tasks required responses that met the AS91092 criteria for Merit and Excellence. Even if the students had not managed this very well they were nevertheless scaffolded towards the grade of Achievement by the task itself.

What might have been the outcome if the students had seen the student-friendly assessment schedule earlier in the year is unknown. These findings seem to indicate 
that sharing a detailed assessment schedule with students may not be strongly correlated to high achievement in AS91092.

\subsection{Theme 3: Assessing the CCP of low achieving students}

This theme addresses both research questions and is related to the practices of composing, teaching, and assessment. Its central concept is the relationship between summative assessment and student confidence. It examines data related to the summative assessment of low achieving students' CCP.

\subsubsection{Shared skills and knowledge in group composing}

Some students chose group composing because they did not believe they had the instrumental skills and knowledge to achieve alone:

$V T: \quad$ Would you possibly compose by yourself?

Oliver: Possibly. But it would have to be on guitar because my trombone skills aren't that good at the moment. I could write out the piece of music. I could write it out but seeing as I'm not as good a performer then it would be kind of harder to see if it sounds good together.

The students recognised that some instruments limited a solo composer's ability to work alone, particularly the drummers. As has been discussed earlier, the model allowed the boys and David to recognise that drummers could make a significant $\mathrm{CCP}$ :

Alex: $\quad$ Yeah, he [Callum] builds it up and takes it down. Coz you can't really do that on the guitar. You can't stop and turn up the volume on the guitar but you can hit it harder on the drums. [BSIIR]

Rob: Without that [Angus' drumming] we wouldn't necessarily have the tune because one thing I'm working on, on my guitar, is timing and Angus as a drummer he's kind of, not necessarily as good as Fraser, but he got the beat for the start so when we came in this year we knew what beat and what kind of rhythm we had. [BSIAM]

\subsubsection{Validity: Written representation by only one group member}

Most of the St Bathan's student participants created written representations of their compositions together. On examination of the completed compositions for David's Year 11 class in 2012 however, Josh and Luke (former members of Big Group) composed two rap pieces for which Luke received a Merit grade. Josh created the accompaniment using Garageband loops and some of his own musical ideas, while Luke composed the rap itself. Josh went on to compose two solo pieces for which he was assessed for AS91092, and only presented one of his group-composed pieces for assessment whereas Luke's grade was derived from the two collaborative pieces. It 
seems likely therefore, that Josh group-composed with Luke to ensure that his friend could achieve the composition standard. I emailed David and asked what he thought:

VT's email: Would Luke have been able to do one on his own without Josh?

David's reply: Luke has the lyric writing skills but is not strong in actually creating the accompaniment yet. It will be interesting to see how he goes next year, without Josh ... I think that is exactly true. It will be a priority next year to start to give students like Luke the skills to become independent song writers. [Email communication 23 November, 2012]

Nevertheless, David awarded both boys a Merit grade, which was subsequently accepted by the national moderator.

\subsubsection{Big Group fail to compose a valid piece}

There is evidence to suggest that in some circumstances, grading CCP might be detrimental to a novice's confidence and achievement. The Kotare data suggest that Aaron might have been de-motivated when his lack of CCP and potential NotAchieved grade was brought to his attention. Sarah was concerned about this too. While all of the St Bathan's students achieved AS91092, initially one group of students did not.

When reviewing progress at the end of Term 1, most students in the class seemed on track to compose pieces at Merit or Excellence level but Big Group's first composition was not successful and clearly a Not-Achieved. David and I considered how we might share this news with the boys. David was concerned that a Not-achieved grade might negatively affect their motivation and confidence, particularly Chris who was a beginner musician:

For some of them who already know that they are good musicians, like Richard and Mike, they'll lift their game because they know that they can. For someone like Chris who's never done this before, that's going to reinforce the idea that this is hard. I'm conscious of that. This is a practice run.

As Alice and I had decided to do with Jay, David and I gave the boys informal, verbal feedback on their composition, telling them that we regarded this as a practice run. David then gave the boys feed-forward on how they might improve their composing, along with a strong reemphasis that they must compose in a specific style. He reported that the boys seemed to accept the informal feedback as a "so far, so good" progress report, rather than a grade. All of the boys successfully composed two more 
pieces, but not in Big Group. This was because, following David's informal feedback, the boys recognised that Big Group was not a productive grouping.

\subsubsection{Implications for teacher practice}

David and I viewed the video of Big Group's performing their composition and noticed that Chris was sidelined to play a simple repetitive rhythm on a single drum, rather than his usual instrument (bass guitar) while more skilled and confident boys played similar but more complex material. The group was clearly too big for a novice student like Chris because the others did not need his input:

David: I think that Chris needs to be in a group with two other boys who will lift him up. Whereas I think in that group it's easy for him to be just sort of shunted off to the side and I think that's what happened.

Chris had very similar skills and knowledge to Jay in Blues Rock. If he had been group-composing rock music as the sole bass player, then he, like Jay, might not have been sidelined because his part would have been necessary to compose in that style.

It is not known what would have happened if Chris had been given a formal, written Not Achieved grade but with David's encouragement, Chris used computer software to overcome his lack of instrumental skills and eventually received an Excellence grade for two solo-composed digital pieces. The implication for teacher practice here is that, if grading the $\mathrm{CCP}$ of novices or low-achieving students is timely and carefully managed, then students can go on to achieve without any apparent blows to confidence or achievement expectations. This is in stark contrast to what happened for Aaron at Kotare.

Following this episode, David made some modifications to his teaching practice, deciding to ensure that novices were not in groups where they could be lost, but rather, worked in a zone of proximal development with one or two more skilled and knowledgeable peers.

\subsection{Theme 4: Achievement in group composing, and the NCEA}

This theme addresses both research questions and is related to the practices of group composing and assessment. Its central concept is student and teacher expectation of achievement in group composing, and the NCEA. It examines data related to David 
and his students' perceptions and beliefs about what are valid contributions to group composing, and how these relate to NCEA achievement.

\subsubsection{Achievement expectancy of the whole class}

The St Bathan's students all shared an expectation of high achievement in music. Once all Year 11 students had completed the first composition task, I gave the class the same tick sheet questions I had given the seven Kotare group composers I had interviewed ( $n=19$ ). Like the Blues Rock boys, 75\% (15) of the students indicated that achieving AS91092 and getting either Merit or Excellence was "very important" to them, while $25 \%$ indicated that it was "quite important" to them. Only $40 \%$ of the class (8 students) indicated that composing a "really good piece of music" was very important to them, $50 \%$ (10) felt that this was "quite important" to them, and it was "not very important" to $10 \%$ (2) students.

As has been explained in Chapter 3, I added new questions related to "doing my best" and "doing just enough" to achieve in the NCEA. Ninety percent of the class aimed to "do their best no matter what" in the NCEA, and aimed to get an endorsement certificate for NCEA music which requires substantial achievement at either Merit or Excellence across most of the music NCEA achievement standards. Sixty five percent of the students were aiming for Excellence in all subjects. Only 10\% (2) of the class indicated that they were aiming to "do my best in some subjects".

Most (85\%) found the first composition task "challenging but achievable". Two students thought it was "easy" and one student found it "challenging and almost too hard". Significantly, all students predicted that they would be able to achieve the next task, with 10\% (2) believing it would be "easy", and 10\% (2) believing it would be "almost too hard".

\subsubsection{Achievement expectancy of the research participants}

At no point during the St Bathan's research did either the students or David mention the possibility of failure to achieve the standard, other than Angus who implied that this is a serious matter:

You think, I'm not coming up with anything, I've got a composition due in a month, it's for my NCEA mark. If we fail it we lose these credits and it's a big amount of credits.

During the student interviews the boys referred to Excellence 44 times in relation to their own or group member's NCEA achievement. This is in stark contrast 
to the Kotare boys who only mentioned Excellence four times, and then only twice in relation to Jimmi's actual achievement.

Analysis of a discussion with Big Group reveals a connection between hard work and achievements:

$V T: \quad$ The other stuff is about stylistic control. Does it sound like what it is, if you know what I mean?

Richard: Maybe not yet but if we work a bit harder, maybe we can get there.

David shared this view and expected all of his students to achieve:

All of the kids in this class aren't at risk of not achieving because they are all gifted, talented kids. There are a couple who if they don't achieve, it won't be because they lack ability, it will be because they haven't got their shit together. They'll be the ones I want to watch.

\subsubsection{Student beliefs about high achievement and group composing}

Some St Bathan's boys believed that composing in a group gave them a better chance of an Excellence:

Angus: If three people say something's an Excellence rather than one, then it's obviously, going to have a lot more chance of being an Excellence. If someone's thinking it's Merit, then you're going to be thinking, "I want that Excellence. What can we do to bring this up in his opinion?"

All of the students interviewed believed that a classroom environment where they had a high level of freedom, and choice, as well as multiple opportunities for collaboration, produced optimal conditions for high achievement:

Angus: I learn a lot better if I figure out things myself and kind of analyse it and do it my own way. In Music you can kind of make your own decisions and what you want to do. I find it a lot better.

Some indicated that they liked being responsible for their own achievement in group composing.

Alex: $\quad$ You get more independence. Because you're controlling what you're doing I guess. You're not waiting for the teacher to tell you what to do. They give you the guidelines and then you have freedom to make what you want out of it.

Oliver: You have a week of freedom and then you have to front up with something. [BSIIR]

Angus: In music composition you manage your own time. [BSIAM] 


\subsubsection{Achievement and the St Bathan's Collegiate environment}

Data analysis shows a strong correlation between expected and actual student achievement. In 2012, as predicted by the students in the questionnaire, 19 out of 20 students achieved AS91092 at either Merit or Excellence level. The student who did not achieve was an international student who chose not to submit work prior to his return to China. The Pikachu boys, who did not participate in the practitioner research, all had high expectations of achievement in NCEA Music and so it seems likely that this is a feature of the learning environment in which the research took place, rather than the intervention itself.

I suggested to David that his students probably would have achieved well without our collaboration but he disagreed, saying that student achievement in composing would have been lower without back-engineering and conceptual knowledge about creative processes. He believes that these two pedagogies have led to significant gains in student achievement at all year levels, particularly for less confident, experienced or knowledgeable students:

$V T: \quad$ If we hadn't done this project, do you think that the achievement would have been any different from how it turned out?

David: Oh yes! I think that group composing for young musicians who are inexperienced with composing is such a great confidence builder and such a great tool for helping them to learn to compose, as opposed to sending them off to do it by themselves.

While it is not possible to verify these beliefs, there is evidence that some students, such as Chris, Callum and Angus, might not have achieved the standard, or possibly not have achieved Merit or Excellence, if David and the students had not been able to use the conceptual model to uncover their contributions to the creative process.

\subsubsection{Group composing is about more than just NCEA achievement}

David believed that once they were in focused phase, the boys' motivation to complete their compositions seemed to be more about artistic fulfilment than NCEA credits.

I've noticed that, initially when we started it was "am I going to pass this?" but as they get more involved in the process they forget about that and they just focus on writing a good piece of music. When I interviewed Action Movies that's what came through for both of their compositions. It was more about creating something good, creating a good song. 
Analysis of student data also suggests this. For example, the Action Movies boys said they would have been composing songs whether or not their music was assessed for the NCEA:

Angus: We're doing it for fun because we come in here every lunch time. If music wasn't a subject I'd be coming in here every day anyway.

Some students said that they chose group composing for the satisfaction of creating music they liked:

Angus: You know that this is something you actually want to build on and you actually want to focus on and do it more for fun than just getting an Excellence. [BSIAM]

Callum: I wouldn't put it on my iPod if I heard it, but if I knew that I had made it, then I might. [BSIIR]

On the other hand, the Indie Rock boys believed that composing was hard to do, and not the soft option their peers seemed to think it was:

Oliver: It's not really regarded as an academic subject. People often regard it as a "drop" subject, but I'd like to see them compose a piece.

Callum: If you're looking for a "drop" subject ...

Oliver: Don't do music.

\subsubsection{Altruistic motivations: supporting others to achieve}

Like Jay at Kotare, Tom, the novice musician and composer in the 2011 Pikachu group, gained a great deal of confidence from the support he received from the more skilled and knowledgeable Jake and Shin. Jake and Shin also indicated that they really enjoyed helping Tom to become a better composer and musician. Similarly, the Action Movies boys said they chose to group-compose because Angus, the drummer, would not have been able to compose by himself:

Angus: One of the reasons we're probably not all doing solo is because I can only write lyrics. I don't play any other instruments. I play a bit of drums but it doesn't help you when you're trying to find like a riff or something.

Similarly, the Indie Rock boys recognised that their drummer Callum could not have composed a piece without the musical support of the group:

Callum: I can't really compose a piece on drums.

$V T: \quad$ So you need each other to compose together?

Oliver: Callum needs us. 
It seems likely that the boys in both groups were, in part, motivated to group compose in order to support peers to achieve who might not have done so otherwise. This illustrates, once again, the practice tension between achieving valuable outcomes for low-achieving students and NCEA assessment validity for AS91092.

\subsubsection{Open-mindedness and tolerance of friends' different tastes}

The Action Movies boys each had different musical tastes but had made new friends through group composing:

Rob: Angus and I never talked last year or the year before really and now we're hanging out every lunchtime, jamming to music and it's just really good for establishing friendships, getting to know other people.

Fraser: We're completely different from each other. He [Angus] likes kind of western, country kind of stuff and he [Rob] used to like death metal.

Angus: He [Rob] listens to, like, the most scariest music ever!

The boys' shared understanding of the nature and diversity of musical styles they had learned about through back engineering allowed them to accept each other's different personal tastes and work together.

Fraser: It makes yourself more open to other types of music, Like before, I mean, I will admit when I started and I knew he [Angus] listened to western, I was like ... [pause]

$V T: \quad$ You were a bit judgmental?

Fraser: Yeah, but now, especially since we did that western thing with $\mathrm{Mr}$ [David]. It's interesting the way different instruments and stuff work and you grow into liking it and it makes you more open about different types of music.

Rob: When you do group [composing] you learn a lot more about styles of music and you can learn to appreciate more and get along with people.

In contrast, however, the Indie Rock boys shared the same tastes and so did not have to negotiate a style in which to compose. They believed that it was important that everyone liked the same style of music.

Alex: Otherwise you'd get a stupid piece. Someone that likes classical music, and someone that likes heavy metal then it would just sound horrible.

This was not the case for the Action Movies boys. Their choice of style (a tongue-in-cheek indie rock song about action movies) became a neutral, common ground for composing: 
Rob: Our tastes are kind of serious, like mine ... pretty heavy stuff, obviously. Fraser's is completely different and Angus's is different again and yet when we mix that, most of our songs are kind of comedic, or indie rock sort of stuff which is nothing compared to what we usually like.

Contrary to David's belief that students who did not share similar tastes could not work well together, the Action Movies boys believed that their collaboration was successful because they were good friends who wanted to work together, not because they liked the same music. They recognised that the diversity of their personal tastes encouraged them to accommodate different ideas and musical perspectives so that they could get the job done:

Rob: The thing you really need to have is flexibility. If I pick up a guitar it's always going to come out kind of distorted, heavy power riff sort of thing, except when I'm actually playing I've got to kind of figure out that's not going to happen because that doesn't really suit Angus's style or it doesn't suit Fraser's style necessarily so you've got to kind of adapt to other people.

The practice implication here is that positive interpersonal and social factors can lead to students overcoming their differences in order to pursue a shared goal.

\subsubsection{Flow}

Some students said they got enjoyably lost in the creative process, and found it academically refreshing in a busy school day. Given the combination of challenge and enjoyment, it is perhaps unsurprising that data analysis generated flow as a significant motivational theme (Csikszentmihalyi, 1992).

Fraser: If I get in the zone I can go straight through and like, “crap, it's been an hour!"

Fraser made this comment after completing the Flow graph in class and so it is possible that this is why he used the word "zone". Like Rāwiri at Kotare, some students expressed frustration with the limitations of a timetabled school day, particularly when in flow.

Fraser: You can't do that in Maths class ... yeah, interrupted ... whereas with music you can zone out and you can just keep going.

The implication for teacher practice here is that students need time and space without interruption if they are to reach a state of flow when composing. These data also suggest that students place a high value upon such experiences. 


\subsection{The implications of the research for David's practice}

This section examines data related to the extent to which the collaborative practitioner research at St Bathan's was catalytic, leading to changes in David's practice (Guba \& Lincoln, 2008). These changes pertain to the second research question and provide evidence of the practice impact of the assessment of group composing.

When I visited David's classroom in early 2013, one wall displayed a variety of scores of Year 11 students' compositions, linked to a large sign "Want to get Excellence for your compositions?" There was another large (new) poster with N, A, M, E criteria for achievement.

I joined the senior Music students while viewing a video of all of the Year 11 to 13 compositions, which David had set as the sound track to a montage of clips from movies and digital games popular with teenage boys. The boys seemed to engage in intense, yet respectful, critical discussion about what they were listening to.

David told me he had shown the video and exemplars of students' work to junior students (11-12 year olds) as an example of what they too might achieve:

The middle school boys were composing on Garageband next door. I brought them in here and I said "This is what you guys can do" and I showed them that [points to the scores]. It was amazing. They were learning from it and saying "Wow we didn't know we could do that". Then I played them the montage I made of the senior boys' compositions. Then, rather than seeing Garageband as a toy, just something to drag and drop sounds into, they suddenly realised that it was a tool.

David told me he has incorporated conceptual models and the backengineering strategy into all of his courses, leading to a radical change in the way he approaches music teaching:

It's changed my approach to everything. Now when I'm teaching anything, I'm thinking more holistically. I'm literally rewriting every one of my programmes so that they are all inclusive, they're holistic.

\subsection{Conclusion}

The research at St Bathan's Collegiate initially focused upon composing and teaching through the development of two pedagogies designed support the students to compose valid music. The findings indicate that the conceptual model provided a framework for students to work productively together, while reassuring them and 
David that divergent and messy creative stages, such as jamming, were in fact valid contributions to composing and not time wasting. Discussion using the model also helped David and the students to uncover and thus assess CCP, particularly that of drummers whose contributions were not always easy to perceive as valid. Once more, it seems likely that assessing the CCP of novices or low-achieving students requires considerable sensitivity on the part of the teacher.

The back-engineering strategy data suggest that when group composers developed and shared an understanding of musical style and its relationship to the music, they composed valid music and could explain to each other and their teacher how they did it. It seems that teaching students about how music is constructed in specific styles and genres might influence how they perceive music in their daily lives. When composition tasks are aligned with summative assessment criteria, then the tasks themselves can lead the students to valid achievement without the need for detailed assessment criteria because stylistic examples act as exemplars of achievement.

Teacher and student expectations of success on both group composing and the NCEA have been shown to be key variables in student achievement, particularly for students who were not immediately successful. Like Alice, David's lived experience of assessment proved to be a significant variable in his assessment practice. Teacher isolation had a negative impact upon David's assessment practice.

While this chapter has revealed considerable alignment with the Kotare findings, there were significant disparities in student achievement in AS91092: 30\% at Kotare College; 95\% at St Bathan's Collegiate. This dynamic is examined in the next chapter. Finally, I had used findings from an impoverished setting to support learning and achievement in an affluent one, and this continues to trouble me. This issue is discussed in the final chapter. 


\section{Chapter 7 A valid contribution to social jamming and group composing}

This chapter aims to gain a clearer understanding of how the students viewed valid contribution to social jamming and group composing by analysing their responses to them. It presents an analysis of findings related to two activities: social jamming and group composing. Activity theory is used as an analytical framework to examine and illuminate tensions and contradictions within and between these interrelated activities, and their relationships with student achievement in AS91092. It addresses the first research question. What is revealed is that a valid contribution to an activity depends upon how the activity itself is perceived by the actors.

\subsection{Social jamming and its relationship to group composing}

The previous two chapters have shown that some Kotare and St Bathan's students had different expectations of group composing and NCEA achievement. There appeared to be a number of tensions or contradictions between the students' reported reasons for jamming and composing, and their expectations of achievement in NCEA Music.

While jamming is usually the starting point of group composing, it is not until an idea begins to be recognised and is subsequently shaped into a coherent whole that composing really happens (Tobias, 2013). Jamming socially could be therefore equated to kicking a ball around the field, and group composing as playing an actual game of football. Jamming as a recreational activity will be referred to here as "social jamming", where "jamming" is an element of group composing.

Blues Rock, Pikachu, Action Movies and Indie Rock all reported that they engaged in social jamming, and these bands successfully completed the compositions required for AS91092. Social jamming therefore seems to be an integral part of group formations and the subsequent group composing process. For the bands that did not achieve however, social jamming in class seemed to be the extent of their compositional processes and they did not meet outside of class to do it.

I wondered if some students, particularly those at Kotare who did not achieve AS91092, viewed jamming differently from group composing. What follows is an exploration and discussion of findings related to these two activities using cultural 
historical activity theory as an analytical framework. The relationship between jamming for fun and group composing in a Year 11 class is examined in the light of my findings.

\subsection{Social jamming as an activity system}

Social jamming is an activity that may or may not happen at school. Therefore, the subjects of this activity are teenage boys engaged in a socially enjoyable activity, rather than Year 11 students, where the object is to play together.

The student participants in both schools reported that the outcome of jamming was feeling good. It was fun, they enjoyed being with their friends, they liked being independent, and they enjoyed helping each other. The tools needed were instruments and gear appropriate to the musical style, as well as the skills to use them. Language was gestural, verbal or musical, informed by stylistic knowledge of the music. Players also needed a sound-proof space when jamming in high-volume styles.

The musical style and its associated instrumental roles defined the divisions of labour (for example playing electric guitar, drums or bass in a heavy metal piece). These were also mediated by the skill-level of the players. For example, a beginner bass player like Jay, played a different role in the group to the more skilled Jimmi. Musical and cultural conventions acted as rules, but no doubt there are rules related to social hierarchies that were not perceivable by an outsider, such as their teacher or me.

Jamming was situated within peer/friendship communities associated with cultures related to musical tastes, social milieu, youth cultures, as well as cultures related to whānau, home and ethnicities (Dillon, 2007; Tarrant et al., 2001). For example, the two Pāsifika boys, referred to in Chapter 5, jammed in an island reggae style not studied in their music class, but seemingly related to their own culture and, by association, their home and family communities. Therefore, while jamming happened at school, school may have been just the community location, not the community itself.

In the present study, the main tension the students reported was a lack of access to the appropriate material tools, mainly sound-proof rooms and gear such as amplifiers, mikes and drum kit. As will be shown in the next section, contradictions and tensions emerged when social jamming became part of group composing. Social jamming is represented in Figure 7.1 as an activity, and the tension is represented by a dotted arrow. 


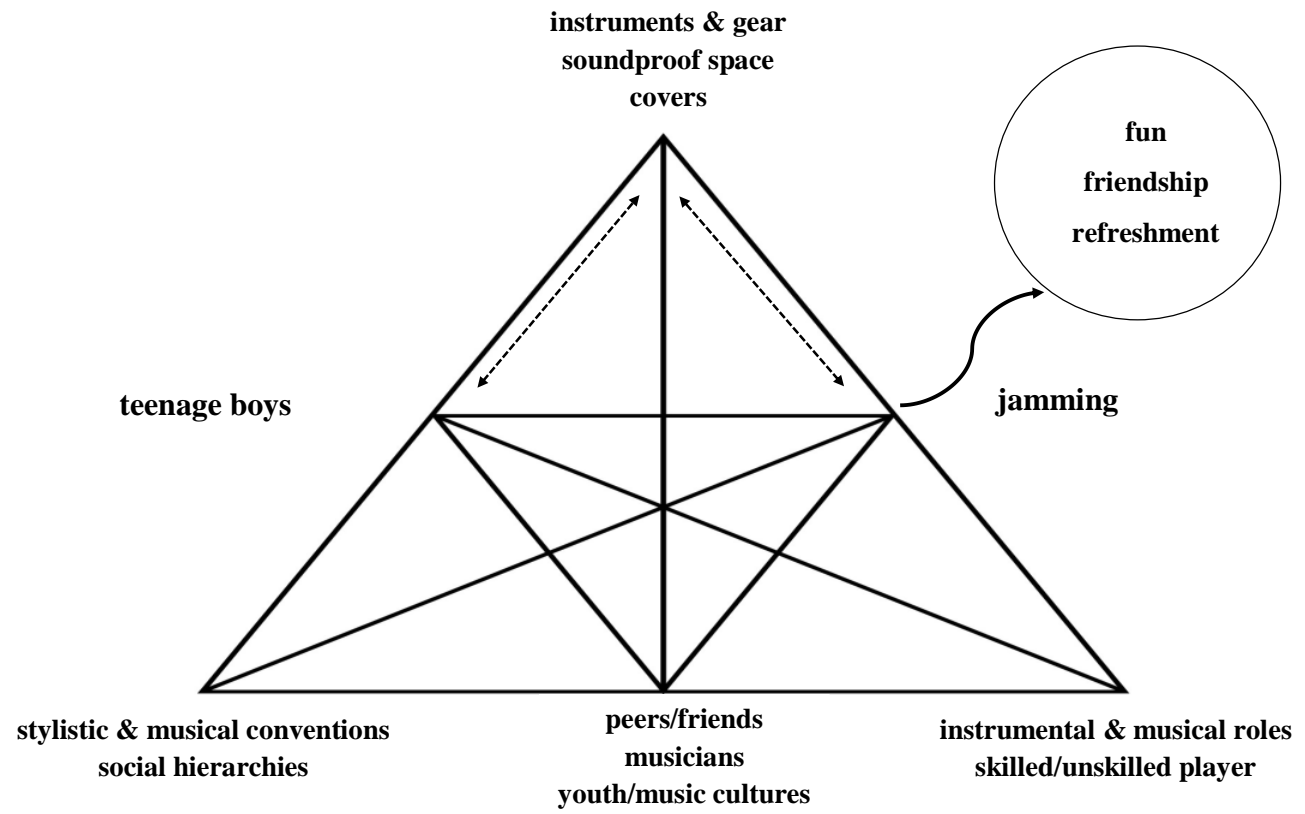

Figure 7.1. Social jamming as an activity system

\subsection{NCEA group composing as an activity system}

When the object of one activity develops over time to become a tool in a related activity then it is "nested" within the system (Barab, et al., 2002). Thus, when considering group composing as a school-based activity, jamming becomes nested within it as a tool for composing.

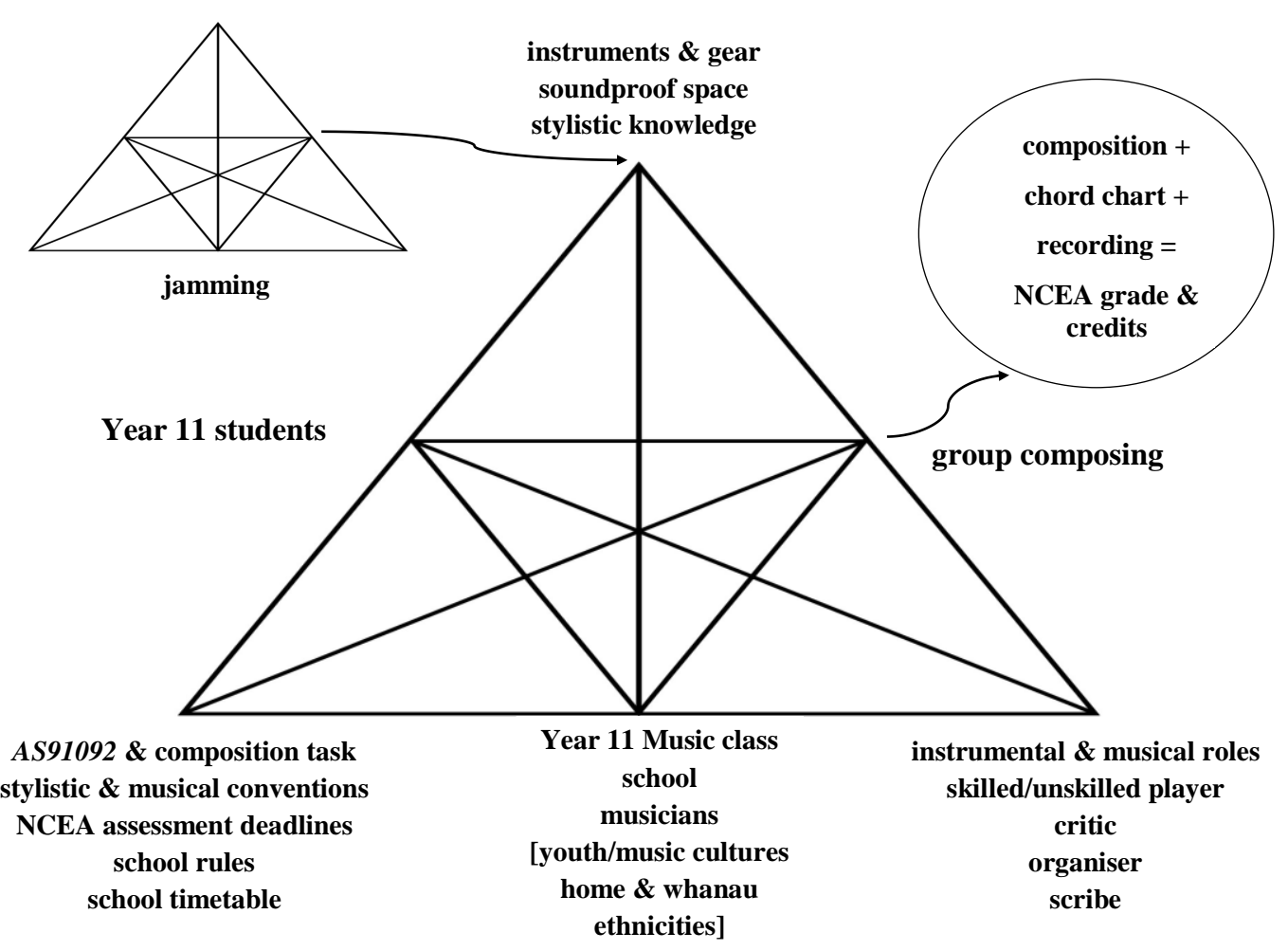

Figure 7.2. NCEA group composing 
As group composing involves jamming, some of the same elements are incorporated into the group's composing activity system. For example, some boys said that playing together refreshed them, and for some it may have even been a reason for coming to class.

While composing may involve the same musical styles as social jamming, when it occurs at school, the subjects are now Year 11 students, embedded in the communities of the classroom and the school. Rather than a recreational pursuit, jamming is integrated into a school-based activity connected to a qualification system, the NCEA. Cognitive as well as affective aspects are involved, where the object of the activity is group composing, and the outcome a composition, chord chart, recording and the associated NCEA grades and Level 1 credits. Different rules are at play here, associated with the classroom teacher, school managers and the NZQA. The same musical divisions of labour as jamming are evident, but there is an additional responsibility to provide a chord chart or other form of written representation, meaning that both music and English literacy skills are required on the part of at least one of the subjects who must act as the scribe. As the conceptual model of group composing has demonstrated, successful group composing also requires that members organise and critique their work. Therefore, students have a number of valid roles to play within the activity of NCEA group composing.

\subsubsection{Inner contradictions within the NCEA group composing activity system}

Unlike social jamming, there are a number of primary and secondary inner contradictions within the activity system of NCEA group composing, labelled as (1), (2), (3), (4), 5), on Figure 7.3. 


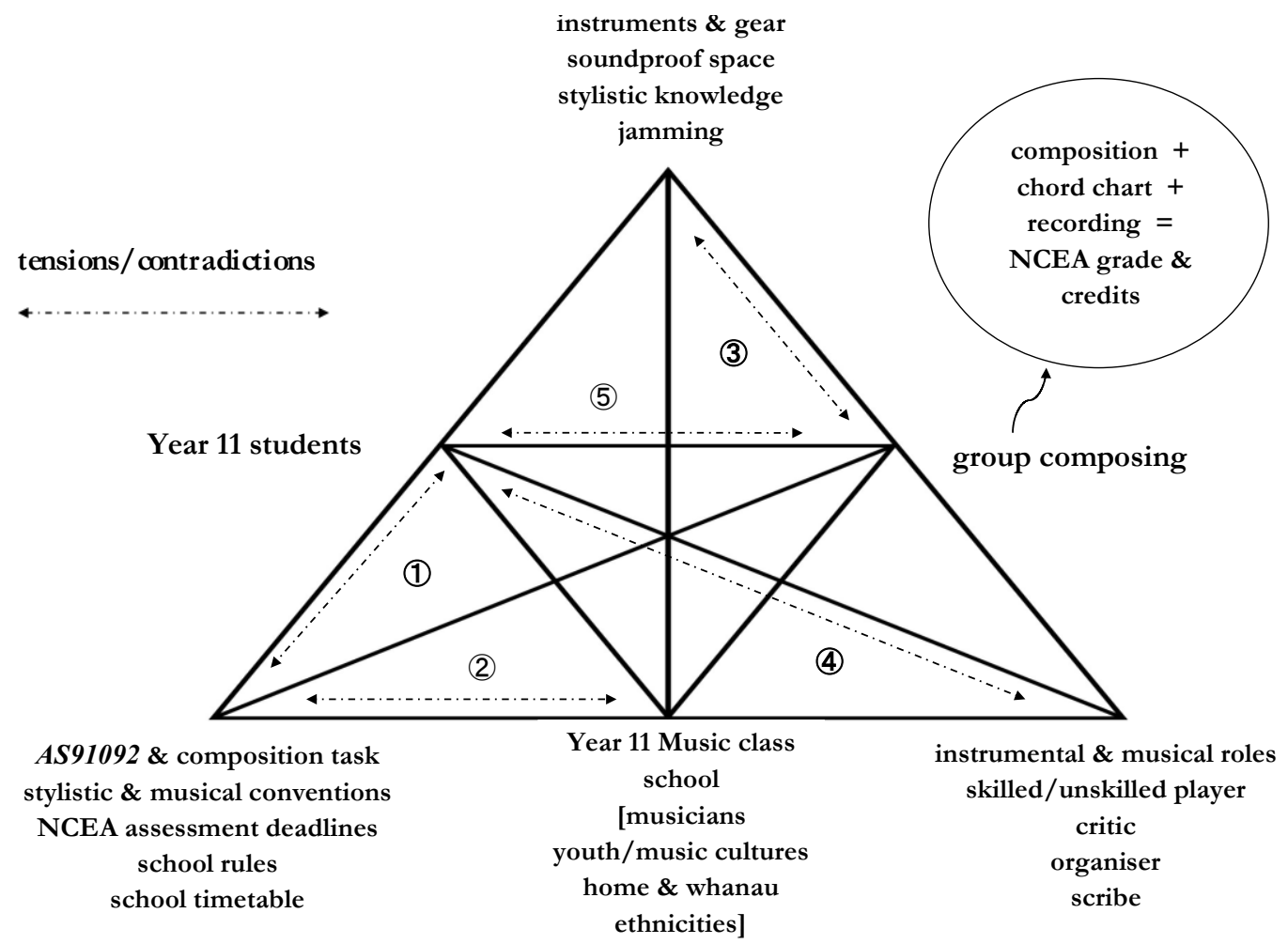

Figure 7.3. NCEA group composing as an activity system

\subsubsection{Conflicts of values between jamming and group composing}

Contradictions (1) and (2) are primary, that is, more than one value system is attached to an element of the activity (Engeström, 1987). They relate to values associated with jamming and NCEA achievement. Group composing usually starts with jamming in popular music styles that are embedded within communities of peers and their associated cultures (Campbell, 1995; Davis, 2005; Jaffurs, 2006). For group composing, the rules are to some extent the composition task set by the teacher, who must in turn, abide by the rules of AS91092. Therefore, to achieve the standard, the students must compose structured music and submit a written representation. To achieve Merit or Excellence they must also compose music that is stylistically “controlled" or "assured" (Ministry of Education, 2010, p.2.).

If some students value playing in the group because they see it as an jamming activity system, or if they value music that does not comply with the requirements of the teacher's composition task and/or the rules of AS91092, then conflict may be the result. McPhail (2012a) identified this tension as occurring between two knowledge systems of informal music making (horizontal) and formal music learning (vertical). 
One could speculate that this might be an underlying reason for Aaron's sudden departure from Blues Rock. Perhaps, for Aaron, the music classroom at Kotare was "simply a bigger place in which to play" (McPhail, 2012c, p.206). Video data certainly suggests that he seemed upset when Alice interrupted the band's jamming to ask him about his CCP.

Tension was certainly evident when many St Bathan's composers did not initially compose the stylistically controlled pieces required by the first composition task. This may have been because there was a mismatch between the teacher-designed composition task, and the nature of the activity which was, at least to start with, both musically and socially motivated.

\subsubsection{Appropriate tools, knowledge and resources are required for group composing}

Contradictions (3), (4) and (5) pertain to the inclusion of NCEA requirements into an activity that was, for some students, social in nature. These contradictions relate mainly to the Kotare data and are associated with the demands of NCEA group composing, the artefacts available, and the roles AS91092 required to engage fully in the activity of NCEA group composing.

Contradiction (3) relates to tools. The Kotare findings indicate that, while the students all jammed from time to time in class, they did not have access to sufficient resources to group-compose over sustained periods. As there were not enough practice rooms and the only band room was not sound-proofed, the boys had to await their turn to access a productive composing space. The Blues Rock boys chose not to access the music classroom at lunchtimes and after school. Why this was the case is not known as I did not ask them about it.

Aaron did not have access to digital media to mediate his lack of playing skills with his knowledge acquired as a listener of sophisticated digital musical forms. While he jammed socially with his friends, he struggled with CCP. It is not known if Aaron would have been motivated to compose if he had had access to such technology. General disengagement with school led to frequent absences for some Kotare students, making it difficult for the Heavy Rock and Island Reggae to access the human resources they needed, and may have been a factor in the break-down in the NCEA group composing activity system for both bands. 
Contradiction (4) highlights a tension between the communities associated with school and those associated with the music to which the students jam and compose. There is some evidence to suggest that some students in both schools regarded group composing as an authentic, real-world activity associated with professional music communities, not just a school-based activity.

Callum: You don't get that professionally. [BSIIR]

Jason: Later on, if you get to join a band professionally, you get the experience. [KSIHR]

Contradiction (5) relates to a contradiction between social jamming as a pleasurable, open-ended social activity, and the more goal-oriented activity of group composing. While for some students social jamming was seen as an opportunity for socio-musical fun, it is also the precursor to the generation of valuable musical ideas, and therefore part of group composing. There is some evidence to suggest that Aaron, and possibly other students, did not connect jamming with the activity of group composing, and by association, NCEA achievement.

\subsubsection{Divisions of labour when composing specific musical styles}

There were some contradictions (4) related to roles and divisions of labour in group composing. The Kotare students lacked a broad prior knowledge of diverse musical styles and so struggled to fulfil the musical and stylistic roles that group composing required of them. This meant that they also struggled to critique and organise their music because they were not able to communicate effectively with one another about what they were doing.

This also happened at St Bathan's at first, but David helped to resolve this contradiction by teaching a second cycle of back-engineering related to movie music to which the students could relate. This did not occur at Kotare. While Alice made links between music works study and composing in terms of musical structure and form, it was in the context of Vivaldi's Four Seasons and Dave Brubeck's Take Five, not the styles of music they were composing. There is no evidence that the students transferred this knowledge to their composing.

Finally, Jay and Liam, who were musical novices, struggled to fulfil their required instrumental and stylistic roles when group composing because they did not have the skills and knowledge they needed to do so. 


\subsubsection{Identity within the community: composer, jammer, or NCEA achiever?}

Youth culture literature indicates that adolescents use popular music and its associated cultures as social identifiers in order to construct identities for themselves (Tarrant et al., 2001). Macdonald, Miell, and Wilson (2005) differentiate between "listeners" and "players", although the two are by no means mutually exclusive (p.323). While listeners identify with the music, accessing the implicit body of knowledge they acquire through listening, players can actually embody that knowledge.

Group composers have the opportunity not only to identify with a musical culture and community, but also to participate in it as an activity (Thorpe, 2009). In this way they are linked both to structures that form and maintain peer and friendships, and possible or imagined futures (Campbell, 1995; Tarrant et al., 2001; Wenger, 1998; Zillman \& Gan, 1997). While Jason of Heavy Rock did not actually complete a song, for example, he hints that he had dreams of doing so as a professional musician.

From a socio-cultural perspective, some students may possibly have regarded themselves as legitimate peripheral participants in an adult musical community of practice (Lave \& Wenger, 1991). A community of practice is a group of people, such as a group-composing band, or group of friends jamming socially together, who "share a concern, a set of problems, or a passion about a topic" (Wenger, 1998, p.133), Learning occurs within the community of practice, regardless of its purpose (Lave \& Wenger, 1991). This implies that group composing or social jamming might have provided the boys with opportunities to negotiate meaning and thus construct identities through their engagement in an activity associated with authentic work in the adult world (Wenger, 1998).

Although it is not possible to gain a complete understanding of the students' motivations to jam and group-compose, some inferences may be drawn from the Kotare and St Bathan's findings. The student participants in both schools seemed to value the act of composing as much as, or more highly than NCEA achievement. All of the St Bathan's boys indicated that NCEA achievement at Merit or Excellence level was either "important" or "very important" to them. On the other hand, there is little evidence that the Kotare students constructed identities such as "NCEA high-achiever" when group composing together, or that their band was a community of practice engaged in NCEA achievement. 
Both Alice and David observed that the boys seemed to value the act of composing and the music they created as much as, or more highly than, NCEA achievement in composing. For example, Angus from Action Movies commented that he valued the composition itself and the fun he had creating it with his friends more highly than NCEA achievement.

\subsection{Third generation analysis of social jamming and NCEA group composing}

When social jamming and group composing are viewed as adjacent activities, third generation analysis reveals a number of contradictions and tensions that are represented on Figure 7.3 as (6).

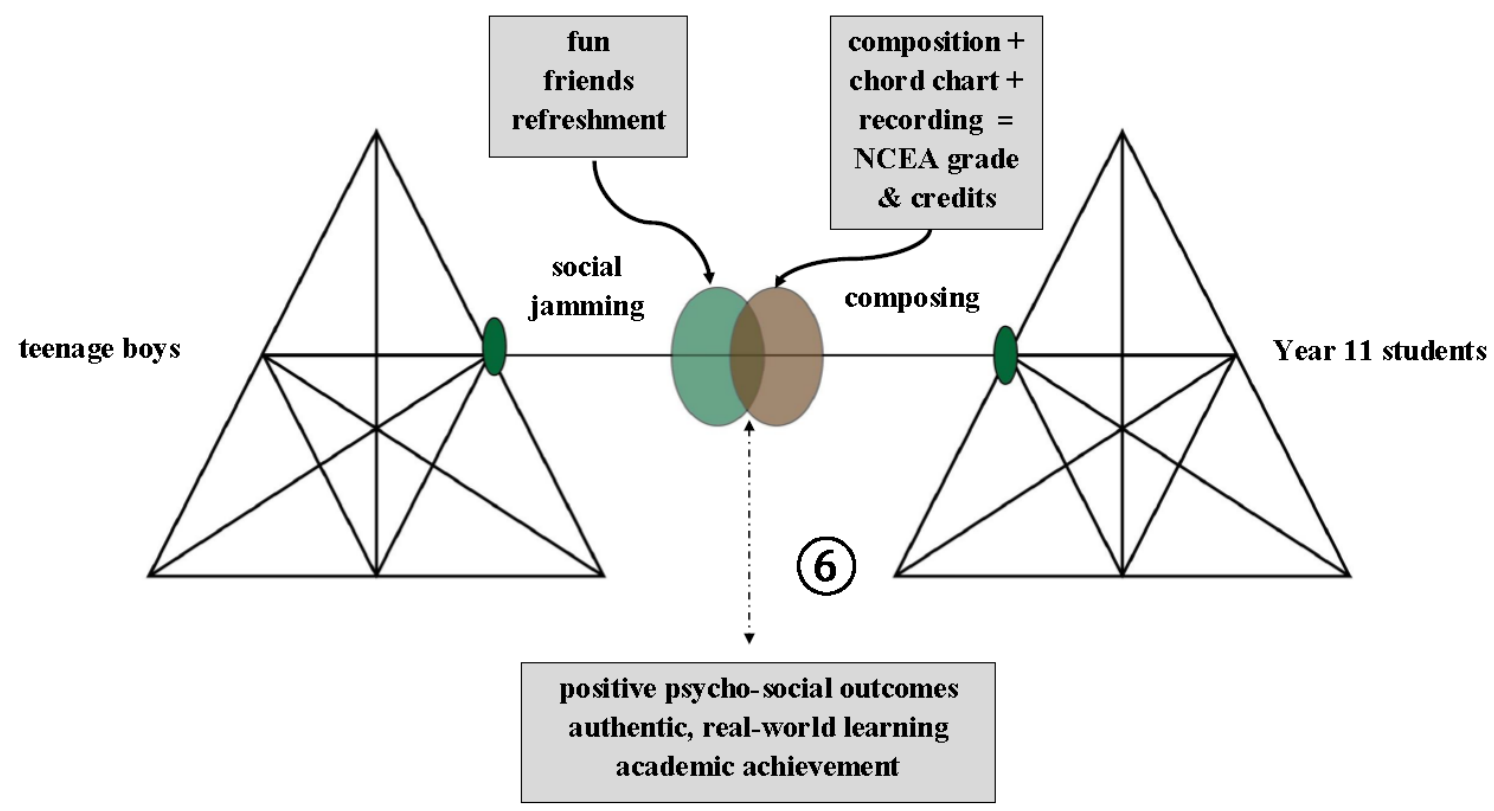

Figure 7.3. Social jamming and group composing as adjacent systems (after Engeström, 2001)

There is a potential disconnect between student expectations of NCEA achievement and the benefits of social jamming if the student does not view social jamming as integral to group composing. All student participants reported that jamming was a "feel good" activity, but some also said that group composing was too. For those who achieved AS91092, their NCEA achievement was associated with positive psycho-social outcomes. 


\subsection{Social jamming, group composing and student motivation to achieve in the NCEA}

In his examination of students' motivation in relation to their achievement and engagement at school, Brophy (2008) asserts that "if a curriculum strand has significant value for learners, it will be because its content network is structured around big ideas that provide a basis for authentic applications to life outside school" (p.135). When viewed as nested activity systems, social jamming and NCEA group composing can be seen to have considerable potential to foster the kinds of authentic learning, learner connection and meaningful achievement Brophy calls for in school curriculum design. Furthermore, the community of practice of a productively composing band provides considerable opportunities for learning autonomy, identity construction, and meaning-making for its members (Wenger, 1998).

The previous analysis has identified contradictions and tensions within the activity of NCEA group composing that have the potential to militate against engagement and achievement for some students, such as Aaron at Kotare, and Chris at St Bathan's. Then again, student achievement has been shown to be optimal when students are self-regulated and autonomously motivated (Brophy, 2008), and motivation determines the relation between the subject and the object in an activity (Engeström, 2001; Leont'ev, 1981). There is certainly considerable evidence to suggest that many of the student participants were self-regulated and intrinsically motivated in one or both of the activity systems.

\subsubsection{Student motivation to achieve at school}

Educational theories related to students' motivations to achieve generally focus upon three psychological aspects: social milieu, value, and expectancy (Wigfield, Tonks, \& Eccles, 2004). Social milieu has already been substantially examined and shown to be a key variable in the students' motivations to play, jam and compose together (Allsup, 2003; Davis, 2005; Green, 2008; Jaffurs, 2004). In this section, value and expectancy will be discussed in relation to my findings. Wigfield et al. (2004) focus on four aspects of value in relation to student motivation to achieve: intrinsic, attainment, utility, and cost.

Intrinsic value is related to enjoyment, such as the level of satisfaction in completing a composition, as well as enjoyment and aesthetic appreciation during the creative process. Such activity is autotelic, in that the subjects engage in an activity 
such as jamming or composing for its own sake (Csikszentmihalyi, 1996). Enjoyable activity frequently results in the state of flow where:

There is no worry of failure, there are clear goals every step of the way, there is immediate feedback, distractions are excluded from consciousness, there is a balance between challenge and skill, self-consciousness disappears, sense of time becomes distorted and action and awareness are merged. (Sheridan \& Byrne, 2002, p.140)

Intrinsic motivation in a creative endeavour such as composing is also linked to enjoyment, the discovery of unorthodox solutions, and sustained and persistent effort (Ruscio, Whitney, \& Amabile, 1998). Intrinsically motivated people also demonstrate deeper levels of creative problem solving than those who are not (Barratt, 2005).

When considering this kind of motivation in relation to the activity systems of jamming and group composing, it is helpful to consider Waterman's (2005) delineation of enjoyment into hedonic, which can be experienced through simple participation (such as social jamming) and eudemonic, associated with sustained, goal-oriented effort (such as group composing).

Attainment value is the value the learner places upon attainment of the object (Wigfield \& Eccles, 2000). When considering the hedonic activity of social jamming, it is clear that all of the student participants valued the object of the activity, but that it was only tenuously related to the more eudemonic group composing activity, in which not all are meaningfully engaged. Not everyone, particularly the Heavy Rock boys, seemed to associate jamming and group composing with NCEA achievement.

The same can be said for utility value, that is, the perceived value of group composing and the NCEA to their future lives. As has been shown earlier, all students associated NCEA achievement with extrinsic goals while many intrinsically valued group composing and the music they created for its own sake. When asked about the purpose and function of the NCEA, all of the Kotare boys associated NCEA achievement with immediate employment in the adult workforce, other than Rāwiri who associated it with the local technical college. As has been shown in the analysis and in Chapter 5, some of the Kotare boys therefore valued group composing as something that might be useful to them in the workplace, but actual achievement in NCEA music itself did not seem to be highly valued. 
In contrast, all of the St Bathan's boys associated NCEA achievement with gaining access to university courses. While they seemed intrinsically engaged in group composing as an aesthetic and social pursuit, the analysis here and in Chapter 6 indicates that high NCEA achievement at Level 3 was an important goal for their future lives.

If, as has been suggested earlier, group composing presents students with opportunities to negotiate meaning and thus construct identities, there is some evidence that while the St Bathan's and the Kotare boys' musician identities may have been similar (when jamming for example), their student identities may have been different (Wenger, 1998).

When we consider cost in relation to social jamming and NCEA group composing, it is in relation to how much engaging in one activity might limit another (Wigfield \& Eccles, 2000). To create a structured and coherent piece of music, the creative process requires composers to move out of the divergent creative phase and into a more convergent, focused phase (Webster, 2002). There is a social cost to doing this if hedonic enjoyment is the only motivation. It may be that for some of the Kotare students, such as Aaron, the value of social jamming enjoyment outweighed the extrinsic goal of achieving NCEA credits, particularly if NCEA achievement in music was not highly valued.

\subsubsection{Achievement expectancy and group composing difficulty are linked}

Expectancy of achievement, and the achievement itself, are mitigated by the level of difficulty experienced by the learner, not too easy, not too difficult (Brophy, 2008). On the whole, the St Bathan's boys had a higher level of musical skills and knowledge to bring to the task of group composing than the Kotare students. Group composing was probably easier for them.

Furthermore, David attempted to make links between the music curriculum and the boys' lives outside of school. For example, the second composition task was based upon movie genres with which the boys were familiar. The St Bathan's boys composed in a well-resourced environment. Under those circumstances, the activity of NCEA group composing was probably easier for them to achieve in than the Kotare boys.

Data analysis presented in Chapter 4 reveals that the Kotare boys did not achieve well in the NCEA. Despite some attempts to do so during the research, Alice 
and I were not successful in making effective links between group composing and the students' lives outside of school. It is therefore not surprising that their NCEA expectancy was low, as was their actual NCEA achievement. Some students, like Jay and Liam, struggled to compose with minimal skills and knowledge, and woefully inadequate resources. Even a skilled player like Jimmi believed that composing was difficult, and, despite composing two stylistically controlled pieces, said that he did not know very much about composing, and did not believe that he could compose on his own.

In the months following the conclusion of the project, the Kotare boys either left school, or returned to the hedonic pleasures of social jamming. None went on to achieve in composing in NCEA Music Levels 2 or 3 in 2012 and 2013. It seems that low expectations of achievement, on the part of both Alice and her students, along with low value placed upon it, resulted in no subsequent NCEA achievement in composing for any of the Kotare student participants.

Inadequate resourcing of group composing was another significant factor in the low achievement of these students. This is in stark contrast to the St Bathan's boys who had access to multiple spaces and well-equipped facilities. David reported that the boys who chose Music as a Level 2 subject in 2013 all gained NCEA credits in composing at Merit or Excellence level.

\subsection{Conclusion}

A student's identity as "a member of a collaboratively composing band" may not necessarily be the same as "a successful NCEA candidate". Motivation to groupcompose may not necessarily be driven by the extrinsic rewards of a school qualification, but rather have its roots in the enjoyment of social music making. The relationships between this enjoyable social activity and the requirements of NCEA music are complex and contain a number of tensions and contradictions.

These findings align closely with research into student expectancy of achievement at secondary school. Low student aspirations of NCEA achievement both predict and reinforce low achievement (Walkey et al., 2013). Furthermore, students in low-socioeconomic communities are more likely to have low expectations of academic success than those for high socio-economic backgrounds (Bishop \& Glynn, 1999; Tavani \& Losh, 2003). When a teacher promotes low or even moderate expectations 
and aspirations for student achievement in the NCEA, there is significant evidence to suggest that this may actually reinforce low academic achievement (Savage et al., 2011).

Nevertheless, there is considerable evidence to suggest that, in the right environment, a group of composers can be a community of practice where novices gain confidence and friends support each other to achieve. The intrinsic rewards inherent in social jamming also have the potential to lead to significant student achievement in NCEA group composing, given the right conditions. The implications these findings have for teacher practice are discussed in the next chapter. 


\section{Chapter 8 Teaching and assessment}

This chapter examines and discusses the findings of the study in relation to teaching and assessment. It addresses both research questions, beginning with a reexamination of the assessment conceptions of Alice, David and myself. This is followed by a CHAT analysis and discussion of the implications of the research question: "what are the implications for teacher practice when group composing is introduced into an established summative assessment programme?"

In the second half of this chapter, Harlen's (2012) assessment dimensions (informal-formative, formal-formative, informal-summative, formal-summative) are used as a framework to address the research question, "what is a valid contribution when group composing is summatively assessed for a secondary qualification?"

\subsection{A socio-cultural view of teaching and assessment}

When framing the assessment issues raised by the pilot study, I asserted that group composing is a fundamentally socio-musical activity involving highly complex interactions (Burnard \&Younker, 2008; Espeland, 2003). As demonstrated in the previous chapters, interpreting and assessing the interactions, contributions and motivations of the participants did prove to be complex. Arriving at a summative grade was not simply a matter of evaluating the composition (complex and problematic as that may also be) because the learning and its subsequent achievement are distributed between members of the group (Fautley, 2005; Wilson \& Myers, 2000).

The findings and discussion in the previous chapters have shown that James' (2012) socio-cultural view of summative assessment examined in Chapter 2 is highly apposite. In particular, this investigation has shown that valid and authentic assessment involves evaluating "how well people exercise agency in their use of resources or tools (intellectual, human, material) to formulate problems, work productively and evaluate their efforts" (James, 2012, p.31) For example, when David, Alice and I used the conceptual model to assess the CCP of individual students we were able, to some extent, to assess how well each student was able to exercise personal agency within the group composing process, and thus achieve. 
The findings also suggest that group composing is situated learning, possessing some of the characteristics of authentic, real-world activity. The assessment of this learning was done by Alice, David and me, not an external assessor. The students had a role to play because valid summative judgements also required self and peer assessment.

When viewed through this socio-cultural lens, formal-summative assessment of group composing is also situated. If this assessment is to be both valid and authentic, then all participants need to be involved in making holistic and qualitative judgements about collaborative learning and achievement. As the findings have shown, this is easier said than done! While holistic judgements involving both teacher and group composers did occur at St Bathan's, mostly they did not at Kotare, where it was very much a teacher-focused activity, with far less student input.

NCEA assessment is not socio-culturally situated, and requires a much more cognitivist view on the part of the teacher and the school where the achievement of individual students is atomised as a single grade for composing. From this perspective, assessing group composing as a distributed process is problematic. This tension will be examined later in this chapter (see 8.6.4).

\subsection{Assessment conceptions revisited}

As explained in Chapter 2, the assessment of group composing and its implications for teacher practice must be viewed from several perspectives because it has multiple purposes related to both learning, and the evaluation of learning. When considering the complex socio-musical factors associated with learning to compose in a group, and how this learning might be assessed, it was necessary for me to develop a strong assessment conceptualisation and to develop the tools to enact it (Bennett, 2011).

\subsubsection{My initial assessment conceptions}

Initially, my aim was to explore the assessment of group composing with an emphasis upon the summative assessment requirements of AS91092. To achieve this I assumed it would be necessary to have student achievement data to work with. Examining early entries in my reflective diary for the Kotare project, it can be seen that to some extent I considered teaching the class as the means of accessing those data. While I espoused the importance of assessment for learning, my initial actions focused upon the practice of summative assessment of learning. This is represented in Figure 8.1. 


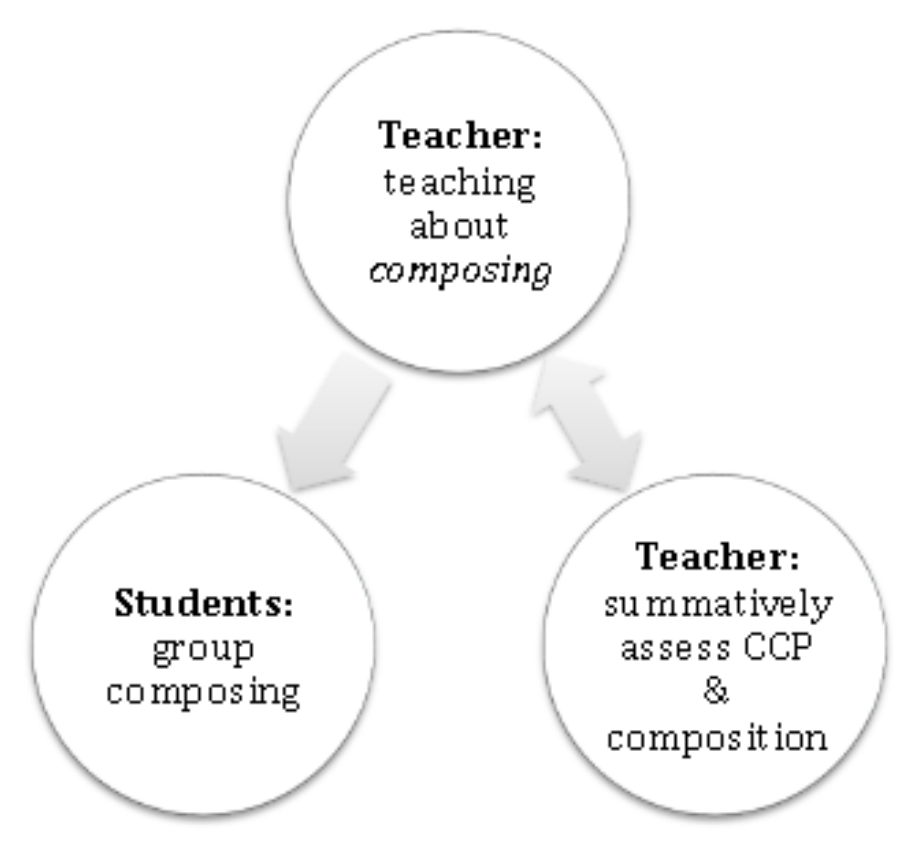

Figure 8.1. Initial research focus

\subsubsection{Shifts in assessment conception}

As the research progressed, I gained a deeper understanding of the nature of valid contributions to group composing and their implications for teacher practice. The difficulties Alice and I experienced while teaching and facilitating group composing further highlighted for me the complexity of music learning and the challenges it raises for teacher practice (Burnard et al., 2008). Furthermore, the usefulness of the conceptual model and the back-engineering strategy as teaching and assessment tools reinforced the notion that it is the learning journey, not the assessment destination that is critical when evaluating student achievement in groups (Black \& Wiliam, 2009).

This shift in perspective led me to understand that group composing and its assessment have the potential to be integral, if not central, to effective music teaching and learning (Fautley, 2010) and that, in the context of this study, assessment, teaching, and composing are closely interrelated practices.

Hickey's (2012) vision of teaching an entire school music curriculum through composing resonates here because this, in essence, is the intention of the backengineering strategy. Rather than teaching and assessing composition as an activity separate from the other aspects of music learning, the goal of back-engineering was to teach and assess musical understanding holistically. Thus, I eventually viewed teaching, composing, and assessment as interrelated practices. The teachers with whom I collaborated also changed their assessment conceptions, although in different ways. 


\subsubsection{Alice and David's conceptions of assessment}

As discussed in Chapter 2, there is evidence to suggest that teachers' beliefs about assessment are linked to their identities, their experiences as learners and their professional philosophies about teaching and learning (Brown, 2011). This certainly seemed to be so for David and Alice.

When asked at the outset of each project about their conceptions of assessment, both David and Alice equated "assessment" with assigning a grade to student-composed music. This conception of summative assessment is not uncommon among teachers (Brown \& Hirschfeld, 2008, Brown, 2011) and is sometimes referred to as the "folk view", widely held within society in general (Fautley, 2010; James, 2008). Analysis of both teachers' discourses reveals the multiple and conflicting conceptions of assessment.

Initially, both Alice and David believed that for them, summative assessment of composing as an irrelevant interruption to their teaching, imposed upon them by a qualification system:

Alice: If I'm trying to help a class with something, I don't really care if they all fail and I get kicked out of my job. It doesn't really worry me much, that sort of thing. I'm motivated more by what I think enriches them to know things. [KTI1]

David: I think it's the process that we should be focusing on, the actual journey and not the end result. [BTI1]

Alice maintained her beliefs about the low value of summative assessment throughout the project, and the data suggest that she did not place a high value upon achievement in the NCEA for its own sake:

I'm not motivated by NCEA results and that stuff. My buzz is when I see some kid has done well and is a bit of a nicer person.

When I asked Alice about what she had learned from the project however, her conceptions of NCEA assessment did seem more closely linked to teaching and learning than previously. The very nature of the NCEA requirement to account for individual students' CCP seemed to have compelled her to consider the students' engagement in process, although this did not translate into significant changes in practice:

I've got to be questioning the students, "What's your contribution, what can you show me that you're actually doing?" So it does become part of the assessment process, because it would be very hard to assess it just on the day, take a video of them and then try to assess [the composition] without talking to the kids a lot and then seeing the progress. 
For David, the experience of changing his conceptions of summative assessment was highly empowering. While the notion of assessment for learning was embedded in his teaching philosophy, initially he resisted sharing exemplars and the NCEA assessment criteria with the students because he saw these as irrelevant to his teaching, and unintelligible to the students. As the project proceeded however, he observed that involving the students in self and peer assessment of process engaged them in dialogue about their musical understanding, congruent with his aim for his students to become autonomous learners.

David noticed that using the conceptual model as an assessment-for-learning tool led to an emphasis upon engaging the students in thinking and talking about their compositional processes. This, in part, led to him radically changing his assessment practice:

It's been a complete turnaround. I've got loads of data, folders over there [gestures] full of student assessment tasks, my notes on them. I mean, just the amount of feedback, written and verbal feedback I'm giving them through the process ... There's been these little checkpoints along the way.

Nevertheless, these findings highlight how isolated both teachers were, a common situation for secondary music teachers in New Zealand (Donaldson, 2012; McPhail, 2009). As McPhail (2009) observes "teachers now [NCEA] assess mostly in isolation ... rather than working in cluster groups to develop shared understandings in a community of practice for standards development" (p.21). This remains a considerable threat to assessment validity because, prior to collaborating with me, neither teacher had access to professional learning about the NCEA in a community of practice, nor could they engage in a meaningful moderation process (Black et al., 2010).

\subsection{The implications of group composing for teacher practice}

The summative assessment of group composing involves both the outcome of the learning (the composition) as well as the actions that lead to its creation (CCP). The literature on the assessment of individuals in groups indicates that valid assessment of such processes requires both self and peer assessment alongside that of the teacher (Johnston \& Miles, 2004) and so the students also have a role to play in the summative assessment of their work. Therefore, any examination of the summative 
assessment of group composing must also focus upon the relationship between how the students achieved and how the teacher supported them.

Student achievement has been examined in the previous chapter. In this chapter teacher practice is examined as the activity: teaching group composing. (See Figure 8.2) In this activity the subject is the teacher, the object of the activity is to develop new ways to teach composing that are responsive to the needs of the students, where the outcome is improved student achievement in NCEA composing.

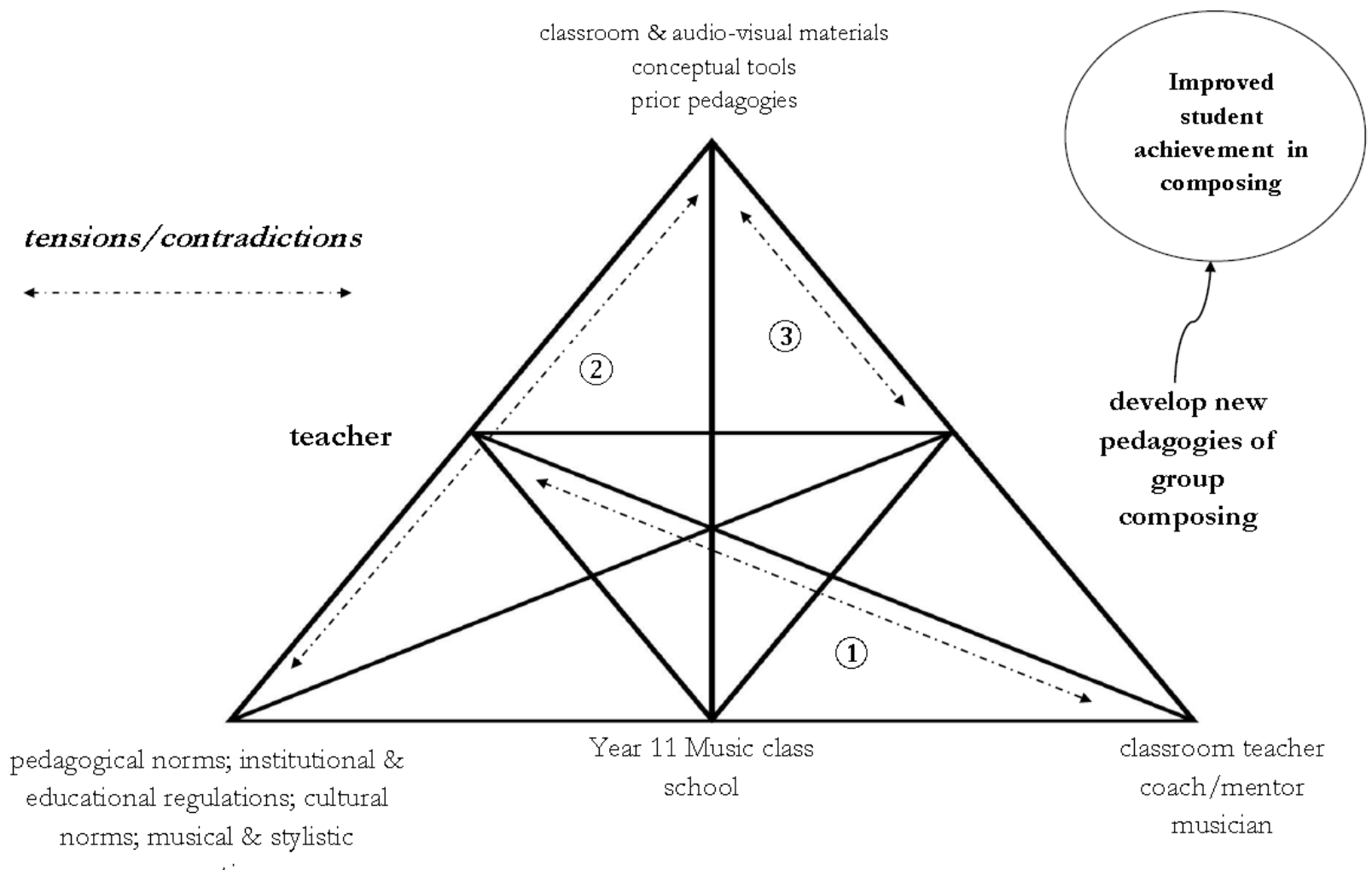

Figure 8.2. Teaching group composing

\subsubsection{Divisions of labour: teacher and student}

As discussed in the previous chapter, social jamming and group composing are often eudemonic activities, valued by the students for their own sake. Students' motivation to engage in this kind of music-making, and to self-regulate their behaviours when doing so were found to be significant variables in the establishment of productive groups. As such, few aspects of the music curriculum have more potential for meaningful connection to be made between the students' enjoyment of music outside of school and learning in the music classroom. Furthermore, these two activities may involve informal peer-mediated learning and so, to some extent, group composers are teachers as well as learners. 
When examined from these perspectives, the music teacher (ipso facto practitioner researcher) becomes a cultural manager whose task is to create optimal learning environments that integrate diversity and build upon the music making knowledge and skills acquired by both the teacher and students in their everyday lives (Cabedo-Mas \& Diaz-Gomez, 2013; Dillon, 2007). The intent is more than just to encourage the students to compose in groups, rather, it is to enact a series of deliberate pedagogical decisions aimed at collaborative knowledge creation (Hakkarainen et al., 2013). The teacher is not only a constructor of the knowledge for students, but also a coach, mentor and guide to artists engaged in the practice of composing together (Allsup, 2003; Dillon, 2007).

\subsubsection{Changing role of the teacher}

When David, Alice and I engaged in teaching the students about group composing, and facilitating groups to be as productive as possible, we found that we needed to change what we were doing. This did not mean catering to students' current preferences or agendas however, but rather, shaping the curriculum so that learning had a valued purpose for the students (Brophy, 2008).

The data indicated that the traditional divisions of labour between music teacher and student were often inappropriate for these kinds of teaching and learning. This tension is labelled (1) on the diagram. As has been explained in Chapters 5 and 6, David was more open to this idea than Alice, due to a complex web of interrelated factors, such as teacher and student expectations of success, teacher identity, students' intrinsic motivation for music making and NCEA achievement, as well as external structures such as material resources, school rules and timetables.

\subsubsection{Communities: authentic music making and group composing at school}

When considering group composing and its relationship to teacher practice, the intersections of multiple communities reveal a complex and somewhat murky mix. The analyses of students' responses in the previous chapter contain a number of assumptions about the authentic nature of group composing at school that have a bearing upon the response a teacher might make.

One must consider to what extent group composing at school is an authentic "real world" activity. To some extent the communities the students worked in were those of peers, home, and the wider local community, as well as peripheral ones related to youth and music cultures. There is some evidence to suggest that the intention of 
the writers of the achievement standard was to capture what young musicians are already doing outside of school. Yet, the Year 11 Music curriculum at both schools was driven by the qualifications structure within which the teachers and students worked. Group composing in Year 11 was "on the menu", because it could be summatively assessed for the NCEA, and students could gain NCEA credits. While some students stated that they probably would have composed together even if the activity had not been a part of their school programme, others said that they only moved from social jamming to group composing because it was part of the NCEA and they wanted to get the credits.

Group composing at school is both an artificially constructed activity located within the school community, included in the Year 11 course because it can be assessed, and a real world musical activity located outside of school and linked to multiple communities (Green, 2002, 2008). For some students group composing may have been an authentic, real-world activity, while for others, it may not.

At Kotare, I attempted to bridge different forms of knowledge through making links between music the students enjoyed and group composing for AS91092. I did not succeed in doing so. The Kotare data strongly suggest that this disconnection was a significant contributing factor to subsequent low student achievement. This was more successful at St Bathan's because, from the outset of the research, David and I shared the goal of making valid connections between the students' tacitly acquired knowledge of popular styles and the AS91092-oriented composing tasks we designed. Nevertheless, there were tensions.

Even though we sought to make connections to the peripheral communities associated with the students and their music, David's and my dominant frames of reference were still derived from our memberships of teaching and learning communities, as well as our own experiences as teachers and musicians (Donaldson, 2012). Furthermore, we were accountable to our own professional communities, such as school management, NZQA, and the university. While the students may have been referencing real-world musical contexts, and possibly acting in accordance with the rules associated with real-world music communities, the requirements of school, NZQA and the university were also drivers of the activity of group composing.

While authentic assessment of music means authentic musical tasks performed under stylistically authentic conditions, NCEA assessment is also an authentic aspect 
of schooling and serves the needs of the wider community. There is a deep tension here. Referencing the students' musical and social communities while also being subject to NCEA assessment rules and external qualifications structures was, and remains, a pedagogical challenge.

\subsubsection{Pedagogical tools}

At the outset of the project I used a number of established tools, including two student surveys I had used in secondary school classrooms over the years and had given to my own student teachers. I soon found that, while these looked good on paper, in practice they did not produce useful data about the students' CCP or learning and, crucially, did not productively engage the students.

The Kotare boys did not make the connection between social jamming and the written material given to them by Alice or me. They handed sheets back blank, or filled them in with minimal, meaningless information. Most sheets were left on the classroom floor at the end of class. They clearly did not think much of it. In any case, the data indicate that some students did not have sufficient musical knowledge to give me written feedback about their CCP.

When considering the written question "what was the most frustrating thing about this [back-engineering] task?", one St Bathan's boy's comment, "I think the most frustrating thing about this task is having to reflect on it" was met with laughter and general agreement from the other boys. I reflected that it was very easy for a teacher-educator like me to devise seemingly useful tools for teachers to use, without the deep understanding needed to develop tools that were fit for purpose, and that catered for the needs of specific students. This is labelled (2) on the diagram.

The only really effective teaching tools were those that were designed with group composers in mind, and crucially, that required Alice, David or myself to make changes in our practice. These were the back-engineering strategy, the conceptual model of group composing and the Flow graph, all developed during the project.

Creativity is very hard to define, and it is difficult for teachers to foster creativity if they do not have an understanding of creative processes (Hammershøg, 2014). The findings suggest that the conceptual model helped both teachers construct new meanings about the nature of collaborative music making, thus adding to their 
knowledge of practice. When asked about her most important learning during the project, Alice replied:

I think, what I learned from that is, even though you've got those scallywags who make it sound loud and stuff, there's a lot of kids who are really focusing in, listening and focusing on what you're asking. So I think that, for me, accepting that messy stage is actually an important stage.

As has been explained in Chapters 5 and 6, when the teachers and groupcomposing students shared an understanding of creative process, then this understanding acted as both a creative and pedagogical tool.

\subsubsection{Changes in practice lead to changes in pedagogical rules}

There is some evidence to show that the conceptual model led to changes in how the teachers perceived the rules of teaching group composing. Understanding that divergent and messy music making was part of the creative process led Alice to consider using more student- centred pedagogies with her current Year 10 students:

A couple of them had a go and got involved in the composing. One kid, who's been a real pain in the neck, actually performed and he did a marvellous job, considering he's done nothing all year. He actually got involved and I thought "that's why he probably came to music, to do that. He didn't come to listen to me".

The contradiction here (labelled (3) in Figure 8.3) is that new learning about teaching composing did not lead Alice to change her practice. Whether she has subsequently done so is unknown. David claims that his understanding of the conceptual model has led to profound changes to his practice.

\subsubsection{Back-engineering changes the rules}

When David and I devised the back-engineering strategy, we deliberately changed the rules of our established practice. This had been a fairly conventional approach aiming to build students' skills and knowledge in the other aspects of the music curriculum, taught as separate units of work and prior to composing. The intention of this approach is to scaffold the students towards a demanding task like composing by providing them with a wide range of skills and knowledge before they needed them (see Figure 8.3). 


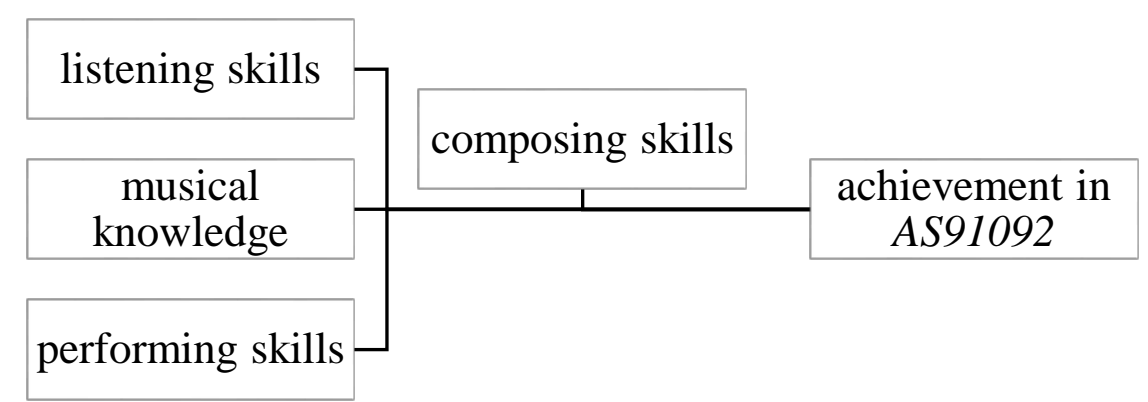

Figure 8.3. Traditional pedagogical model for NCEA composing

Rather than take this established approach, we decided to "throw away the rule book" as David put it and begin the school year with composing and back-engineering. This approach was influenced by what we both knew about the underlying principles of the Musical Futures project. These activities required the students to develop the listening and playing skills, and musical knowledge as needed while composing.

The flow graph helped us to interpret and respond to the students' individual experiences of back-engineering and subsequently inform our planning. While we based our initial approach upon these principals, we also wove formal instruction into the pedagogy, as and when the data indicated that the students needed it. Thus, we aimed to re-contextualise both the students' informally acquired music knowledge and skills, and the disciplinary knowledge we believed they needed (McPhail, 2012b). Our aim was to cross the boundaries of the two knowledge systems. This is represented in Figure 8.4. 


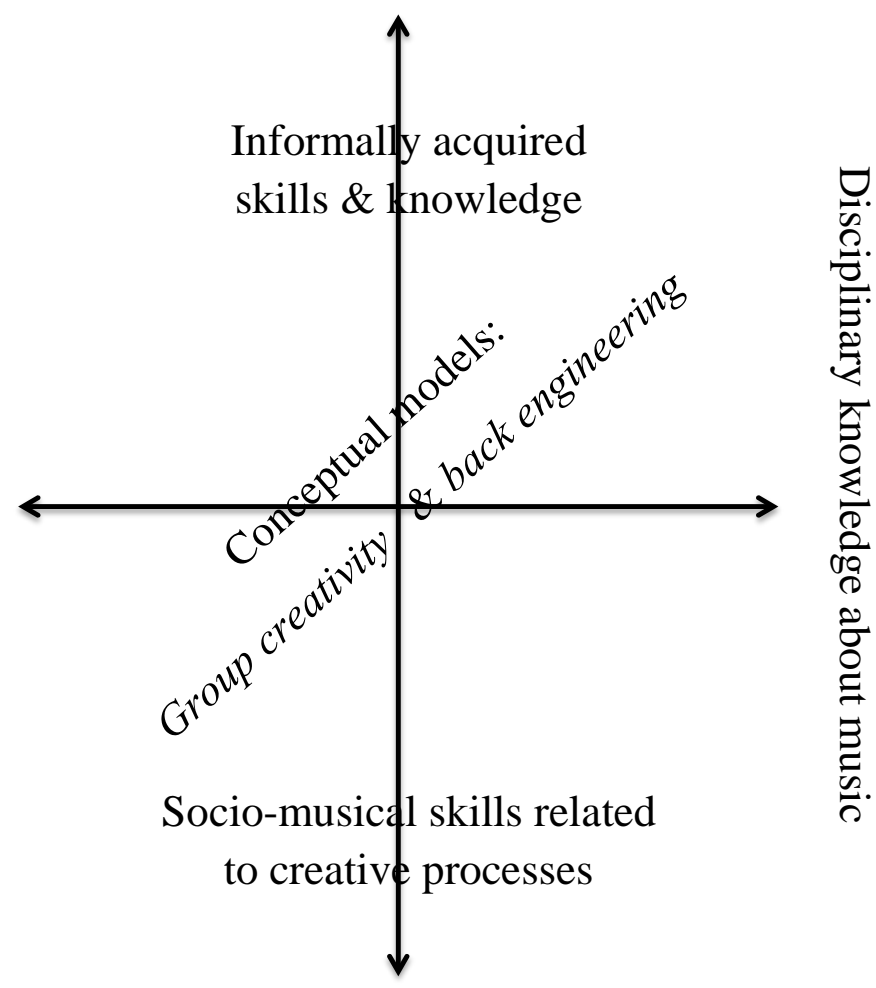

\section{Figure 8.4. Crossing the boundaries of informal and formal practices and knowledge}

\subsubsection{Changes in practice}

The back-engineering strategy acknowledges the distributed nature of group creativity and makes the assumption that group composers share a diverse range of informally-acquired skills and knowledge. There is evidence to suggest that teaching composing in this way not only supported the St Bathan's students to compose stylistically controlled or assured music, but also increased their musical understanding:

Fraser: Actually, it did teach you about music. [BSIAM]

Rob: It's like you're thinking about it. It kind of ruins music for you in a way, but it makes it better at the same time. [BSIAM]

Richard: I was watching a horror movie the other day and I was just listening to those semitones and thinking "oh yeah, that works really well". [BSIR]

The activity teach group composing can now be viewed more broadly as facilitate and support productive groupings, nested within the activity teaching music (See Figure 8.5). 


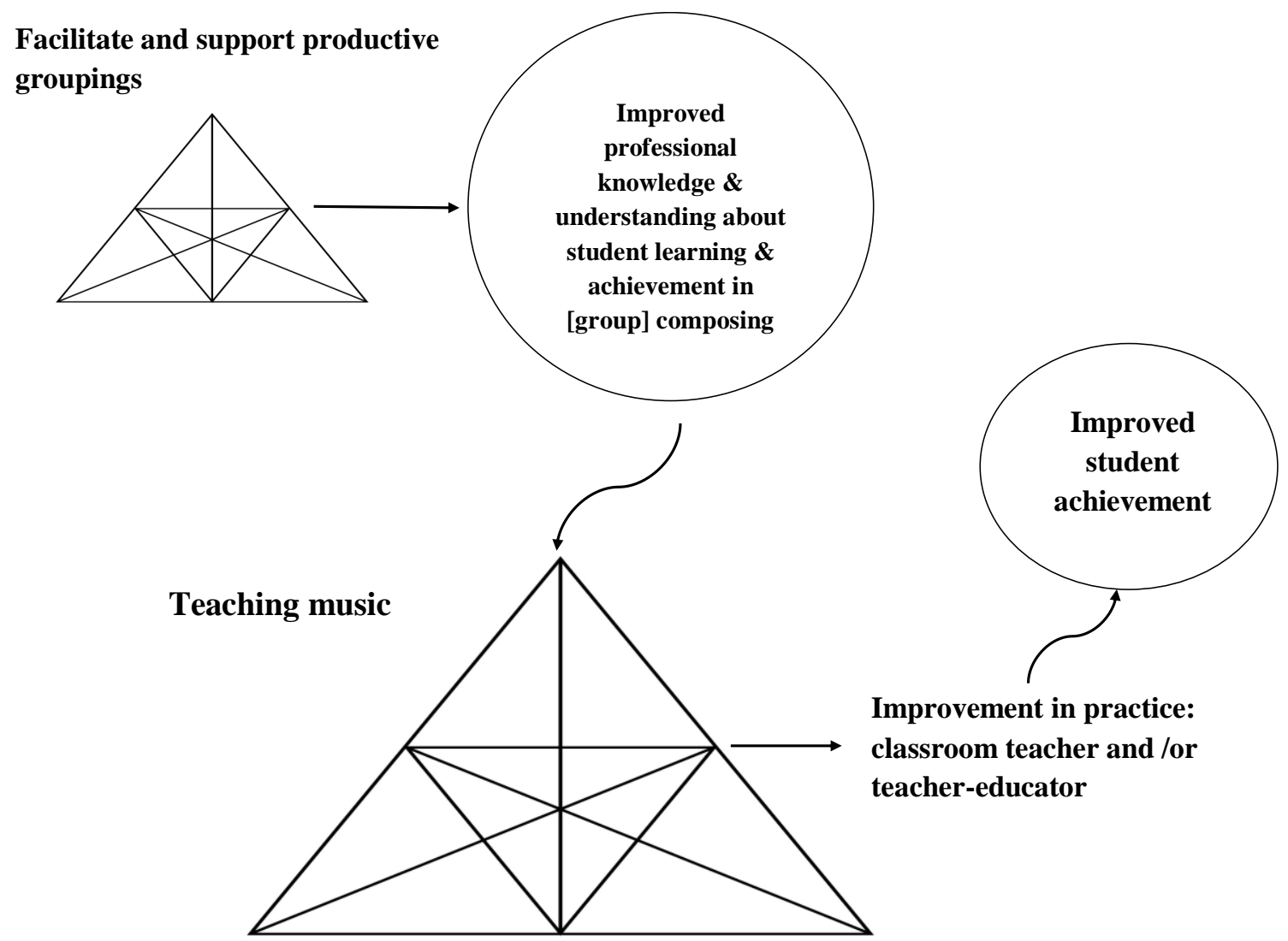

Figure 8.5. Nested activities of professional learning associated with group composing

The relationship between teaching music and assessing group composing is discussed in the following sections.

\subsection{Assessment's purpose and function for group composing}

Assessments that reflect a socio-cultural view of learning such as AS91092, require a portfolio of self, peer and teacher assessed evidence, the meanings of which are constructed between the teacher and the students (James, 2012). Observation of the process and the actual composition itself was not sufficient because Alice, David and I could not know all that went on among and between group members. A broad range of evidence was therefore needed to adequately assess the complexity of each student's responses and subsequent contributions.

In the present study these contained running records of student actions, self, peer and teacher assessments of CCP, the two compositions, audio and video recordings and the written representations. (See Figure 8.6.) 


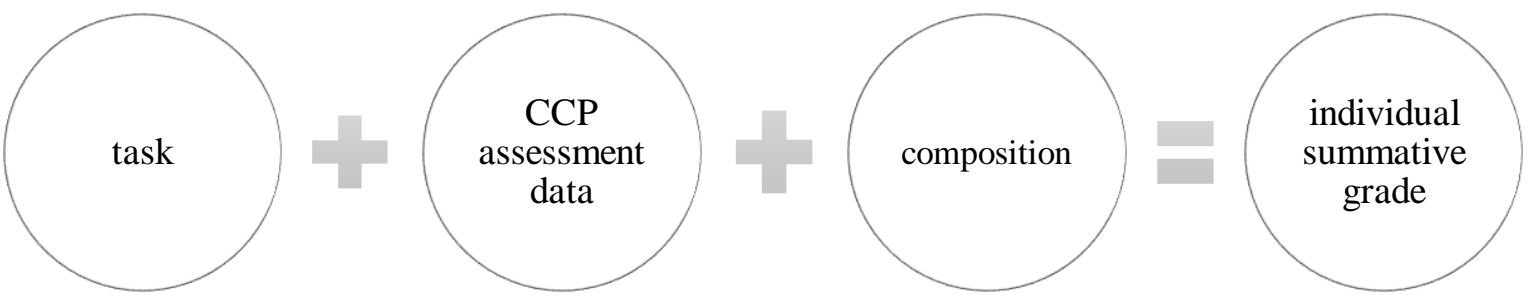

Figure 8.6. Portfolio of student evidence

\subsubsection{The assessment dimensions of group composing}

While portfolios were used to arrive at an NCEA grade for each student, the data arose from within multiple assessment dimensions and had multiple purposes. As explained in Chapter 2, a useful conceptual framework for a discussion of these dimensions is derived from Harlen's (2012) assessment concepts. These are reinterpreted in terms of group composing assessment in the table below.

Table 8.1. The assessment dimensions of group composing (adapted from Harlen, 2012, p.98)

\begin{tabular}{|c|c|c|c|c|}
\hline \multicolumn{2}{|r|}{ Formative } & \multicolumn{2}{|c|}{ ه } & Summative \\
\hline & $\begin{array}{l}\text { Informal- } \\
\text { formative }\end{array}$ & $\begin{array}{l}\text { Formal- } \\
\text { formative }\end{array}$ & $\begin{array}{l}\text { Informal- } \\
\text { summative }\end{array}$ & Formal-summative \\
\hline Major focus & \multicolumn{2}{|c|}{$\begin{array}{l}\text { What are the next steps for learning } \\
\text { to group-compose? }\end{array}$} & \multicolumn{2}{|c|}{$\begin{array}{l}\text { What has been achieved in terms of CCP, } \\
\& \text { composition/s as a whole? }\end{array}$} \\
\hline Purpose & $\begin{array}{l}\text { Teacher: support } \\
\text { students to } \\
\text { compose } \\
\text { stylistically } \\
\text { controlled or } \\
\text { assured music. } \\
\text { Support formation } \\
\text { of productive } \\
\text { groupings. }\end{array}$ & $\begin{array}{l}\text { Teacher: } \\
\text { inform next } \\
\text { steps in teaching } \\
\text { Group } \\
\text { composers: } \\
\text { inform each } \\
\text { other of next } \\
\text { steps to } \\
\text { successfully } \\
\text { complete their } \\
\text { composition }\end{array}$ & $\begin{array}{l}\text { Teacher: monitor } \\
\text { progress towards } \\
\text { NCEA achievement } \\
\text { \& to inform next } \\
\text { steps in teaching } \\
\text { Group composers: } \\
\text { inform next steps to } \\
\text { successfully submit } \\
\text { the composition, } \\
\text { representation \& } \\
\text { recordings for } \\
\text { AS91092 grading }\end{array}$ & $\begin{array}{l}\text { Teacher: grade } \\
\text { group \& individual } \\
\text { achievement, award } \\
\text { AS91092 credits }\end{array}$ \\
\hline Evidence & $\begin{array}{l}\text { Back-engineering } \\
\text { compositional } \\
\text { exercises, "flow" } \\
\text { data, informal } \\
\text { teacher } \\
\text { observations \& } \\
\text { discussions with } \\
\text { groups using } \\
\text { conceptual model } \\
\text { as a framework }\end{array}$ & $\begin{array}{l}\text { Incomplete } \\
\text { composition \& } \\
\text { associated } \\
\text { student CCP } \\
\text { data, teacher } \\
\text { interviews with } \\
\text { groups } \\
\text { (peer/self } \\
\text { assessment) } \\
\text { using } \\
\text { conceptual } \\
\text { model }\end{array}$ & $\begin{array}{l}\text { Completed } \\
\text { composition \& } \\
\text { associated student } \\
\text { CCP data, teacher } \\
\text { interviews with } \\
\text { groups (peer/self } \\
\text { assessment) using } \\
\text { conceptual model, } \\
\text { NAME slider, } \\
\text { (written feedback?) }\end{array}$ & $\begin{array}{l}\text { Two or more } \\
\text { compositions, } \\
\text { video/ audio } \\
\text { recordings, written } \\
\text { representations, } \\
\text { individual's CCP } \\
\text { data, teacher } \\
\text { interviews with } \\
\text { groups (peer/self } \\
\text { assessment), } \\
\text { written feedback }\end{array}$ \\
\hline
\end{tabular}




\begin{tabular}{|l|l|l|l|}
\hline $\begin{array}{l}\text { Basis of } \\
\text { judgment }\end{array}$ & $\begin{array}{l}\text { Student \& } \\
\text { criterion } \\
\text { referenced } \\
\text { (musical style) }\end{array}$ & $\begin{array}{l}\text { Student \& criterion referenced } \\
\text { (musical style, conceptual model \& } \\
\text { AS91092) }\end{array}$ & $\begin{array}{l}\text { Criterion } \\
\text { referenced } \\
\text { (AS91092) }\end{array}$ \\
\hline Judged by & $\begin{array}{l}\text { Teacher \& group } \\
\text { composers }\end{array}$ & $\begin{array}{l}\text { Teacher (composition) } \\
\text { Teacher \& group composers (CCP) }\end{array}$ & $\begin{array}{l}\text { Teacher \& NZQA } \\
\text { national moderator } \\
\text { for Music }\end{array}$ \\
\hline $\begin{array}{l}\text { Action taken } \\
\text { Eeedback to } \\
\text { students \& } \\
\text { teacher about } \\
\text { stylistic } \\
\text { productive } \\
\text { groupings. }\end{array}$ & $\begin{array}{l}\text { Teacher: feedback into teaching plans. } \\
\text { Group composers: feedback into } \\
\text { compositional processes }\end{array}$ & $\begin{array}{l}\text { Report to student, } \\
\text { parent, NZQA. }\end{array}$ \\
\hline Epithet & $\begin{array}{l}\text { Assessment for learning. } \\
\text { Assessment as learning. }\end{array}$ & Assessment of learning. Marking. Grading \\
\hline
\end{tabular}

These definitions are used in the next sections to examine the functions and purposes of assessment for group composing.

\subsection{Assessment dimension: formative}

Hattie and Timperley (2007) contend that students need three key questions addressed when receiving feedback on their work: "Where am I going?", "How am I going?", and "Where to next?" (pp.88-90). This kind of feedback has been identified as having a powerful influence upon learning and achievement (Black \& Wiliam, 2009; Hattie \& Timperley, 2007; Willis, 2011). Both the Kotare and the St Bathan's data strongly suggest that sharing a conceptual model of the process in which the students were engaged enabled group composers and their teacher to engage in assessing the learning together, and thus address Hattie and Timperley's key questions.

For group composing, valid feedback requires dynamic formal and informal assessment conversations between teacher and group composers. Sometimes, these conversations might be just a data-gathering exercise, such as when Alice interviewed Aaron about his CCP. On other occasions, however, informal formative assessment can take the form of conversations between creative artists and a more experienced musician, the teacher, within a "workable space, a landscape for exploring the curiosities of a given genre" (Allsup, 2003, p.35). In this context, there is some evidence to suggest that these can be learning occasions for everyone. 
Recording the outcomes of feedback was found to be very challenging, however. As has been explained in Chapters 5 and 6, it is one thing to have an informal conversation with a group of boys about their composing, and quite another to gather, store and interpret the hard data (written or videoed) about what happened, when there are 17 other students also needing attention. This tension is examined in 8.6.4.

\subsubsection{Using a conceptual model for formative assessment}

While many scholars represent the process of composing as conceptual models, few have shared these with students with the intention of engaging with them in the process. Savage and Challis (2002), and Tsisserev, (1997) do provide some evidence that once students had an understanding of the process in which they were engaged, they were better able to monitor and engage in the compositional process.

Tsisserev explains that a conceptual model enabled helping young (solo) composers to become aware of the creative filtering of ideas during the exploratory process that is, in essence, an act of self-assessment. Tsisserev also employs a conceptual model to assess "weak" or "strong" compositional skills, noting that weak composers tended to stay in exploratory phases rather than moving on to refine and structure their pieces (p.191).

In the context of the present study, there is compelling evidence that sharing a conceptual model of group composing with students provided Alice and David with a conceptual framework for discussions about process, and that these conversations entailed assessment of various kinds.

\subsubsection{Informal-formative discussion}

Firstly, in order to verify participation in the process, the model acted as an informal-formative tool to uncover and then discuss the extent of individual students' CCP. This assisted the teachers to gather evidence for making formal-summative judgments.

For example, following a discussion with Alice, Jay realised that he needed to make more of an active creative contribution to process on a macro level, rather than just play along with Jimmi. Jay reported that he was quite motivated to achieve AS91092 and this may be why he subsequently took a far more proactive role, leading to the inclusion of his ideas in the second composition, and the attainment of $A S 91092$. 
David used the model in a similar way, but also to give the boys targeted feedback and feed-forward about their composing.

That gave me a very clear idea of where they were at [VT: and them too?] ... and them too, which meant that my feedback could be a lot clearer and a lot quicker and a lot more tailored to exactly what they needed to do to achieve.

David reported that in discussions framed by the model he and the boys were able to tease out the complexity of their diverse contributions, particularly those made by the rhythm section players, thereby verifying individual CCP. The students reported that the model provided them with a framework so that they knew where to go next.

Angus: You kind of know where to go from there, so you can follow a cycle and you know what steps you're actually in, and what to do next and build on.

Furthermore, sharing the conceptual model with the whole class enabled discussion about the nature of the composing, providing a common framework and series of terms for the St Bathan's students to locate themselves and their composing within the process, as my observational notes show:

Observation 8. 12 March. Boys spend about five minutes filling in their progress report about their week in terms of music learning. David uses the terms in the model to talk them through how they might use the tool on p.109 [of the class handbook]. He says "One thing I noticed last week was that there were a lot of critiquers coming through". One boy said "Sir, we're in focused stage". One boy asks "Can we be on both stages at once?" Class discussion about how this is quite possible when group composing.

\subsubsection{Feedback and emotional safety of group composers}

Feedback can be both positive and negative for learning (Hattie \& Timperley, 2007). This is particularly the case when giving feedback to students about their composing (Hickey, 2012). As discussed in Chapter 2, the subjective nature of artistic expression is problematic for assessment systems (Eisner, 2002). Furthermore, adolescent identification with band membership as well as the socio-musical cultures associated with certain musical styles might mean that feedback about composing might tread upon very personal ground indeed (Green, 2002; McDonald, et al., 2009; Tarrant, et al., 2001) Teachers' feedback to student composers needs to be timely, facilitative and above all sensitive to a student's creative ideas because these ideas are linked to the student's musical identity (Hickey, 2012; McDonald, et al., 2009; Wiggins, 2007). 
How students receive feedback is also closely linked to their beliefs about themselves as successful learners and therefore must be given in an environment of emotional safety (Earl \& Katz, 2008; Hickey, 2012). As Hattie and Timperley (2007) explain, "at the self-regulation level, the commitment to goals is a major mediator of the effectiveness of positive and negative feedback". (p.99). This study has shown how students view their group composing (NCEA activity, or as a social-jamming activity) may also be a key variable in their motivation to complete and submit their compositions.

Furthermore, in group composing, processes, resources and ideas are distributed across the group so that compositional process and product have the potential to become shared artefacts owned by all members of the group, regardless of the extent of individual CCP (Fautley, 2005; Thorpe, 2012). Therefore, negative feedback to one group composer may have repercussions for others. Therefore, the way assessment is framed has a bearing upon subsequent student motivation to achieve.

\subsubsection{Ethical concerns about the assessment of low-achieving students' CCP}

While some of the Kotare students seemed to find that the model provided them with a safe structure within which to work and to receive feedback, for at least one student (Aaron) receiving feedback on his CCP may have been a negative experience that did not lead to his engagement or subsequent achievement. Aaron indicated that he did not value achievement in NCEA music, but did value jamming in the band with his friends. As explained in Chapter 5, receiving negative feedback about his lack of CCP may have been de-motivating for Aaron.

Like Sarah in the pilot study, David had ethical concerns about grading the CCP of novices. He was also worried about the effect of negative feedback upon novices or students who lacked confidence. This was one of the reasons why he said he was reluctant to formally grade the first composition of Big Group:

That's how to shut someone down ... For someone like [Chris] who's never done this before, that's going to reinforce the idea that this is hard. I'm conscious of that.

David and I avoided giving the Big Group boys an informal-summative grade of Not Achieved, focussing instead upon informal-formative feedback, framed as an opportunity for achievement. I had Aaron in mind when I made the suggestion below: 
So maybe you sit down with those boys and say "Well, so far, so good. Some people in the class have been given theirs and have managed to get to this level. I don't think you are quite there yet and this is why. But that's OK because this is a practice run and here are the suggestions that I have for you" ... "You need to do this, and this and this." ... Say, "you're nearly there. Great, go for it" and be encouraging.

In her discussion of the relationships between formative and summative assessment, Harlen (2008) asks, "Can evidence used to summarize learning be used to help learning? Can evidence collected and used to help learning be used for summative purposes?” (p.141). Boud (2009) and Fautley (2010) also assert that assessment is able to do "double duty", so that formative assessments made to enhance and support learning also inform summative judgments, and vice versa. While most of David's class received a formal-formative/informal-summative grade for their first piece, the Big Group boys did not because we made the ethical decision to frame the assessment data within the dimension of informal-formative. All of the Big Group boys went on to achieve AS91092 with no evidence of having been negatively affected by this feedback, including Chris, the novice student, who ultimately achieved an Excellence.

\subsubsection{Using stylistic exemplars as assessment models}

If students are aware of the quality of the work the teacher is aiming for them to produce then they are much more likely to aim for this quality themselves (Sadler, 1989). Sadler (2012) asserts that this is the prerequisite for students taking responsibility for their own learning and for setting their own learning and achievement goals. Exemplars can also act as success criteria for the students, showing them what they need to aim for (Black \&Wiliam, 2009). The back-engineering strategy was underpinned by these assessment principles.

There is some evidence to suggest that this strategy and its accompanying stylistic examples helped the students to formatively self and peer assess their work by comparing it to musical styles they were emulating. The Kotare data indicate that to group-compose at school, the students needed to be able to make explicit links between their informal music making, the music they enjoyed listening to ,and their learning in class. This was only marginally successful however, leading me to build on what I had learned from this in the work I subsequently did with David.

\subsubsection{Assessment practice changes teaching practice}

In order to complete the back-engineering tasks, the St Bathan's students needed to refer back to the examples that they had deconstructed earlier during class 
discussion and thus assess their own work and that of the others in their group. Using a combination of the kinds of informal and formal assessment practices described above, David, and I ascertained that while the students had completed the first collaborative creative task fairly successfully, we had not fully engaged their musical understanding of musical style.

These evaluations helped us to understand that unless students' preconceptions and prior knowledge of the world is linked to their learning in the classroom, they may fail to grasp the purposes of an activity, and thus fail to make meaningful connections to their own learning (Bransford, Brown, \& Cocking, 2000). Therefore, because the initial task did not in itself mean much to the students, they were not inclined to engage in assessing their own learning against the stylistic exemplars. Thus, an examination of our assessment practice led to refinements in teaching practice.

Once implications of this had been understood, the changes David made to his practice supported the students to compose more stylistically controlled music in these and subsequent tasks. Crucially, because David ensured that he shared this understanding with the students, they also gained understanding about what they were doing and thus were able to assess the success, or otherwise, of their composing:

Angus: Personally I think the second one we came up with is better.

Rob: It's catchy... it's got a bit of a more in the lyrics. We're calling it a ballad of Angus's love life and it's a bit funnier. I think it's a bit more musically talented. It kind of brings out a bit more than the last composition did with just four chords and just keep playing that.

Fraser: This is three chords, isn't it?

Rob: $\quad$ Yes, but it's got a solo.

Furthermore, some were able to transfer this learning back to their day-to-day experiences of music, an act of assessment as learning by "active, engaged and critical assessors who make sense of information, relate it to prior knowledge and use it for new learning" (Earl \& Katz, 2008, p.91):

Rob: I'm so much more critical of music now and it's ridiculous.

There is also some evidence to suggest that the ability to assess their own work enabled some students to learn autonomously and thus evaluate the success, or otherwise, of their efforts: 
Alex: $\quad$ You get more independence. Because you're controlling what you're doing I guess. You're not waiting for the teacher to tell you what to do. They give you the guidelines and then you have freedom to make what you want out of it.

\subsubsection{Task design and assessment criteria: tensions, contradictions and dilemmas}

Both the assessment process and the instrumentation used to carry out assessment must be appropriate to the learning being measured, and closely aligned with it (Bennett, 2011; Newton, 2011). As has been shown in the last section, there is some evidence to show that sharing the compositional process explicitly with the student, and linking this to stylistic examples, helped to clarify the assessment process for both David and his students. (See Figure 8.7.)

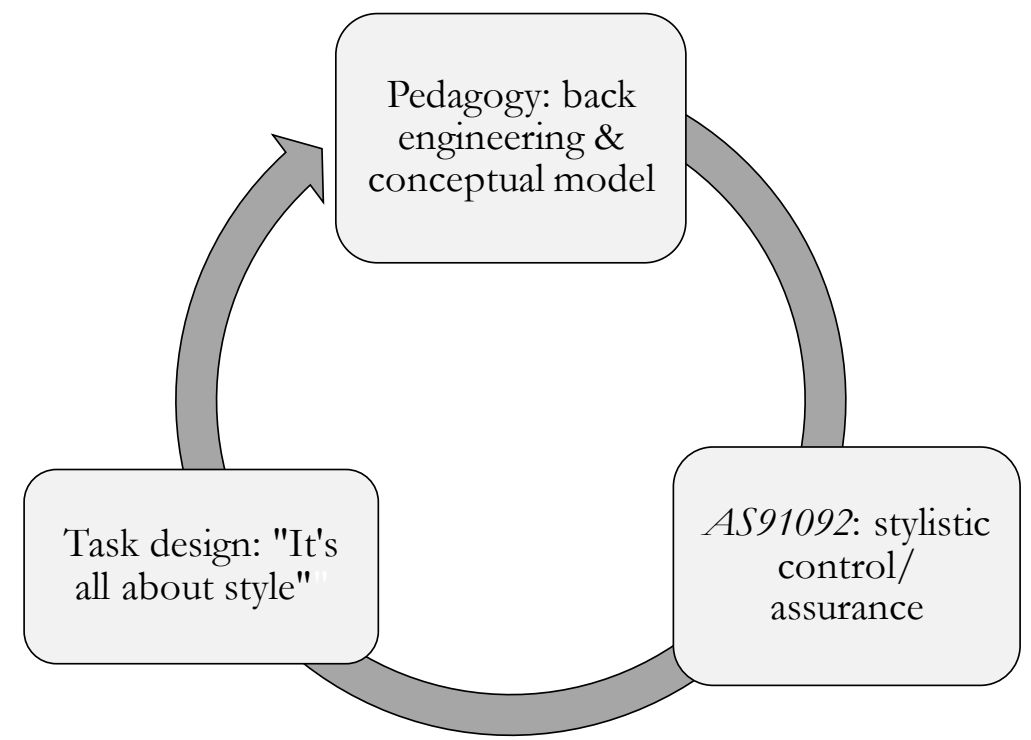

Figure 8.7. Alignment between task design, pedagogy, and assessment criteria

Engaging with both teachers in the formal-formative processes required for the NCEA was not as successful. For example, Alice chose not to use the highly detailed exemplar tasks and assessment materials provided by NZQA because she did not believe that a written task or assessment criteria would be meaningful for either her, or her students. The poster she provided, based on the criteria for Achieved, was the only written assessment information available to the students.

David did not engage with the NZQA materials until he and I had addressed his anxiety associated with formal-summative processes. While the aim of the backengineering strategy was to provide the students with a platform upon which to compose at Merit and Excellence level through achieving stylistic control of their 
compositions, what was missing from the first task was clear, written criteria for achievement.

David and I agreed that a highly detailed rubric might have a limiting effect upon creative responses to tasks because it could channel the students in prescribed ways, "promoting routine over non-routine approaches" (Black et al., 2011, p.457). However, when we re-examined the compositional task we could see that the task itself invited a multiplicity of responses. These kinds of responses are referred to by Swaffield (2011) as "expressive outcomes", arising from tasks that Eisner (2002) likens to design specifications, rather like an architect's brief, where outcome are both intentional and potentially unexpected. The evaluation of such outcomes is therefore "rooted in a sense of quality and an appreciation of the unexpected" (Swaffield, 2011, p.440). It seems that at least some of the students viewed the task in this way:

Angus: It all starts off from what you want to do. There might be a guideline, like, the one we're doing now is composing and you've got to have a genre and you've got to identify it as that genre. But other than that there's no guidelines, you can pretty much run free on what you want to do.

If the task itself is designed well enough so that the expressive outcomes lead the students to achieve within the criteria of the summative assessment, then this raises the questions of the utility of an assessment schedule. Was it really necessary? And who, in fact, was it for? While the St Bathan's composition tasks included specific requirements (composed in a specific style, recorded, written down in some form), the quality and nature of the students' responses to the task depended on their choice of style or genre.

\subsubsection{Student responses to the task and to the assessment criteria}

There is evidence to suggest that even if the students had had access to written assessment criteria, they might not have used it. Certainly the Kotare boys did not read written instructions other than the poster on the classroom wall, and the St Bathan's boys seemed to regard the composition task as a guideline, rather than a list of instructions. While none of the student participants had access to an assessment schedule when composing, all who completed compositions could tell me what they needed to hand in to their teacher to "get" AS91092. 
While Alice did not focus on the Merit or Excellence criteria, I observed David use an assessment criterion ("stylistically assured") when giving feedback to the Big Group students. Yet none of the student participants in the study actually received written criteria specific to the back-engineering task until after they had completed their first piece. This is probably why none of the St Bathan's students could tell me what they needed to do in order to achieve at Merit or Excellence level:

Angus: No, we haven't got a marking schedule.

Fraser: We don't really look at that.

Fraser implies that, as collaborative composers, referring to a written marking schedule is not part of the practice of their group-composing community. None of the students seemed concerned about this, and the Pikachu boys thought an assessment schedule for composing was meaningless.

\subsubsection{Popular music sets the benchmark, not AS91092}

Like the students in the pilot study, the criteria the St Bathan's boys used seemed to be their own, based upon their enjoyment of popular music:

Anna: I'm not expecting to hear it on the radio or anything. [PSII]

VT: $\quad$ So what would Excellence be?

Oliver: More like that you can really, really listen to it and read the music.

Alex: I'd say enjoyable to listen to. [BSIIR]

It is clear here that Oliver is offering his personal opinion, rather than telling me about set assessment criteria, although he did tell me that a clear representation is required for an Excellence grade. Alex may also have been speculating because in the same interview he commented, "I don't know what to mark it against, coz I don't know." [BSIIR]

\subsubsection{If the task is well designed, are written criteria really necessary?}

Despite the lack of explicit assessment criteria, all of the student participants who completed composing for AS91092 achieved the standard, and all but one student (Jay) did so at either Merit or Excellence level. The Blues Rock boys composed stylistically controlled music, not because Alice and I had set them the task of doing so, but because Jimmi had learned from his friend Mario how to play riffs and improvisations in a particular style, and Jay and Rāwiri learned to accompany him in a stylistically appropriate manner. 
There is some evidence to indicate that, because the composition tasks at $\mathrm{St}$ Bathan's required the students to compose stylistically controlled or assured music, then the students were placed on a trajectory for Merit and Excellence achievement in any case. By completing both tasks, the St Bathan's students composed music that met the assessment criteria of AS91092 because they were required to compose music that was recognisably stylistic.

In contrast, group-composing students who did not achieve the standard (Heavy Rock boys, Island Reggae boys, and Aaron) did not complete even one composition. As has been explained earlier, this was for a number of reasons, some of which are known, and some of which are unknown. It seems that composing two pieces, recording and writing them down is an achievement in itself, whether or not the composition is of a certain standard. This also underlines the challenging nature of composing (Burnard, 2007; Hickey, 2012; Odena, 2012a). Whether or not these students might have benefitted from having access to detailed assessment criteria is not known. Given the significant motivational and pedagogical issues related to their achievement at Kotare College, it seems unlikely.

\subsection{Assessment dimension: summative}

Each of the groups was required to submit two compositions for AS91092, so that each group member could potentially receive not one but five grades: one for each composition, one or two or even three for their CCP, and one official Achieved, Merit or Excellence grade for AS91092 that aggregated each boy's achievement for the two compositions.

1. Assessing the CCP of each group member

2. Grading two compositions

3. Aggregating and/or rationalising grades from 1 and 2 in order to award a single, summative grade to each student.

Arriving at a summative grade for each student was not merely a matter of assessing a single piece of evidence as one might do for a test or written examination: a broader perspective is required. A socio-cultural focus on assessment necessitates holistic rather than atomised judgment (James, 2008). This means that formalsummative assessment entails the evaluation of an evidence portfolio of student achievement data derived from collaborative interactions within the group. 
For solo composers, all Sarah, Alice or David had to do to grade the work was to assess two pieces and written representations, and then aggregate the two grades as one. The formal-summative assessment of group composing, however, required the aggregation of data across a wide variety of evidence, gathered over time, for each group member. Making these kinds of judgments' is more difficult than those based on one or two pieces of evidence but also has the potential to provide a richer, and thus more credible, view of a student's achievement (Bennett, 2011).

\subsubsection{Teacher identity and cognitive domain knowledge when assessing individual CCP}

In the pilot study, Sarah made the decision just to verify $\mathrm{CCP}$, rather than qualitatively assess it. In contrast, Alice, David and I made the assumption that in order to verify meaningful participation in the creative process, individual students' CCP must be graded, although the achievement standard is by no means clear about this.

Bennett (2011) contends that good pedagogical knowledge is not sufficient to assure effective assessment practice but that teachers need to have "deep cognitivedomain understanding and knowledge of measurement fundamentals" (p.18). It was not enough to know about music teaching and composing. We also needed knowledge of assessment. None of us was experienced in assessing CCP within the context of $A S 91092$, yet each of us brought a different level of experience and domain-related knowledge to the act of CCP assessment.

At least three sets of cognitive-domain knowledge were brought into play when we summatively assessed CCP. These three domains relate to the identities discussed in Chapter 3: musician, music-educator and teacher-educator, linked to the assessment conceptions discussed earlier in this chapter. Teacher identities played a significant role in the way each of us approached the task of summatively grading CCP.

Alice tended to make judgments as a musician, rather than a music educator. For example, she expressed doubt about the validity of Jay's CCP because it was almost always in response to Jimmi's musical and creative leadership. In her experience as a session musician, this did not make him a composer:

I've been in lots of situations where someone is doing a recording and I'm playing [my instrument]. I might invent something and they might like what I invent and it might get used on the recording but I still don't really feel that I was a co-writer in that song. I'm using my [instrumental] skills to make their song sound as good as I can. Studio musicians do that all the time. 
In contrast, David's judgments were generally from the perspective of a music educator and also reflected his socio-cultural view that the learning was situated and therefore a student should be rewarded for the progress he had made and for his participation in process with other students, rather than judged against external, standards-based criteria:

When I was reading your article [Thorpe, 2012] I was thinking about when I wouldn't give a Not-Achieved to someone who was group composing, and the only time I would do that would be if they were actively disrupting the group, or just not showing up, which is passive disruption. That would be the only time I would Not-Achieve because I think if you are there, even if you're not going "hey what about this, what about that?" I think you're still contributing to the composition.

When assessing or discussing CCP with Alice or David, I was aware of my dual roles as both music educator and teacher educator. This awareness influenced my responses when discussing or assessing CCP with both teachers, particularly when we were wrestling with the problematic issue of grading a drummer or bass player's CCP. For example, sometimes when David and I were engaged talking about how we might grade CCP, I was also guiding his thinking about practice:

$V T: \quad$ The role of different instruments in the group composing process ... "what's my role in the kind of music that we're aiming to create? What do other people do when they play this music? Let's unpack some of the patterns that we hear in this kind of music, for my instrument." I can see you smiling: do you like where I'm going with this?

David: I was thinking today I had my Year 10s playing the songs they had done so far. The bass players, and only one of them was a bass player, and the other group he just picked the bass up and worked it out. They kind of knew what the role of the bass player was.

$V T: \quad$ Intrinsically?

David: Yeah, intrinsically.

$V T: \quad$ Why was that do you think?

David: Probably because they've listened to that genre so much and they've sort of become experts in that genre. Oh ... really interesting! [tone implies that he's just realising this].

Despite expressing some doubts about the validity of Jay's contribution as a bass player, Alice was more prepared to consider Rāwiri's CCP as being valid because he was a more skilful musician, although she remained doubtful about his overall contribution. I used this as an opportunity to suggest to Alice some pedagogical responses she might choose to make in the future: 
$V T: \quad$ I'm thinking about teaching composition next year, to say "let's have a think about some of the roles in a band. You drummers one of your roles might be to..." Let's unpack what everybody does within that structure.

Alice: Yes, when you think about it, without Rāwiri's skills it would have been a much lesser band. He brought a hell of a lot to the band.

$V T: \quad$ What did he bring?

\subsubsection{Interpreting assessment criteria}

When I first began the project, the Merit and Excellence criteria, "stylistically controlled" and "stylistically assured" seemed hard to interpret. At Kotare, however, I observed that the students' paucity of knowledge about musical forms, structures, styles and genres severely limited their ability to communicate meaningfully, creatively and productively with one another. I had previously observed three groups of young people communicating with great stylistic assurance about music that they all knew well, and in which all were thoroughly enculturated (Thorpe, 2008). There is considerable evidence that students who possess such knowledge are able to make significant contributions to the creative process, not just through playing their own instrument, but also through engaging in the entire collaborative compositional process because they have the stylistic and musical knowledge to do so (Fautley, 2010; Hickey, 2012).

At St Bathan's I also observed that students who were able to apply their stylistic knowledge (even bass players and drummers) were also able to make significant contributions to compositional process in its fullest sense, that is, macro CCP. Students who achieved at Merit and Excellence level were those who had the knowledge and skills (acquired informally and through back-engineering) to compose music that was stylistically controlled and/or assured.

\subsubsection{Inhabiting our castles: power relationships when making assessment judgments}

At no point was the delineation between the teacher and teacher educator "castles" of school and university more obvious than when we came to award summative grades to the actual compositions (Somekh, 1994). Both teachers told me that they regarded me as the NCEA "expert" whose opinions were more likely to be "right" than their own. While I did have more experience of NCEA assessment than they, unless I had a very clear understanding of the CCP of each group, then my judgments could not be valid. Until now this had been privatised practice for both 
teachers and neither had had the opportunity to share their assessment judgements with another teacher (Wyatt-Smith, Klenowski, \& Gunn, 2010). Both teachers seemed to lack confidence and had not sought to share their assessment judgements with colleagues or peers. There is considerable evidence in the literature that such assessment collaborations are highly beneficial to teacher practice (Black et al., 2011; Crisp, 2012).

\subsubsection{Gathering summative CCP data about each student is stressful and demanding in a large class}

Gathering CCP data required methodical and well-organised administration. While gathering a portfolio of evidence for each group composer at Kotare was fairly straightforward because there was only one group of students to assess, Alice found this stressful because she had 17 other students to keep an eye on when she did so. Alice may have also found gathering CCP data stressful because it required her to document the low level of achievement of many of her students.

Initially, David struggled to gather any written or videoed CCP data for the first composition. Although we had made extensive plans in January 2012 to methodically collect CCP data about individual students, as explained earlier, when overworked and stressed he tended to revert to his previous practice of relying on his memory about students. While this had been a fairly straightforward process for David in the previous year (when he only had three students to consider), assessing the CCP of twelve students in a class of 20 was challenging. Once the underlying issues associated with David's avoidance of written assessment had been addressed however, he went on to methodically gather written and audio CCP data through interviewing the students and using the conceptual model as a framework for doing so. Nevertheless he reported that he continues to struggle with managing the large amount of data this generated, particularly the digital data. This is an aspect of teacher practice that was not sufficiently explored in this study and will be discussed in the next chapter.

\subsubsection{CCP and the validity of formal-summative judgments}

Judgement can sometimes precede analysis, emerging as a feeling or gut reaction, particularly when the assessment involves the examination of relatively ephemeral qualities such as creative flair (Black et al., 2011). Analysis of observations and the interview data reveal that both teachers tended to use written data as memory prompts to verify and justify holistic judgments, based on gut feelings and intuition, 
about a student's CCP observed over time. These terms also emerged as significant in the NVivo analysis. For example, Alice frequently used such terms when grading CCP which she based upon her extensive experience as a musician.

I've got to go by my gut feeling, my experience of hearing music and things. And I feel pretty confident about that sort of thing these days, because I know this composition is good.

At first, David did not believe he that knew about the CCP of all of the group composers, but our discussions served to prompt his memory.

David: I could probably say for [Big Group], I could probably say I do know who did what in that group.

$V T: \quad$ How do you know that?

David: Because they were in here, they were under my nose. And so I witnessed it. The trio of Indie Rock, I know who contributed what in that group too.

$V T: \quad$ Why?

David: Because I don't know if I visited them more but for some reason their progress stuck in my head. I think I was impressed because of the equal input I saw similar to last year's [Pikachu] group. Where each of them had their own role instrumentally they were all building their parts equally together. Whereas unlike the [Big Group] that was in here which seemed to be more run by Richard.

David: There's Action Movies. [Looks through his records]

$V T: \quad$ That was a piece they had already composed wasn't it? From last year in Year 10?

David: And that was fine.

$V T: \quad$ How do you know it was fine?

David: Because I've seen them working on it since last year. I've seen the contribution each boy has made to that. It only started off with Rob and Fraser last year and then they added Angus to the mix this year.

$V T$ Why did Angus join the group? What was his role?

David: Because they needed a drummer. They needed someone to develop a drum part. And Angus did that. So his contribution was equal then to the other two.

This is a common assessment practice for teachers, sometimes referred to as the "log in the head" (Parr \& Timperley, 2008, p.58). Sarah seemed to be describing such a process when she said: 
I'd like my sort of written log which is just very brief statements, so I can build up a mental progression in my head, because that's the way, you know.

As Parr and Timperley observe, these kinds of judgments are "seldom recorded and available for systematic examination and reflection" (p.58). While the recognition of quality is an act of evaluation in itself (Eisner, 2007), subjective, intuitive judgments have the potential to be challenged as invalid, variable and inconsistent if there is no hard evidence available for others, such as the NZQA external moderator, to verify them. Experienced assessors are able to look below surface features to draw inferences and thus create sets of conjectures to account for a student's achievement. However, less experienced assessors with lower levels of professional skills and domain-specific knowledge are not able to do so with the same degree of validity (Bennett, 2011; Sadler, 2012).

In effect, summative assessment judgments risk being seen as personal opinions unless validity can be demonstrated through professional expertise. Gut feeling and intuition, while valid in some contexts, are insufficient for a qualifications system like the NCEA because it requires explicit, written accounts of how judgments are made.

\subsubsection{Plausible rather than accurate}

Presenting evidence of a valid pathway to achievement, rather than the recorded evidence of achievement itself, emphasises the plausibility of the assessment process, rather than its accuracy (Allal, 2013). Allal contends that "accuracy implies that a competent professional is able to apprehend correctly a true state of events and act accordingly; plausibility implies that a judgement or decision is socially constructed in a manner that is persuasive for all concerned parties" (p.23). In this instance, shared understanding and acceptance between concerned parties is more valuable than a single, albeit accurate, grade where the act of assessment is itself socially situated practice (Allal, 2013).

While verifying formative or even informal-summative judgements this way is entirely appropriate, the validation of formal-summative judgements for qualification requires hard evidence of student achievement because the grade is part of an external qualification system and thus accountable to the wider community, not just the community of the classroom. Tensions may arise when socio-cultural assessment practices appropriate in the classroom intersect with cognitivist assessment 
requirements related to external qualifications like the NCEA. This was why a portfolio of evidence was needed for AS91092 that related directly to the external criteria of the achievement standard. How all that evidence is aggregated into a single grade must therefore be one of professional, qualitative judgement rather than a simple adding up of marks. What was missing in this study were nationally moderated exemplars of group composing, which, at the point of writing this thesis, have yet to be made available to teachers. Teachers are expected to provide their own exemplars of NCEA-assessed work, collected over the years and verified by the national moderator (McPhail, 2009). Group composing was new to the NCEA in 2011 and neither teacher could refer to a collection of valid and nationally moderated pieces of student work.

\subsubsection{Professional and clinical judgement}

Individual CCP was often difficult to perceive because it occurred within the complex web of interconnected social and activity systems where cognition and creativity were often distributed (Fautley, 2005; Glăveanu, 2014; Wilson \& Myers, 2000). While the teachers and I observed the groups composing together over time, and used the conceptual model and back-engineering strategy as CCP assessment tools, we could not possibly know or see all that the boys did and nor could they tell us everything that happened. Furthermore, some boys were unable to explain to us what they did, possibly because they did not have the musical knowledge to be able to explain their processes, or because the nature of their interactions was just too complex for them to do so, or possibly because, like many teenage boys, they were not particularly articulate when talking with adults.

As Urmson (1950) observes in his classic article, "grading is something which you cannot in a full sense do without understanding what you are doing" (p.147). When assessing CCP it was necessary to rely upon our professional experiences and past knowledge as both teachers and musicians to make an interpretive synthesis of a range of data (Allal, 2013). If the design of a composing task can be likened to an architect's brief (Eisner, 2002), then the assessment of CCP can be likened to the clinical judgements made when a health professional examines a patient, bringing professional expertise to make a diagnosis based upon a range of diverse data (Bennett, 2011).

Assessment of this kind is a professional, inferential process where experience across multiple contexts enables professionals to make holistic, intuitive judgements, 
rather than atomised ones that merely tick off achievement against a list of external criteria (Sadler, 2012). Judgements like these are based upon years of experience in the field and are the strongest indicators of expertise (Sadler, 2012). There is an obvious implication here for teacher-educators that novice teachers, or those with little personal experience of composing, particularly in contemporary genres, may not have the professional skills and knowledge to interpret diverse data leading to valid judgements.

\subsubsection{The different roles of valid micro and macro CCP}

The previous chapters have shown that a student's instrument and its role in the construction of the composition were significant variables in the extent and type of $\mathrm{CCP}$ he made. For example, melodic players like Jimmi were able to compose riffs, themes and melodic lines. Consistent with the literature on group composing in bands, productive groups reported that their compositions began when a melodic player came up with an idea while jamming (Biasutti, 2012; Davis, 2005; Jaffurs, 2004).

The micro CCP of melodic players was usually identifiable and thus assessable because their musical line was perceivable. Often melodic players such as Jimmi, Jake and Rob, took lead roles in the compositional process, which also made the verification and assessment of their macro CCP relatively straightforward. Assessing a melodic player's CCP overall was therefore a matter of assessing the music itself because the boy's input was obvious, assuming of course, that he had composed what he was playing. The instrumental skills of melodic players were crucial in the compositional process and it is unlikely that the other group members could have completed a composition without them.

However, assessing the CCP of other players, particularly bass players and drummers, was more difficult. While it was possible for a group to compose a valid piece of music with a drummer or bass player who possessed barely adequate skills, (like Angus) or who could make only minimal CCP (like Jay), productive groups required competent melodic players (like Shin, Jake, Rob, Oliver, or Jimmi) to complete a valid piece of music. In fact, some melodic players explained that the reason they had chosen to compose in a group was to support a drummer or bassplaying friend who, due to the limitations of his instrument, did not believe he could solo-compose. Of course a bass player or drummer might compose a solo piece, but not if his stylistic frame of reference is restricted to popular music forms. This was 
also why a melodic player like Jimmi required a rhythm section to accompany him while he composed a melodic line.

Jimmi's method of composing recalls my Master's research (Thorpe, 2008) where I described the interactions of a band where a melodic player, somewhat like Jimmi, instructed the other (rhythm section) players exactly what to play. He did this to such an extent that the band could not really be described as collaborative. What I observed were the acts of a solo composer realising his creative intentions through others. In contrast to that group, Rāwiri was able to bring considerable instrumental skills and good stylistic knowledge to group composing and invite others to musically engage with him in structuring and refining the composition. This was not at first obvious however, and required Alice and myself to draw on considerable experience as teachers and musicians in order to recognise the validity of Rāwiri's $\mathrm{CCP}$, and eventually, Jay's. Nevertheless, the notion of multiple forms of authorship in group composing remains problematic.

\subsubsection{Assessing the CCP of novice players}

Playing a standard rhythmic or harmonic pattern, as defined by a melodic line composed by another student, cannot be a valid demonstration of a bass player's or drummer's compositional skills and knowledge. The Big Group experience for Chris also suggests that, at the very least, each student needs to be the sole player of their instrument. Even then, it is possible for music to be composed by other members of the group while a bass player or drummer participates in, but does not contribute to, the compositional process.

From a socio-cultural perspective this is a completely valid activity within a community of practice, where a less knowledgeable or experienced member of that community is still a legitimate member of the group's activity through peripheral participation (Wenger, 1998). However, from a formal-summative perspective, group composers needed to take an active role in composing the piece as a whole, not just their own part, because without evidence of macro CCP, their grade could not be comparable to that of a solo composer. Analysis of the discussions with Alice and David reveals that we were aware of this issue and strove to support such students.

The conceptual model proved a valuable tool for helping us all to examine the macro and micro contributions of bass players and drummers. Certainly there is some evidence to indicate that drummers can play a significant role in structuring a 
composition overall, provided that they are competent players. For example, crucial to the decision to award Achieved to Jay, a novice bass player, was evidence that he had moved from a musically passive role to a more active one.

Feedback and discussions with Alice prompted Jay to contribute at both micro and macro levels. He then went composed not only his own part for the second piece, but also part of the verse played by Jimmi and Rāwiri. It is significant that Jay chose to play the electric guitar and not the bass in the second piece because he was able to play the guitar more skilfully and make more of a contribution on a macro level.

\subsubsection{Validity of group composing grades for novice or low-achieving students}

It can be argued that the validity of some of the group composers' grades compared to those of solo composers might be questionable. Sadler (2012) asserts that the assessment of academic achievement requires evidence of the student's ability to perform "advanced types of tasks independently, on demand and consistently well" (p.12). This is not the case for some of the student participants.

Jimmi wrote out the charts for Blues Rock's pieces, because Jay and Rāwiri did not have the musical knowledge to do so. Neither boy was able to demonstrate that he was able to create a written representation of the music and so it is unlikely that either would have been able to achieve AS91092 by themselves. When viewed through a socio-cultural lens, the achievements of novice composers or marginally skilled players who could not have solo-composed, can be seen as occurring within a ZPD where peer influences enabled them to achieve more highly than they would have done on their own (Vygotsky, 1978). From the perspective of a teacher or teacher educator, this is more than just valid assessment, it is a good teaching.

Furthermore, there is considerable evidence to show that such students considered themselves valid members of a group-composing community of practice and, as such, had a right to share in the collective achievement of the group (Wenger, 1998). From the perspective of the group composers, this view of assessment is also completely valid. Novice or less skilled composers were entitled to their grade because their peripheral participation in CCP gave them legitimacy (Lave \& Wenger, 1991).

On the other hand, from her perspective as a musician, Alice questioned the validity and fairness of such assessments. For her, this was not what happened in the real world of professional music-making and therefore she did not believe that the 
educational benefits to novice students justified awarding them grades for something they could not achieve on their own. While Alice went on to award an Achieved grade to Jay and a Merit to Rāwiri, she said that she did so to enable the boys to gain NCEA Music credits, not because she believed that they deserved to do so.

Finally, when viewed from the perspective of a qualifications authority, it is conceivable that grades for novice students might be brought into question because they cannot be aggregated with those of solo composers. This question is examined in the concluding chapter in terms of implications for future research.

\subsection{Conclusion}

A socio-cultural view of assessment has been shown to provide a persuasive theoretical framework for the examination of the assessment of group composing. The analyses presented in this chapter have revealed that both the purpose and function of assessment depends upon the perspective of the participants in the assessment. The assessment of "contribution to creative process" remains problematic, although there is considerable evidence that sharing a conceptual model with group-composing students supports them to place themselves within the process and thus explain to themselves, each other and their teacher just what constitutes their CCP. Conceptions of what constitutes assessment are crucial variables in teacher assessment practice when grading student work for an external qualification like the NCEA, and are highly influenced by teacher identity and associated cognitive domains. Finally, a number of tensions have been identified between the need to support collaborative learning, particularly that of novice students and/or rhythm section players, and formalsummative requirements of an assessment system like the NCEA.

The next chapter concludes this thesis with an examination of the implications the study has for current teacher practice and future research. 


\section{Chapter 9 Conclusion}

The purpose of this study has been to investigate a new educational scenario, namely, the assessment of group composing as part of New Zealand's secondary school qualification, the NCEA. The problem it investigates is how an individual's learning in a collaborative, creative process might be summatively assessed. The impact this assessment might have upon teaching and learning in senior secondary music was unknown. Thus, it addresses two questions:

- What is a valid contribution when group composing is summatively assessed for a secondary school qualification?

- What are the implications for teacher practice when group composing is introduced into an established summative assessment programme?

Engeström (1998) asserts that there is "a middle level between the formal structure of school systems and the content and methods of teaching" (p.76). He refers to this as the "hidden curriculum" involving complex interactions between rules, communities and divisions of labour, and the teachers engaged in the activity of achieving the object and associated outcome (p.76).

This thesis therefore takes the epistemological view that, for group composing, music learning occurs within both vertical discourses of formal music learning at school and horizontal discourses of informal music learning within the lives of students (Green, 2008; McPhail, 2012c; Young, 2010). Group composing has been viewed as a situated practice and in the context of this study, one that is associated with the interrelated situated practices of teaching and assessment.

In the first chapter of this thesis I quoted Hall's (2005) discussion of the relationship between the complexities of the teaching-learning context and the NCEA. Hall (2005) is again quoted here as he neatly summarises the complexities I have addressed in this study, and hopefully, have illuminated in the context of NCEA Music:

The effectiveness of the context in providing a productive learning environment for students is dependent upon a number of factors: the way teachers manage the environment, including their use of a wide range of teaching strategies and their knowledge of how students learn; the expertise of teachers of both their subject and the pedagogy of their subject; the rapport between teachers and students; the attitudes, prior learning and home background (including family 
encouragement) of the students; other characteristics of the students (e.g. learning styles, approaches to learning, interests, motivation and so on); and the nature of the subject matter and the ability of the teacher to provide meaningful and relevant activities (in-class and through assessment tasks) so as to engage the student effectively with this content. As is evident, the teaching-learning context demands a lot of teachers in respect of course design, assessment, their understanding of students learning, and the means by which to motivate students to learn. (pp. 241-242)

Initially, this study was framed as a non-participant's investigation of summative assessment and, to a lesser extent, its relationship with group composing. The findings show that, in order to address the complexities to which Hall (2005) refers, it was necessary to be closer to the action as a collaborative practitioner.

\subsection{The findings of this study}

The findings of this study reveal that practice is mediated by what Kemmis (2009) describes as a complex mix of cultural-discursive, socio-political and materialeconomic preconditions. They also reveal that all participants, teachers and group composers alike, needed to engage in all three practices to make a valid contribution to the assessment of group composing This necessitated making shifts in their "sayings" doings" and "relatings" when composing, teaching and assessing group composing (Kemmis, 2009, p. 463).

\subsubsection{What is a valid contribution when group composing is assessed for a secondary qualification?}

All of the student participants reported that jamming and composing in a group was a lot of fun. Most said that, unlike jamming, composing was a challenging activity and that it was easier to compose in a group than by themselves. The students who participated in my study placed a high value upon the social skills they developed when collaborating. Some said that group composing provided them with opportunities to make meaningful friendships, and that it was satisfying to support less confident, or less knowledgeable, peers. The study shows that the more skilled and knowledgeable students went to some effort to ensure that all members of their group achieved $A S 91092$, including novice players or composers. In order to pursue the shared goal of composing music with their friends, some students endeavoured to overcome differences in music preferences or skills or experience. It seems that, for some students at least, a valid contribution to group composing may not be related 
only to music learning or contributing to a creative process, but also to achieving positive, psychosocial outcomes for a group of friends.

Not all students did moved on from social jamming, where the goal was to have fun, to group composing, where the goal was to compose a valid piece of music. Some students did not seem to regard the music classroom as a place of learning and achievement, but rather, as a place to engage in enjoyable, social music-making. Frequent absences by such students meant that it was difficult for their groups to work consistently together. Those who associated the social, enjoyable aspects of jamming and group composing with achievement at school were generally those who went on to achieve AS91092. They were also the students with higher school attendance and expectations of NCEA achievement in music.

When it came to present their work to the teacher or to the class, many students, particularly those who had not composed before, chose group composing because it represented safety in numbers. The opportunity for critique by members of the group also reassured individuals of the validity of their ideas. Some chose to group-compose the first time in order to gain confidence prior to solo-composing. Some students made the pragmatic choice to work with peers who played instruments appropriate to the styles in which they planned to compose.

The students reported that group composing needed a classroom environment where they could be independent, self-regulate their learning, be accountable for their learning, be emotionally safe, make mistakes, and have sufficient time in which to achieve a state of flow.

Not all group members contributed to the preparation of a written representation of their music. This was because not everybody had the musical knowledge to do so. Not all group members contributed significant macro CCP, particularly drummers and novice bass players. Students playing melodic instruments were usually the leaders of their groups and seemed to find group composing more demanding than the rhythm section players. Melodic players needed a rhythm section if they were to compose in popular, rock styles, however. Some melodic players chose to group compose because a friend was a drummer or bass player whom they believed, with some justification, might not have been able to compose two pieces on his own. Rhythm section players had important roles to play in shaping the music and getting 
the right overall feel but, when it came to assessing their CCP, this contribution was sometimes difficult for them, and their teacher to perceive.

The higher the level of instrumental skills and musical knowledge in the group, the more likely it was that creativity was distributed equally across members, with more group processing, greater accountability and a higher level of interdependence (Glăveanu, 2014; Johnson \& Johnson, 2004). Novice group composers with low levels of playing skills and stylistic knowledge needed to be in groups where there was considerable promotive interaction between more skilled and knowledgeable group members, without which they could not make a valid contribution, even at a micro level (Johnson \& Johnson, 2004). While there is considerable evidence that groups like these placed the novices in a ZPD, the validity of novices' CCP (usually micro rather than macro) remained questionable when it came to awarding NCEA credits. In such cases, the role of the teacher in supporting and facilitating the learning and achievement was a key variable in ensuring assessment validity.

\subsubsection{What are the implications for teacher practice when group composing is introduced into an established summative assessment programme?}

The incorporation of group composing into established NCEA programmes required the teachers to change their practice, both in terms of pedagogy and assessment. Both teachers' experiences as a learner, a musician and a teacher, and perceptions of professional identity were found to be key factors in the extent to which each was able to make those changes. The findings indicate that a teacher whose professional identity was predominately that of a music educator was more readily able to shape and refine assessment practice than a teacher whose predominant professional identity was that of a musician. While it is not possible to know if practice change and professional identity are directly correlated, both teachers' experiences of summative assessment and testing as young learners were found to have strongly influenced their conception of assessment and subsequent assessment practice.

Although NCEA Music has the potential to modularise disciplinary knowledge, a socio-cultural view of both music learning and its assessment necessitates a holistic conception of musical understanding. This, in turn, requires holistic music teaching practice. This view led one teacher to make significant changes to his teaching practice. 
Shared stylistic knowledge was found to be a key aspect of group composing and its assessment. Group composers who did not have appropriate stylistic knowledge were not able to make valid contributions to the group composing process because they did not share the same musical language as the other members of the group and so could not communicate effectively. Similarly, group composers could not express their ideas if they did not have the instrumental or vocal skills to do so. It was found necessary, therefore, to incorporate the study of musical style, as a concept into teaching, through the practice of group-composing short pieces in styles specified by the teacher, but familiar to the students. The effect of this was to form "a braided river" of musical opportunities for the students to engage in mindful analysis of their own compositions, as they composed them (Wise, 2013, p. 354).

Group composing requires multiple, sound-proofed spaces and cannot take place in one crowded, noisy classroom. Group composers needed access to instruments and gear (such as drum kits and amplifiers) appropriate for composing in popular music styles. As these are finite resources, teachers needed to ensure their efficient and equitable allocation. This was much more easily achieved in a well-resourced music department than an impoverished one.

All of the above are important factors to consider when planning and teaching a programme involving group composing, and for managing productive groupings of students. It is a highly complex professional task, requiring teachers to engage students in an exploration of the practice of composing, rather than "pre-loading" them with appropriate skills and knowledge about composing. The teacher's role was thus one of cultural manager, mentor and facilitator, as well the more traditional one of knowledge-keeper.

The reasons why some groupings were more productive than others were complex, diverse, variable, and seemingly subject to a myriad of socio-cultural factors. Overall, the practice aim was to engage the students in their craft as thoughtful, independent artists. The back-engineering strategy represents one attempt to bridge these seemingly separate discourses of formal and informal music learning to foster the optimal classroom environment for achievement in group composing.

Group composing and its assessment present a number of procedural and logistical challenges to teacher practice. Teachers needed to devise new and efficient methods of storing and managing the considerable amounts of data generated. Both 
Alice and David found assessing CCP on an on-going basis very stressful in a large class. This was because it was difficult to find the time group composers and teachers needed to engage in useful discussion and to evaluate each group's compositional processes, while at the same time meeting the needs of 15 to 17 other students. However, valid assessment was only possible when the teacher regularly interacted with group composers.

Gathering data about CCP required both the teachers and students to have a shared understanding of the compositional process, and to talk with each other about it. Sharing a conceptual model of group composing with the students enabled both the teacher and group composers to locate each student's CCP, give feedback on progress, and feed-forward to the completion of their composition. It also gave both the teacher and the students permission to accept messy, divergent practice such as social jamming (previously regarded as recreational time wasting) as valid contributions to group composing. At the same time, the model encouraged students to view social jamming as a tool within the activity of group composing, linked to their achievement in the NCEA. When discussion took place using the model as a framework, there were few assessment surprises for the students or the teacher because they knew what they had achieved thus far and also how to carry on achieving. The teacher was also more able to gather a portfolio of valid summative data, including self and peer assessments based upon these conversations, and by observing the students. Valid summative assessment of group composing therefore needs to be embedded within a teacher/group composers' dialectic.

Summative assessment of novice, low-achieving or unconfident students' CCP remains problematic and possibly harmful to some students. To ameliorate this, the teacher needed to walk a fine line between informal and formal assessment judgements so that such students were both informed of their progress and encouraged to achieve.

The alignment between pedagogy, task design, and assessment criteria was found to be a key variable in the valid assessment of group composing. When the composition task was supported by holistic pedagogies of music learning, not just composing, which were in turn aligned with the assessment criteria for AS91092, the students were placed upon a trajectory of learning towards achievement with Merit or Excellence. Provided the music was stylistic, as required by the task and AS91092, then the subsequent aggregation of data portfolios was a fairly straightforward process 
of making a series of well-informed professional judgements, rather than an atomised "adding up" of marks or grades.

Finally, there is considerable evidence to suggest that professional isolation had a major impact upon the professional confidence of both teachers. This remains a concerning practice issue. Both teachers' practice and confidence improved when their pedagogical and assessment knowledge was strengthened. Both teachers reported that engaging in collaborative summative assessment, in a safe professional environment, relieved them of considerable anxiety about grading, on their own, for a high-stakes internal assessment such as the NCEA. Neither teacher had access to a professional community of music teaching and assessment practice. Neither had the opportunity to observe the practice of others, nor to engage in informal moderation of their assessment judgements with peers. In one school there seemed little teacher accountability for ineffective practice and low student achievement. As collaborative practitioner research, the present study provided both teachers and me with a rare opportunity to engage with another music educator in examining a new problem for music education in New Zealand and its implications for practice.

\subsection{Contributions to knowledge}

This research contributes to bodies of empirical literature on assessment and music education. It is research into a music education scenario that has not existed before. In this respect, it is unique. The thesis throws new light upon what is already known about assessment, collaborative creativity, group learning, and pedagogy.

In particular, it makes a valid contribution to what is known about the summative assessment of an individual's learning in collaborative groups, a field in which little research has been undertaken thus far, and which some scholars have argued it is not possible to do with any validity (van Aalst, 2013).

A considerable body of research already exists within the international literature on relationships between formal and informal learning in music education, particularly investigations of the impacts of informal music learning upon music teaching and the curriculum (Allsup, 2003; Cain, 2013; Folkestad, 2006; Green, 2008). There is also considerable literature that investigates the collaborative compositional processes of children, young people and adults (Burnard \& Younker, 2002, 2004, 2008; Campbell, 1995; Davis, 2005; Jaffurs, 2004, 2006). Few studies focus on 
assessment and music learning, however, and none offers a thick description of how collaborative compositional processes might be assessed. Further, no other studies of which I am aware have investigated the assessment of composing in a New Zealand context, or its relationship to the NCEA.

This thesis makes an explicit, unique link between recent research into the impact of informal music learning upon music teaching and curriculum, and formal summative assessment for a secondary school qualification. It offers possible insights into how music teachers might reconcile the validity demands of a national assessment system with the considerable challenges posed by the ethical requirement to meet the diverse needs of their students. It also adds to the on-going debate about the nature of disciplinary knowledge in music education, what constitutes music curriculum in the $21^{\text {st }}$ century and how such curriculum knowledge might be assessed.

The research makes a unique contribution to what is known about what happens when teachers and students share a conceptual understanding of composing, and how a conceptual model might be used as both a pedagogical and an assessment tool to illuminate collaborative creative processes and support learning. It offers suggestions as to how an individual's contribution to a creative process might be summatively and validly assessed. To extend the metaphor I used in my Master's thesis, I have sought to understand how the butterfly flies by observing it in flight, rather than by pulling off its wings.

The ethics of the assessment of group composing are carefully examined and its weaknesses and strengths investigated. New ways to interpret CCP are presented including the idea of macro and micro contributions. Therefore, this thesis echoes and contributes to international research into what constitutes effective pedagogy in composing, linking it to what is known about effective assessment practice, particularly socio-cultural assessment practice.

Socio-cultural practice is situated practice where the ontological assumption is that learning is collective and exists in coalitions of practice over time. This thesis has examined the tension between this view of assessment and the NCEA, which is designed around the ontological assumption that learning is individualistic and exists as the capital of the individual mind. While van Aalst (2013) asserts that "if assessment is based upon a group product then it is difficult, if not impossible, to ascertain what individual students have learned" (p.280), this research has revealed that it is possible 
to ascertain what individual students have achieved in a group process. This thesis argues that these may not be such intractable theoretical differences after all. A sociocultural approach to teaching, learning, and formative assessment may support meaningful collaborative learning, and also be the only way in which an external assessor can be appropriately informed about the achievement of individuals when it comes time to view their achievement from a cognitivist perspective. Therefore, the reinterpretation of Harlen's (2012) assessment dimensions, presented in 8.4.1, represents new insights into the assessment of collaborative learning.

The study also contributes to methodological knowledge about practitioner research and partnerships between university researchers and classroom teachers. In particular, it presents an examination of the nature of practitioner research, including the challenges and dangers, strengths and weaknesses of such a research paradigm, and how practitioner researchers from different educational contexts might navigate these. This study also adds to what is known about the potential of activity theory when undertaking empirical research about music learning, also an under-researched area (Odena, 2012a). Finally, it presents a number of research and pedagogical resources developed in the course of the study that might have potential for use by music teachers and music education researchers in other contexts.

\subsection{Strengths and limitations of this study}

The strengths and limitations of this study are bound by the constraints imposed by my methodology choices, my position as a researcher, and the scope of the topic.

\subsubsection{Strengths}

As has been demonstrated in the findings of this study, group composing takes time. It takes ten months for a senior programme of music to be taught and assessed for the NCEA. It also takes time for a practitioner (of composing, teaching and/or assessment) to respond to new situations or problems and then refine, change or make shifts in the way they do things. Following the pilot study, data analysis revealed that I needed to get closer to the action and so this meant that I too was bound by the time constraints of the school year. Research in only one school with one teacher would not have provided sufficient triangulation of the data and so the main study was carried out in two diverse schools based in very different communities, in collaboration with two teachers who had very different practices. I worked consecutively in these schools 
and this meant that the research in one context then informed work in the next. To do this, I had to spend a lengthy period of time in the field (26 months). The extended period in the field, accompanied by a consistent reflexive turn, thus ensured the triangulation, internal validity and stability of two rich data sets, as well as the ethical rigour of the research.

At times my collaboration with two busy, stressed-out classroom music teachers was problematic, messy, and ethically uncertain. A strength of this study is the level rigorous reflexivity I engaged in throughout the study, with a particular emphasis upon the ethics of my interventions into the lives of teachers and students. Through this process I strove to make a positive contribution to the professional practice of the teachers with whom I worked, aiming for a "win-win-win" for the teachers, the students and me. Sometimes there were uneasy and uncertain moments, particularly at Kotare College when working with Alice and her students. Reflection upon power, position and identity in practitioner research, accompanied by thoughtful reading of literature such as Elliot (1994), Herr \& Anderson (2005) and Somekh (1994), helped me to illuminate and interpret the situations in which we found ourselves, and to strive to find ways to address them appropriately. My previous practitioner experience of 20 years as a secondary music teacher, followed by 10 years as a school adviser, also informed my responses in the field. Reflexivity also helped me to maintain a certain level of objectivity, particularly in those messy, uncertain times, but also in the times when things seemed to be going particularly well.

\subsubsection{Limitations}

Group composing is a complex social process, involving multiple perspectives, as is its assessment, and therefore a qualitative paradigm was chosen for this study. I made the decision to abandon a five-case-study design because I believed that I risked replicating the pilot study findings. However, whether or not this would have actually happened cannot be known. This means that the findings are limited by the subjective experiences of only three teachers: myself, Alice and David, and to some extent, Sarah, and in three school contexts.

Initially, for the main study I hoped to engage both teachers in collaborative action research. However, as a novice action researcher I did not realise the implications of this decision. Elliot (1988) and Somekh (1994) assert that researchers new to action research should not engage in collaboration with teachers because they 
do not have the experience and knowledge to navigate the power relationships between practitioners. This soon proved to be the case when it was revealed that Alice's primary professional identity was that of a musician, not a teacher. Now that I know more about this kind of research, the first question I would ask a teacher with whom I was proposing to collaborate would be about their professional identity. While Alice was very hospitable and responsive to my requests, and also incorporated some new assessment methods into her teaching, she did not, and it seems, could not, engage with me in an investigation of teaching and assessment practices. Therefore, the findings of the Kotare study are limited by my lack of knowledge and expertise in practitioner research. While David was, and remains, very keen to examine, refine, change and improve his practice, our collaboration could not be really termed action research either. There are, no doubt, many deficiencies in the data because neither David nor I engaged in a really methodical reflexive process together. This is because our collaboration was constrained by our separate professional roles as classroom teacher and teacher educator. David and Alice were not researchers, but rather practitioners engaged in collaborating with a researcher about the practices of composing teaching, and assessment.

Although I spent a lot of time in Alice and David's classrooms, taught their Year 11 students, helped assess the work and, on many occasions, helped facilitate group composing and give the boys feedback, I was not the classroom teacher. I could not be there all the time, and, as such, will have no doubt missed many teachable moments and key events.

Both teachers were very isolated and anxious: about low student achievement (Alice); or about being accountable to authority for NCEA procedures and assessment (David). There is some evidence that David used his professional philosophies of music teaching to hide his lack of confidence from me, leading to a misinterpretation of the data on my part. It is highly likely that Alice also masked aspects of her practice to protect herself professionally. Given that she knew that I was going to write about low student achievement, this is not perhaps surprising. In my view, this makes her willingness to take part in the project all the more laudable, but reticence is probably a limitation too.

Another limitation is the ease with which I worked at St Bathan's compared to Kotare College. While I have considerable experience as an adviser working in schools 
like Kotare, and am very familiar with working with Māori and Pasifika students, most of my classroom teaching has been based in high decile or private schools with mainly Pākehā students. At St Bathan's I was with my tribe, working with a teacher with whom I had a lot in common and so felt very comfortable in that environment. It was also much easier to teach and assess group composing in an affluent school because all of the resources required were so readily at hand. This is a significant limitation for the research in both sites, although a rigorous reflexivity helped me to remain aware of how my responses might be influenced by my own context.

The findings indicate that back-engineering was a very successful pedagogy for engaging group composers in composing stylistic and therefore valid music. However, just because this worked at St Bathan's does not mean that would work in other schools with other students. The Year 11 students at St Bathan's were already highly engaged and expected, as did their teacher, that they would achieve well in NCEA Music. It might well be argued therefore that David and I could have tried anything and the students would all still achieved well in AS91092. Certainly backengineering would have been challenging at Kotare because of the dire lack of appropriate resources.

Finally, this research is limited by my choice not to investigate group composing in digital media. There is substantial literature that indicates this is a fastgrowing musical practice and so the findings of this thesis do not reflect this growing trend (Wise, 2013). This is discussed in the next section.

\subsection{Recommendations for future research}

Lewis (2012) and Tobias (2013) all found that students engaged more meaningfully in composing, particularly group composing, when the task was framed as authentic practice, much like Eisner's (2002) design specifications or an architect's brief. While the back-engineering strategy aimed to do this, my approach was much less rigorous than that of Tobias (2013), who presents an intriguing set of diagrams to illustrate his students' compositional processes. It would be interesting to investigate what potential Tobias' pedagogies and models might have for designing authentic compositional briefs as NCEA group composing tasks.

The study has generated new ways for both teachers and researchers to gather data. As explained earlier, the conceptual model seemed to be effective in two very 
diverse schools and so it might have potential for the interpretation of collaborative creative processes by those both inside and outside of the action. My adaptation of Massimini and Carli's (1988) flow diagram, as cited by Sheridan and Byrne (2002), also resulted in rich data but was used only once, and David and I did not explore its full potential for interpreting students' learning experiences. It would be interesting to see if it was as effective in other settings.

While I taught the conceptual model to all of the students in both classes (40 in total), I only collected data about the responses of group composers. What was its impact, if any, upon the composing of individuals? When I shared the model informally with adult composers, including some of my own students, they all said they recognised these processes and thought it would be useful for their own practice to know more about them. David reports that he now routinely uses other conceptual models, such as the stages towards mastery of musical skills, with his students. He believes that doing so has profoundly changed his practice to teach music more holistically. Research into how conceptual modelling might enrich and inform the practice of music teachers, and possibly the practice of younger or older composers, would make a valuable contribution to knowledge about teaching and learning in music. McPhail (2012b) asserts that conceptual understanding is a crucial aspect of the acquisition of discrete disciplinary knowledge in music. It may be that such research could address some of the issues he and others have raised about the "emptying out" of the music curriculum in secondary music and the NCEA.

I used activity theory as a way to illuminate the multiplicities of the activities within this study. It proved to be a powerful ex post descriptive tool and enabled me to discuss contradictory and complex data. However, like Odena (2012b), Welch (2007), Soares (2012), and Burnard and Younker (2008), I believe that I have only scratched the surface of its potential for research into the complexities of music learning and assessment. Does CHAT have the potential to help researchers, such as myself, to work with teachers in the analysis of the activities in which they are engaged? What if I had used it from the outset of the research? The students in this study responded positively to a conceptual model of composing. Could they use activity theory to explain to the teacher what they were doing? Or is this a bridge too far?

A general lack of vocal confidence for most of the student participants meant that compositions in styles requiring a vocal line, such as indie rock, were less valid 
than they might have been. There is a gap in research into whether the improvement in vocal confidence and singing skills might lead to better outcomes for young composers who do not identify themselves as "singers", particularly those groupcomposing in popular styles.

Group composing has been a part of NCEA music for five years now. When I began the study it was new. This study is limited by its scope because it presents the practice of three teachers (including myself) and, meanwhile, other teachers have also been doing this new kind of assessment. What have they learned when assessing the $\mathrm{CCP}$ of individuals? Has it led to changes in their practice over time, or immediately, or not at all?

While Alice, David and I grappled with the challenges of gathering data and aggregating grades, this study does not present very many new ways for teachers to gather, store, and manage their data. How are other people doing it? Have they changed the ways in which they gather assessment data about group composing? If so, how?

There is considerable literature that examines the influence of music teachers' lived experiences and identities upon their practice (Lewis, 2012; MacDonald, et al., 2009). However, there is very little research on the influence of lived experience of summative assessment or testing as a young learner upon a music teacher's subsequent assessment conceptions, and how these conceptions might influence a teacher's actual, as opposed to espoused, practice. Given the widespread use of grade exams and competitions to test young musicians, often reflecting quite behaviourist assessment views, one could speculate that such experiences may have a formative effect upon the subsequent assessment conceptions and practice of beginning music teachers who have come through such a system. Young teachers who have mainly learned through contemporary music practices and not through grades and/or performance exams may not have the same assessment conceptions. This is worth investigating.

\subsection{Final thoughts}

This research journey began in 2003 during a conversation with a teacher about group composing and whether or not it might be assessed for a secondary school qualification. Since that time I have investigated the group composing processes of young rock musicians in New Zealand, and this research has laid the foundation for the present study. 
I continue to admire the vision shown by those who made the decision to incorporate group composing in the NCEA. It is unique to the New Zealand educational context and reflects the fact that, unlike many countries, composing has been integrated into secondary school qualifications for more than 20 years. The very existence of AS91092 is a sign that the NCEA as a qualification seeks to move beyond traditional assessment structures to measure authentic and relevant learning. This is both its strength and its weakness.

Assessing group composing was complex and demanding. It required a sophisticated pedagogical understanding and a primarily socio-cultural view of assessment. The teachers I collaborated with were professionally isolated, far more so than they have been in past times. There were scant opportunities for Alice and David to develop their skills outside of our collaboration. As a former adviser whose job it was to support music teachers' professional learning, I wonder what Alice and David's practice might have been like had they had access to this kind of (now disestablished) professional support.

Furthermore, the differences between the music department at Kotare College and that of St Bathan's Collegiate are a glimpse of the significant educational and social disparities in New Zealand society, and this continues to trouble me. It also troubles me that, due to circumstances, I used findings derived from an impoverished community of mainly Māori and Pāsifika students to enrich and inform music learning in an already affluent and lavishly resourced community. I wonder, what would have happened if I had begun the study at St Bathan's Collegiate and ended it at Kotare College?

Finally, whenever I talk with, or observe, young group composers I am struck afresh by their engagement in what Davis (2005) refers to as "the relentless pursuit of music passion" (p.1). As McPhail (2012c) asserts, music in the 21st century school is different from other subjects because students bring with them prior knowledge and experiences that influence their choices and preferences in the music classroom. Group composing has great potential to bridge the gap between the horizontal and vertical discourses of music learning when, as Jake observed, students become "this concoction of musical greatness". This is summed up in the Māori whakatauki, or proverb:

\section{Ehara taku toa i te toa takitahi, engari ko taku toa he toa takitini.}

My success is achieved not just through my own efforts, but through the efforts of others. 


\section{References}

Allal, L. (2013). Teachers' professional judgement in assessment: A cognitive act and a socially situated practice. Assessment in Education: Principles, Policy and Practice, 20(1), 20-34. doi:10.1080/0969594X.2012.736364

Allsup, R. E. (2003). Mutual learning and democratic action in instrumental music education. Journal of Research in Music Education, 51(1), 24-37. doi: $10.2307 / 3345646$

Alvarez (Eds.), Sociocultural studies of mind (pp.139-164). Cambridge: Cambridge University Press.

Amabile, T. M. (1996). Creativity in context. Boulder, CO: Westview Press.

Asmus, E. P. (1999). Music assessment concepts. Music Educators Journal, 86(2), 19-24. doi: $10.2307 / 3399585$

Assessment Reform Group (ARG). (2002). Assessment for learning: 10 principles. Cambridge, UK: University of Cambridge Faculty of Education.

Avgitidou, S. (2009). Participation, roles and processes in a collaborative action research project: A reflexive account of the facilitator. Educational Action Research, 17(4), 585-600. doi:10.1080/09650790903309441

Bailey, C. A. (2007). A guide to qualitative field research (2nd ed.). Thousand Oaks: Pine Forge Press.

Barab, S. A., Barnett, M., Yamagata-Lynch, L., Squire, K., \& Keating, T. (2002). Using activity theory to understand the systemic tensions characterizing a technology-rich introductory astronomy course. Mind, Culture, and Activity, 9(2), 76-107. doi:10.1207/S15327884MCA0902_02

Barratt, M. (2005). A systems view of musical creativity. In D. J. Elliot (Ed.), Praxial music education: Reflections and dialogues. Oxford: Oxford University Press.

Barron, B. (2003). When smart groups fail. Journal of the Learning Sciences, 12(3), 307-359. doi:10.1207/S15327809JLS1203_1 
Bell, P., \& Winn, W. (2000). Distributed cognitions, by nature and design. In D. Jonassen \& S. Land (Eds.), Theoretical foundations of learning environments (1st ed., pp.123-145). New York: Routledge.

Bennett, R. E. (2011). Formative assessment: A critical review. Assessment in Education: Principles, Policy and Practice, 18(1), 5-25. doi:10.1080/0969594X.2010.513678

Bernstein, B. (2000). Pedagogy, symbolic control and identity: Theory, research, critique (Rev ed.). New York. Rowman \& Littlefield.

Biasutti, M. (2012). Group music composing strategies: A case study within a rock band. British Journal of Music Education, 29(3), 343-357. doi:10.1017/S0265051712000289

Bishop, K., Bullock, K., Martin, S., \& Thompson, J. (1999). Users' perceptions of the GCSE. Educational Research, 41(1), 35-49.

Bishop, R., \& Glynn, T. (1999). Culture counts: Changing power relations in education. Palmerston North: Dunmore Press.

Black, P., \& Wiliam, D. (1998). Assessment and classroom learning. Assessment in Education: Principles, Policy and Practice, 5(1), 7-74. doi:10.1080/0969595980050102

Black, P., \& Wiliam, D. (2009). Developing the theory of formative assessment. Educational Assessment, Evaluation and Accountability, 21(1), 5-31. doi:10.1007/s11092-008-9068-5

Black, P., Harrison, C., Hodgen, J., Marshall, B., \& Serret, N. (2010). Validity in teachers' summative assessments. Assessment in Education: Principles, Policy and Practice, 17(2), 215-232. doi:10.1080/09695941003696016

Black, P., Harrison, C., Hodgen, J., Marshall, B., \& Serret, N. (2011). Can teachers' summative assessments produce dependable results and also enhance classroom learning? Assessment in Education: Principles, Policy and Practice, 18(4), 451-469. doi:10.1080/0969594X.2011.557020

Black, P., Harrison, C., Lee, C., Marshall, B., \& Wiliam, D. (2003). Assessment for learning: Putting it into practice. Buckingham: Open University Press. 
Blom, D., \& Encarnacao, J. (2012). Student-chosen criteria for peer assessment of tertiary rock groups in rehearsal and performance: what's important? British Journal of Music Education, 29(01), 25-43. doi:10.1017/S0265051711000362

Bloom, B. J. (Ed.). (1956). Taxonomy of educational objectives: Book 1. Cognitive domain. New York: Longman.

Boden, M. A. (1990). The creative mind: Myths and mechanisms. London: Weidenfeld/Abacus \& Basic Books.

Boden, M. A. (1996). What is creativity? In M. A. Boden (Ed.), Dimensions of creativity (pp.75-118). Cambridge MA: MIT Press.

Boud, D. (2009). How can practice shape assessment? In G. Joughin (Ed.), Assessment, learning and judgement in higher education (pp.29-43). Netherlands: Springer. Retrieved from http://link.springer.com/chapter/10.1007/978-1-4020-8905-3_3. doi: 10.1007/978-1-4020-8905-3

Boud, D. (2000). Sustainable assessment: Rethinking assessment for the learning society. Studies in Continuing Education, 22(2), 151-167. doi:10.1080/01580379950177314

Boud, D., Cohen, R., \& Sampson, J. (1999). Peer learning and assessment. Assessment and Evaluation in Higher Education, 24(4), 413-426.

Bowman, W. D. (2005). Why musical performance? Views praxial to performative. In D. J. Boyce-Tillman, J. (2003). Assessing diversity. Arts and Humanities in Higher Education, 2(1), 41-62. doi:10.1177/1474022203002001004

Braatvedt, S. (2002). A history of music education in New Zealand state primary and intermediate schools 1878 - 1989 (Unpublished PhD). University of Canterbury, Christchurch.

Bransford, J. D., Brown, A. L., \& Cocking, R. R. (2000). How people learn. Brain, mind, experience and school. Washington DC: National Academy Press.

Brophy, J. (2008). Developing students' appreciation for what is taught in school. Educational Psychologist, 43(3), 132-141. doi:10.1080/00461520701756511 
Brown, G. T. L. (2004). Teachers' conceptions of assessment: Implications for policy and professional development. Assessment in Education: Principles, Policy and Practice, 11(3), 301-318. doi:10.1080/0969594042000304609

Brown, G. T. L. (2011). Teachers' conceptions of assessment: Comparing primary and secondary teachers in New Zealand. Assessment Matters, 3, 45-70.

Brown, G. T. L., \& Hirschfeld, G. H. F. (2008). Students' conceptions of assessment: Links to outcomes. Assessment in Education: Principles, Policy and Practice, 15(1), 3-17. doi:10.1080/09695940701876003

Brown, G. T. L., Lake, R., \& Matters, G. (2011). Queensland teachers' conceptions of assessment: The impact of policy priorities on teacher attitudes. Teaching and Teacher Education, 27(1), 210-220. doi:http://dx.doi.org/10.1016/j.tate.2010.08.003

Burnard, P. (2007). Routes to understanding musical creativity. In L. Bresler (Ed.), International handbook of research in arts education (pp.1199-1214.). New York: Springer.

Burnard, P. (2008). A phenomenological study of music teachers' approaches to inclusive education practices among disaffected youth. Research Studies in Music Education, 30(1), 59-75. doi:10.1177/1321103x08089890.

Burnard, P. (2012a). Musical creativities in practice. Oxford: Oxford University Press.

Burnard, P. (2012b). Rethinking 'music creativity' and the notion of multiple creativities in music. In O. Odena (Ed.), Musical creativity: Insights from music education research (pp.5-28). Farnham: Ashgate. Retrieved from http://VUW.eblib.com/patron/FullRecord.aspx?p=823580.

Burnard, P., \& Younker, B. A. (2002). Mapping pathways: Fostering creativity in composition. Music Education Research, 4(2), 245-261. doi:10.1080/1461380022000011948

Burnard, P., \& Younker, B. A. (2004). Problem-solving and creativity: Insights from students' individual composing pathways. International Journal of Music Education, 22(1), 59-76. doi:10.1177/0255761404042375 
Burnard, P., \& Younker, B. A. (2008). Investigating children's musical interactions within the activities systems of group composing and arranging: An application of Engeström's Activity Theory. International Journal of Educational Research, 47(1), 60-74. doi:http://dx.doi.org/10.1016/j.ijer.2007.11.001

Burnard, P., Dillon, S., Rusinek, G., \& Sæther, E. (2008). Inclusive pedagogies in music education: A comparative study of music teachers' perspectives from four countries. International Journal of Music Education, 26(2), 109-126. doi:10.1177/0255761407088489

Byrne, C., MacDonald, R., \& Carlton, L. (2003). Assessing creativity in musical compositions: Flow as an assessment tool. British Journal of Music Education, 20(03), 277-290. doi:10.1017/S0265051703005448

Cabedo-Mas, A., \& Díaz-Gómez, M. (2013). Positive musical experiences in education: Music as a social praxis. Music Education Research, 15(4), 455470. doi:10.1080/14613808.2013.763780

Cain, T. (2013). 'Passing it on': Beyond formal or informal pedagogies. Music Education Research, 15(1), 74-91. doi:10.1080/14613808.2012.752803

Campbell, P. S. (1995). Of garage bands and song-getting: The musical development of young rock musicians. Research Studies in Music Education, 4(1), 12-20. doi:10.1177/1321103x9500400103

Carlisle, K. (2013). A study of teacher formative influence upon and student experience of social-emotional learning climate in secondary school music settings. British Journal of Music Education, 30(02), 223-243. doi:10.1017/S0265051713000053

Carr, W., \& Kemmis, S. (1986). Becoming critical. Education, knowledge and action research. London: The Falmer Press.

Carter, K. (2003). Itinerant teachers of music: A state of flux (Master's thesis). Christchurch College of Education, Christchurch, New Zealand. Retrieved from http://ir.canterbury.ac.nz/bitstream/10092/3552/1/Thesis_fulltext.pdf

Charmaz, K. (2006). Constructing grounded theory: A practical guide through qualitative analysis. London: Sage. 
Cohen, L., Manion, L., \& Morrison, K. (2007). Research methods in education (6th ed.). London: Routledge.

Cole, M. (1996). Cultural psychology. The once and future discipline. Cambridge, MA: Harvard University Press.

Cole, M., \& Engeström, Y. (1993). A cultural-historical approach to distributed cognition. In G. Salomon (Ed.), Distributed cognitions: Psychological and educational considerations. Cambridge: Cambridge University Press.

Colwell, R. (2002). Assessment's potential in music education. In R. Colwell \& C. Richardson (Eds.), The new handbook of research on music teaching and learning (pp.1128-1158). Oxford: Oxford University Press.

Cook, T. (2009). The purpose of mess in action research: Building rigour though a messy turn. Educational Action Research, 17(2), 277-291. doi:10.1080/09650790902914241

Craft, A. (2005). Creativity in schools. London: Routledge.

Creswell, J. W. (2009). Research design: Qualitative, quantitative and mixed method approaches (3rd ed.). Thousand Oaks, CA: Sage.

Crisp, V. (2012). Criteria, comparison and past experiences: How do teachers make judgements when marking coursework? Assessment in Education: Principles, Policy and Practice, 20(1), 127-144. doi:10.1080/0969594X.2012.741059

Crooks, T. J. (2002). Educational assessment in New Zealand schools. Assessment in Education: Principles, Policy and Practice, 9(2), 237-253. doi:10.1080/0969594022000001959

Cropley, A. J. (2001). Creativity in education and learning: A guide for teachers and educators. London: Routledge Falmer.

Csikszentmihalyi, M. (1988). The flow experience of human psychology. In M. Csikszentmihalyi, M., \& I. Csikszentmihalyi, (Eds.), Optimal experience: Psychological studies of flow in consciousness (pp.15-35). Cambridge: Cambridge University Press.

Csikszentmihalyi, M. (1990). Flow: Harper \& Row. 
Csikszentmihalyi, M. (1992). Flow: The psychology of happiness. London: Random House.

Csikszentmihalyi, M. (1996). Flow and the psychology of discovery and invention. New York: HarperPerennial.

Csikszentmihalyi, M. (1999). Implications of a systems perspective for the study of creativity. In R. J. Sternberg (Ed.), Handbook of creativity (pp.313-338). Cambridge: Cambridge University Press.

Davis, S. G. (2005). That thing you do! Compositional processes of a rock band. International Journal of Education and the Arts, 6(16), 1-19. Retrieved from http://www.ijea.org/v6n16/

Denzin, N., \& Lincoln, Y. (2005). The discipline and practice of qualitative research. In N. Denzin \& Y. Lincoln (Eds.), Handbook of qualitative research (3rd ed.). London: Sage.

Dillon, S. C. (2007). Music meaning and transformation: Meaningful music making for life. Newcastle, UK: Cambridge Scholars. Downloaded from http://eprints.qut.edu.au/6703/1/Music\%2C_Meaning_and_Transformation.pdf

Donaldson, J. (2012). Between two worlds: Tensions of practice encountered by secondary school music teachers in Aotearoa New Zealand (Doctor of Philosophy in Education). Massey University, Manawatu Campus, New Zealand. Retrieved from http://mro.massey.ac.nz/bitstream/handle/10179/4263/02_whole.pdf?sequence=1

Drummond, J. (2003). Music and the arts: A special kind of knowledge. In E. Grierson \& J. Mansfield (Eds.), The arts in education: Critical perspectives from Aotearoa New Zealand (pp.47-62). Palmerston North: Dunmore Press.

Earl, L., \& Katz, S. (2008). Getting to the core of learning; Using assessment for self-monitoring and self-regulation. In S. Swaffield (Ed.), Unlocking assessment: Understanding for reflection and application (pp.90-104). London: Routledge. 
Eisner, E. (2002). From episteme to phronesis to artistry in the study and improvement of teaching. Teaching and Teacher Education, 18(4), 375-385. doi:http://dx.doi.org/10.1016/S0742-051X(02)00004-5

Eisner, E. (2007). Assessment and evaluation in education and the arts. In L. Bresler (Ed.), International handbook of research in arts education (pp.423-426). New York: Springer.

Elliott, D. J. (1995). Music matters: A new philosophy of music education. Oxford: Oxford University Press.

Elliott, J. (1988). Educational research and outsider insider relations. International Journal of Qualitative Studies in Education, 1(2), 155-166. doi:10.1080/0951839880010204

Elliot, J. (1991). Action research for educational change. Milton Keynes, UK: Open University Press.

Elliott, J. (1994). Research on teachers' knowledge and action research. Educational Action Research, 2(1), 133-137. doi:10.1080/09650799400200003

Emmerson, S. (1989). Composing strategies and pedagogy. Contemporary Music Review, 3(1), 133-144. doi:10.1080/07494468900640091

Engeström, Y. (1987). Learning by expanding: An activity theoretical approach to developmental research. Helsinki: Orienta-Konsultit Oy.

Engeström Y. (1996). Perspectives on activity theory. Cambridge: Cambridge University Press.

Engeström, Y. (1998). Reorganizing the motivational sphere of classroom culture: An activity-theoretical analysis of planning in a teacher team. In F. J. Seeger, J. Voigt, \& U. Waschescio (Eds.), The culture of the mathematics classroom (pp.76-103). Cambridge: Cambridge University Press.

Engeström, Y. (2001). Expansive learning at work: Toward an activity theoretical reconceptualization. Journal of Education and Work, 14(1), 133-156. doi:10.1080/13639080020028747 
Espeland, M. (2003). The African drum: The compositional process as discourse and interaction in a school context. In M. Hickey (Ed.), Why and how to teach music composition: A new horizon for music education (pp. 162-192). Lanham, MD: Rowman \& Littlefield/MENC.

Evelein, F. (2006). Pop and world music in Dutch music education: Two cases of authentic learning in music teacher education and secondary music education. International Journal of Music Education, 24(2), 178-187. doi:10.1177/0255761406065479.

Falchikov, N. (1991). Group process analysis: Self and peer assessment of working together in a group. Paper presented at the Standing Conference on Educational Development: Self and Peer Assessment, Birmingham.

Faulkner, R. (2003). Group composing: Pupil perceptions from a social psychological study. Music Education Research, 5(2), 101-124. doi:10.1080/1461380032000085504

Fautley, M. (2005). A new model of the group composing process of lower secondary school students. Music Education Research, 7(1), 39-57. doi:10.1080/14613800500042109

Fautley, M. (2010). Assessment in music education. Oxford: Oxford University Press.

Fautley, M., \& Savage, J. (2011). Assessment of composing in lower secondary school in the English National Curriculum. British Journal of Music Education, $28(1), 51-67$.

Finney, J. (2007). Music education as identity project in a world of electronic desires. In J. Finney \& P. Burnard (Eds.), Music education with digital technology (pp.9-20). London: Continuum.

Folkestad, G. (2006). Formal and informal learning situations or practices vs formal and informal ways of learning. British Journal of Music Education, 23(02), 135-145. doi:10.1017/S0265051706006887. 
Fontana, A., \& Frey, J. (2005). The interview: From neutral stance to political involvement. In N. Denzin \& Y. Lincoln (Eds.), Handbook of qualitative research (3rd ed., pp.695-728.). London: Sage.

Fredricks, J. A., Blumenfeld, P. C., \& Paris, A. H. (2004). School engagement: Potential of the concept, state of the evidence. Review of Educational Research, 74(1), 59-109. doi:10.3102/00346543074001059

Gardner, J. (2012). Quality assessment practice. In J. Gardner (Ed.), Assessment and learning (pp.103-122). London: Sage.

Georgii-Hemming, E. (2006). Personal experiences and professional strategies. Music Education Research, 8(2), 217-236. doi:10.1080/14613800600779618

Gioka, O. (2008). Teacher or examiner? The tensions between formative and summative assessment in the case of science coursework. Research in Science Education, 39, 411-428.

Glăveanu, V.-P. (2011). How are we creative together? Comparing sociocognitive and sociocultural answers. Theory and Psychology, 21(4), 473-492. doi:10.1177/0959354310372152

Glăveanu, V.-P. (2014). Distributed creativity. Thinking outside the box of the creative individual. Springer Briefs in Psychology. Retrieved from http://www.springer.com/psychology/personality+\%26+social+psychology/bo ok/978-3-319-05433-9\# doi:10.1007/978-3-319-05434-6.

Grant, S., Milfont, T., Herd, R., \& Denny, S. (2010). Health and wellbeing of a diverse student population: The Youth2000 surveys of New Zealand secondary school students and their implications for education. In V. Green \& S. Cherrington (Eds.), Delving into diversity: An international exploration of issues of diversity in education (pp.185-193). New York, NY: Nova Science.

Grbich, C. (2007). Qualitative data analysis: An introduction. Thousand Oaks, CA: Sage.

Green, L. (2002). How popular musicians learn: A way ahead for music education. Aldershot: Ashgate. 
Green, L. (2008). Music, informal learning and the school: A new classroom pedagogy. Aldershot: Ashgate.

Greeno, J. G. (1997). On claims that answer the wrong questions. Educational Researcher, 26(1), 5-17. doi:10.3102/0013189x026001005

Guba, E. G., \& Lincoln, Y. S. (2008). Paradigmatic controversies, contradictions, and emerging confluences. In N. K. Denzin \& Y. S. Lincoln (Eds.), The landscape of qualitative research (3rd ed., pp.255-286). Los Angeles: Sage.

Guilford, J. P. (1950). Creativity. American Psychologist, 5(9), 444-454. doi:http://dx.doi.org/10.1037/h0063487

Hakkarainen, K., Paavola, S., Kangas, K., \& Seitmaa-Hakkarainen, P. (2013). Sociocultural perspectives on collaborative learning. In C. Hmelo-Silver, C. A. Chinn, C. K. Chan \& A. M. O'Donnell (Eds.), International handbook of collaborative learning (pp.57-73). New York: Routledge.

Hall, C. (2005). The National Certificate of Educational Achievement (NCEA). Is there a third way? In J. Codd \& K. Sullivan (Eds.), Education policy directions in Aotearoa New Zealand (pp.235-265). Wellington, NZ: Dunmore Press.

Hammershøj, L. G. (2014). Creativity in education as a question of cultivating sensuous forces. Thinking Skills and Creativity, 13(0), 168-182. doi:http://dx.doi.org/10.1016/j.tsc.2014.05.003

Hargreaves, D. J. (1986). The developmental psychology of music. Cambridge: Cambridge University Press.

Hargreaves, E. (2005). Assessment for learning? Thinking outside the (black) box. Cambridge Journal of Education, 35, 213-224.

Harlen, W. (2004). A systematic review of the evidence of reliability and validity of assessment by teachers used for summative purposes. Research Evidence in Education. http://eppi.ioe.ac.uk/cms/Default.aspx?tabid=117\&language=en-US

Harlen, W. (2005). Teachers' summative practices and assessment for learning: Tensions and synergies. Curriculum Journal, 16, 207-223. 
Harlen, W. (2008). Trusting teachers' judgements. In S. Swaffield (Ed.), Unlocking assessment: Understanding for reflection and application (pp.138-153). London: Routledge.

Harlen, W. (2012). On the relationship between assessment for formative and summative purposes. In J. Gardner (Ed.), Assessment and learning (pp.87102). London: Sage.

Harlen, W., \& James, M. (1997). Assessment and learning: Differences and relationships between formative and summative assessment. Assessment in Education: Principles, Policy and Practice, 4(3), 365-379. doi:10.1080/096959497004030

Hattie, J., \& Timperley, H. (2007). The power of feedback. Review of Educational Research, 77(1), 81-112. doi:10.2307/4624888

Hauenstein, A. D. (1998). A conceptual framework for educational objectives. A holistic approach to traditional taxonomies. Lanham, MD: University Press of America.

Herr, K., \& Anderson, G. L. (2005). The action research dissertation. Thousand Oaks, CA: Sage.

Hickey, M. (1999). Assessment rubrics for music composition. Music Educators Journal, 85(4), 26-33. doi:10.2307/3399530

Hickey, M. (2001). An application of Amabile's consensual assessment technique for rating the creativity of children's musical compositions. Journal of Research in Music Education, 49(3), 234-244. doi:10.2307/3345709

Hickey, M. (2002). Creativity research in music, visual art, theater and dance. In R. Colwell \& C. Richardson (Eds.), The new handbook of research on music teaching and learning (pp.398-415). Oxford: Oxford University Press.

Hickey, M. (2003). Why and how to teach music composition: A new horizon for music education. Lanham, USA: Rowman \& Littlefield Education.

Hickey, M. (2012). Music outside the lines: Ideas for composing in K-12 classrooms. Oxford: Oxford University Press. 
Hipkins, R. (2010). The evolving NCEA: Findings from the NZCER National Survey of Secondary Schools 2009. Wellington, NZ: New Zealand Council for Educational Research.

Hipkins, R., \& Vaughan, K. (2002). Learning curves: Meeting student learning needs in an evolving qualifications regime: from cabbages to kings: A first report. Wellington: NZCER.

Hipkins, R., \& Vaughan, K. (2004). Learning curves: Meeting student learning needs in an evolving qualifications regime: Shared pathways and multiple tracks: A second report. Wellington: NZCER.

Hipkins, R., \& Vaughan, K. with Beals, F., Ferral, H., \& Gardiner, B. (2005). Shaping our futures: Meeting secondary students' learning needs in a time of evolving qualifications: Final report of the Learning Curves project. Wellington: NZCER.

Hofer, B. K., \& Pintrich, P. R. (1997). The development of epistemological theories: Beliefs about knowledge and knowing and their relation to learning. Review of Educational Research, 67(1), 88-140. doi:10.2307/1170620

Houmann, A., \& Sæther, E. (2014). Using a survey on creativities as reflective practice in music teacher education. In P. Burnard (Ed.), Developing creativities in higher music education (pp.174-185). London: Routledge.

Hynds, A., Sleeter, C., Hindle, R., Savage, C., Penetito, W., \& Meyer, L. H. (2011). Te Kotahitanga: A case study of a repositioning approach to teacher professional development for culturally responsive pedagogies, 39, 339-351. doi:10.1080/1359866X.2011.614684

Inbar-Lourie, O. (2008). Language assessment culture. In E. Shohamy \& N. H. Hornberger (Eds.), Encyclopedia of language and education (2nd ed., Vol. 7, pp.285-299). New York: Springer.

Jaffurs, S. (2004). The impact of informal music learning practices in the classroom, or how I learned how to teach from a garage band. International Journal of Music Education, 22(3), 189-200. doi:10.1177/0255761404047401. 
Jaffurs, S. (2006). The intersection of informal and formal music learning processes. International Journal of Community Music. Retrieved from http://www.intljcm.com/.

James, M. (2008). Assessment and learning. In S. Swaffield (Ed.), Unlocking assessment: Understanding for reflection and application (pp.20-35). London: Routledge.

James, M. (2012). Assessment in harmony with our understanding of learning: Problems and possibilities. In J. Gardner (Ed.), Assessment and learning (pp.187-205). London: Sage.

James, M., \& Pollard, A. (2011). TLRP's ten principles for effective pedagogy: Rationale, development, evidence, argument and impact. Research Papers in Education, 26(3), 275-328.

Johnson, D. W., \& Johnson R. T. (2004). Assessing students in groups. Thousand Oaks: Sage.

Johnston, L., \& Miles, L. (2004). Assessing contributions to group assignments. Assessment and Evaluation in Higher Education, 29(6), 751-768. doi:10.1080/0260293042000227272.

Kaufman, J. C., \& Beghetto, R. A. (2009a). Beyond big and little: The four c model of creativity. Review of General Psychology, 13(1), 1-12. doi:10.1037/a0013688

Kaufman, J. C., \& Beghetto, R. A. (2009b). Creativity in the schools: A rapidly developing area of positive psychology. In R. Gilman, E. S. Heubner \& M. J. Furlong (Eds.), Handbook of positive psychology (pp.175-188). New York: Routledge.

Kelly, A. (2005). Education or indoctrination? The ethics of school-based action research. In R. G. Burgess (Ed.), The ethics of educational research (pp.93105). New York: Falmer.

Kelly, G. A. (1991). The psychology of personal constructs: A theory of personality. London: Routledge. 
Kemmis, S. (2009). Action research as a practice based practice. Educational Action Research, 17(3), 463-474. doi:10.1080/09650790903093284

Kemmis, S., \& Grootenboer, P. (2008). Situating praxis in practice. In S. Kemmis \& T. J. Smith (Eds.), Enabling praxis: Challenges for education (pp.88-108). Rotterdam, The Netherlands: Sense.

Kemmis, S., \& Smith, M. L. (2008). Personal praxis: Learning through experience. In S. Kemmis \& M. L. Smith (Eds.), Enabling praxis: Challenges for education (pp.15-36). Rotterdam, The Netherlands: Sense.

Kennedy, M. A. (2002). Listening to the music: Compositional processes of high school composers. Journal of Research in Music Education, 50(2), 94-110. doi: $10.2307 / 3345815$

Knight, J. (2004). Comparison of student perception and performance in individual and group assessments in practical classes. Journal of Geography in Higher Education, 28(1), 63-81.

Kratus, J. (2012). Nurturing the songcatchers: Philosophical issues in the teaching of music composition. In W. D. Bowman \& A. L. Frega (Eds.), The Oxford handbook of philosophy in music education (pp.367-385). Oxford: Oxford University Press.

Lassig, C. J. (2013). Approaches to creativity: How adolescents engage in the creative process. Thinking Skills and Creativity, 10(0), 3-12. doi:http://dx.doi.org/10.1016/j.tsc.2013.05.002

Lave, J. (1988). Cognition in practice. Cambridge: Cambridge University Press.

Lave, J., \& Wenger, E. (1991). Situated learning: Legitimate peripheral participation. Cambridge: Cambridge University Press.

Lebler, D. (2008). Popular music pedagogy: Peer learning in practice. Music Education Research, 10(2), 193-213. doi:10.1080/14613800802079056.

Lejk, M., \& Wyvill, M. (2001). Peer assessment of contributions to a group project: A comparison of holistic and category-based approaches. Assessment and Evaluation in Higher Education, 26(1), 61-72. doi:10.1080/02602930020022291 
Leont'ev, A. N. (1981). The problem of activity in psychology. In J. V. Wertsch (Ed.), The concept of activity in Soviet psychology (pp.37-71). Armonk, NY: Sharpe.

Lewin, K. (1947). Frontiers in group dynamics: Concept, method and reality in social science: Social equilibria and social change. Human Relations, 1(1), 5-41. doi:10.1177/001872674700100103

Lewis, R. (2012). Composing the curriculum: Teacher identity. British Journal of Music Education, 29(02), 153-161. doi:10.1017/S0265051712000198

Li,Y., Doyle Lynch, A., Kalvin, C., Jianjun L., \& Lerner, R. M. (2011). Peer relationships as a context for the development of school engagement during early adolescence. International Journal of Behavioral Development, 35(4), 329-342. doi:10.1177/0165025411402578

Lincoln, Y. S. (1995). Emerging criteria for quality in qualitative and interpretive research. Qualitative Inquiry, 1(3), 275-289. doi:10.1177/107780049500100301

Locke, T., Alcorn, N., \& O’Neill, J. (2013). Ethical issues in collaborative action research. Educational Action Research, 21(1), 107-123. doi:10.1080/09650792.2013.763448

Lund, A. (2008). Assessment made visible: Individual and collective practices. Mind, Culture, and Activity, 15(1), 32-51. doi:10.1080/10749030701798623

Macdonald, R., Hargreaves, D. J., \& Miell, D. (2009). Musical identities. In S. Hallam, I. Cross \& M. Thaut (Eds.), The Oxford handbook of music psychology (pp.462-480). Oxford: Oxford University Press.

Macdonald, R., \& Miell, D. (2000). Creativity and music education: The impact of social variables. International Journal of Music Education, 36(1), 58-68. doi:10.1177/025576140003600107

Macdonald, R., Miell, D., \& Mitchell, L. (2002). An investigation of children's musical collaborations: The effect of friendship and age. Psychology of Music, 30(2), 148-163. doi:10.1177/0305735602302002 
Macdonald, R., Miell, D., \& Wilson, G. (2005). Talking about music: A vehicle for identity development. In D. Miell, R. MacDonald \& D. J. Hargreaves (Eds.), Musical communication (pp.321-338). Oxford, UK: Oxford University Press.

Macfarlane, A. (2004). Kia hiwa ra! Listen to culture: Maori students' plea to educators. Wellington: NZCER.

Major, A. E. (2008). Appraising composing in secondary-school music lessons. Music Education Research, 10(2), 307-319. doi:10.1080/14613800802079171

Mandolini, R. (2012). Musical heuristics: Contributions to the understanding of musical creative processes. In W. D. Bowman \& A. L. Frega (Eds.), The Oxford handbook of philosophy in music education (pp.346-366). Oxford: Oxford University Press.

Marzano, R. J. (2001). Designing a new taxonomy of educational objectives. Thousand Oaks, CA: Corwin.

Massimini F., \& Carli, M. (1988). The systematic assessment of flow in daily experience. In M. Csikszentmihalyi \& I. Csikszentmihalyi (Eds.), Optimal experience: Psychological studies of flow in consciousness (pp.266-287). Cambridge: Cambridge University Press.

McGillen, C., \& McMillan, R. (2005). Engaging with adolescent musicians: Lessons in song writing, cooperation and the power of original music. Research Studies in Music Education, 25(1), 1-20. doi:10.1177/1321103x050250010401.

McNiff, J., \& Whitehead, J. (2002). Action research: Principles and practices (2nd ed.). London: Routledge Falmer.

McNiff, J., \& Whitehead, J. (2010). You and your action research project. New York: Routledge.

McPhail, G. (2009). Searching for standards in the NCEA: Assessing musical performance. Waikato Journal of Education, 14, 15-30.

McPhail, G. (2012a). Knowledge and the curriculum: Music as a case study in educational futures. New Zealand Journal of Educational Studies, 47(1), 33-46. 
McPhail, G. (2012b). The canon or the kids: Teachers and the recontextualisation of classical and popular music in the secondary school curriculum (Doctor of Education thesis). University of Auckland, Auckland, NZ. Retrieved from http://researchspace.auckland.ac.nz.

McPhail, G. (2012c). From singular to over-crowded region: Curriculum change in senior secondary school music in New Zealand. British Journal of Music Education, 29(03), 317-330. doi:10.1017/S0265051712000058

McPhail, G. (2013). The canon or the kids: Teachers and the recontextualisation of classical and popular music in the secondary school curriculum. Research Studies in Music Education, 35(1), 7-20. doi:10.1177/1321103x13483083

Mellor, L. (2000). Listening, language and assessment: The pupils' perspective. British Journal of Music Education, 17(03), 247-263.

Merriam, S. B. (1998). Qualitative research and case study applications in education. San Francisco: Jossey-Bass.

Meyer, L. H., McClure, J., Walkey, F., Weir, K. F., \& McKenzie, L. (2009). Secondary student motivation orientations and standards-based achievement outcomes. British Journal of Educational Psychology, 79, 273-293.

Miell, D., \& Littleton, K. (2008). Musical collaboration outside school: Processes of negotiation in band rehearsals. International Journal of Educational Research, 47(1), 41-49. doi:http://dx.doi.org/10.1016/j.ijer.2007.11.006

Miles, M., \& Huberman, A. M. (1994). Qualitative data analysis. Thousand Oaks: Sage.

Mills, G. E. (2007). Action research: A guide for the teacher researcher (3rd ed.). Columbus, $\mathrm{OH}$ : Pearson.

Ministry of Education. (2000). The arts in the New Zealand curriculum. Wellington: Learning Media.

Ministry of Education. (2007). The New Zealand curriculum. Wellington: Learning Media. 
Ministry of Education. (2010). 91092: Compose two original pieces of music.

Downloaded from

http://www.nzqa.govt.nz/ncea/assessment/search.do?query_Music\&view_all\&1 evel_01.

Mockler, N. (2007). Ethics in practitioner research: Dilemmas from the field. In A. Campbell \& S. Groundwater-Smith (Eds.), An ethical approach to practitioner research (pp.88-98). Abingdon, Oxon: Routledge.

Murphy, R., \& Espeland, M. (2007). Making connections in assessment and evaluation in arts education. In L. Bresler (Ed.), International handbook of research in arts education. New York: Springer.

Newton, P. E. (2007). Clarifying the purposes of educational assessment. Assessment in Education: Principles, Policy and Practice, 14(2), 149-170. doi:10.1080/09695940701478321

Newton, P. E. (2011). Making sense of decades of debate on inter-subject comparability in England. Assessment in Education: Principles, Policy and Practice, 19(2), 251-273. doi:10.1080/0969594X.2011.563357

New Zealand Music Industry Commission. (2005). Making music: Te waihanga pũoro. Wellington: Ministry of Education.

North, A. C., \& Hargreaves, D. J. (1999). Music and adolescent identity. Music Education Research, 1(1), 75-92. doi:10.1080/1461380990010107.

Odam, G. (2001). Research in the arts: Issues in the development of new and relevant techniques of arts research in music, the arts and arts education. Music Education Research, 3(1), 77-86. doi:10.1080/14613800020029978

Odena, O. (2001). The construction of creativity: Using video to explore secondary school music teachers' views. Educate, 1(1), 104-122. Retrieved from http://www.educatejournal.org/index.php/educate/article/view/52/48

Odena, O. (2012a). Creativity in the secondary music classroom. In G. E. McPherson \& G. F. Welch (Eds.), The Oxford handbook of music education (Vol. 1, pp.512-528). Oxford: Oxford University Press. 
Odena, O. (2012b). Musical creativity: Insights from music education research. Retrieved from http://VUW.eblib.com/patron/FullRecord.aspx?p=823580

Odena, O., \& Welch, G. (2009). A generative model of teachers' thinking on musical creativity. Psychology of Music, 37(4), 416-442. doi:10.1177/0305735608100374

Odena, O., \& Welch, G. F. (2007). The influence of teachers' backgrounds on their perceptions of musical creativity: A qualitative study with secondary school music teachers. Research Studies in Music Education, 28(1), 71-81. doi:10.1177/1321103x070280010206

Odena, O., \& Welch, G. F. (2012). Teachers' perceptions of creativity. In O. Odena (Ed.), Musical creativity (pp.29-48). Farnham, UK: Ashgate e-Book.

OECD. (2004). Problem solving for tomorrow's world-first measures of crosscurricular competencies from PISA 2003. Paris: Organisation for Economic Co-operation and Development.

O'Flynn, J. (2006). Vernacular music-making and education. International Journal of Music Education, 24(2), 140-147. doi:10.1177/0255761406065475.

Pajeres, M. F. (1992). Teachers' beliefs and educational research: Cleaning up a mess. Review of Educational Research, 62(3), 307.

Parr, J. M., \& Timperley, H. S. (2008). Teachers, schools and using evidence: Considerations of preparedness. Assessment in Education: Principles, Policy and Practice, 15(1), 57-71. doi:10.1080/09695940701876151

Parr, J. M., \& Townsend, M. A. R. (2002). Environments, processes, and mechanisms in peer learning. International Journal of Educational Research, 37(5), 403-423. doi:http://dx.doi.org/10.1016/S0883-0355(03)00013-2

Peterson, E. R., \& Irving, S. E. (2008). Secondary school students' conceptions of assessment and feedback. Learning and Instruction, 18(3), 238-250.

Reinharz, S. (1997). Who am I? The need for a variety of selves in the field. In R. Hertz (Ed.), Reflexivity and voice. (pp.3-20). Thousand Oaks, CA: Sage. 
Reinharz, S. (2011). Observing the observer: Understanding ourselves in field research. Oxford: Oxford University Press.

Robson, C. (2011). Real world research (3rd ed.). Chichester, UK: Wiley.

Rogoff, B. (1990). Apprenticeship in thinking: Cognitive development in social context: Oxford: Oxford University Press.

Rogoff, B. (1995). Observing sociocultural activity on three planes: Participatory appropriation, guided participation, and apprenticeship. In J. V. Wertsch, P. Del Rio \& A. Alvarez (Eds.), Sociocultural studies of mind. (pp.139-164). Cambridge: Cambridge University Press.

Rohan, T. (2011). Teaching music, learning culture: The challenge of culturally responsive music education ( $\mathrm{PhD}$ thesis). University of Otago, Dunedin, NZ. Retrieved from http://otago.ourarchive.ac.nz/handle/10523/1865

Ruscio, J., Whitney, D. M., \& Amabile, T. M. (1998). Looking inside the fishbowl of creativity: Verbal and behavioral predictors of creative performance. Creativity Research Journal, 11(3), 243-263. doi:10.1207/s15326934crj1103_4

Rusinek, G. (2012). Action-research on collaborative composition: An analysis of research questions and designs. In O. Odena (Ed.), Musical creativity: Insights from music education research. Farnham: Ashgate. Retrieved from http://VUW.eblib.com/patron/FullRecord.aspx $? \mathrm{p}=823580$

Russell, J. A., \& Austin, J. R. (2010). Assessment practices of secondary music teachers. Journal of Research in Music Education, 58(1), 37-54. doi:10.2307/40666230

Sadler, D. R. (1987). Specifying and promulgating achievement standards. Oxford Review of Education, 13(2), 191-209.

Sadler, D. R. (1989). Formative assessment and the design of instructional systems. Instructional Science, 18(2), 119-144.

Sadler, D. R. (1998). Formative Assessment: revisiting the territory. Assessment in Education: Principles, Policy and Practice, 5(1), 77-84. doi:10.1080/0969595980050104 
Sadler, D. R. (2012). Assuring academic achievement standards: From moderation to calibration. Assessment in Education: Principles, Policy and Practice, 20(1), 519. doi:10.1080/0969594X.2012.714742

Salomon, G. (1993). No distribution without individuals' cognition: A dynamic interactional view. In G. Salomon (Ed.), Distributed cognitions: Psychological and educational considerations (pp.111-138). Cambridge: Cambridge University Press.

Savage, C., Hindle, R., Meyer, L. H., Hynds, A., Penetito, W., \& Sleeter, C. E. (2011). Culturally responsive pedagogies in the classroom: Indigenous student experiences across the curriculum. Asia-Pacific Journal of Teacher Education, 39(3), 183-198. doi:10.1080/1359866X.2011.588311

Savage, J. (2003). Viewpoints informal approaches to the development of young people's composition skills. Music Education Research, 5(1), 81-85. doi:10.1080/14613800307106.

Savage, J., \& Challis, M. (2002). A digital arts curriculum? Practical ways forward. Music Education Research, 4(1), 7-23. doi:10.1080/14613800220119741

Savage, J., \& Fautley, M. (2007). Creativity in secondary education. Exeter, UK: Learning Matters.

Savage, J., \& Fautley, M. (2011). The organisation and assessment of composing at Key Stage 4 in English secondary schools. British Journal of Music Education, 28(02), 135-157. doi:10.1017/S0265051711000040

Sawyer, R. K., \& DeZutter, S. (2009). Distributed creativity: How collective creations emerge from collaboration. Psychology of Aesthetics, Creativity, and the Arts, 3(2), 81-92. doi:10.1037/a0013282

Schmuck, R. A. (2008). Practical action research for change. Thousand Oaks, CA: Corwin.

Scriven, M. (1967). The methodology of evaluation. Washington DC: American Educational Research Association.

Sell, D. (2003). The changing face of music education in New Zealand. Sound Ideas, 6(1), 43-46. 
Sheridan, M., \& Byrne, C. (2002). Ebb and flow of assessment in music. British Journal of Music Education, 19(2), 135-143. doi:10.1017/S0265051702000220

Sloboda, J. (1985). The musical mind: The cognitive psychology of music. Oxford: Clarendon Press.

Sloboda, J. (2001). Emotion, functionality and the everyday experience of music: Where does music education fit? Music Education Research, 3(2), 243-253.

Smagorinsky, P. (1995). The social construction of data: Methodological problems of investigating learning in the zone of proximal development. Review of Educational Research, 65(3), 191-212. doi:10.2307/1170682

Soares, J. (2012). The nature of engagement of Brazilian adolescents in composing activities. In O. Odena (Ed.), Musical creativity: Insights from music education research. Farnham: Ashgate. Retrieved from http://VUW.eblib.com/patron/FullRecord.aspx $? \mathrm{p}=823580$

Somekh, B. (1995). The contribution of action research to development in social endeavours: A position paper on action research methodology. British Educational Research Journal, 21(3), 339-355. doi:10.2307/1501651

Somekh, B. (2009). Agency through action research: Constructing active identities through metaphorical models and metaphors. In S. E. Noffke \& B. Somekh (Eds.), The Sage handbook of educational action research (pp.370-380). London: Sage.

Somekh, B., \& Nissen, M. (2011). Cultural-historical activity theory and action research. Mind, Culture, and Activity, 18(2), 93-97. doi:10.1080/10749039.2010.523102

Stake, R. (2003). Qualitative case studies. In N. Denzin \& Y. Lincoln (Eds.), Handbook of qualitative research (3rd ed., pp.443-466). London: Sage.

Stake, R. E. (1995). The art of case study research. Thousand Oaks: Sage.

Stålhammar, B. R. (2003). Music teaching and young people's own musical experience. Music Education Research, 5(1), 61-68. doi:10.1080/14613800307100. 
Stauffer, S. L. (2002). Connections between the musical and life experiences of young composers and their compositions. Journal of Research in Music Education, 50(4), 301-322. doi:10.2307/3345357.

Stefanic, N., \& Randles, C. (2014). Examining the reliability of scores from the consensual assessment technique in the measurement of individual and small group creativity. Music Education Research, 1-18.

doi:10.1080/14613808.2014.909398

Swaffield, S. (2011). Getting to the heart of authentic assessment for learning. Assessment in Education: Principles, Policy and Practice, 18(4), 433-449. doi:10.1080/0969594X.2011.582838

Tarrant, M., North, A. C., \& Hargreaves, D. J. (2001). Social categorization, selfesteem, and the estimated musical preferences of male adolescents. The Journal of Social Psychology, 141(5), 565-581. doi:10.1080/00224540109600572

Tavani, C. M., \& Losh, S. C. (2003). Motivation, self-confidence, and expectations as predictors of the academic performances among our high school students. Child Study Journal, 33(3), 141-151.

Thompson, A. G. (1992). Teachers' beliefs and conceptions: A synthesis of the research. In D. A. Grouws (Ed.), Handbook of research on mathematics teaching and learning (pp.127-146). New York: Macmillan.

Thorpe, V. (2009). Help from my friends: Group composing and informal music learning. Proceedings of the Joint Conference of XXXIst ANZARME Annual Conference and the Ist Conference of the Music Educators Research Center (MERC), Akaroa, NZ: ANZARME.

Thorpe, V. (2012). Assessment rocks? The assessment of group composing for qualification. Music Education Research, 14(4), 417-429. doi:10.1080/14613808.2012.699957

Thorpe, V. (2008). We made this song: The group song writing processes of three adolescent rock bands (Unpublished Masters thesis). New Zealand School of Music, Wellington. 
Tobias, E. S. (2012). Hybrid spaces and hyphenated musicians: Secondary students' musical engagement in a songwriting and technology course. Music Education Research, 14(3), 329-346. doi:10.1080/14613808.2012.685459

Tobias, E. S. (2013). Composing, songwriting, and producing: Informing popular music pedagogy. Research Studies in Music Education, 35(2), 213-237. doi:10.1177/1321103x13487466

Torrance, E. P. (1988). The nature of creativity as manifest in its testing. In R. J. Sternberg (Ed.), The nature of creativity (pp.43-73). New York: Cambridge University Press.

Tsisserev, A. (1997). An ethnography of secondary school student composition in music: A study of personal involvement within the compositional process (Unpublished doctoral thesis). University of British Columbia, Vancouver, Canada.

Ulichny, P., \& Schoener, W. (2010). Teacher-researcher collaboration from two perspectives. In W. Luttrell (Ed.), Qualitative educational research: Readings from reflexive methodology and transformative practice (pp.421-447). New York: Routledge.

Urmson, J. O. (1950). On grading. Mind, 59(2), 145-169. doi:10.2307/2250658

van Aalst, J. (2013). Assessment of collaborative learning. In C. Hmelo-Silver, C. A. Chinn, C. K. Chan \& A. M. O'Donnell (Eds.), International handbook of collaborative learning (pp.280-296). New York: Routledge.

Vygotsky, L. (1978). The mind in society. Cambridge, MA: Harvard University Press.

Vygotsky, L. (1986). Thought and language. Cambridge, MA: MIT Press.

Walkey, F. H., McClure, J., Meyer, L. H., \& Weir, K. F. (2013). Low expectations equal no expectations: Aspirations, motivation, and achievement in secondary school. Contemporary Educational Psychology, 38(4), 306-315. doi:http://dx.doi.org/10.1016/j.cedpsych.2013.06.004

Wallas, G. (1926). The art of thought. London: Jonathon Cape. 
Waterman, A. S. (2005). When effort is enjoyed: Two studies of intrinsic motivation for personally salient activities. Motivation and Emotion, 29(3), 165-188. doi:10.1007/s11031-005-9440-4

Waters, S. K., Cross, D., \& Shaw, T. (2010). How important are school and interpersonal student characteristics in determining later adolescent school connectedness, by school sector? Australian Journal of Education, 54(2), 223-243. doi:10.1177/000494411005400207

Webb, N. M. (1997). Assessing students in small collaborative groups. Theory into Practice, 36(4), 205-213. doi:10.2307/1477365

Webb, N. M., Farivar, S. H., \& Mastergeorge, A. M. (2002). Productive helping in cooperative groups. Theory into Practice, 41(1), 13-20. doi:10.2307/1477532

Webb, N. M., Nemer, K. M., Chizhik, A. W., \& Sugrue, B. (1998). Equity issues in collaborative group assessment: Group composition and performance. American Educational Research Journal, 35(4), 607-651. doi:10.2307/1163461

Webster, P. R. (1990). Creative thinking in music: introduction. Music Educators Journal, 76(9), 21.

Webster, P. R. (2002). Creative thinking in music: Advancing a model. In T. Sullivan \& L. Willingham (Eds.), Creativity and music education (pp.16-34). Edmonton, Canada: Canadian Music Educators' Association. Retrieved from http://online.uncg.edu/courses/mue704/readings/unit3/Webster\%202002.pdf. doi:10.1177/1321103x070280010203

Welch, G. F. (2007). Addressing the multifaceted nature of music education: An activity theory research perspective. Research Studies in Music Education, 28(1), 23-37. doi:10.1177/1321103x070280010203

Welch, G. F. (2012). Musical creativity, biography, genre, and learning. In D. J. Hargreaves, D. Miell \& R. MacDonald (Eds.), Musical imaginations: Multidisciplinary perspectives in creativity, performance and perception (pp.385-398). Oxford: Oxford University Press.

Wenger E. (1998). Communities of practice: Learning, meaning and identity. Cambridge: Cambridge University Press. 
Wengraf, T. (2001). Qualitative research interviewing: Semi-structured, biographical and narrative methods. Thousand Oaks, CA: Sage.

Wheelahan, L. (2010). Why knowledge matters in the curriculum. London, UK: Routledge.

Whitehead, J., \& McNiff, J. (2006). Action research: Living theory. London: Sage.

Wigfield, A., \& Eccles, J. S. (2000). Expectancy-value theory of achievement motivation. Contemporary Educational Psychology, 25(1), 68-81. doi:http://dx.doi.org/10.1006/ceps.1999.1015

Wigfield, A., Tonks, S., \& Eccles, J. S. (2004). Expectancy value theory in crosscultural perspective. In D. McInerney \& S. Van Etten (Eds.), Research on sociocultural influences on motivation and learning: Big theories revisited (Vol. 4, pp.165-198). Greenwich, CT: Information Age.

Wiggins, J. H. (2007). Compositional process in music. In L. Bresler (Ed.), International handbook of research in arts education (pp.453-470). Dordrecht: Springer.

Wiles, R., Crow, G., Heath, S., \& Charles, V. (2008). The management of confidentiality and anonymity in social research. International Journal of Social Research Methodology, 11(5), 417-428. doi:10.1080/13645570701622231

Wiliam, D., \& Black, P. (1996). Meanings and consequences: A basis for distinguishing formative and summative functions of assessment? British Educational Research Journal, 22(5), 537-548.

Willis, J. (2011). Affiliation, autonomy and assessment for learning. Assessment in Education: Principles, Policy and Practice, 18(4), 399-415. doi:10.1080/0969594X.2011.604305

Wilson, B., \& Myers, K. M. (2000). Situated cognition in theoretical and practical context. In D. Jonassen \& S. Land (Eds.), Theoretical foundations of learning environments (pp.57-88). Mahwah, NJ: Lawrence Erlbaum. 
Winne, P. H., \& Hadwin, A. F. (1998). Studying as self-regulated learning. In D. J. Hacker, J. Dunlosky \& A. C. Graesser (Eds.), Metacognition in educational theory and practice (pp.277-304). Mahwah, NJ: Erlbaum.

Wise, S. (2013). Variations on the loops: An investigation into the use of digital technology in music education in secondary schools ( $\mathrm{PhD}$ thesis). University of Canterbury, Christchurch, NZ. Retrieved from http://hdl.handle.net/10092/8485

Wyatt-Smith, C., Klenowski, V., \& Gunn, S. (2010). The centrality of teachers' judgement practice in assessment: A study of standards in moderation. Assessment in Education: Principles, Policy and Practice, 17(1), 59-75. doi:10.1080/09695940903565610

Yamagata-Lynch, L. C., \& Haudenschild, M. T. (2009). Using activity systems analysis to identify inner contradictions in teacher professional development. Teaching and Teacher Education, 25(3), 507-517. doi:http://dx.doi.org/10.1016/j.tate.2008.09.014

Yin, R. K. (2009). Case study research: Design and methods (4th ed.). Thousand Oaks: Sage.

Young, M. F. D. (2010). The future of education in a knowledge society: The radical case for a subject-based curriculum. Pacific-Asian Education Journal, 22(1), 2132.

Zillmann, D., \& Gan, S. (1997). Musical taste in adolescence. In D. J. Hargreaves, A. C. North (Eds.), The social psychology of music (pp.161-187). New York: Oxford University Press.

Zimmerman, B. J., \& Schunk, D. H. (2008). Motivation: An essential dimension of self-regulated learning. In B. J. Zimmerman \& D. H. Schunk (Eds.), Motivation and self-regulated learning: Theory, research, and applications (pp.1-30). Mahwah, NJ: Erlbaum.

Zuber-Skerrit, O. (1996). New directions in action research. London: Falmer. 


\section{Appendices}




\subsection{NCEA Music Achievement Standards in 2011}

\section{Music Matrix 2011}

Note: Expiring Level 1 internal achiev ement standards can also be used for assessment in 2011. All registered and expiring achievement standards can be accessed at NZQA

\begin{tabular}{|c|c|c|c|}
\hline Level 1 & Level 2 & Level 3 Making Music & Level 3 Music Studies \\
\hline $\begin{array}{l}\text { AS } 1090 \\
\text { Perform two pieces of music as a featured } \\
\text { soloist. }\end{array}$ & $\begin{array}{l}\text { AS90264 } \\
\text { Present contrasting performances as a } \\
\text { featured soloist }\end{array}$ & $\begin{array}{l}\text { AS } 90526 \quad 3.1 \\
\text { Present a performance of a programme of } \\
\text { music as a member of a group }\end{array}$ & $\begin{array}{l}\text { AS90497 } \\
\text { Examine the contexts that influence the } \\
\text { expressive qualities of music }\end{array}$ \\
\hline 6 Credits & 5 credits & 4 credits & 3 credits \\
\hline $\begin{array}{l}\text { AS91091 } 1.2 \\
\text { Demonstrate ensemble skills through } \\
\text { performing a piece of music as a member of } \\
\text { a group. }\end{array}$ & $\begin{array}{l}\text { A.S } 90265 \\
\text { Present a music performance as a member of } \\
\text { a group }\end{array}$ & $\begin{array}{l}\text { AS90775 } \\
\text { Present a portfolio of musical } \\
\text { composition }\end{array}$ & $\begin{array}{l}\text { AS90498 } \\
\text { Compare and contrast music works }\end{array}$ \\
\hline 4 Credits & 2 credits & 8 credits & 8 credits \\
\hline $\begin{array}{l}\text { AS9 } 1092 \text { 1.3 } \\
\text { Compose two original pieces of music. }\end{array}$ & $\begin{array}{ll}\text { A.S90266 } & \mathbf{2 . 3} \\
\text { Compose effective pieces of music } & \end{array}$ & $\begin{array}{l}\text { AS90776 } 3.7 \\
\text { Prepare and present performances of } \\
\text { music as a featured soloist }\end{array}$ & $\begin{array}{l}\text { AS } 90499 \\
\text { Research and present a music topic }\end{array}$ \\
\hline 6 Credits & 5 credits & 8 credits & 6 credits \\
\hline $\begin{array}{l}\text { AS } 91093 \\
\text { Demonstrate aural and theoretical skills } \\
\text { through transcription }\end{array}$ & $\begin{array}{ll}\text { AS90267 } & \mathbf{2 . 4} \\
\text { Create an instrumentation } & \end{array}$ & $\begin{array}{l}\text { AS90777 } 3.8 \\
\text { Demonstrate aural skill across a range of } \\
\text { musical styles and genres }\end{array}$ & $\begin{array}{l}\text { AS } 90530 \quad 3.5 \\
\text { Demonstrate an understanding of } \\
\text { harmonic and tonal procedures in a } \\
\text { range of music }\end{array}$ \\
\hline 4 Credits & 2 credits & External & 3 credits \\
\hline $\begin{array}{l}\text { AS91094 } 1.5 \\
\text { Demonstrate knowledge of conventions } \\
\text { used in music scores. }\end{array}$ & $\begin{array}{l}\text { AS90268 } \\
\text { Identify, describe and transcribe elements of } \\
\text { music through listening to a range of music }\end{array}$ & & $\begin{array}{l}\text { AS90527 } \\
\text { Arrange music }\end{array}$ \\
\hline 4 Credits & External & & 4 credits \\
\hline $\begin{array}{l}\text { AS } 91095 \text { Demonstrate knowledge of two music } \\
\text { works from contrasting contexts. } \\
6 \text { Credits }\end{array}$ & $\begin{array}{l}\text { AS } 90269 \\
\text { Demonstrate an understanding of the } \\
\text { materials and processes of music in a range } \\
\text { of scores } \\
2 \text { credits }\end{array}$ & & \\
\hline & $\begin{array}{lr}\text { A.S } 90270 & 2.7 \\
\text { Demonstrate knowledge and understanding } \\
\text { of music works } \\
5 \text { credits }\end{array}$ & & \\
\hline
\end{tabular}




\section{$1.2 \quad$ Achievement Standard AS91092}

Number AS91092

Version

Page 1 of 2

\section{Achievem ent Standard}

$\begin{array}{ll}\text { Subject Reference } & \text { Music } 1.3 \\ \text { Title } & \text { Compose two original pieces of music }\end{array}$

$\begin{array}{llllll}\text { Level } & 1 & \text { Credits } & 6 & \text { Ass essment Internal } \\ \text { Subfield } & \text { Music } & & \\ \text { Domain } & \text { Making Music } & & \end{array}$

$\begin{array}{llll}\text { Status } & \text { Registered } & \text { Status date } & 17 \text { December } 2010\end{array}$

Planned review date 31 December 2014 Date version published 17 December 2010

This achievement standard involves the individual and/or collaborative composition of two original pieces of music.

\section{Achievement Criteria}

\begin{tabular}{l|l|l|}
\hline Achievement & Achievement with Merit & $\begin{array}{l}\text { Ach ievement with } \\
\text { Excellence }\end{array}$ \\
\hline $\begin{array}{l}\text { Compose two original } \\
\text { pieces of music. }\end{array}$ & $\begin{array}{l}\text { - Compose two effective } \\
\text { original pieces of } \\
\text { music. }\end{array}$ & $\begin{array}{l}\text { Compose two convincing } \\
\text { original pieces of music. }\end{array}$ \\
\hline
\end{tabular}

\section{Explanatory Notes}

1 This achievement standard is derived from The New Zealand Curriculum, Learning Media, Ministry of Education, 2007; Level 6 strand, Developing ldeas in Music Sound Arts, and is related to the material in the Teaching and Learning Guide for Music - Sound Arts, Ministry of Education, 2010 at http.//seniorsecondary.tki.org.nz.

2 Compose involves the individual and/or collaborative generation, development, structuring, and representation of original musical ide as to create music. A student may compose either two compositions as an individual, or two compositions as a member of a group(s), or one of each.

Compose effective pieces of music means that the musical ideas are developed, structured and represented coherently, and the music demonstrates stylistic control.

Compose convincing pieces of music means that the musical ideas are developed, structured and represented skilfully, and the music is stylistically assured.

3 Generation refers to the creation of musical ideas eg riffs, motifs, chords, ostinato, use of tonal centre(s). 
Number

Development refers to the way that musical ideas are manipulated using timbre, textures, and compositional devices eg repetition, sequence, layering, te mita o te reo Māori.

Structure refers to the ways in which musical ideas are organised eg verse/chorus, ABA, whakapapa (genealogical narrative).

4 Representation must convey compositional intent as appropriate to the style/genre. Representation must include both audio and visual representation.

Representation of a composition must comprise:

- an audio or audio visual file playable on a CD player or computer without specialised music software

- a visual representation that is appropriate to the style/genre and conveys compositional intent eg standard music notation, lyric and chord chart, lead sheet, tab, graphic notation, narrative description, or a combination of the se.

5 Collaborative composition must involve 2-5 students, working in a group. Each student's creative contribution to the group composition must be individually assessed.

6 For improvisation sufficient detail must be supplied in the visual representation to give a clear indication of the composer's intentions.

7 The assessment criteria must be applied to provide an overall judgment based on the weight of evidence across both compositions.

8 Conditions of Assessment related to this achievement standard can be found at www.tki.org.nz/e/communit $/$ ince a/conditions-assessment.php.

\section{Replacement Information}

This achievement standard replaced unit standard 10654 and AS90014.

\section{Quality Ass urance}

1 Providers and Industry Training Organisations must be accredited by NZQA before they can register credits from assessment against achievement standards.

2 Accredited providers and Industry Training Organisations assessing against achievement standards must engage with the moderation system that applies to tho se achievement standards. 


\subsection{Ethics Documents}

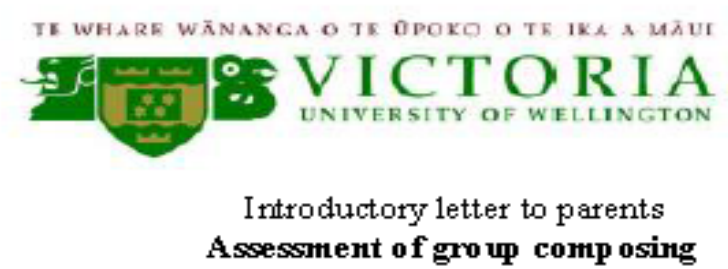

Dear

My name is Vicki Thorpe and I am a $\mathrm{PhD}$ student at the Faculty of Education, Victoria University of Wellington (V UW). I am al so a lecturer at the V UW Faculty of Education and have had a long involve ment in music education as a secondary Music teacher and schools adviser.

I am writing to ask if you would be willing to give permission for your son to participate in a study for my $\mathrm{PhD}$ research

\section{What is the p roject about?}

There is a new NCEA Level 1 Music standard for composing this year. This means that, for the first time in New Zealand, composing that takes place in a group can be assessed for NCEA. My research project aims to find out, from the points of view of both students and teachers, what happens when this new standard is used to assess composing in a group. Another aim of the project is to enhance student achievement in NCEA Music and I hope that this will be of benefit to in his work in class.

I will be working with ....., $Y$ ear 11 Music teacher at ...... to find about more about group composing and how to assess it for NCEA.

I will ask to:

- Take part in a group interview to talk about composing in a group and how the asse ssment went.

- Be interviewed individually

- Privately record his thoughts about the assessment on a digital voice recorder.

\section{What data or information will be collected?}

- I will make audio and video recordings and transcribe the data.

- I will collect copies of any written work or recordings that the teacher requires to do for the assessment

- I will also interview ....... about this assessment.

\section{What $w$ ill happ en to this information and who sees it?}

- I will keep 's identity and any information he gives me strictly confidential at all times. I will use pseudonyms in the writing up of the research, ensuring that he is not identifiable in any published material.

- Video recordings of students will not be published and will be used for analysis only.

- I will analyse this information and present my findings as a thesis.

- I will present my research at a conference and write papers about it. 
- The data will be securely stored at all times and then deleted 2 years after the project has been completed

What if I change my mind and want to withdraw from the project?

Participation is voluntary. I do not think that will experience any harm or discomfort from taking part in this research $\mathrm{H}$ owever, you have the choice to withdraw him from the project at any time before the data collection is complete, without any disadvantage. Should you wish to do so then all data about will be deleted.

What is the timeframe?

I will be visiting ...... between ...... this year. I will be working with .... in hisher Year 11 dassroom.

I have the permission of ...... principal, ....., to carry out this research This research has been assessed and approved by the VUW Faculty of Education ethic com mittee (reference no. 17727). My $\mathrm{PhD}$ is supervised by Dr Anne Hynds, phone (04) 4639558 , and Professor Luanna Meyer, phone (04) 4639598.

If you have any questions regarding this research please don't hesitate to contact me on(04) 4639629 or email vicki.thorpe(d)ww.ac.nz.

Many thanks for considering this request.

Yours sincerely,

Vicki Thorpe 


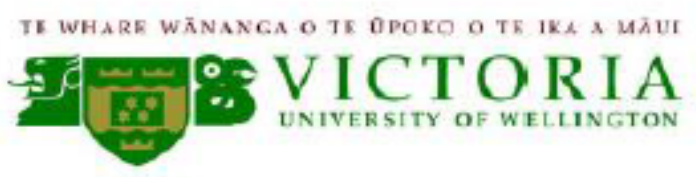

\section{PhD Research Project: Assessment of group composing \\ Parent/caregiver's consent form}

1. I have been given and have understood an explanation of this research project. I have read the information sheet relating to this research and have had the opportunity to ask questions and have them answered to $\mathrm{my}$ satisaction.

YES $\square$ (please tick)

2. I give consent for data collection to take place using:

Interview

YES

Audio recording

YES

Video recording

YES

My child's achievement and assessment materials YES

relating to group composing

3. I understand that I have the right to withdraw

from the research before the data gathering is complete.

YES

4. I understand that the data collected will be kept confidential to the researcher, Vic ki Thorpe and her supervisors.

\section{YES}

5. I understand that the published results will not uæe the school's name, my child's name, or include any descriptions, video footage or information that in any way identifies himiher.

$$
\text { YES }
$$

6. I understand that all data will be securely stored and then destroyed 2 years after the completion of the research project.

\section{YES $\square$}

7. I would like a summary of the final report.

YES $\square$ No

8. I understand that by signing this form I give my consent for to take part in this research. YES 
Name of parent/caregiver:

Signed:

Name of student:

Name of school:

Date:

The ethical procedures outlined for this project have been reviewed and approved by Victoria University of Wellington $F$ aculty of Education Ethics Committee (reference no.17727) 


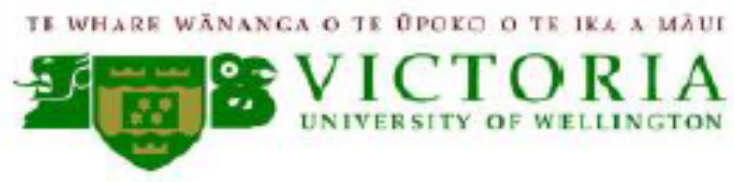

Introductory letter to students

Assessment of gro u comp osing

Dear

My name is Vicki Thorpe and I am a $\mathrm{PhD}$ student at Victoria Uriversity in Wellington I am also a musician who plays original songs in a band.

\section{What is this project ab out?}

There is a new NCEA Level 1 Music standard for composing this year. This means that, for the fir st time, composing done in a group can be assessed for NCEA. My research project aims to find out about what happens, from the points of view of students and teachers, when this new standard is used to assess composing/song writing done in a group. I decided to choose this as the topic for my research because not much is known about what happens when secondary students get together to compose music in a group, or how this music might be assessed. Your Music teacher ...... and I are working together to find out more about composing in a group and how to assess it for NCEA. I will be working with him/her in your music class over the next few months.

\section{What will you ask me to do?}

You will be asked to compose two pieces of music in a group. ..... will then assess your work, and give you a grade using the new level 1 NCEA standard.

\section{If you agree to take $p$ art in this research this means that I will ask you to:}

- Be interviewed with the other people in your group. This interview will be recorded on audio and video

- Be interviewed by yourse if

- Privately record on a digital voice recorder your own thoughts about composing in a group, and the assessment

- Play me your composition and talk to me about it while you are working. I may record this on audio or video, or maybe write down some notes.

\section{What data or information will be collected?}

- I will make audio and video recordings of the interviews

- I may take notes

- I will transcribe (write down what is said in) all of the recordings, including the recording you will make on your own

- I will collect copies of any written work or recordings that .... asks you to do for your assessment

- I will also interview ...... about your composing and your leaming 


\section{What $w$ ill happ en to this information and who sees it?}

- I will keep your identity, the name of your group and the titles of your compositions strictly confidential at all times. You can choose a name for the to use in the research when I refer to you. I will also keep all of the information you give me strictly confide ntial. ..... and I will share information that is about your learning at school but I will keep material from your interviews. Y ou, ..., your compositions, your group and your school will not be identifiable in anything I present or publish

- I will store the data securely and the delete it 2 years after the project has been completed

- I will analyse the collected data and present my findings as a thesis

- I will present my research at conferences and write papers about it

- You will be given a summary of the final report

What if I change my mind and want to withdraw from the project?

Participation is up to you. I do not think that you will experience any harm or discomfort from participating in this research and I hope you will enjoy doing so. However, you have the choice to pull out of the project before the data collection is complete. Should you wish to withdraw, then anything I have recorded that includes you will be deleted.

\section{When will this happ en?}

I will be visiting your Year 11 Music class at ..... between June and October this year.

This research has been assessed and approved by the VUW Faculty of Education ethics committee (reference no. 17727). If you have any questions about this research please contact the on (04) 4639629 or 021673957 (txt is fine) or vicki.thorpe(a) nuw.ac.nz.

Many tharks for considering this request.

Yours sincerely,

Vicki Thorpe

$\checkmark$ Thorpe $\mathrm{PhD}$ student letterm ain study 


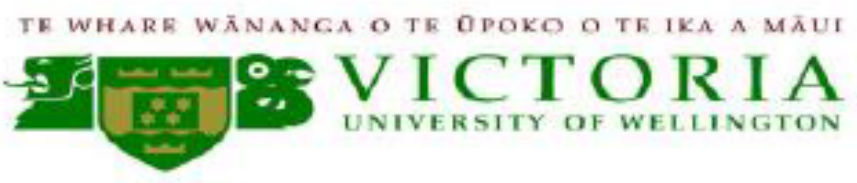

PhD Action Research Project: Assessment of group composing

Dear

My name is Vicki Thorpe and I am a lecturer at the Faculty of Education, Victoria University of Wellington (VUW). I have had a long involvement in music education as a secondary Music teacher and schools adviser. I am also a PhD student at the VUW Faculty of Education.

I am writing to ask if you would be willing to give permission for ...... and Year 11 Music students to participate in an action research project for $\mathrm{my} \mathrm{PhD}$.

\section{What is this project about?}

This project aims to investigate teachers' professional learning and their students' experiences of this learning when they undertake the NCEA assessment of composing achieved in groups, using the new NCEA achievement standard for Level 1 Music. Group composing has not been assessed for the NCEA before and this research is a world first. It is hoped that this study will shed some light on what happens when young people compose together in groups, how a teacher might facilitate this learning, and how this learning might be assessed for qualification. This project builds upon my Masters research where I investigated group composing in Rockquest bands.

\section{What would this involve?}

This is an action research project involving collaboration between ..... and myself as co-researchers in a cyclical process of planning, investigating, analysing data, and reflecting and evaluating. My roles in this process would be that of colleague, coach and researcher. I will also work with .... in his/her dassroom, with the Year 11 students who are group composing. During this time I will in terview ...... and groups of Year 11 students. 
I will also gather data such as notes made during classroom observations, video and audio recordings of work in the classroom and student achievement data. I will also keep an on-going research diary. I may team-teach with ..... and teach while $s / h e$ observes. .... will keep a journal, undertake professional reading, reflect upon his/her professional learning and try new ways to both teach and assess composing.

\section{What is the timeframe?}

I would like to visit the ...... Music Department on an on-going basis between .......2011 and ......2012. I will negotiate the times for these visits with ......, at his/her convenience. I do not anticipate that either $s /$ he or his/her students will need to be released from other classes, nor will their studies be interrupted. On the contrary, the aim here is to enhanoe student achievement through .......'s ongoing professional learning.

As a former secondary teacher and secondary music adviser, I am familiar with school routines and I will ensure that I am as flexible and unobtrusive as possible. I am also a fully registered secondary teacher. You have the right to withdraw ...... and the students from the research at any time during the data collection process.

\section{What will be done with the research information and who} sees it?

- I will analyse all data and write up my findings as a thesis.

- I will present my research at conferences and write academic papers about it.

- I will keep the school's, the teacher's and the students' identities and all data strictly confidential at all times. In particular, I will not share any information about the research with other students, parents or staff at .......

- I will obtain written permission from the boys' parents before proceeding.

- I will use pseudonyms in the writing up of the research, ensuring that the teacher, the students and the school are not identifiable in any published material.

- The data will be stored securely at all times and deleted 2 years after the project has been completed.

- You, the teacher, the students and the students' parents will be given a summary of the final report.

- ..... and ..... College will own the intellectual property of resources developed and used within the school's community. 
This research has been approved by the VUW Faculty of Education ethics committee. Parent, teacher and student informed, written consent will also be gained prior to beginning the research. My PhD is supervised by Dr Anne Hynds, phone (04) 463 9558, and Professor Luanna Meyer, phone (04) 4639598.

If you have any questions regarding this research please don't hesitate to contact me on (04) 4639629 or email vicki, thorpe(i)vuw, ac.nz.

Many thanks for considering this request.

Vours sincerely,

Vicki Thorpe 


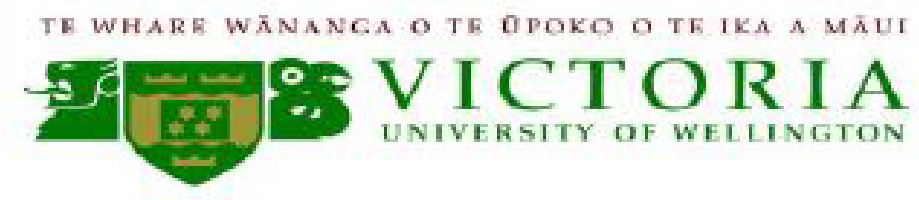

PhD Action Research Project: Assessment of group composing

Dear ......

I am writing to ask if you would be willing to participate in an action research project for my PhD.

\section{What is this project about?}

This project aims to investigate teachers' professional learning and their students' experiences of this learning when they undertake the NCEA assessment of composing achieved in groups, using the new NCEA achievement standard for Level 1 Music. Group composing has not been assessed for the NCEA before. It is hoped that this study will shed some light on what happens when young people compose together in groups, how a teacher might facilitate this learning, and how this learning might be assessed for qualification. This project builds upon my Masters research where I investigated group composing in Rockquest bands.

\section{What would this imolve?}

This is an action research project involving collaboration between us as coresearchers in a cyclical process of planning, irwestigating, analysing data, and reflecting and evaluating. My roles in this process would be that of your colleague and coach as well as a researcher. I will also work with you in your classroom, with Year $10-11$ students who are group composing. During this time I will interview you several times. I will also interview one group of students which we will have chosen jointly.

I will also gather data such as notes made during classroom observations, video and audio recordings of work in the classroom and student achiev ement and assessment data. I will also keep an on-going research diary. I may teamteach with you, or possibly model teaching while you observe.

\section{What will I be asked to do?}

I will ask you to keep a journal, undertake professional reading, reflect upon your professional learning, keep written records, and try new ways to both teach and assess composing. You will need to stay engaged in this process until after you have assessed the students' work and awarded summative NCEA grades.

\section{What if I change my mind and want to pull out of the project?}

You have the right to withdraw from the research at any time during the data collection process 
What is the timeframe?

I would like to visit the ...... Music Department on an on-going basis between ..... 2011 and .... 2012. I will negotiate the times for these visits with you, at your convenience. I do not antic ipate that either you or your students will need to be released from other classes, not will their studies be interrupted. On the contrary, the aim here is to enhance student achievement. We will meet regularly, sometimes weekly, sometimes even daily, depending on what is happening in the classroom.

As a former secondary teacher and secondary music adviser, I am familiar with school routines and I will ensure that I am as flexible as possible.

What will be done with the research information and who sees it?

- I will analyse all data and write up my findings as a thesis.

- I will present $m y$ research at conferences and write academic papers about it. You may also wish take part in some form of collaboration in this too.

- While you and I will share student information regarding students' learning and achievement, I will keep all data, including student interview data, strictly confidential.

- I will use pseudonyms in the writing up of the research, ensuring that you, the students and the school are not identifiable in any published material.

- The data will be stored securely at all times and deleted 2 years after the project has been completed.

- You, your principal, the students and the students' parents will be given a summary of the final report.

- You will own the intellectual property of ary findings published within the school community or presented to the school's Board of Trustees.

This research has been approved by the VUW Faculty of Education ethics committee. Informed, written consent will also be gained from all participants prior to beginning the research. My PhD is supervised by Dr A nne Hynds, phone (04) 463 9558, and Professor Luanna Mey er, phone (04) 4639598.

If you have any questions regarding this research please dont hesitate to contact me on (04) 4639629 or email vic ki. thorpefovuw. ac. nz.

Many thanks for considering this request.

Yours sincerely,

Vicki Thorpe

$\checkmark$ Thorpe $\mathrm{PhD}$ Teacher letter m ain study 


\section{Am endm ents to Vicki Thorpe's PhD research ethics}

\section{Change of m ethodology}

During the course of my pilot studyit became clear that the asse ssment of group composing was proving to be as complex and difficult as the review of literature indicated it was likely to be. The stance of 'non-particip ant observer' became ethically uncomfortable for me as I observed the te acher wre stle with the growing aw areness that she neede to assess individual process and that this was difficult. I potentially had the knowledge to help her do something I knew was going to be problematic, and yet did not do so.

At the conclusion of the pilot I began the process of recruiting te achers to take part in the main study. Yet, de spite strenuous efforts, using all of the networks available to me, there were no offers to take part in the study. Clearly there was a problem with the de sign and te achers were reluctant to take part. The analysis of the pilot study data reve aled that it is likely that teachers did not want to be observed while they tried something new without any assistance. Therefore, the findings of the pilot study re quired me to adapt my research and employ a methodology that involves addressing the rese arch problem in partnership with a te acher. For the se re asons I have decided to use action research.

\section{Action research}

I have attached here a copy of the email I sent out to the local subject association. I have two te achers in two different schools who are both ke en to take part in the research.

I would like to work with one teacher and his Year 11 Music class as soon as possible. I plan to conduct a second cycle of action research with the second te acher later in 2011 and early 2012. The teachers and I will be working collaboratively over a period of several months where myrole will be that of colle ague, co-rese archer, coach and professional mentor. I will also be w orking with one group of students in each school as a teacher and re se archer.

This change of methodology has necessitated some amendments to my ethics procedures. I have attached them here. Apologies - I have not used track changes. The main difference from the original documents is to outline clearly the re quirements of action re se arch to the participating te acher and school princip al and to ensure that they fully understand the se requirements. The focus is less on the students with this approach and so there have be en only minor changes to the ethics documents for students and care givers.

Many thanks for your consideration of the se amendments.

Vicki Thorpe 


\subsection{Indicative examples of interview and discussion questions}

Teacher Interview 1 Questions (Pilot study)

1. Overall context

- Tell me about the class and the group of students we have chosen

- Could you explain to me how composing fits into the Year 10 programme?

\section{The task}

- Could you explain the task to me? Talk me through it

- How did you go about designing it?

- What do you want the students to learn from doing this task?

- What do you think about composing in a group compared with composing alone?

\section{Working in groups}

- Have the students chosen their groups?

- Do students work differently in groups?

- How have you managed the group work?

- Anything else about group composing you would like to comment on?

\section{The assessment}

- How do you give feedback to student while they are composing, and what form does that feedback take?

- Could you please talk me through the draft standard? What does it require and how do you think you might use it?

- What aspects of composing will you be summatively assessing? Process as well as product or just the composition?

- What kinds of evidence do you anticipate you will end up with when you come to make the final summative judgement for each student?

- What are your thoughts about how you might assess the work of the students working in groups?

- What do you think the students will think about this process?

- Do you think this process will differ from previous NCEA assessments you have done?

5. Your background as a teacher of composing

- Could you tell me the story of your experiences of teaching composing? Maybe start with your background as a musician and a teacher? 
Teacher Interview 1 Questions (Main study. Alice: 15 June, 2011. David: 1 December, 2011)

1. We'll start by thinking about assessment in general terms and then go on to the NCEA. Then we'll talk about composing, group composing and the project.

- You have brought with you something that, for you, symbolises "assessment". Can you tell me about it?

- What do you think is the purpose of assessment? What's it for?

- What has been your experience of assessment? (as a teacher)

2. We're now going to focus on NCEA

- What do you feel you do well in NCEA assessment?

- What would you like to do better?

- What do you feel least confident about in NCEA assessment?

3. We're now going to focus on composing and the project

- You have brought with you something that, for you, symbolises "composing". Can you tell me about it?

- Why have you chosen to assess group composing in Year 11 this year?

- What are your reasons for taking part in this project? What do you hope to get out of it?

Teacher discussion questions example (excerpt from discussion with David 14 September, 2012)

- So now, thinking about our project, the process as a whole, if you were able to turn yourself into two people, a confident one and a doubtful one, and had to describe the whole NCEA assessment side of things, with the confident lens on, how would you describe what we've done this year?

- In terms of what you wanted from this project? Did you get what you wanted?

- Thinking about your own learning for this year, in terms of the positive confident side of things, how do you feel about NCEA assessment now? What have you learned as part of this project?

- What about gathering data?

- So what about sharing that with the boys? Are the boys clear about what the standard is and what they are aiming for?

- Maybe this is where we look at things through the doubtful lens, stuff that didn't work out the way you thought it would, or that haven't been so successful?

Student Interview 2 Questions (Kotare College, Blues Rock: 3 November, 2011)

- Could you tell me the story of how you composed your piece/s?

- What did each of you do?

- (I've asked you this question before.) Now that you have done a bit more composing since I interviewed you last time, what have you learned through group composing? 
- If you decide to do group composing in Year 12 Music next year, what do you know now that will be useful for you? Is there anything that you might do differently?

- What did you have to hand in to [your teacher] to achieve this standard?

- What did you need to do to get Achieved in this standard?

- How would you know that your composition was Merit or Excellence?

- What about the group composing process? How did [your teacher] go about assessing what each of you contributed? How did she know what each of you did?

- If you could choose, which would you prefer, an individual or a group grade?

- Now that you have received your grade do you agree with what you got?

- Anything else you would like to add? 


\subsection{Assessment confidence scales}

\section{Students}

\section{O}
..... had no idea about
your piece, what you
did or how it wos
composed

\section{Teachers}

0 10

I have no idea about what individual

student's achievement

or contribution was to

the composition

\author{
I completely \\ understand what \\ individual student's \\ achievement or \\ contribution was to the \\ composition
}




\subsection{St Bathan's Collegiate questionnaire}

Please tick the best answer.

Name:

1. Achieving the Level 1 composing achievement standard is:

Very important to me Quite important to me Not very important to me 口
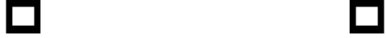

Not at all important to me

2. Getting Merit or Excellence for this achievement standard is:

Very important to me Quite important to me Not very important to me

Not at all important to me

3. Composing a really good piece of music is

Very important to me

Quite important to me Not very important to me

Not at all important to me

4. Finishing the piece we worked on last term was:

Very important to me

Quite important to me

Not very important to me

Not at all important to me

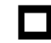

口

$\square$

口

5. For NCEA across all my subjects, I aim to:

Do just enough to get Level 1 Do my best in some subjects

Do my best across all subjects

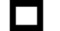

口

口

6. For NCEA Music overall this year I aim to:

Do just enough to get 'Achieved'

(circle which)

Get a Merit/Excellent subject endorsement

Do my best, no matter what 


\title{
4.1 Pilot Study: Song Writing Task and Assessment Schedule
}

Y10 Compose unit

\section{SONG COMPOSITION TASK}

MARKING SCHEDULE

\author{
Steo 2 Notabian
}

In order to achieve in this group composition task each student must be able to provide written evidence and proof of participation for at least 2 of the steps being assessed. These steps are; Step One - The creative process and Step 3 - The Performance. To achieve at a Merit or Excellen:e level each student must be able to provide written evidence and proof of participation for all 3 steps.

Please answer each question fully and to the best of your ability.

STEP ONE: The creative process.

STUDENT: What did you contribute personally to the initial creation of the music? For example which area did you contribute to, Lyrics, Chords, Melody, Rhythm, Instrumentation? Please comment on your contribution below.

TEACHER: Can you corroborate the above student statement? What evidence can you provide to support this statement? This can be informal or formal observation, visual or audio, interview etc.

STEP TWO: The Notation

STUDENT: What did you contribute personally to the notation of the music? For example what part of the score did you take responsibility for notating? Bass line, Chord structure, Lyrics, Melody? Please comment on your contribution below.

TEACHER: Can you corroborate the above student statement? What evidence can you provide to support this statement? This can be informal or formal observation, visual or audio, interview etc. 


\title{
SONG COMPOSITION TASK
}

\section{MARKING SCHEDULE}

\author{
STEP THREE: The Performance
}

STUDENT: How did you contribute to the performance of the music? What instrument did you play? What was your fole? Please comment on your contribution below.

TEACHER: Can you corroborate the above student statement? What evidence can you provide to support this statement? This can be informal or formal observation, visual or audio, interview etc.

\section{SCHEDULE}

\begin{tabular}{|c|c|c|}
\hline \multicolumn{1}{|c|}{ Achievement } & \multicolumn{1}{|c|}{ Achievement with Merit } & Achievement with Excellence \\
\hline $\begin{array}{l}\text { Can reflect and comment on Step } \\
\text { One and Three of the marking } \\
\text { schedule. Teacher can corroborate } \\
\text { these steps. }\end{array}$ & $\begin{array}{l}\text { Can sensibly reflect and comment on } \\
\text { all three steps in the marking } \\
\text { schedule. Teacher can corroborate } \\
\text { these steps. }\end{array}$ & $\begin{array}{l}\text { Can insightfully reflect and comment } \\
\text { on all three steps in the marking } \\
\text { schedule making valid connections. } \\
\text { Teacher can corroborate these steps. }\end{array}$ \\
\hline $\begin{array}{l}\text { Compose music that shows } \\
\text { development or structuring of } \\
\text { ideas, and is represented } \\
\text { through generally clear notation. }\end{array}$ & $\begin{array}{l}\text { Compose music that shows some } \\
\text { character, development and } \\
\text { structuring of ideas, and is } \\
\text { represented through clear } \\
\text { notation. }\end{array}$ & $\begin{array}{l}\text { Compose music that shows } \\
\text { character, skilful development } \\
\text { and structuring of ideas, and is } \\
\text { represented through clear and } \\
\text { detailed notation. }\end{array}$ \\
\hline
\end{tabular}

STUDENT SUMMARY: How do you feel the task went? How do you feel your group responded to the task? How would you rate your performance overall? Comment and using the above schedule award yourself a mark. 
5.1 Feedback Sheet (Blues Rock's first piece: Jay)

NCEA Music Level 1: Group Composing

Feedback to improve your 2nd composition

Student: Jay

Others in group: Jimmi and Rāwiri

Name of piece: Blues rock guitar piece

Grade:

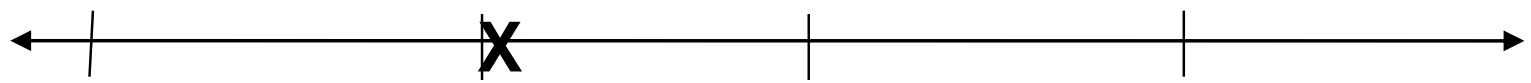

Not Achieved Achieved $\quad$ Merit $\quad$ Excellence

\section{Next steps:}

It is good that you were able to develop the bass line for your first group composition. Your challenge for your next composition is to be more involved in coming up with original ideas and planning the structure.

It would be a good idea for you to listen to examples of the sort of music you like and check out how these pieces have been put together.

Are there riffs? Are there lyrics? What are the chord progressions like?

What makes these pieces really sound individual?

Signed:

Date: 


\subsection{First composition task (St Bathan's Collegiate)}

\section{Year 11 Music composition task: "Back-engineering"}

You are going to compose a piece of music either by yourself or in a group of up to 5 students, using the 'back-engineering' technique we have been learning to do over the past three weeks.

Choose the style or genre of music you are going to work in. Remember that your piece doesn't have to be complex music and it's best to work in a style you already know well.

Listen to lots of examples of this style and create a 'blue print' of it. If you are in a group, come to an agreement about the elements of the blueprint. Don't forget feel or groove when identifying the special characteristics of your chosen music.

$\underline{\text { Jam, }}$ explore, try out your chosen style. Try to capture the unique and identifiable sound and feeling of the style

Compose a short piece of music in that style. Your piece needs to have:

$\checkmark$ A clear structure that a listener can hear

$\checkmark$ Two or three good ideas that have been developed in some way

$\checkmark$ Sound like the style you have chosen - stylistically assured

$\checkmark$ Be recorded (audio or video)

$\checkmark$ Be written down in a form so that other people could play it accurately

And remember, repetition is good! If you aren't making mistakes and having fun you aren't doing it right $(:)$

Try not to make it too complicated, use too many ideas (just 2 3 ), or make it too long (2 minutes max) 


\subsection{Assessment schedule for Task 1 based upon exemplar from the TKI website}

\begin{tabular}{|c|c|c|}
\hline $\begin{array}{c}\text { Evidence/Judgements towards } \\
\text { Achievement }\end{array}$ & $\begin{array}{l}\text { Evidence/Judgements towards } \\
\text { Achievement with Merit }\end{array}$ & $\begin{array}{l}\text { Evidence/Judgements towards Achievement } \\
\text { with Excellence }\end{array}$ \\
\hline $\begin{array}{l}\text { Your composition sounds like your chosen } \\
\text { genre and shows : } \\
\text { - At least } 2 \text { or } 3 \text { ideas such as riffs, melodies, } \\
\text { chord sequences, repeated patterns that } \\
\text { are typical of your chosen style or genre } \\
\text { - These good ideas have been developed, } \\
\text { extended, or changed in some way that is } \\
\text { typical of your chosen style or genre } \\
\text { - Ideas are organised into a structure that is } \\
\text { typical of your chosen style or genre } \\
\text { - Represented so that Mr ---- can assess it, } \\
\text { and so that other players who don't know } \\
\text { the music can play it: a score or chord } \\
\text { chart, lyrics, screen shot with annotations } \\
\text { etc }\end{array}$ & $\begin{array}{l}\text { Your composition sounds like your chosen } \\
\text { genre and shows : } \\
\text { - At least } 2 \text { or } 3 \text { good ideas such as riffs, } \\
\text { melodies, chord sequences, repeated } \\
\text { patterns that are typical of your chosen style } \\
\text { or genre } \\
\text { - Your ideas show stylistic control: they are } \\
\text { linked together clearly and work well } \\
\text { together because they have been } \\
\text { developed, extended, or changed in a way } \\
\text { that is typical of your chosen style or genre } \\
\text { - Your Ideas are organised into a clear } \\
\text { structure typical of your chosen style or } \\
\text { genre, and show some unity and contrast } \\
\text { - Represented very clearly so that Mr ---- can } \\
\text { assess it, and so that other players who } \\
\text { don't know the music can accurately play it: } \\
\text { a score or chord chart, lyrics, screen shot } \\
\text { with annotations etc. }\end{array}$ & $\begin{array}{l}\text { Your composition sounds like your chosen } \\
\text { genre and shows : } \\
\text { - At least } 2 \text { or } 3 \text { catchy \& memorable ideas } \\
\text { such as riffs, melodies, chord sequences, } \\
\text { repeated patterns that are typical of your } \\
\text { chosen style or genre } \\
\text { - Your ideas show real familiarity \& } \\
\text { understanding of your chosen style or genre: } \\
\text { ideas are linked together really well, show } \\
\text { unity and contrast, and work well together } \\
\text { because they have been developed, } \\
\text { extended, or changed in ways that sound } \\
\text { original but are still typical of your chosen } \\
\text { style or genre } \\
\text { - Skilfully represented in a way that makes } \\
\text { your intentions completely clear so that other } \\
\text { players who don't know the music can } \\
\text { accurately play it : score or chord chart, } \\
\text { lyrics, screen shot with annotations etc. }\end{array}$ \\
\hline
\end{tabular}

All compositions must be recorded and presented as a CD in...... format or they will not be assessed!

Group composers must:

- make a significant contribution to the creative process (messy, focussed, recorded, represented)

- fill in their progress report every week $(+,-$ etc)

- complete at least 2 video diary entries where all members report on their contributions to the creative process

- keep Mr ---- up to date about progress on the composition 